\title{
Catalizadores metálicos estructurados en reacciones de Química Sostenible
}

Tesis doctoral

Presentada por:

Irene López Hernández

Dirigida por:

Dr. A. Eduardo Palomares Gimeno

Dr. Jesús Mengual Cuquerella

Valencia, julio 2021 



\section{Agradecimientos}

Quisiera aprovechar estas líneas para mostrar mi más sincero agradecimiento a todas las personas que han formado parte de esta tesis y de mi vida durante estos años.

En primer lugar, quisiera dar las gracias a mis directores, Eduardo y Jesús, los cuales han hecho posible esta tesis, y a los que sin duda volvería a elegir. Gracias Eduardo por tu paciencia infinita, por confiar en mí, por haberme enseñado tanto, por escucharme y apoyarme siempre. Gracias Jesús por haber estado disponible para ayudarme con cualquier duda o problema. Ha sido un lujo haber tenido la oportunidad de trabajar con vosotros.

Gracias a todos los investigadores del ITQ que me han resuelto muchas dudas, en especial, a Fernando Rey, por habernos aportado sus ideas y conocimientos siempre que se lo hemos pedido.

Gracias a Noelia Barrabés, por su amistad y su ayuda en todo lo que he necesitado, antes, durante y después de mi estancia en Viena. Also, I am grateful to my colleagues in the ClusCat lab, Clara, Stephan and special thanks to Vera for being always kindness and very helpful.

También quisiera agradecer a todo el personal del ITQ de administración y conserjería, y especialmente a los técnicos de caracterización, sin los que esta tesis tampoco sería posible. Agradezco al ITQ por la ayuda recibida para los gastos de impresión de la tesis (Fondo de sostenibilidad).

Gracias a mis "hermanos" mayor y menor de tesis: J. L. Cerrillo, por tu amistad, por todo lo que hemos compartido (sincrotrones, congresos, comidas, cenas...) por tus consejos y tu ayuda siempre que te lo he pedido; Adrián Plá, por tu amistad y por hacerme algún que otro recado en el laboratorio mientras yo terminaba esta tesis, ahora ya tienes al jefe solo para ti!!

Gracias a todos mis compañeros del ITQ, por vuestra amistad, por haberme echado una mano siempre que os lo he pedido, y por todas las risas y momentos de almuerzo, comida, congresos, reacción y cervezas que he compartido con vosotros: Edi, Elena, Yannick, Fran, Vicent, Nuria, Cris I., Chelo, Javi...este es un breve resumen de nombres, por no aburrir, muchos quedan sin nombrar, pero 
os estoy igual de agradecida por haber compartido algún rato de vuestras vidas conmigo, dentro o fuera del laboratorio. Gracias a Cris "Almería" por su amistad y por llevarme a comer helado, haga frío o haga calor. Gracias también a Christian por su amistad (y la de Francine), y por su entera disposición para ayudarme con la parte de sincrotrón.

Gracias a Isabel Millet, por hacerme reír tanto, tanto, tanto.

Gracias a Aina, a la que conocí por casualidad, pero con la que tengo una gran amistad (aunque tardé 2 años en decir bien tu nombre). Gracias por tantas conversaciones sobre tesis y no tesis, y por proponerme más planes de los que me da tiempo a hacer.

Este párrafo se lo dedico a mi familia en Valencia: mis amigos. A todos gracias por aguantar mis disparates, pero sobre todo por haber estado a mi lado en los buenos momentos y en los menos buenos. ¡Os quiero mucho! Agus, gracias por estar siempre (sobre todo a partir de las $11 \mathrm{~h}$ ), por tus chistes y tus planes, mi Valencia no sería lo mismo sin ti. Millones de gracias a Juan: has sido mi compañero de clase, de piso, mi amigo y un gran apoyo siempre, te has convertido en un hermano para mí...aunque seas de la isla de enfrente!! te espero en Canarias, no tardes!! Mi día a día no hubiera sido igual sin una de las personas más importantes para mí, mi Fany, gracias por escucharme incluso cuando no sé ni en qué día vivo, por apoyarme cuando más lo necesito, por entenderme con solo una mirada y por ser cómplice de tantos y tantos buenos momentos: que nos quiten lo bailao!! Gracias a Rocío, por demostrarme que mi locura al lado de la tuya es despreciable, por todas las anécdotas que me has dejado (en las que normalmente no sales bien parada) y por todas las risas dentro y fuera del laboratorio. A Eli, por ser mi compañera de deporte, y de lo que haga falta, porque no es necesario conocer a una persona de toda la vida para quererla tanto como si lo conocieras de toda la vida!!. No me puedo olvidar de Manel y Martí que, sin ni siquiera saberlo me han sacado muchas sonrisas, ni tampoco de Jose, por ponerle la guinda a esta tesis con el diseño de la portada.

¡Os echaré mucho de menos a todos! Pero volveré...que este año han quedado muchos abrazos y muchas cervezas pendientes.

Por último, pero no por ello menos importante, quisiera mostrar mi agradecimiento a todas las personas que me han apoyado desde Tenerife: 
Gracias a mis padres, quienes me han apoyado en todo momento. Gracias infinitas a Juan y a mi madre (Flores, ¿qué haría yo sin ti?): por estar siempre, por apoyarme en todas mis decisiones, por aconsejarme y por enseñarme las cosas importantes de la vida. Gracias a mi padre, Santi, por sacarme una sonrisa siempre, por enseñarme que la vida con alegría y actitud positiva es mucho mejor, incluso en los días nublados. No me olvido tampoco de Tere, gracias! Por último, gracias a mi hermana Lucía, cofundadora del "club de hermanas" y a la que he echado tanto de menos estos años.

Gracias a mis abuelos Carmen y Manuel. Carmita, el mercado de las velas y yo te agradecemos la inversión que has hecho para encenderme una vela por cada examen, congreso, exposición que he hecho. Gracias también por mantenerme informada de las condiciones meteorológicas en Valencia, incluso antes que la AEMET, por recordarme que coma, y por todo lo que sólo una abuela como tú es capaz de hacer por mí!. Esta tesis también se la dedico a mis yeyos Juana y Pepe que, aunque ya no están, han dejado una gran huella en mí. Y por supuesto a mi abuelo postizo, Cayetano, por quererme como a una nieta más.

Gracias al resto de mi familia, tíos/as, primos/as que siempre se han preocupado por mí.

Gracias a mis amigos de la isla, en especial a Ani y Acerina, por seguir manteniendo nuestra amistad a pesar de la distancia como si no hubiera pasado el tiempo.

Finalmente, gracias a Alberto, por escuchar mis charlas sobre catalizadores y reacciones como si fuese el tema más interesante del mundo, por apoyarme y cuidar de mis alas, pero sobre todo por haber vuelto a nacer! 

A mi madre 



\section{Resumen}

En esta tesis doctoral se ha investigado sobre el empleo de catalizadores metálicos estructurados en diversas reacciones relacionadas con la Química Sostenible. En concreto, en la reacción de reducción catalítica selectiva de $\mathrm{NO}_{\mathrm{X}}$, en la reacción de oxidación catalítica de $\mathrm{CO}$ y en la hidrogenación catalítica de alquinos a alquenos.

En primer lugar, se ha estudiado la eliminación de los óxidos de nitrógeno mediante su reducción catalítica selectiva empleando amoniaco. Para ello, se han empleado catalizadores bimetálicos $\mathrm{Mn}-\mathrm{Fe}$ soportados sobre zeolitas con distinta relación Si/Al y morfología (BEA, CHA, ITQ-2 y FAU), materiales mesoporosos (MCM-41 y SBA-15) y óxidos metálicos $\left(\mathrm{MgO}, \mathrm{TiO}_{2}\right.$ y $\left.\gamma-\mathrm{Al}_{2} \mathrm{O}_{3}\right)$. Las propiedades físicas, químicas y estructurales de los catalizadores se han determinado mediante el empleo de diversas técnicas de caracterización y se han relacionado con los resultados catalíticos obtenidos. Se ha comprobado que existe una fuerte influencia del tipo de soporte sobre la actividad catalítica, obteniéndose los mejores resultados con los catalizadores cuyos soportes presentaban propiedades ácidas y que tenían una elevada área superficial. El análisis particular de cada grupo de catalizadores ha mostrado que, para el caso de las zeolitas, su morfología no influye tanto en la actividad catalítica como la relación Si/Al, obteniéndose los mejores resultados con los catalizadores soportados sobre zeolitas con alta relación Si/Al. Estos materiales microporosos dieron mejores resultados que los catalizadores soportados en materiales mesoporosos. Los catalizadores soportados sobre óxidos metálicos han mostrado una gran influencia del área superficial y de las propiedades ácido/base del soporte en su actividad catalítica, obteniéndose los mejores resultados con aquellos catalizadores soportados en óxidos que presentan alta área superficial y propiedades ácidas. Todos los catalizadores presentaron una selectividad a $\mathrm{N}_{2}$ superior al $90 \%$. Los resultados más prometedores, sobre todo por su elevada estabilidad hidrotérmica, se obtuvieron con el catalizador preparado con la zeolita CHA ( $\mathrm{Si} / \mathrm{Al}=10)$, que mantiene toda su actividad catalítica después de ser sometido a un tratamiento de envejecimiento. 
En segundo lugar, se ha estudiado la reacción de oxidación de CO utilizando catalizadores basados en Ag y Ag-Au, soportados en la zeolita ITQ-2. Los catalizadores de plata se han empleado para estudiar la influencia de la naturaleza de las especies de Ag en la actividad catalítica. Para ello, los catalizadores se han preparado mediante tres métodos diferentes que conducen a la formación de distintas especies de plata. Estos métodos son: i) impregnación a volumen de poro, ii) intercambio iónico, y iii) con nanoclusters de $\mathrm{Ag}_{25}(\mathrm{SR})_{18}$ soportados. El análisis de los resultados catalíticos obtenidos con los diferentes materiales, junto con los resultados de caracterización han permitido determinar que la especie activa en esta reacción es la plata metálica, logrando los mejores resultados con los catalizadores que presentaban una mayor cantidad de esta especie en su superficie, lo cual viene determinado por el método de adición de la plata y por la evolución de estas especies durante su activación y durante los sucesivos ciclos de reacción. Por otra parte, los catalizadores bimetálicos $\mathrm{Ag}$-Au fueron preparados mediante la impregnación de nanoclusters $\operatorname{Ag}_{x} A_{25-x}(S R)_{18}$ sobre la zeolita ITQ-2. Los resultados mostraron que la mejor actividad era obtenida cuando se producía la formación de nanopartículas aleadas de Ag-Au, que favorecían la adsorción del $\mathrm{CO}$ y del $\mathrm{O}_{2}$. Estas partículas se formaban tras la destrucción parcial de los ligandos tiolatos que protegen a los nanoclusters, lo que ocurría en mayor medida tras un pretratamiento con hidrógeno. Sin embargo, se ha comprobado que, durante la reacción, todos los nanoclusters evolucionaban hacia la formación de nanopartículas $\mathrm{Ag}-\mathrm{Au}$ independientemente del pretratamiento aplicado. Estos resultados, han permitido mostrar que la reacción de oxidación de $\mathrm{CO}$ es una herramienta muy útil para seguir la evolución de los nanoclusters metálicos durante los procesos de activación, y durante la propia reacción sin necesidad de recurrir a complejas técnicas de caracterización.

Por último, se ha estudiado la actividad en la semihidrogenación del fenilacetileno a estireno de los catalizadores basados en nanoclusters de oro con distinto número de átomos, $\mathrm{Au}_{25} \mathrm{y} \mathrm{Au}_{11}$, y con diferentes ligandos (tipo tiolato para $\mathrm{Au}_{25} \mathrm{y}$ tipo fosfina para $\mathrm{Au}_{11}$ ). Estos catalizadores fueron soportados sobre óxidos metálicos con distintas propiedades ácido/base $\left(\mathrm{MgO}, \gamma-\mathrm{Al}_{2} \mathrm{O}_{3}\right.$ e hidrotalcita con relación $\mathrm{Mg} / \mathrm{Al}$ de 4), observándose que la actividad depende 
tanto de la composición de los nanoclusters, como del soporte y del pretratamiento empleado. Se ha determinado que la activación parcial del $\mathrm{H}_{2}$ es un factor clave para conseguir una actividad y selectividad elevadas, estando esto directamente relacionado con las propiedades ácido/base del soporte. Los mejores resultados se obtuvieron con los catalizadores preparados con nanoclusters $\mathrm{Au}_{25}$ sobre la hidrotalcita $\mathrm{Mg} / \mathrm{Al}$, la cual presenta una basicidad intermedia entre el $\mathrm{MgO}$ y la alúmina, lo que favorece la activación del hidrógeno, pero evita la sobrehidrogenación de los alquinos a alcanos.

Los resultados obtenidos en las distintas reacciones con los diferentes catalizadores han mostrado que la interacción soporte-metal es fundamental a la hora de diseñar catalizadores activos para una reacción concreta. Esta interacción depende en gran medida de las propiedades ácido/base del soporte y de los pretratamientos aplicados a los catalizadores, y estos deben ser seleccionados para cualquier reacción en particular. Se ha comprobado, además, que los centros metálicos evolucionan a lo largo de la reacción pudiendo llevar a la formación de nuevas especies que serán más o menos activas según la reacción estudiada. 


\section{Summary}

The use of structured metallic catalysts in reactions related to Sustainable Chemistry have been investigated in this Doctoral Thesis. In particular, they have been used for the selective catalytic reduction of $\mathrm{NO}_{\mathrm{X}}$, for the catalytic oxidation of $\mathrm{CO}$ and for the hydrogenation of alkynes to alkenes.

Firstly, the removal of nitrogen oxides through the selective catalytic reduction with ammonia has been studied. In this case, bimetallic Mn-Fe catalysts supported on zeolites with different $\mathrm{Si} / \mathrm{Al}$ ratio and morphology (BEA, CHA, ITQ-2 and FAU), on mesoporous materials (MCM-41 and SBA-15) and on metallic oxides $\left(\mathrm{MgO}, \mathrm{TiO}_{2}\right.$ and $\left.\gamma-\mathrm{Al}_{2} \mathrm{O}_{3}\right)$ have been employed. The physical, chemical, and structural properties of the catalysts have been determined by several characterization techniques and they have been related to the catalytic results. It has been proved that there is a strong influence of the type of support in the catalytic activity, obtaining the best results with the catalysts supported on materials with acidic properties and high surface area. The analysis of the results obtained for each group of catalysts have shown that the morphology of zeolitebased catalysts does not influence the catalytic activity as much as the $\mathrm{Si} / \mathrm{Al}$ ratio does, obtaining the best results with the catalysts supported on zeolites with high $\mathrm{Si} / \mathrm{Al}$. These microporous materials lead to better results than those obtained with mesoporous materials. It has been shown that the activity of the catalysts supported on metallic oxides is strongly influenced by the surface area of the support and by its acid/base properties, obtaining the best results with the catalysts supported on oxides with high surface area and acidic properties. Furthermore, all catalysts present a selectivity towards $\mathrm{N}_{2}$ greater than $90 \%$. The most promising results, mainly for its hydrothermal stability, are obtained with the catalysts prepared with $\mathrm{CHA}$ zeolite $(\mathrm{Si} / \mathrm{Al}=10)$, that maintain the catalytic activity after the hydrothermal aging.

Secondly, the activity in the catalytic oxidation of $\mathrm{CO}$ of $\mathrm{Ag}$ and $\mathrm{Ag}$-Au catalysts supported on ITQ-2 zeolite has been studied. Silver-based catalysts were used in order to investigate the influence of the nature of silver species in the catalytic 
activity. For this, catalysts were prepared using different methods, leading to different silver species. These methods are: i) incipient wetness impregnation, ii) ion exchange, and iii) as supported $\mathrm{Ag}_{25}(\mathrm{SR})_{18}$ nanoclusters. The catalytic results together with the characterization results have allowed to determine that metallic silver is the active specie in this reaction, obtaining the best results with the catalysts containing a higher concentration of this species on the surface. This is determined by the preparation method and by the evolution of these species during the activation and the reaction cycles. In the other hand, the Ag-Au bimetallic catalysts were prepared by the impregnation of $\operatorname{Ag}_{\mathrm{x}} \mathrm{Au}_{25-\mathrm{x}}(\mathrm{SR})_{18}$ nanoclusters on the ITQ-2 zeolite. The results showed that the best activity is obtained when $\mathrm{Ag}-\mathrm{Au}$ alloy nanoparticles are formed, favouring the $\mathrm{CO}$ and $\mathrm{O}_{2}$ adsorption. These types of particles were formed after the partial destruction of thiolate ligands that are protecting the nanoclusters, that is favoured by the pretreatment with hydrogen. However, it has been shown that during reaction, nanoclusters evolved to the formation of Ag-Au alloyed nanoparticles regardless of the pretreatment applied. These results proved that the $\mathrm{CO}$ oxidation reaction is a useful tool to follow the metallic nanoclusters evolution during the activation processes and during reaction, avoiding the use of complex characterization techniques.

Finally, the activity of catalysts based on gold nanoclusters with different number of atoms, $\mathrm{Au}_{25} \mathrm{y} \mathrm{Au} 11$, and different ligands (thiolates for $\mathrm{Au}_{25}$ and phosphines for Au11) in the semihydrogenation of phenylacetylene to styrene has been studied. These catalysts were supported on various metallic oxides with different acid/base properties $\left(\mathrm{MgO}, \gamma-\mathrm{Al}_{2} \mathrm{O}_{3}\right.$ and $\mathrm{Mg} / \mathrm{Al}=4$ hydrotalcite), observing that catalytic activity depends on the nanoclusters composition, but also on the support and on the pretreatment. It has been shown that $\mathrm{H}_{2}$ partial activation is a key factor in order to obtain high activity and selectivity, which is directly related to the acid/base properties of the support. The best results were obtained with the catalysts prepared with $\mathrm{Au}_{25}$ nanoclusters supported on the $\mathrm{Mg} / \mathrm{Al}$ hydrotalcite, that presents a medium basicity between $\mathrm{MgO}$ and alumina, favouring the hydrogen activation, but avoiding the overhydrogenation of alkynes to alkanes. 
The results obtained for the different reactions with the different catalysts have shown that the support-metal interaction is essential when designing active catalysts for a particular reaction. This interaction strongly depends on the $\mathrm{acid} / \mathrm{base}$ properties of the supports and on the pretreatments, and they must be selected for any reaction. Moreover, it has been proved that metallic sites evolve during the reaction leading to new species that can be more or less active, depending on the studied reaction. 


\section{Resum}

En aquesta tesi doctoral s'ha investigat sobre l'ús de catalitzadors metàl-lics estructurats en diverses reaccions relacionades amb la Química Sostenible. En concret, en la reacció de reducció catalítica selectiva de $\mathrm{NO}_{\mathrm{X}}$, en la reacció d'oxidació catalítica de $\mathrm{CO}$ i en la hidrogenació catalítica de alquins a alquens.

En primer lloc, s'ha estudiat l'eliminació dels òxids de nitrogen mitjançant la seua reducció catalítica selectiva emprant amoníac. Per a això, s'han emprat catalitzadors bimetàlics $\mathrm{Mn}-\mathrm{Fe}$ suportats sobre zeolites amb diferent relació $\mathrm{Si} / \mathrm{Al}$ i morfologia (BEA, CHA, ITQ-2 and FAU), materials mesoporosos (MCM-41 and SBA-15) i òxids metàl $\cdot \mathrm{lics}\left(\mathrm{MgO}, \mathrm{TiO}_{2}\right.$ and $\left.\gamma-\mathrm{Al}_{2} \mathrm{O}_{3}\right)$. Les propietats físiques, químiques i estructurals dels catalitzadors s'han determinat mitjançant l'ús de diverses tècniques de caracterització i s'han relacionat amb els resultats catalítics obtinguts. S'ha comprovat que existeix una forta influència del tipus de suport sobre l'activitat catalítica, obtenint-se els millors resultats amb els catalitzadors els suports dels quals presentaven propietats àcides i que tenien una elevada àrea superficial. L'anàlisi particular de cada grup de catalitzadors ha mostrat que, per al cas de les zeolites, la seua morfologia no influeix tant en l'activitat catalítica com la relació $\mathrm{Si} / \mathrm{Al}$, obtenint-se els millors resultats amb els catalitzadors suportats sobre zeolites amb alta relació $\mathrm{Si} / \mathrm{Al}$. Aquests materials microporosos van donar millors resultats que els catalitzadors suportats en materials mesoporosos. Els catalitzadors suportats sobre òxids metàl-lics han mostrat una gran influència de l'àrea superficial i de les propietats àcid/base del suport, obtenint-se els millors resultats amb aquells catalitzadors suportats en òxids que presenten alta àrea superficial $\mathrm{i}$ propietats àcides. Tots els catalitzadors van presentar una selectivitat a $\mathrm{N}_{2}$ superior al $90 \%$. Els resultats més prometedors, sobretot per la seua elevada estabilitat hidrotèrmica, es van obtindre amb el catalitzador preparat amb la zeolita $\mathrm{CHA}(\mathrm{Si} / \mathrm{Al}=10)$, que manté tota la seua activitat catalítica després de ser sotmés a un tractament d'envelliment.

En segon lloc, s'ha estudiat l'activitat en l'oxidació de CO de catalitzadors basats en $\mathrm{Ag}$ i Ag-Au, suportats sobre la zeolita ITQ-2. Els catalitzadors de plata es van 
emprar per a estudiar la influència de la naturalesa de les espècies de Ag en l'activitat catalítica. Per a això, els catalitzadors s'han preparat mitjançant tres mètodes diferents: i) impregnació a volum de porus, ii) intercanvi iònic, i iii) amb nanoclusters de $\mathrm{Ag}_{25}(\mathrm{SR})_{18}$ suportats. L'anàlisi dels resultats catalítics obtinguts amb els diferents materials, juntament amb els resultats de caracterització han permés determinar que l'espècie activa en aquesta reacció és la plata metàl·lica, aconseguint els millors resultats amb els catalitzadors que presentaven una major quantitat de d'aquesta espècie en la seua superfície, la qual cosa ve determinada pel mètode d'addició de la plata i per l'evolució de les espècies durant la seua activació i durant els cicles de reacció. D'altra banda, els catalitzadors bimetàl-lics $\mathrm{Ag}-\mathrm{Au}$ van ser preparats mitjançant la impregnació de nanoclusters $\mathrm{Ag}_{\mathrm{x}} \mathrm{Au}_{25}$ ${ }_{x}(\mathrm{SR})_{18}$ sobre la zeolita ITQ-2. Els resultats van mostrar que la millor activitat era obtinguda quan es produïa la formació de nanopartícules aliades de $\mathrm{Ag}$-Au, que afavorien l'adsorció del $\mathrm{CO}$ i del $\mathrm{O}_{2}$. Aquestes partícules es formaven després de la destrucció incompleta dels lligands tiolats que protegeixen els nanoclusters, la qual cosa ocorria en major mesura després d'un pretractament amb hidrogen. No obstant això, es va comprobar que, durant les condicions de reacció, tots els nanoclusters evolucionaven cap a la formació de nanopartícules $\mathrm{Ag}-\mathrm{Au}$ independentment del pretractament aplicat. Aquests resultats han permés mostrar que la reacció d'oxidació de CO és una eina molt útil per a seguir l'evolució dels nanoclusters metàl-lics durant els processos d'activació i durant la pròpia reacción, sense necessitat de recórrer a complexes tècniques de caracterització.

Finalment, s'ha estudiat l'activitat en la semihidrogenació del fenilacetilè a estiré dels catalitzadors basats en nanoclusters d'or amb diferent nombre d'àtoms, $\mathrm{Au}_{25}$ $\mathrm{i} \mathrm{Au}_{11}, \mathrm{i}$ amb diferents lligands (tipus tiolat per a $\mathrm{Au}_{25} \mathrm{i}$ tipus fosfina per a $\mathrm{Au}_{11}$ ). Aquests catalitzadors van ser suportats sobre òxids metàl-lics amb diferents propietats àcid/base $\left(\mathrm{MgO}, \gamma-\mathrm{Al}_{2} \mathrm{O}_{3}\right.$ i hidrotalcita $\left.\mathrm{Mg} / \mathrm{Al}=4\right)$, observant-se que l'activitat depén tant de la composició dels nanoclusters, com del suport i del pretractament emprat. S'ha determinat que l'activació de l'hidrogen és un factor clau per aconseguir una activitat i selectivitat elevades, estant això directament relacionat amb les propietats àcid/base del suport. Els millors resultats es van obtindre amb els catalitzadors preparats amb nanoclusters $\mathrm{Au}_{25}$ sobre la 
hidrotalcita $\mathrm{Mg} / \mathrm{Al}$, la qual presenta una basicitat intermèdia entre el $\mathrm{MgO}$ i l'alúmina, la qual cosa afavoreix l'activació de l'hidrogen, però evita la sobrehidrogenación dels alquins als alcans.

Els resultats obtinguts en les diferents reaccions amb els diferents catalitzadors han mostrat que la interacció suport-metall és fonamental a l'hora de dissenyar catalitzadors actius en les reaccions estudiades. Aquesta interacció depén en gran manera de les propietats àcid/base del suport i dels pretractaments aplicats als catalitzadors. S'ha comprovat, a més, que els centres metàl-lics evolucionen al llarg de la reacción, podent portar a la formació de noves espècies que poden ser més o menys actives segons la reacció estudiada. 



\section{ÍNDICE}

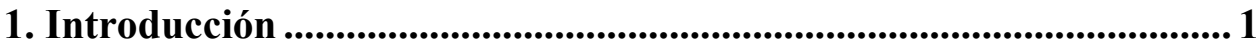

1.1. Química Sostenible.................................................................... 3

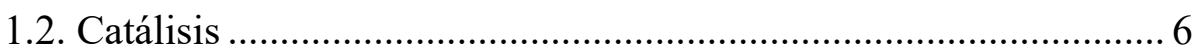

1.3. Contaminación atmosférica ...................................................... 10

1.3.1. Principales contaminantes atmosféricos............................... 11

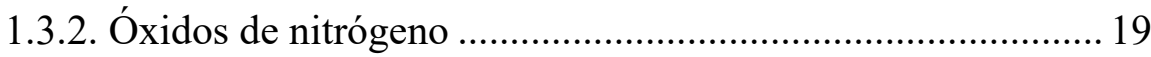

1.3.2.1. Emisiones y efectos de los óxidos de nitrógeno............. 21

1.3.2.2. Control de las emisiones de los óxidos de nitrógeno .....26

1.3.2.3. Reducción catalítica selectiva de los óxidos de nitrógeno

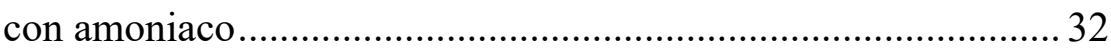

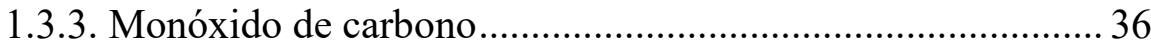

1.3.3.1. Emisiones y efectos del monóxido de carbono ............... 36

1.3.3.2. Control de las emisiones de monóxido de carbono........ 38

1.3.3.3. Oxidación catalítica de monóxido de carbono ................ 40

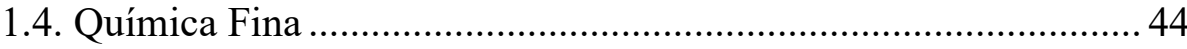

1.4.1. Semihidrogenación de alquinos............................................ 47

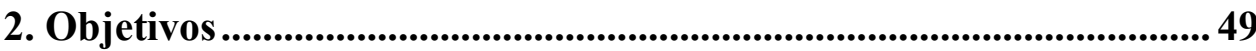

3. Procedimiento experimental ..................................................................... 53

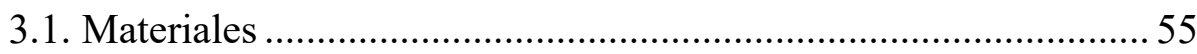

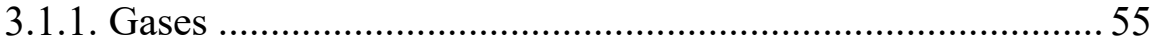




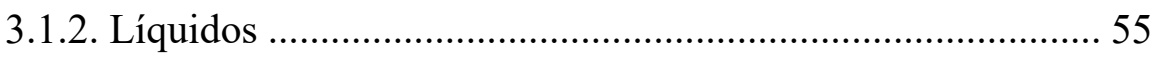

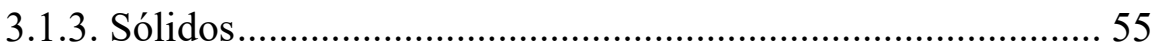

3.2. Preparación de los catalizadores ....................................................... 56

3.2.1. Síntesis de soportes ............................................................... 57

3.2.1.1. Síntesis de óxidos de alta superficie específica............... 57

3.2.1.2. Síntesis de la hidrotalcita $\mathrm{Mg} / \mathrm{Al}$....................................... 58

3.2.1.3. Síntesis de la zeolita CHA ................................................ 59

3.2.2. Síntesis de nanoclusters............................................................ 59

3.2.2.1. Síntesis de nanoclusters $\mathrm{Au}_{25}\left(\mathrm{SC}_{2} \mathrm{H}_{4} \mathrm{Ph}\right)_{18}$..................... 59

3.2.2.2. Síntesis de nanoclusters $\mathrm{Au}_{11}\left(\mathrm{PPh}_{3}\right)_{7} \mathrm{Br}_{3}$.......................... 60

3.2.2.3. Síntesis de nanoclusters $\mathrm{Ag}_{25}\left(\mathrm{SPhMe}_{2}\right)_{18}\left(\mathrm{PPh}_{4}\right)$............ 60

3.2.2.4. Síntesis de nanoclusters $\mathrm{Ag}_{\mathrm{x}} \mathrm{Au}_{25-\mathrm{x}}\left(\mathrm{SC}_{2} \mathrm{H}_{4} \mathrm{Ph}\right)_{18}$............ 61

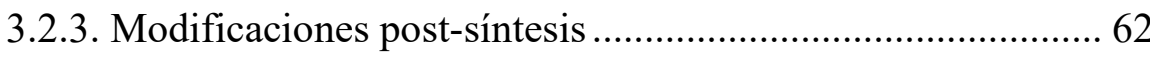

3.2.3.1. Catalizadores preparados por impregnación .................... 62

3.2.3.2. Catalizadores preparados por intercambio iónico ........... 63

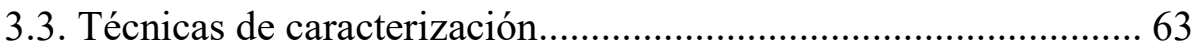

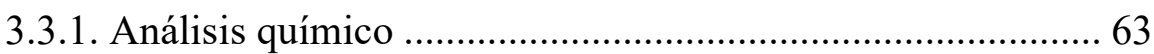

3.3.2. Análisis textural: adsorción volumétrica de nitrógeno........... 64

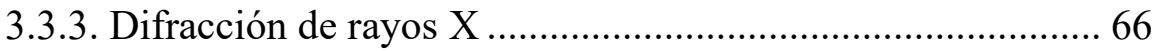

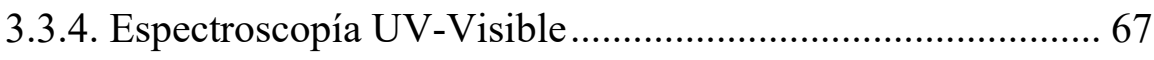

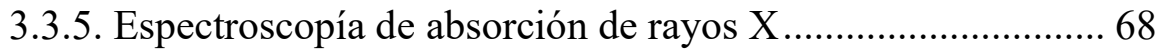

3.3.6. Espectroscopía infrarroja de reflectancia difusa por transformada de Fourier ................................................................. 70 
3.3.7. Espectroscopía de infrarrojo de transmisión con piridina como

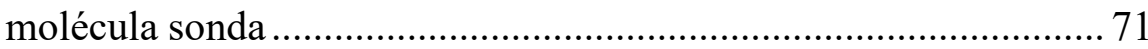

3.3.8. Espectroscopía fotoelectrónica de rayos X …...................... 72

3.3.9. Espectroscopía de resonancia magnética nuclear................. 73

3.3.10. Espectrometría de masas por desorción/ionización láser

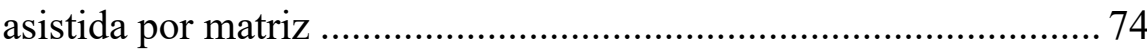

3.3.11. Reducción a temperatura programada ................................ 75

3.3.12. Microscopía electrónica .................................................... 75

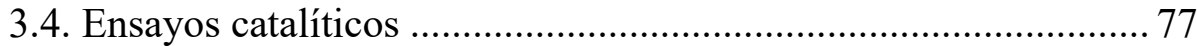

3.4.1. Reacción de reducción catalítica selectiva de $\mathrm{NO}_{\mathrm{X}} \ldots \ldots \ldots \ldots . . . . . .77$

3.4.2. Reacción de oxidación catalítica de CO................................ 81

3.4.3. Reacción de semihidrogenación de alquinos.......................... 82

4. Reducción catalítica selectiva de óxidos de nitrógeno con

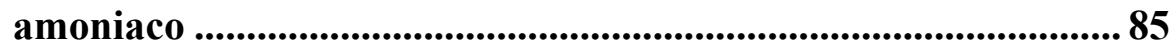

4.1. Catalizadores Mn-Fe soportados sobre zeolitas .......................... 88

4.1.1. Catalizadores Mn-Fe sobre la zeolita FAU ......................... 96

4.1.2. Catalizadores Mn-Fe sobre la zeolita CHA......................... 97

4.1.3. Catalizadores Mn-Fe sobre la zeolita BEA ........................... 99

4.1.4. Catalizadores Mn-Fe sobre la zeolita ITQ-2 ...................... 101

4.1.5. Comparación de los resultados obtenidos con los distintos catalizadores Mn-Fe soportados sobre las distintas zeolitas ......... 103

4.2. Catalizadores Mn-Fe soportados sobre materiales mesoporosos 105

4.3. Catalizadores Mn-Fe soportados sobre óxidos metálicos 111

4.4. Estabilidad de los catalizadores. 118 


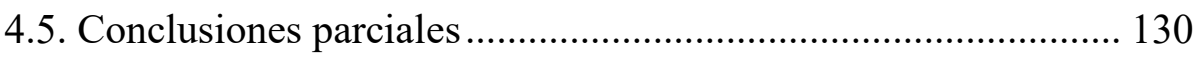

5. Oxidación catalítica de monóxido de carbono .................................. 131

5.1. Catalizadores de Ag/ITQ-2 ….................................................. 133

5.1.1. Nanoclusters de plata sobre ITQ-2 …............................... 134

5.1.2. Otros catalizadores de Ag/ITQ-2 .................................... 146

5.1.3. La reacción de oxidación de $\mathrm{CO}$ como reacción test para determinar especies de plata ...................................................... 149

5.1.4. Conclusiones parciales ................................................... 152

5.2. Catalizadores bimetálicos $\mathrm{Ag}_{\mathrm{x}} \mathrm{Au}_{25-\mathrm{x}} / \mathrm{ITQ}-2$........................... 153

5.2.1. Actividad catalítica............................................................. 155

5.2.2. Caracterización de los catalizadores $\mathrm{Ag}_{\mathrm{x}} \mathrm{Au}_{25-\mathrm{x}} / \mathrm{ITQ}-2$....... 160

5.2.3. Evolución dinámica de los nanoclusters $\operatorname{Ag}_{x} A u_{25-x}$ durante la reacción de oxidación catalítica de CO........................................ 176

5.2.4. Conclusiones parciales........................................................ 178

6. Semihidrogenación de alquinos......................................................... 181

6.1. Caracterización de los catalizadores ........................................ 183

6.2. Resultados catalíticos .............................................................. 187

6.3. Conclusiones parciales ............................................................... 199

7. General conclusions............................................................................ 201

8. Bibliografía.................................................................................................. 207 


\section{INTRODUCCIÓN}



Esta tesis se ha desarrollado dentro del programa de doctorado de Química Sostenible, y trata sobre el uso de catalizadores metálicos estructurados en reacciones de Química Sostenible. Es por ello que, en este apartado de Introducción, se desarrollarán los conceptos de Química Sostenible y Catálisis aplicados al control de determinados contaminantes atmosféricos (óxidos de nitrógeno y monóxido de carbono) y a una reacción de interés en Química Fina, la semihidrogenación de alquinos.

\subsection{Química Sostenible}

El siglo pasado se caracterizó por un importante crecimiento de la industrialización, lo que supuso un hito en la evolución económica. Este desarrollo económico e industrial vino acompañado por una mejora sustancial en la calidad de vida de las personas, pero también por la aparición de problemas medioambientales relacionados con el aumento de las actividades industriales [1]. En este sentido, empezó a hablarse del cambio climático y de sus consecuencias; el adelgazamiento de la capa de ozono fue una preocupación mundial; y la acumulación de compuestos contaminantes en la atmósfera empezó a ser un problema evidente [2]. Además, el rápido aumento de la población originó un aumento vertiginoso en la producción de alimentos y en la industrialización, por lo que los recursos naturales empezaron a usarse de manera descontrolada sin tener en cuenta las consecuencias que tendría esto en el agotamiento de los mismos [3].

En este contexto, en 1962 se publicó el libro La Primavera Silenciosa de Rachel Carson [4], donde se exponían los peligros y problemas medioambientales, y de salud generados por el aumento del uso de pesticidas en Estados Unidos después de la II Guerra Mundial. La visión crítica de la autora influyó en la toma de conciencia de los problemas medioambientales que existían en el mundo, apareciendo pocos años después las primeras medidas gubernamentales para el control de los mismos.

Una década más tarde, se celebró la primera gran conferencia sobre cuestiones medioambientales, la Conferencia de Estocolmo (Suecia, 1972), con el fin de 
evaluar el estado del medio ambiente a nivel mundial. Es a partir de esta conferencia cuando se empiezan a considerar los posibles daños que puede causar el agotamiento de los ecosistemas a la humanidad [1], organizándose nuevas conferencias al respecto durante la década siguiente.

En 1983, tras una revisión de las acciones medioambientales propuestas en la Conferencia de Estocolmo, la Organización de las Naciones Unidas funda la Comisión Mundial sobre el Medio Ambiente y el Desarrollo. En 1987, dicha comisión publicó el informe "Nuestro Futuro Común", también conocido como Informe Brundtlan [5]. En el mismo, se define el Desarrollo Sostenible como aquel desarrollo que satisface las necesidades del presente sin comprometer la capacidad de satisfacer las necesidades de las generaciones futuras. Este paradigma ha hecho que muchas disciplinas implementen el concepto de sostenibilidad en sus procesos, como es el caso de la Química.

La Química Sostenible o Química Verde nace como respuesta a esta necesidad de avanzar hacia un desarrollo más sostenible de la sociedad. Este área de la Química trata de implementar el concepto de sostenibilidad en la producción y en el uso de los productos químicos, y busca la aplicación de la química y de los productos químicos como herramienta que posibilite el desarrollo sostenible [6]. Este concepto, tal y como lo conocemos hoy en día, nace en 1991 de la mano de Paul Anastas y John Warner, quienes en 1998 desarrollaron los 12 Principios de la Química Verde (Figura 1) en su libro Química Verde: Teoría y Práctica [7].

Estos doce principios de la Química Verde buscan la disminución (o eliminación) del uso de productos tóxicos en los procesos químicos, así como la reducción (o eliminación) de los residuos generados en esos procesos. Esta filosofía entiende que el impacto de la química no acaba en la síntesis de un determinado producto, sino que llega hasta la persona que usa ese producto y hasta el entorno donde se emplea. Es por ello que la industria química ha desarrollado y continúa desarrollando nuevos métodos de síntesis, condiciones de reacción, catalizadores, reactivos y procesos acordes con estos principios [8]. 


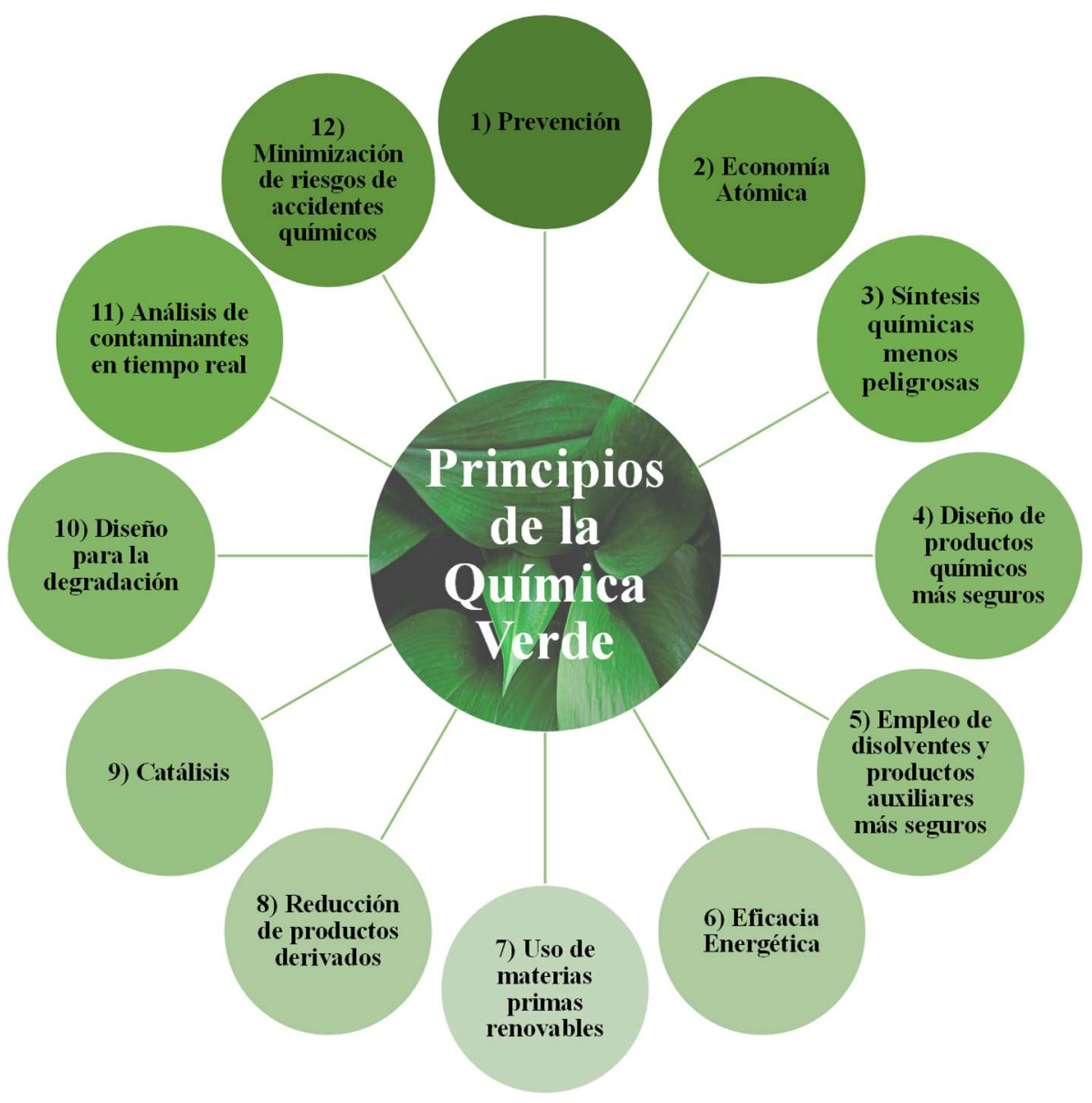

Figura 1. Los 12 Principios de la Química Verde.

La Química Sostenible aspira a minimizar los efectos de sus procesos y productos sobre la salud humana y el medio ambiente, abordando desafíos sociales, como la inclusión de la investigación, la ciencia y la cultura en la sociedad. Asimismo, pretende conseguir una gestión sostenible de los recursos de nuestro planeta [9] y la creación de tecnologías respetuosas con el medio ambiente, pero que a la vez cumplan los criterios de eficacia y de eficiencia económica necesarios para que sean empleadas de manera generalizada por la industria [8]. 


\subsection{Catálisis}

La Química Sostenible promueve el empleo de recursos renovables, disminuyendo la cantidad de subproductos formados en una reacción y evitando el empleo de reactivos y disolventes adicionales. Un factor fundamental para conseguir estos objetivos es el empleo de la Catálisis, que ha emergido como una herramienta clave para un desarrollo más sostenible [10]. La Catálisis es el noveno Principio de la Química Verde [7], el cual propone que el empleo de reactivos catalíticos (lo más selectivos posible) ha de ser superior al de los reactivos estequiométricos.

Según la IUPAC (Unión Internacional de Química Pura y Aplicada), un catalizador es una sustancia que aumenta la velocidad de una reacción sin modificar la variación de energía libre de Gibbs de la misma [11]. Por lo tanto, el empleo de catalizadores hace que disminuyan los requerimientos energéticos y aumente la selectividad de los procesos. Esto permite disminuir los productos de desecho y mejorar la economía atómica de las reacciones. Es por ello, que el empleo de la Catálisis lleva implícito la aplicación del resto de Principios de la Química Verde [12].

La Catálisis puede considerarse como un área multidisciplinar, la cual involucra ingeniería química, química física, síntesis química, química teórica y ciencias de materiales [10]. En una reacción catalítica, el catalizador interacciona con los reactivos y aumenta la velocidad de reacción al disminuir la energía de activación del proceso (Figura 2). En este proceso, el catalizador permanece sin ser consumido durante toda la reacción. Además, en el caso de procesos en los que haya varias reacciones simultáneas, la elección del catalizador adecuado permitirá conseguir que la reacción deseada tenga lugar y que el resto de reacciones competitivas no ocurran [13], es decir, aumentará la selectividad al producto deseado. 


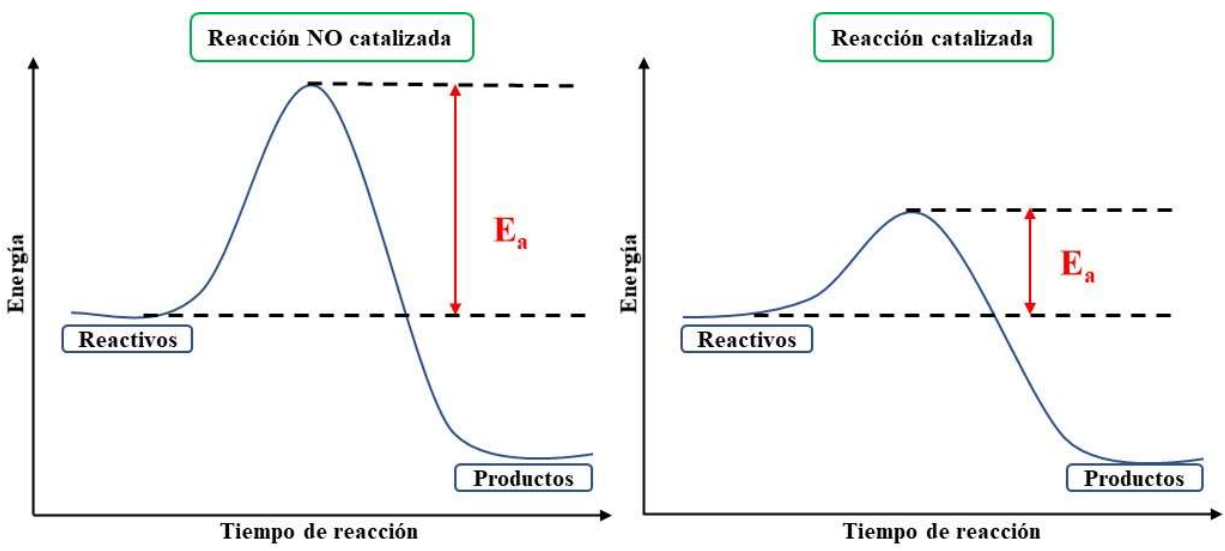

Figura 2. Diagrama de la energía de activación de una reacción no catalizada y de una reacción catalizada.

Los procesos catalíticos pueden ser clasificados como heterogéneos $u$ homogéneos. En la catálisis heterogénea, el catalizador se encuentra en una fase distinta a la de los reactivos (normalmente, el catalizador está en fase sólida y los reactivos en fase líquida o gas), mientras que, en la catálisis homogénea, el catalizador y los reactivos se encuentran en la misma fase.

La catálisis homogénea, facilita la accesibilidad de los reactivos a los centros activos, lo que resulta en una alta actividad catalítica y en una elevada selectividad al producto deseado. Sin embargo, por el mismo motivo, estos catalizadores presentan una menor estabilidad. Además, al finalizar la reacción es complicado separar el catalizador de los productos de reacción, por lo que para poder reciclar el catalizador es necesario realizar etapas y tratamientos adicionales, con lo que, a veces, acaba siendo un proceso menos sostenible y con un coste más elevado [14].

En la catálisis heterogénea, las reacciones químicas ocurren en la superficie del catalizador. Por esta razón, los catalizadores deben tener una alta área superficial. La catálisis heterogénea presenta la ventaja de permitir una fácil separación del 
catalizador de la mezcla de reacción. Esto hace que el catalizador pueda ser regenerado y reutilizado con gran facilidad [15].

Además, en las últimas décadas ha surgido un nuevo tipo de catálisis, la biocatálisis, basada en el empleo de enzimas como catalizadores. Este tipo de catalizadores están siendo ampliamente aplicados en procesos industriales de síntesis orgánica, farmacéuticos y de química fina [16]. Los biocatalizadores son altamente selectivos y permiten el desarrollo de procesos sostenibles siguiendo la filosofía de los 12 Principios de la Química Verde [17]. Sin embargo, una de las mayores desventajas que presenta su uso es que, por lo general, las biotransformaciones en las que se usan acaban degradando a las enzimas. Es por ello que resulta necesario el diseño de nuevos biocatalizadores que consigan preservar las propiedades funcionales de las enzimas y que sean estables en condiciones de reacción [18].

A nivel industrial, alrededor del $85 \%$ de los procesos químicos son llevados a cabo catalíticamente. De todos esos procesos, el $80 \%$ emplea catálisis heterogénea, dadas las ventajas que ésta presenta en cuanto a la separación y reutilización de los catalizadores (Figura 3). El 17 \% restante emplean la catálisis homogénea, mientras que la biocatálisis es utilizada por el $3 \%$ de procesos [19].

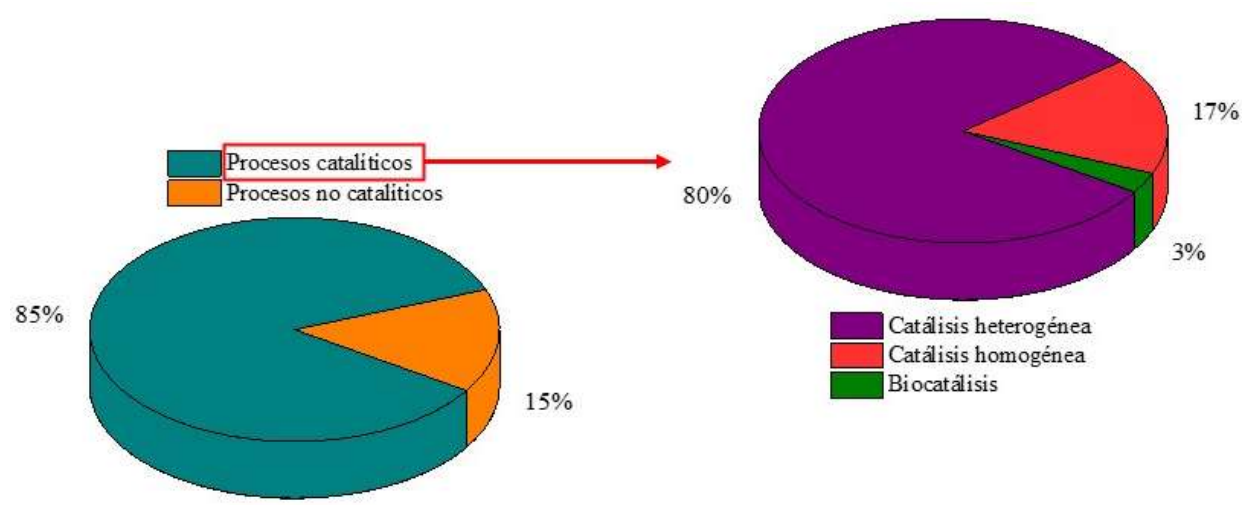

Figura 3. Diagrama de la contribución de la catálisis en los procesos industriales y de los tipos de catálisis empleados [19]. 
La Catálisis está presente en una amplia variedad de procesos que afectan a nuestro día a día. De hecho, prácticamente todas las reacciones que ocurren en el cuerpo humano y en todas las células vivas son catalíticas. Además, nuestra sociedad necesita los procesos catalíticos que ocurren a nivel industrial en distintas áreas como la industria petroquímica, la farmacéutica, la agroalimentaria, la síntesis de materiales, la protección del medio ambiente, el refino del petróleo, etc. (Figura 4) [20].

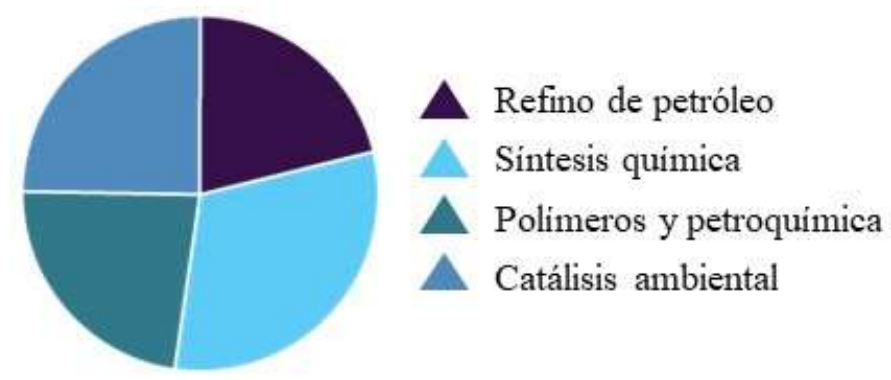

Figura 4. Distribución de los procesos catalíticos según la aplicación [21].

Tal y como se observa en la figura anterior, una de las aplicaciones más amplias de la catálisis es la protección del medioambiente. Alrededor del $40 \%$ de las ventas de catalizadores son destinadas a la catálisis ambiental y de este porcentaje, el $50 \%$ se corresponde con los catalizadores empleados para el control de las emisiones de los automóviles [13].

En la Tabla 1 se incluyen algunos ejemplos de procesos que emplean catalizadores para el control de problemas medioambientales. 
Tabla 1. Ejemplos de aplicaciones de la catálisis ambiental [13].

\begin{tabular}{ccc}
\hline$\underline{\text { Proceso }}$ & Catalizador & Condiciones \\
\hline $\begin{array}{c}\text { Emisiones de automóviles } \\
\text { Emisiones de NOx de fuentes } \\
\text { estacionarias }\end{array}$ & Óxidos de Ti, W, $\mathrm{P}$ u óxidos & $400-500^{\circ} \mathrm{C}$ \\
\hline $\begin{array}{c}\text { Control de inquemados } \\
\text { mixtos }\end{array}$ & $300-400^{\circ} \mathrm{C}$ \\
\hline $\begin{array}{c}\text { Descomposición de ozono en } \\
\text { automoción o aviación }\end{array}$ & Óxidos $\mathrm{Pt}-\mathrm{Pd}, \mathrm{LaCeCoO}{ }_{3} ; \mathrm{W}, \mathrm{V}$, & $150-700^{\circ} \mathrm{C}$ \\
\hline $\mathrm{Cu}, \mathrm{Mn}, \mathrm{Fe}$ & \\
\hline
\end{tabular}

Siguiendo los principios de la Química Verde, en esta tesis se ha empleado la catálisis heterogénea para el control de gases contaminantes de la atmósfera $\left(\mathrm{NO}_{\mathrm{X}}\right.$ y CO) y para trabajar en una reacción de interés en la industria química (la hidrogenación de alquinos a alquenos).

\subsection{Contaminación atmosférica}

En España, la Ley Ley 34/2007, de 15 de noviembre, de calidad del aire y protección de la atmósfera define la contaminación atmosférica como "la presencia en la atmósfera de materias, sustancias o formas de energía que impliquen molestia grave, riesgo o daño para la seguridad o la salud de las personas, el medio ambiente y demás bienes de cualquier naturaleza" [22].

Según esta definición, una sustancia contaminante no es necesariamente una sustancia distinta a las presentes normalmente en el aire (Tabla 2), sino aquélla que aparezca en una proporción diferente a la habitual y cause daños al medio. 
Tabla 2. Composición del aire seco [23].

\begin{tabular}{|c|c|c|c|}
\hline$\underline{\text { Sustancia }}$ & Concentración & $\underline{\text { Sustancia }}$ & Concentración \\
\hline Nitrógeno & $78.08 \%$ (vol) & Óxido nitroso & 0.3 ppm \\
\hline Oxígeno & $20.95 \%$ (vol) & $\begin{array}{l}\text { Dióxido de } \\
\text { nitrógeno }\end{array}$ & $\sim 0.1 \mathrm{ppm}$ \\
\hline Argón & $0.93 \%$ (vol) & $\begin{array}{l}\text { Monóxido de } \\
\text { carbono }\end{array}$ & $\sim 0.1 \mathrm{ppm}$ \\
\hline $\begin{array}{l}\text { Dióxido de } \\
\text { carbono }\end{array}$ & 360 ppm (variable) & Xenón & 0.09 ppm \\
\hline Neón & $18.2 \mathrm{ppm}$ & Dióxido de azufre & $\sim 0.02 \mathrm{ppm}$ \\
\hline Helio & $5.2 \mathrm{ppm}$ & Amoniaco & $\sim 0.01$ ppm \\
\hline Metano & 1.6 ppm & Ozono & Trazas \\
\hline Criptón & $1.1 \mathrm{ppm}$ & Yodo & Trazas \\
\hline Hidrógeno & 0.5 ppm & Otros hidrocarburos & Trazas \\
\hline
\end{tabular}

Según la Organización Mundial de la Salud (OMS), la contaminación atmosférica en las ciudades y zonas rurales de todo el mundo provoca cada año 4.2 millones de muertes prematuras. Por tanto, cuanto menores sean los niveles de contaminación del aire, mejor será la salud de las personas, tanto a corto como a largo plazo [24].

\subsubsection{Principales contaminantes atmosféricos}

Los principales contaminantes atmosféricos son los óxidos de azufre, las partículas en suspensión, los compuestos orgánicos volátiles, el monóxido de carbono y los óxidos de nitrógeno [25]. Estos contaminantes pueden tener dos fuentes de emisión: natural y antropogénica. Las fuentes naturales son los 
volcanes, los incendios forestales y los procesos de descomposición de materia orgánica, entre otros. Por otra parte, las principales fuentes antropogénicas de emisión son las chimeneas de las instalaciones donde se producen procesos de combustión, los vehículos y los procesos industriales en general. En la Tabla 3 se muestran las fuentes de emisión de los principales contaminantes atmosféricos. Tal y como se observa, el porcentaje de emisiones procedentes de fuentes naturales es mayor para todos los contaminantes. Sin embargo, son los contaminantes procedentes de la actividad antropogénica los que suponen un mayor peligro para la salud humana y el medioambiente, ya que se emiten de forma continua y en zonas densamente pobladas.

Tabla 3. Fuentes de emisión de los principales contaminantes [25].

\begin{tabular}{ccc}
\hline \multirow{2}{*}{ Contaminante } & \multicolumn{2}{c}{ Fuentes de emisión } \\
\cline { 2 - 3 } Partículas & Antropogénicas (\%) & Naturales (\%) \\
\hline Óxidos de azufre & 11.3 & 88.7 \\
\hline Monóxido de carbono & 42.9 & 57.1 \\
\hline Óxidos de nitrógeno & 9.4 & 90.6 \\
\hline Hidrocarburos & 11.3 & 88.7 \\
\hline
\end{tabular}

La creciente preocupación por los efectos de la contaminación atmosférica ha dado lugar al establecimiento de políticas que controlen las emisiones de los contaminantes, y gracias a ello, hay una tendencia generalizada hacia la disminución de las emisiones. Sin embargo, es necesario continuar investigando en nuevos métodos y técnicas para la eliminación de estos contaminantes, así como ir actualizando la legislación en función de los hitos alcanzados. Con este fin se aprobó, en 1999, el protocolo de Gotemburgo para la reducción de la 
acidificación, de la eutrofización y del ozono en la troposfera. Este protocolo establece valores límite de emisiones a nivel nacional de cada uno de los países que lo firmaron. Los contaminantes objeto de estudio son los óxidos de nitrógeno, los óxidos de azufre, los compuestos orgánicos volátiles y el amoniaco. Dichos límites fuero negociados entres los países participantes en base a las evidencias científicas sobre los efectos de la contaminación y a las opciones de eliminación de los contaminantes disponibles. En ese sentido, los países que deben hacer un mayor esfuerzo en la reducción de las emisiones son aquellos en los que las emisiones tienen un impacto mayor en el medioambiente o en la salud, y aquellos países que tengan emisiones que sean relativamente fáciles de reducir. En este protocolo se establece que los países han de informar de sus emisiones una vez al año. En 2012, el protocolo fue modificado y se incluyeron nuevos límites a alcanzar a partir del año 2020. La Comunidad Europea se adhirió al Protocolo en 2003 y España lo ratificó en 2005 [26]. En la Figura 5 se muestran los porcentajes que separan las emisiones de España durante el año 2018 de los techos nacionales de emisión establecidos por el Protocolo de Gotemburgo.

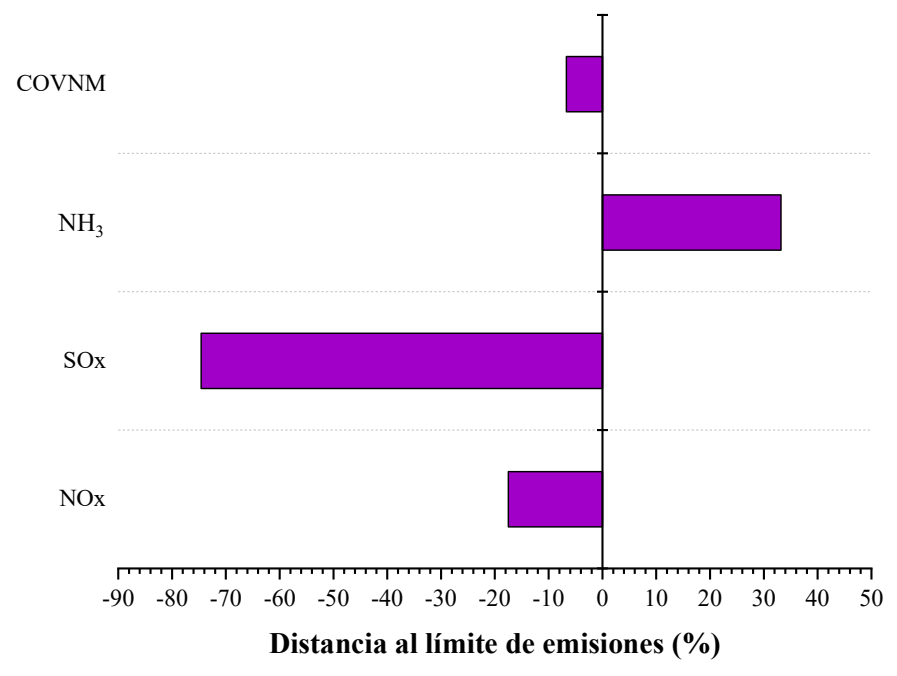

Figura 5. Distancia a los límites de emisiones del Protocolo de Gotemburgo de España en el año 2018 [27]. 
Como se observa, España ha conseguido rebajar las emisiones de todos los contaminantes por debajo del límite establecido, con excepción de las emisiones de amoniaco, las cuales sobrepasan un $33.2 \%$ el límite correspondiente a este contaminante. Estas emisiones provienen prácticamente en su totalidad de las actividades agrícolas y ganaderas. España es el país que más sobrepasa el límite de las emisiones de este contaminante, coincidiendo con que es uno de los países europeos con una mayor actividad agraria.

Cabe reseñar que la pandemia iniciada a finales de 2019 en Wuhan (China) a causa del COVID-19 ha tenido un enorme impacto en la reducción de las emisiones contaminantes, debido a la disminución de las actividades cotidianas. Esta reducción ha sido especialmente significativa en el sector del transporte. Los datos recogidos durante la pandemia muestran que las concentraciones de dióxido de nitrógeno (un contaminante emitido principalmente por los vehículos) disminuyeron significativamente en muchas ciudades de Europa en las que el confinamiento fue impuesto por los distintos gobiernos. Estas emisiones se redujeron hasta en un $70 \%$ en las grandes ciudades de los países más afectados por el COVID-19 (España, Italia y Francia). Sin embargo, estos niveles están volviendo a los valores previos a los confinamientos a medida que se levantan las restricciones.

Los principales contaminantes atmosféricos y sus características, efectos y fuentes de emisión se describen a continuación:

\section{- Óxidos de azufre (SO $\mathrm{x})$ :}

Los óxidos de azufre, nombrados como $\mathrm{SO}_{\mathrm{x}}$, se refieren al dióxido de azufre $\left(\mathrm{SO}_{2}\right)$ y al trióxido de azufre $\left(\mathrm{SO}_{3}\right)$. El primero es emitido a la atmósfera en mayor cantidad, sin embargo, el $\mathrm{SO}_{3}$ presenta una toxicidad diez veces mayor que el $\mathrm{SO}_{2}$ y es altamente corrosivo [28]. El $\mathrm{SO}_{3}$ emitido o formado al oxidarse el $\mathrm{SO}_{2}$, puede absorber agua y producir ácido sulfúrico, el cual permanece en la atmósfera en forma de aerosoles. Cuando estos aerosoles se depositan sobre la tierra pueden provocar los siguientes problemas: 
- Salud humana: problemas respiratorios, irritación de nariz y garganta.

- Medioambiente: daños sobre la vegetación y el suelo. Formación de lluvia ácida.

- Bienes materiales: degradación de materiales de construcción.

En la Tabla 4 se muestran las emisiones de $\mathrm{SO}_{\mathrm{X}}$ de los distintos sectores industriales en el año 2018 en España. Como se observa, las emisiones de los óxidos de azufre provienen principalmente de la quema de combustibles fósiles que contienen azufre en las centrales térmicas de producción de energía, seguido por la minería y la metalurgia no férrica.

Tabla 4. Emisiones de SOx en España en el año 2018 [27].

\begin{tabular}{|c|c|}
\hline$\underline{\text { Sector }}$ & SOx $(\mathbf{G g})^{\mathrm{a}}$ \\
\hline Producción de energía & 89 \\
\hline Procesos de fabricación y extracción & 72 \\
\hline Transporte & 11 \\
\hline Emisiones domésticas, comerciales e institucionales & 22 \\
\hline Agricultura-ganadería & 2 \\
\hline Eliminación y tratamiento de residuos & 2 \\
\hline TOTAL & 198 \\
\hline
\end{tabular}

\section{- Partículas en suspensión (PM):}

Las partículas en suspensión se encuentran en forma de aerosoles en la atmósfera y pueden ser tanto sólidas como líquidas, siendo clasificadas según el tamaño de sus diámetros. Las partículas con un diámetro inferior a $10 \mu \mathrm{m}$ son denominadas $\mathrm{PM}_{10}$ y las que poseen un diámetro menor a $2.5 \mu \mathrm{m}$ se denominan $\mathrm{PM}_{2.5}$. Estas 
últimas, tienen un mayor impacto negativo en la salud [29]. Los problemas que esta clase de contaminante pueden provocar son los siguientes:

- Salud humana: problemas pulmonares. Irritación de ojos y mucosas.

- Medioambiente: reducción de la visibilidad. Daños en la vegetación al depositarse sobre las plantas e impedir la fotosíntesis y la respiración

- Bienes materiales: erosión y abrasión de los materiales al depositarse sobre las superficies.

Tabla 5. Emisiones de PM en España en el año 2018 [27].

\begin{tabular}{ccc}
\hline$\underline{\text { Sector }}$ & $\mathbf{P M}_{2.5}(\mathbf{G g})^{\mathbf{a}}$ & $\mathbf{P M}_{\mathbf{1 0}}(\mathbf{G g})^{\mathbf{a}}$ \\
\hline $\begin{array}{c}\text { Producción de energía } \\
\text { Procesos de fabricación y extracción }\end{array}$ & 4.5 & 6.1 \\
\hline Transporte & 15.3 & 27.0 \\
\hline $\begin{array}{c}\text { Emisiones domésticas, comerciales e } \\
\text { institucionales }\end{array}$ & 11.7 & 16.0 \\
\hline $\begin{array}{c}\text { Agricultura-ganadería } \\
\text { Eliminación y tratamiento de residuos }\end{array}$ & 83.6 & 57.1 \\
\hline TOTAL & 125.3 & 34.0 \\
\hline
\end{tabular}

a $1 \mathrm{Gg}=1000 \mathrm{~T}$

En la Tabla 5 se recogen las emisiones de partículas en 2018 en España. Tal y como se observa, uno de los sectores que más emisiones de partículas produce es la agricultura. Sin embargo, la mayor parte de esas emisiones corresponden a las partículas de mayor tamaño $\left(\mathrm{PM}_{10}\right)$, las cuales son menos dañinas que las más pequeñas $\left(\mathrm{PM}_{2.5}\right)$. En ese sentido, las emisiones provenientes de emisiones 
domésticas, comerciales e industriales (como las emitidas por las calefacciones domésticas de fuel) son las más preocupantes.

\section{- Metales tóxicos:}

El problema de los metales tóxicos es que no son degradables, produciéndose la bioacumulación de los mismos en los organismos. Los metales más peligrosos son el mercurio y el plomo, los cuales atacan al sistema nervioso [25]. La Tabla 6 muestras las emisiones de estos dos metales en España en el año 2018. Como se observa, en España las emisiones de $\mathrm{Hg}$ son mucho más bajas que las del $\mathrm{Pb}$, proviniendo principalmente estas últimas de procesos de fabricación y extracción.

Tabla 6. Emisiones de Hg y Pb en España en el año 2018 [27].

\begin{tabular}{ccc} 
Sector & Hg $(\mathbf{G g})^{\mathbf{a}}$ & Pb $(\mathbf{G g})^{\mathbf{a}}$ \\
\hline Producción de energía & 2 & 2 \\
\hline $\begin{array}{c}\text { Procesos de fabricación y extracción } \\
\text { Transporte }\end{array}$ & 2 & 27 \\
\hline $\begin{array}{c}\text { Emisiones domésticas, comerciales e } \\
\text { institucionales }\end{array}$ & - & 1 \\
\hline $\begin{array}{c}\text { Agricultura-ganadería } \\
\text { Eliminación y tratamiento de residuos }\end{array}$ & - & 5 \\
\hline TOTAL & 4 & 90 \\
\hline
\end{tabular}

a $1 \mathrm{Gg}=1000 \mathrm{~T}$ 


\section{- Compuestos orgánicos volátiles (COV's):}

Se conoce como compuestos orgánicos volátiles a los compuestos químicos que se volatilizan fácilmente hacia la atmósfera. Dentro de este grupo, los más importantes son los hidrocarburos como el metano, el etano, el propano, el benceno y algunos disolventes. Los efectos dañinos de los COV's dependen del tipo de compuesto, pero por lo general, estos efectos son causados por contaminantes secundarios que se forman tras diversas reacciones fotoquímicas de los COV's en la atmósfera [30]. Los efectos nocivos más importantes son:

- Salud humana: muchos de ellos son cancerígenos.

- Medioambiente: efecto invernadero (metano). Smog fotoquímico

Tabla 7.Emisiones de COVNM en España en el año 2018 [27].

\begin{tabular}{cc}
\hline$\underline{\text { Sector }}$ & COVNM (Gg) ${ }^{\mathbf{a}}$ \\
\hline Producción de energía & 14 \\
\hline Procesos de fabricación y extracción & 357 \\
\hline Transporte & 30 \\
\hline Emisiones domésticas, comerciales e institucionales & 40 \\
\hline Agricultura-ganadería & 173 \\
\hline Eliminación y tratamiento de residuos & 10 \\
\hline
\end{tabular}

${ }^{\mathrm{a}} 1 \mathrm{Gg}=1000 \mathrm{~T}$

En la Tabla 7 se presentan los datos de las emisiones de compuestos orgánicos volátiles no metánicos (COVNM). 
Como se observa, la mayor parte de estos contaminantes proviene de industrias que emplean disolventes orgánicos, de la ganadería y de las emisiones producidas por el transporte.

\section{•Óxidos de nitrógeno y monóxido de carbono:}

Las emisiones y los problemas generados por el monóxido de carbono y los óxidos de nitrógeno se desarrollarán en los siguientes apartados, ya que la eliminación de ambos contaminantes es uno de los objetivos de esta tesis.

\subsection{2. Óxidos de nitrógeno}

La naturaleza reactiva del nitrógeno atómico $(\mathrm{N})$ y los diferentes estados de valencia que presenta $(+1,+2,+3,+4 \mathrm{y}+5)$ permiten a este elemento formar siete óxidos distintos que aparecen descritos en la Tabla 8 , en la que además se presentan algunas de sus características.

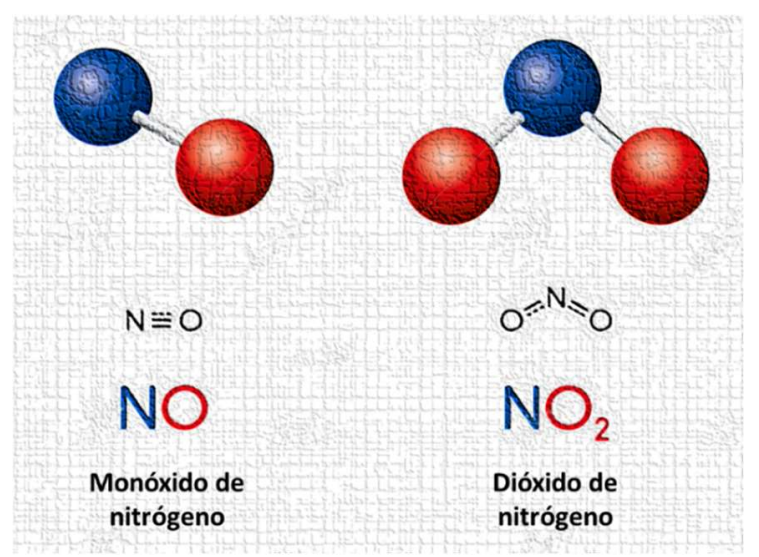

Figura 6. Moléculas de los NOx 
Tabla 8. Características de los óxidos de nitrógeno.

\begin{tabular}{|c|c|c|c|c|}
\hline Fórmula & $\underline{\text { Color }}$ & Estado de agregación $^{\mathrm{a}}$ & $\frac{\text { Solubilidad en agua }}{\left(\mathrm{g} \cdot \mathrm{dm}^{-3}\right)}$ & Propiedades \\
\hline $\mathbf{N}_{2} \mathrm{O}$ & Incoloro & Gas & 0.111 & $\begin{array}{c}\text {-Anestésico } \\
\text {-Participa en el efecto invernadero }\end{array}$ \\
\hline NO & Incoloro & Gas & 0.032 & $\begin{array}{l}\text {-Altamente tóxico } \\
-90-95 \% \text { de las emisiones } \\
\text { antropogénicas }\end{array}$ \\
\hline $\mathbf{N}_{2} \mathbf{O}_{3}$ & Negro & Líquido & 500 & $\begin{array}{c}\text {-Inestable } \\
\text {-Descompone rápidamente }\end{array}$ \\
\hline $\mathrm{NO}_{2}$ & Rojo pardo & Gas & 213 & -Tóxico \\
\hline $\mathbf{N}_{2} \mathbf{O}_{4}$ & Transparente & Líquido & 213 & $\begin{array}{c}\text {-Inestable } \\
\text {-Descompone formando } \mathrm{NO}_{2}\end{array}$ \\
\hline $\mathbf{N}_{2} \mathrm{O}_{5}$ & Blanco & Sólido & 500 & $\begin{array}{c}\text {-Inestable } \\
\text {-Descompone formando } \mathrm{NO}_{\text {y NO}}\end{array}$ \\
\hline
\end{tabular}


De todos los óxidos descritos, sólo el $\mathrm{N}_{2} \mathrm{O}$, el $\mathrm{NO}$ y el $\mathrm{NO}_{2}$ son estables en la atmósfera y se encuentran en concentraciones lo suficientemente altas como para tener efectos negativos en el medio ambiente y en la salud humana. En general, se distingue el $\mathrm{N}_{2} \mathrm{O}$ que es poco reactivo de los $\mathrm{NO}_{\text {y }} \mathrm{NO}_{2}$, que son muy reactivos y se agrupan bajo la nomenclatura de $\mathrm{NO}_{\mathrm{X}}$ (Figura 6).

\subsubsection{Emisiones y efectos de los óxidos de nitrógeno}

Las emisiones de los $\mathrm{NO}_{\mathrm{x}}$ pueden provenir de fuentes naturales y de fuentes antropogénicas. Las primeras engloban las emisiones resultantes de incendios forestales, de tormentas eléctricas o de descomposición de compuestos nitrogenados del suelo por actividad bacteriana. Sin embargo, los óxidos de nitrógeno que mayor impacto ambiental tienen son los provenientes de fuentes antropogénicas, especialmente las generadas durante combustiones a alta temperatura como las que se producen en los motores de los vehículos de automoción.

En España, en el año 2018, las emisiones de $\mathrm{NO}_{\mathrm{x}}$ se habían reducido en un 48 \% con respecto al año 1990. Sin embargo, a pesar de esta marcada disminución de las emisiones, en el año 2018 se vertieron 699000 toneladas de $\mathrm{NO}_{\mathrm{X}}$. En la Tabla 9 se recogen las contribuciones a las emisiones de este contaminante de los distintos sectores industriales. Tal y como se observa, las emisiones de $\mathrm{NO}_{\mathrm{X}}$ provienen principalmente del transporte. A este sector le siguen las emisiones provenientes de la ganadería y la agricultura, y las relacionadas con procesos de fabricación de fertilizantes. 
Tabla 9. Emisiones de NOx en España en el año 2018 [27].

\begin{tabular}{cc}
\hline$\underline{\text { Sector }}$ & NOx $(\mathbf{G g})^{\mathbf{a}}$ \\
\hline Producción de energía & 79 \\
\hline Procesos de fabricación y extracción & 117 \\
\hline Transporte & 281 \\
\hline Emisiones domésticas, comerciales e institucionales & 33 \\
\hline Agricultura-ganadería & 155 \\
\hline Eliminación y tratamiento de residuos & 34 \\
\hline TOTAL & 699 \\
\hline
\end{tabular}

a $1 \mathrm{Gg}=1000 \mathrm{~T}$

La presencia de los $\mathrm{NO}_{\mathrm{x}}$ en la atmósfera puede dar lugar a diversos problemas medioambientales y de la salud humana:

\section{a) Smog fotoquímico}

El smog fotoquímico es un tipo de contaminación asociadas con la presencia de los $\mathrm{NO}_{\mathrm{x}}$ y los COV's en la atmósfera, consistiendo en la formación de un aerosol compuesto por sustancias fuertemente irritantes y oxidantes. Estas sustancias se originan cuando los $\mathrm{NO}_{\mathrm{x}}$, los hidrocarburos, el oxígeno y la radiación ultravioleta del sol interaccionan entre sí. Suele producirse en áreas urbanas, en donde las emisiones industriales se combinan con la de los automóviles. El mecanismo de formación del smog fotoquímico es el siguiente: 
- Durante las primeras horas de la mañana se produce una gran cantidad de $\mathrm{NO}_{\mathrm{X}}$ e hidrocarburos debido al inicio de la actividad industrial y del aumento del transporte.

- En las horas más intensas de radiación solar, el $\mathrm{NO}_{2}$ absorbe radiación y se disocia en $\mathrm{NO}$ y en oxígeno atómico:

$$
\mathrm{NO}_{2}+\mathrm{h} v \rightarrow \mathrm{NO}+\mathrm{O}
$$

- El oxígeno atómico es muy reactivo, por lo que se combina con el oxígeno molecular para formar ozono:

$$
\mathrm{O}+\mathrm{O}_{2} \rightarrow \mathrm{O}_{3}
$$

- Siguiendo este ciclo, el ozono reaccionaría con el $\mathrm{NO}$ para dar $\mathrm{NO}_{2}$ y $\mathrm{O}_{2}$, por lo que las concentraciones de los $\mathrm{NO}_{\mathrm{X}}$ no variarían, ya que el $\mathrm{NO}$ y el $\mathrm{NO}_{2}$ se formarían y desaparecerían en cantidades iguales. Sin embargo, la presencia de hidrocarburos en la atmósfera altera este ciclo, ya que al reaccionar con el oxígeno atómico se generan numerosos radicales libres muy reactivos. Entre ellos, se encuentran los radicales peroxi que oxidan al NO:

$$
\mathrm{ROO}+\mathrm{NO} \rightarrow \mathrm{RO}+\mathrm{NO}_{2}
$$

- Muchos de los radicales RO generados condensan y dan lugar a cetonas, aldehídos, ácidos peróxidos, etc., los cuales reaccionan con el $\mathrm{NO}_{2}$ y forman aerosoles fuertemente irritantes que producen el smog fotoquímico. Los efectos del smog fotoquímico incluyen irritación de mucosas y vías respiratorias, reducción de la visibilidad y daños en la vegetación. 
En este ciclo también se forma ozono troposférico, que además de contribuir a la formación del smog fotoquímico, tienen otros efectos como la degradación de tejidos de animales, plantas y humanos, calcificación acelerada de los huesos de las personas y puede producir daños en el sistema nervioso si la exposición es alta y continuada.

\section{b) Lluvia ácida}

La lluvia ácida consiste en una precipitación que ha sido acidificada $(\mathrm{pH}<5.6)$ por la acción del ácido sulfúrico y el ácido nítrico. El ácido sulfúrico comprende un 60-70 \% de la lluvia ácida, mientras que el ácido nítrico representa alrededor de un $30 \%$. El resto (5-6 \%) lo componen otros ácidos como el ácido clorhídrico. El ácido nítrico que conforma la lluvia ácida se forma por los procesos de oxidación e hidratación de los $\mathrm{NO}_{\mathrm{x}}$ :

$$
\begin{gathered}
2 \mathrm{NO}+\mathrm{O}_{2} \rightarrow 2 \mathrm{NO}_{2} \\
3 \mathrm{NO}_{2}+\mathrm{H}_{2} \mathrm{O} \rightarrow 2 \mathrm{HNO}_{3}+\mathrm{NO}
\end{gathered}
$$

Los efectos de la lluvia ácida en el medioambiente y en la salud son muy variados. Puede producir la muerte de la vegetación y, en casos extremos, de bosques enteros. Otro efecto es la acidificación de los ríos y lagos, lo que produce la muerte de especias acuáticas. Además, la variación del $\mathrm{pH}$ de las aguas puede aumentar la solubilidad de metales tóxicos. El suelo también puede sufrir acidificación, que por un lado aumenta la movilidad de algunos cationes metálicos, afectando a las raíces de las plantas, y por otro, modifica los microorganismos presentes. Por último, la lluvia ácida puede degradar numerosos materiales de construcción y corroer algunos metales y aleaciones. Otra característica de la lluvia ácida es que, tras su formación, puede ser arrastrada durante kilómetros por la acción del viento, por lo que sus efectos se pueden notar incluso en zonas rurales en las que las emisiones de contaminantes son despreciables. 


\section{c) Efecto invernadero}

El $\mathrm{N}_{2} \mathrm{O}$ es un gas que participa en el llamado efecto invernadero, ya que absorbe la radiación infrarroja y contribuye al calentamiento terrestre. Esto, en principio, es beneficioso para la vida en la Tierra, pues evita variaciones bruscas de temperatura entre el día y la noche, y permite mantener unas condiciones de temperatura adecuadas para la vida. Sin embargo, el aumento de las emisiones de este contaminante y de otras moléculas (vapor de agua, metano, dióxido de carbono, clorofluorocarbonos, ozono) que dan lugar a este proceso también puede provocar un sobrecalentamiento de la superficie terrestre. Aunque las emisiones de este gas son menores que las de $\mathrm{CO}_{2}, \mathrm{el}_{2} \mathrm{O}$ tiene una capacidad de absorción de la radiación infrarroja 270 veces mayor que el dióxido de carbono.

\section{d) Adelgazamiento de la capa de ozono}

El ozono es uno de los principales componentes de la estratosfera. Su principal función es la de actuar como filtro de las radiaciones ultravioletas que provienen del sol. Este ozono se forma y se destruye cíclicamente, por lo que el espesor de la capa que conforma está en continua variación. Sin embargo, la presencia de determinados contaminantes en la estratosfera puede dar lugar a la alteración de este ciclo natural. Uno de estos contaminantes son los óxidos de nitrógeno provenientes de los aviones supersónicos y de los cohetes espaciales, que reaccionan con el ozono y provocan su descomposición:

$$
\begin{gathered}
\mathrm{NO}+\mathrm{O}_{3} \rightarrow \mathrm{NO}_{2}+\mathrm{O}_{2} \\
\mathrm{NO}_{2}+\mathrm{O} \rightarrow \mathrm{NO}+\mathrm{O}_{2}
\end{gathered}
$$

La presencia de este contaminante junto con otros (como los clorofluorocarbonos, CFC) en la estratosfera provoca un adelgazamiento de la capa de ozono, disminuyendo su capacidad para retener la radicación más energética proveniente del sol. 


\subsubsection{Control de las emisiones de los óxidos de nitrógeno}

La preocupación y la concienciación a nivel mundial sobre los problemas causados por la presencia de este contaminante en la atmósfera han dado lugar a una legislación cada vez más estricta para regular estas emisiones. Sin embargo, esto no es fácil ya que el número de vehículos, de plantas de producción de energía e industrias en general continúa aumentando. Todo ello hace que sea necesario el desarrollo de nuevas tecnologías efectivas y económicas para el control y eliminación de las emisiones de óxidos de nitrógeno [31]. Las tecnologías disponibles pueden ser clasificadas en dos grandes grupos:

\section{- Medidas primarias de control}

Las técnicas dentro de este grupo están diseñadas para la prevención o minimización de la formación de los $\mathrm{NO}_{\mathrm{x}}$ en los procesos de combustión. Estas técnicas se basan en la modificación de las condiciones de combustión, minimizando los picos de temperatura y el exceso de aire. En la Tabla 10 se resumen las principales técnicas primarias disponibles. 
1. Introducción

Tabla 10. Características de las principales medidas primarias para el control de los NOx.

\begin{tabular}{|c|c|c|c|c|}
\hline$\underline{\text { Técnica }}$ & Descripción & $\underline{\text { Ventajas }}$ & Desventajas & $\frac{\text { Reducción de }}{\underline{\text { NOx }}}$ \\
\hline $\begin{array}{l}\text { Quemadores LEA } \\
\text { (Low excess air) }\end{array}$ & $\begin{array}{c}\text { Reduce la } \\
\text { cantidad de } \mathrm{O}_{2} \\
\text { disponible } \\
\end{array}$ & $\begin{array}{c}\text {-Fácil instalación } \\
\text {-Aplicación en instalaciones ya } \\
\text { existente }\end{array}$ & $\begin{array}{l}\text {-Baja reducción de } \mathrm{NO}_{\mathrm{x}} \\
\text {-Puede generar } \mathrm{CO}\end{array}$ & $10-44 \%$ \\
\hline $\begin{array}{l}\text { Quemadores BOOS } \\
\text { (Burners out of } \\
\text { service) }\end{array}$ & \multirow[t]{2}{*}{$\begin{array}{l}\text { Combustión } \\
\text { escalonada }\end{array}$} & $\begin{array}{c}\text {-No requiere inversión } \\
\text { económica } \\
\text {-Aplicación en instalaciones ya } \\
\text { existente }\end{array}$ & $\begin{array}{l}\text {-Restringido a quema de } \\
\text { gases o fuel-oil }\end{array}$ & \multirow[t]{2}{*}{$10-70 \%$} \\
\hline $\begin{array}{l}\text { Quemadores OFA } \\
\text { (Over fire air) }\end{array}$ & & $\begin{array}{c}\text {-Se puede emplear en la quema } \\
\text { de todos los combustibles }\end{array}$ & -Inversión económica & \\
\hline $\begin{array}{l}\text { Quemadores LNB } \\
\text { (Low NOX burners) }\end{array}$ & $\begin{array}{l}\text { Combustión } \\
\text { interna } \\
\text { escalonada }\end{array}$ & -Baja inversión económica & $\begin{array}{l}\text {-Formación de coque } \\
\text {-Formación de } \mathrm{CO} \text { de } \mathrm{H}_{2} \mathrm{~S} \\
\text { y cenizas }\end{array}$ & $\begin{array}{l}\text {-LNB de aire } \\
\text { escalonado: } \\
25-35 \% \\
\text {-LNB de } \\
\text { recirculación: } \\
\text { hasta } 20 \% \\
\text {-LNB de } \\
\text { combustible } \\
\text { escalonado: } \\
50-60 \%\end{array}$ \\
\hline
\end{tabular}




\begin{tabular}{|c|c|c|c|c|}
\hline Técnica & Descripción & Ventajas & $\underline{\text { Desventajas }}$ & $\frac{\text { Reducción de }}{\underline{\text { NOx }}}$ \\
\hline $\begin{array}{l}\text { Recirculación de } \\
\text { gas de combustión }\end{array}$ & $\begin{array}{c}\text { Recirculación de } \\
\text { parte de los gases } \\
\text { de combustión } \\
(30 \%) \text { hacia el } \\
\text { flujo de aire }\end{array}$ & $\begin{array}{l}\text {-Alta eficiencia en combustibles } \\
\text { con bajo contenido en nitrógeno }\end{array}$ & $\begin{array}{l}\text {-Inversión económica } \\
\text { moderada } \\
\text {-Alto consumo energético } \\
\text {-Inestabilidad de la llama }\end{array}$ & $20-50 \%$ \\
\hline $\begin{array}{l}\text { Inyección de agua o } \\
\text { vapor }\end{array}$ & $\begin{array}{c}\text { Disminuye la } \\
\text { temperatura de la } \\
\text { llama }\end{array}$ & -Fácil instalación & $\begin{array}{l}\text {-Formación de } \mathrm{CO} \\
\text {-Pérdidas de eficiencia }\end{array}$ & $70-80 \%$ \\
\hline Recombustión & $\begin{array}{l}\text { Inyección de } \\
\text { combustible para } \\
\text { reducir los } \mathrm{NO}_{\mathrm{X}}\end{array}$ & -Coste económico moderado & $\begin{array}{l}\text {-Aumento del tiempo de } \\
\text { residencia } \\
\text {-Combustión incompleta } \\
\text {-Menos apropiada para } \\
\text { instalaciones ya existentes }\end{array}$ & $50-60 \%$ \\
\hline
\end{tabular}


A pesar de la gran variedad de técnicas primarias disponibles, la reducción máxima de $\mathrm{NO}_{\mathrm{X}}$ que se alcanza con estas técnicas no sobrepasa el $70-80 \%$, por lo que muchas veces no son suficientes para cumplir la normativa vigente. Asimismo, la eficacia de estas medidas primarias depende del diseño de la instalación y del tipo de combustible, por lo que no pueden ser aplicadas en todas las instalaciones de manera generalizada, sino que requieren de una aplicación especializada. Es por ello que se hace necesario el desarrollo de otras tecnologías que permitan un mayor porcentaje de reducción de $\mathrm{NO}_{\mathrm{X}}$, como son las medidas secundarias.

\section{- Medidas secundarias de control}

Este tipo de tecnologías tienen como fin la eliminación de los óxidos de nitrógeno presentes en los gases formados en los procesos de combustión. Estas medidas secundarias pueden ser divididas en dos grandes grupos: el primero consiste en la retención de los $\mathrm{NO}_{\mathrm{x}}$ presentes en los gases de combustión, y el segundo se enfoca en la destrucción de los $\mathrm{NO}_{\mathrm{X}}$ formados. En el primer caso, los óxidos de nitrógeno son eliminados mediante procesos de absorción o adsorción. Sin embargo, este tipo de medidas, además de no ser sencillas, conllevan la generación de residuos, los cuales será necesario tratar para poder desecharlos. Este problema no ocurre con las medidas del segundo grupo, ya que los $\mathrm{NO}_{\mathrm{X}}$ son transformados en productos benignos o inertes, como el nitrógeno [32]. Es por ello que las tecnologías de este segundo grupo son las más usadas en la actualidad. Las principales técnicas de este tipo son:

- La reducción selectiva no catalítica de los $\mathrm{NO}_{\mathrm{X}}$

- La reducción catalítica no selectiva de los $\mathrm{NO}_{\mathrm{X}}$

- La reducción catalítica selectiva de los $\mathrm{NO}_{\mathrm{X}}$.

\section{i) Reducción selectiva no catalítica de los $\mathrm{NO}_{\mathrm{X}}$}

La reducción selectiva no catalítica de los $\mathrm{NO}_{\mathrm{X}}(\mathrm{SNCR})$ consiste en la reducción selectiva de los óxidos de nitrógeno a $\mathrm{N}_{2}$ en presencia de oxígeno, empleando 
amoniaco como agente reductor. Se trata de un proceso homogéneo de reducción en fase gas que ocurre en el rango de temperaturas de $850-1175^{\circ} \mathrm{C}$ (Figura 7). El amoniaco se puede sustituir por urea que actuaría como precursor del amoniaco [33].

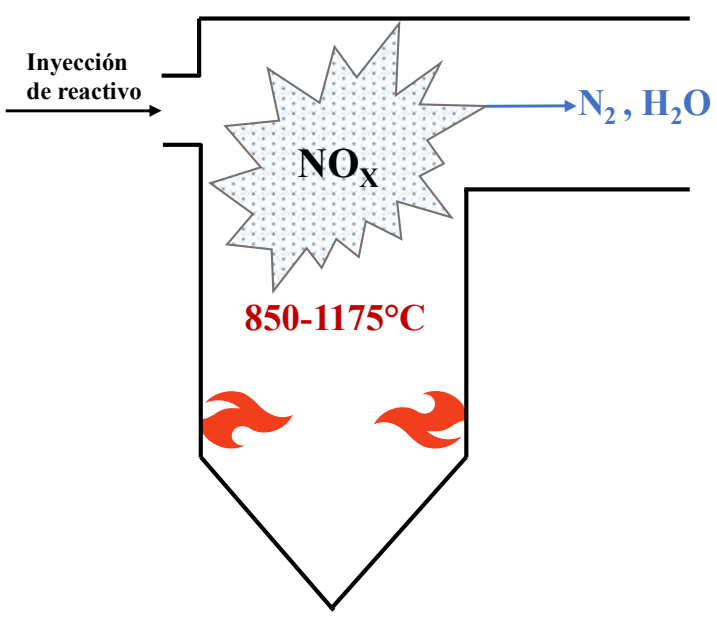

Figura 7. Esquema del proceso SNCR.

La primera aplicación comercial de este proceso tuvo lugar en 1974 por la compañía Exxon, alcanzando una eficacia de reducción de $\mathrm{NO}_{\mathrm{x}}$ de hasta el $65 \%$ empleando amoniaco [34]. Posteriores mejoras en el proceso han permitido alcanzar hasta un $90 \%$ de eficacia. Las reacciones que tienen lugar en el proceso con amoniaco son las siguientes [35]:

$$
\begin{gathered}
4 \mathrm{NH}_{3}+6 \mathrm{NO} \rightarrow 5 \mathrm{~N}_{2}+6 \mathrm{H}_{2} \mathrm{O} \\
4 \mathrm{NH}_{3}+4 \mathrm{NO}+\mathrm{O}_{2} \rightarrow 4 \mathrm{~N}_{2}+6 \mathrm{H}_{2} \mathrm{O}
\end{gathered}
$$




$$
8 \mathrm{NH}_{3}+6 \mathrm{NO}_{2} \rightarrow 7 \mathrm{~N}_{2}+12 \mathrm{H}_{2} \mathrm{O}
$$

A pesar de la elevada eficacia conseguida, es necesario trabajar a altas temperaturas, con el consiguiente coste energético, y con una elevada relación $\mathrm{NH}_{3} / \mathrm{NO}_{\mathrm{X}}$, lo cual puede dar lugar a la emisión del amoniaco que no ha reaccionado.

\section{ii) Reducción catalítica no selectiva de los $\mathrm{NO}_{\mathbf{x}}$}

La reducción catalítica no selectiva de los $\mathrm{NO}_{\mathrm{x}}(\mathrm{NSCR})$ consiste en la reducción de $\mathrm{NO}_{\mathrm{X}}$ mediante $\mathrm{CO}, \mathrm{H}_{2} \mathrm{o}$ hidrocarburos, empleando para ello un catalizador de $\mathrm{Pt}, \mathrm{Pd}, \mathrm{Rh}$ o $\mathrm{Ru}$. La reacción NSCR está relacionada con el empleo de los denominados catalizadores de tres vías. Mediante el empleo de estos catalizadores, primeramente, se oxida el $\mathrm{CO}$ y los hidrocarburos, ya que éstos reaccionan más rápidamente con el $\mathrm{O}_{2}$ que los $\mathrm{NO}_{\mathrm{x}}$. Este primer paso, hace que disminuya la cantidad de $\mathrm{O}_{2}$ en la mezcla de gases, permitiendo que los $\mathrm{NO}_{\mathrm{X}}$ sean reducidos a $\mathrm{N}_{2}$ y agua. El principal problema de esta reacción es que es necesario que la relación aire/combustible esté lo más cerca posible del valor estequiométrico, de lo contrario se produciría la oxidación de los reductores y se impediría la reducción de los $\mathrm{NO}_{\mathrm{x}}$.

\section{iii) Reducción catalítica selectiva de los $\mathrm{NO}_{\mathbf{x}}$}

De todas las tecnologías disponibles, la reducción catalítica selectiva de los óxidos de nitrógeno (SCR) es una de las más eficientes. Este proceso consiste en la reducción de los $\mathrm{NO}_{\mathrm{X}}$ a $\mathrm{N}_{2}$ y agua empleando un catalizador, en presencia de un agente reductor. Se trata de una reacción selectiva ya que, el reductor reacciona selectivamente con los $\mathrm{NO}_{\mathrm{x}}$ en presencia de $\mathrm{O}_{2}$, evitando la oxidación de los mismos. De los posibles agentes reductores descritos como amoniaco [36], hidrocarburos [37], monóxido de carbono [38], hidrógeno [39] y etanol [40], sólo los hidrocarburos y el amoniaco son suficientemente selectivos para ser empleados en gases de combustión que contienen oxígeno junto con los $\mathrm{NO}_{\mathrm{X}}$. En 
las emisiones de fuentes móviles, los hidrocarburos serían los reductores ideales, ya que éstos pueden estar presentes en los gases de combustión. Sin embargo, los catalizadores activos descritos para esta reacción (zeolitas intercambiadas con $\mathrm{Cu}$ o Co $[41,42]$ ) presentan problemas relacionados con la estabilidad hidrotérmica, lo que impide su uso a nivel comercial. Esto no ocurre con algunos de los catalizadores que usan $\mathrm{NH}_{3}$ como agente reductor, por lo que, el amoniaco (o su precursor, la urea) es el agente reductor más empleado industrialmente. Dado que la $\mathrm{SCR}$ de los $\mathrm{NO}_{\mathrm{x}}$ con amoniaco es uno de los objetivos principales de esta tesis, esta tecnología se describe más ampliamente en el siguiente apartado.

\subsubsection{Reducción catalítica selectiva de los óxidos de nitrógeno con amoniaco}

Como se ha comentado en el apartado anterior, la reducción catalítica selectiva de los $\mathrm{NO}_{\mathrm{X}}$ con amoniaco $\left(\mathrm{SCR}-\mathrm{NO}_{\mathrm{X}}\right.$ ) es una de las tecnologías disponibles para la eliminación de los $\mathrm{NO}_{\mathrm{X}}$ más eficiente y más empleada. Las principales reacciones que tienen lugar en este proceso son [43]:

$$
\begin{aligned}
& \text { SCR-estándar: } 2 \mathrm{NH}_{3}+2 \mathrm{NO}+\frac{1}{2} \mathrm{O}_{2} \rightarrow 2 \mathrm{~N}_{2}+3 \mathrm{H}_{2} \mathrm{O} \\
& \text { SCR-rápida: } 2 \mathrm{NH}_{3}+\mathrm{NO}+\mathrm{NO}_{2} \rightarrow 2 \mathrm{~N}_{2}+3 \mathrm{H}_{2} \mathrm{O} \\
& \text { SCR- } \mathrm{NO}_{2}: 4 \mathrm{NH}_{3}+3 \mathrm{NO}_{2} \rightarrow \frac{7}{2} \mathrm{~N}_{2}+6 \mathrm{H}_{2} \mathrm{O}
\end{aligned}
$$

Este proceso requiere de catalizadores que presenten una alta conversión de $\mathrm{NO}_{\mathrm{X}}$, que sean estables térmica e hidrotérmicamente, y que sean activos en un amplio rango de temperaturas. Los catalizadores disponibles en la actualidad son muy variados, pero pueden ser divididos en tres grandes grupos: a) metales nobles soportados, b) óxidos metálicos, y c) zeolitas $[32,44]$. 
El empleo de catalizadores basados en metales nobles como Pt, Pd, Ru, y $\mathrm{Rh}$ ha sido ampliamente investigado desde principios de los años 70. Estos catalizadores presentan una alta actividad catalítica en la reducción de los $\mathrm{NO}_{\mathrm{x}}$. Sin embargo, no destacan por su selectividad a $\mathrm{N}_{2}$, pues también oxidan al $\mathrm{NH}_{3}$ formando $\mathrm{NO}$ [45]. Esta baja selectividad, unido al elevado coste de estos materiales ha llevado a los investigadores a la búsqueda de otros tipos de catalizadores que solventen estas desventajas.

Los metales de transición han surgido como una alternativa interesante a los metales nobles debido a su bajo coste y su alta estabilidad hidrotérmica. Asimismo, estos metales tienen una gran facilidad para ganar o perder electrones del orbital $d$, lo que les confiere excelentes propiedades redox [46-48]. De hecho, los catalizadores más empleado comercialmente son los catalizadores basados en $\mathrm{V}_{2} \mathrm{O}_{5}-\mathrm{WO}_{3} / \mathrm{TiO}_{2}$ y $\mathrm{V}_{2} \mathrm{O}_{5}-\mathrm{MoO}_{3} / \mathrm{TiO}_{2}$ [49]. El óxido de titanio es comúnmente empleado como soporte, ya que da lugar a una alta dispersión de los metales soportados, presentando, además, una buena resistencia al envenenamiento. Por otra parte, estos sistemas formados por catalizadores de vanadio son altamente selectivos y activos en la reacción SCR-NOx con amoniaco. Sin embargo, la selectividad a $\mathrm{N}_{2}$ disminuye a altas temperaturas, y además, el vanadio es altamente tóxico[45]. Es por ello que se ha estudiado el uso de otros catalizadores para evitar estos problemas.

En este sentido, catalizadores basados en óxidos mixtos de metales de transición o metales de transición soportados en óxidos metálicos como $\mathrm{Cr} / \mathrm{TiO} 2$ [50], $\mathrm{Cr}$ $\mathrm{MnO}_{\mathrm{x}}$ [51], $\mathrm{Fe}-\mathrm{MnO}_{\mathrm{x}}$ [52], $\mathrm{Mn} / \mathrm{TiO}_{2}$ [53], $\mathrm{Fe}_{\mathrm{x}} \mathrm{TiO}_{\mathrm{y}}$ [54], $\mathrm{MnO}_{\mathrm{x}} / \mathrm{CeO}_{2}$ [55] y $\mathrm{Cu} / \mathrm{TiO}_{2}[56]$ han mostrado una buena actividad catalítica en la reacción SCR de los $\mathrm{NO}_{\mathrm{x}}$ con amoniaco. Peña et al. [57] estudiaron la reacción SCR-NOx con amoniaco en presencia de exceso de oxígeno con catalizadores basados en metales de transición soportados sobre $\mathrm{TiO}_{2}$ y encontraron que la actividad catalítica de los catalizadores disminuía en el orden $\mathrm{Mn}>\mathrm{Cu} \geq \mathrm{Cr}>>\mathrm{Co}>\mathrm{Fe}$ $>>\mathrm{V}>>\mathrm{Ni}$. Las excelentes propiedades catalíticas del Mn pueden deberse a sus propiedades redox, relacionadas con los distintos estados de valencia que presenta [58,59]. Panagiotis et al. [60] desarrollaron catalizadores basados en 
óxido de manganeso $\left(\mathrm{MnO}_{\mathrm{x}}\right)$ soportado sobre distintos óxidos $\left(\mathrm{TiO}_{2}, \mathrm{Al}_{2} \mathrm{O}_{3}\right.$ y $\mathrm{SiO}_{2}$ ), encontrando diferentes actividades en función del soporte empleado. Se vio que con estos catalizadores la actividad disminuye en el siguiente orden: $\mathrm{TiO}_{2}$ (anatasa, alta área superficial) $>\mathrm{TiO}_{2}$ (rutilo) $>\mathrm{TiO}_{2}$ (anatasa, rutilo) $>\mathrm{Al}_{2} \mathrm{O}_{3}>$ $\mathrm{SiO} 2>\mathrm{TiO}_{2}$ (anatasa, baja área superficial). El catalizador más activo $\left(\mathrm{Mn} / \mathrm{TiO}_{2}\right)$ mostró conversión completa de $\mathrm{NO}$ con una selectividad a $\mathrm{N}_{2}$ del $100 \%$ a $120{ }^{\circ} \mathrm{C}$. Resultados similares fueron obtenidos por Kang et al., obteniendo actividades catalíticas en el siguiente orden: $\mathrm{MnO}_{\mathrm{x}} / \mathrm{TiO}_{2} \approx \mathrm{MnO}_{\mathrm{x}} / \mathrm{Al}_{2} \mathrm{O}_{3}>$ $\mathrm{MnO}_{\mathrm{x}} / \mathrm{SiO}_{2}>\mathrm{MnOx} / \mathrm{Y}-\mathrm{ZrO}_{2}$, logrando el $100 \%$ de conversión a $175^{\circ} \mathrm{C}$ con el catalizador más activo y apareciendo una ligera disminución de la actividad al añadir $\mathrm{SO}_{2}$ o agua en el medio de reacción. Asimismo, se ha descrito que la adición de otros metales de transición a los catalizadores de manganeso, puede dar lugar a un aumento de la actividad catalítica y de la selectividad de los mismos [53,57,61-63], siendo la adición de hierro la que mejores resultados presenta. Qi et al. [62] estudiaron la actividad de catalizadores de Mn y Fe con distintas relaciones $\mathrm{Mn} / \mathrm{Fe}$ y soportados sobre $\mathrm{TiO}_{2}$. Los resultados mostraron que la adición de hierro a los catalizadores de manganeso no sólo aumenta la conversión de NO, sino que también aumenta la selectividad hacia nitrógeno y la resistencia frente a la presencia de $\mathrm{SO}_{2}$ y agua. La relación $\mathrm{Mn} / \mathrm{Fe}$ de 1 fue la que mejor resultados catalíticos presentó, obteniendo casi el $100 \%$ de conversión a $120^{\circ} \mathrm{C}$ con un $100 \%$ de selectividad a $\mathrm{N}_{2}$. Estos resultados concuerdan con los obtenidos por Wang et al. [64] quienes investigaron la actividad catalítica de catalizadores Mn-Fe soportados sobre alúmina, obteniendo los mejores resultados con el catalizador que contenía un $8 \%$ de Mn y un $8 \%$ de hierro. La actividad de estos catalizadores fue superior a la de los catalizadores monometálicos análogos, obteniendo más de un $98 \%$ de conversión a $120{ }^{\circ} \mathrm{C}$ con una selectividad a $\mathrm{N}_{2}$ del $100 \%$.

El otro gran grupo de catalizadores utilizados para la reacción $\mathrm{SCR}-\mathrm{NO}_{\mathrm{X}}$ con amoniaco es el de los catalizadores basados en zeolitas. Las zeolitas más investigadas para su empleo como catalizadores en esta reacción son las zeolitas de poro grande MOR y BEA, las zeolitas de poro medio ZSM-5 y FER, y las zeolitas de poro pequeño SSZ-13 y SAPO-34 [65]. En las últimas décadas, se ha 
hecho especial hincapié en las zeolitas de poro pequeño debido a la mayor estabilidad hidrotérmica que presentan [65]. En concreto, las zeolitas intercambiadas con cobre y hierro han mostrado excelente actividad catalítica en esta reacción. Este tipo de catalizadores es activo en un amplio rango de temperaturas, presentando además alta resistencia al envenenamiento con azufre y mejor estabilidad hidrotérmica que los catalizadores basados en vanadio. Leistner et al. [66] realizaron un estudio comparativo de catalizadores basados en cobre soportado en las zeolitas BEA, SSZ-13 y SAPO-34 para la reacción de reducción de $\mathrm{NO}_{\mathrm{X}}$ con amoniaco. Los resultados obtenidos mostraron que los catalizadores Cu-SAPO-34 y Cu-SSZ-13 eran más activos a $150{ }^{\circ} \mathrm{C}$ y menos selectivos hacia la formación de $\mathrm{N}_{2} \mathrm{O}$ que el catalizador Cu-BEA. Putluru et al. [67] investigaron la actividad catalítica de catalizadores basados en zeolitas con $\mathrm{Cu}, \mathrm{Fe}$ y $\mathrm{Mn}$. Las zeolitas empleadas fueron BEA, SSZ-13 y ZSM-5. Los resultados muestran que la adición de los tres metales a las distintas zeolitas da lugar a catalizadores activos en la SCR-NO $\mathrm{X}_{\mathrm{x}}$ con amoniaco, observando que las zeolitas con cobre y con manganeso son más activas a temperatura media, mientras que las zeolitas con hierro lo son a más altas temperaturas. En cuanto a la estabilidad hidrotérmica, los resultados más prometedores se encontraron con los catalizadores $\mathrm{Cu}$-CHA y Fe-BEA. Por otra parte, Gao et al. [68] encontraron que los catalizadores Fe-CHA no sólo presentan buena actividad catalítica, sino que además tienen una mayor estabilidad hidrotérmica en comparación con los catalizadores Fe-BEA y Fe-ZSM-5, manteniendo su estructura y la actividad catalítica por encima de $400{ }^{\circ} \mathrm{C}$. Sin embargo, la actividad de este catalizador a bajas temperaturas disminuye, por lo que sería necesaria su combinación con un catalizador $\mathrm{Cu}-\mathrm{CHA}$ para mantener la actividad y la selectividad en todo el rango de temperaturas. En ese sentido, Sultana et al. [69] encontraron que los catalizadores $\mathrm{Cu}-\mathrm{Fe}-\mathrm{ZSM}-5$ presentan mayor actividad en comparación con Fe-ZSM-5 o Cu-ZSM-5. Esto se relacionaría con el hecho de que la presencia de $\mathrm{Cu}$ aumenta la reducibilidad del $\mathrm{Fe}$, aumentando también la fortaleza de los centros ácidos en los catalizadores Cu-Fe-ZSM-5. 


\subsubsection{Monóxido de carbono}

El monóxido de carbono (Figura 8) es un gas incoloro e inodoro constituido por un átomo de carbono y otro de oxígeno. Se trata de un gas muy poco soluble en agua y cuya densidad es el $96.5 \%$ de la del aire. El CO es una molécula estable que tiene una vida media en la atmósfera de 2 a 4 meses, siendo uno de los principales contaminantes atmosféricos. Este gas se genera principalmente en las combustiones incompletas, es decir, cuando hay un exceso de combustible o un defecto de comburente en la mezcla de reacción.

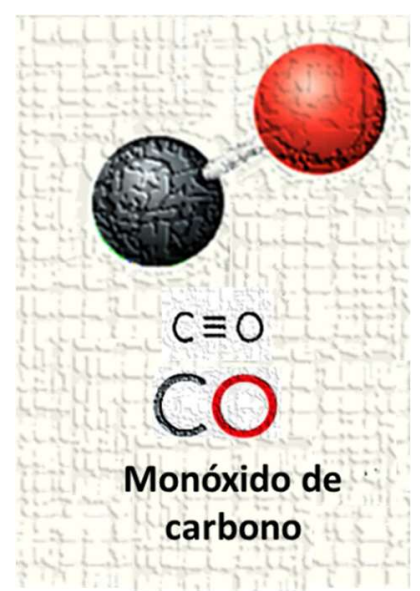

Figura 8. Molécula de CO.

\subsubsection{Emisiones y efectos del monóxido de carbono}

$\mathrm{Al}$ igual que ocurre con los $\mathrm{NO}_{\mathrm{x}}$, la mayor parte del $\mathrm{CO}$ presente en la atmósfera proviene de fuentes naturales como incendios forestales, descomposición de materia orgánica, volcanes, etc. Sin embargo, las emisiones preocupantes no son estas, sino las producidas por fuentes antropogénicas.

Estas emisiones han disminuido casi un $60 \%$ con respecto al año 1990, sin embargo, la cantidad de $\mathrm{CO}$ emitida sigue siendo alta. Tal y como se observa en la Tabla 11, uno de los sectores que más emisiones produce es el de los procesos de fabricación y extracción, en concreto, la metalurgia ferrosa. A este sector le 
siguen las emisiones domésticas que provienen principalmente de las calderas térmicas. En cuanto al sector de eliminación y tratamiento de residuos, las emisiones son debidas a la incineración de estos. Por último, cabe resaltar que el transporte también emite una cantidad significativa de CO.

Tabla 11. Emisiones de CO en España en el año 2018 [27].

\begin{tabular}{cc}
\hline$\underline{\text { Sector }}$ & CO (Gg) \\
\hline Producción de energía & 35 \\
\hline Procesos de fabricación y extracción & 497 \\
\hline Transporte & 190 \\
\hline Emisiones domésticas, comerciales e institucionales & 455 \\
\hline Agricultura-ganadería & 49 \\
\hline Eliminación y tratamiento de residuos & 421 \\
\hline a $1 \mathrm{Gg}=1000 \mathrm{~T}$ & 1647 \\
\hline
\end{tabular}

El principal problema asociado a este contaminante es su alta afinidad con la hemoglobina de la sangre. La hemoglobina $(\mathrm{Hb})$ es la encargada de transportar el oxígeno en los organismos. Para ello, se une a las moléculas de oxígeno que entran en los organismos mediante la respiración formando la oxihemoglobina $\left(\mathrm{HbO}_{2}\right)$. Sin embargo, dado que la afinidad de la hemoglobina por el $\mathrm{CO}$ es unas 200-250 veces mayor que por el oxígeno, cuando entran moléculas de CO al organismo, se forma la carboxihemoglobina ( $\mathrm{HbCO}$ ), desplazando la formación de la $\mathrm{HbO}_{2}$. De esta manera, el transporte de oxígeno por el organismo queda limitado, ya que el enlace $\mathrm{CO}-\mathrm{Hb}$ es irreversible y la hemoglobina ya no tendría 
la capacidad de captar el oxígeno. La reducción de la capacidad de transporte de oxígeno es proporcional a la cantidad de $\mathrm{HbCO}$ presente en la sangre, pudiendo producir la muerte en caso de altas concentraciones. Esto no sólo afecta a los seres humanos, sino que también a los animales. La respiración de las plantas también puede verse afectada por la presencia de este contaminante.

Además de interferir en el transporte de oxígeno, el CO puede tener un efecto tóxico al unirse a otras proteínas como la mioglobina, catalasas, peroxidasas, provocando distintos problemas de salud, como problemas cardíacos, cefaleas, y en casos extremos, dando lugar a la muerte.

\subsubsection{Control de las emisiones de monóxido de carbono}

Dada la alta toxicidad que presenta este contaminante para la salud, es necesario el desarrollo de tecnologías que permitan el control de sus emisiones. Al igual que para los $\mathrm{NO}_{\mathrm{X}}$, estas tecnologías pueden ser divididas en dos grupos:

\section{- Medidas primarias de control}

Como ya se ha explicado anteriormente, este tipo de medidas busca la modificación de las condiciones de los procesos de combustión para evitar la formación de los contaminantes, en este caso, del monóxido de carbono. Esto se consigue trabajando con un exceso de aire sobre la cantidad estequiométrica, aumentando la temperatura de la cámara de combustión, el tiempo de residencia del combustible y la turbulencia de los gases. Esto permitirá que tenga lugar una oxidación completa de los combustibles, evitando la formación de CO. Sin embargo, esto también puede aumentar la emisión de otros contaminantes tales como los $\mathrm{NO}_{\mathrm{X}}$.

\section{- Medidas secundarias de control:}

A diferencia de las medidas primarias que buscan evitar la formación de $\mathrm{CO}$, las medidas secundarias se basan en la eliminación del CO formado en los procesos, antes de que los gases sean emitidos a la atmósfera. Las tecnologías más empleadas debido a su eficacia son: 


\section{i) Absorción}

Esta técnica se basa en la eliminación de las emisiones de CO mediante su absorción en líquidos que contienen metales de transición, los cuales se enlazan con el CO, eliminándolo selectivamente del flujo gaseoso. Para ello, las unidades de absorción de las instalaciones han de permitir un contacto total entre el gas y el líquido absorbente, de manera que haya difusión en la interfase entre el líquido y el gas. Los absorbedores más empleados son las torres empacadas o los absorbedores Venturi. Estos contienen una disolución de formato de cobre o amoniaco en la que el CO queda absorbido. No obstante, la capacidad de absorción de estas unidades es limitada.

\section{ii) Oxidación térmica}

La oxidación térmica es una técnica ampliamente usada cuando la concentración de CO de la corriente de los gases residuales es baja. Por lo general, los gases son precalentados en un intercambiador de calor y a continuación, se hacen pasar por un quemador provisto con combustible adicional, en el cual los gases se queman completamente con el oxígeno presente en la corriente gaseosa. Si la cantidad de oxígeno no es suficiente para la combustión completa, hay que añadir un soplador o ventilador al sistema. La principal ventaja de esta técnica es que opera en un intervalo de temperaturas de $550-800{ }^{\circ} \mathrm{C}$, lo que hace menos costoso el diseño del quemador, a la vez que hace menos probable la formación de óxidos de nitrógeno.

\section{iii) Oxidación catalítica}

En esta técnica, los gases a tratar se hacen pasar a través de un lecho catalítico que favorece la reacción entre el $\mathrm{CO}$ y el $\mathrm{O}_{2}$. En este caso, los tiempos de residencia requeridos son de unas 20 a 50 veces menores que en los quemadores de tipo térmico. Asimismo, es posible conseguir eficiencias de eliminación de CO del 95-98 \%, operando a temperaturas inferiores a las usadas en la oxidación térmica. Dado que esta tecnología es uno de los objetivos principales de esta tesis, sus características serán desarrolladas más ampliamente en el siguiente apartado. 


\subsubsection{Oxidación catalítica de monóxido de carbono}

Como se ha comentado previamente, una de las tecnologías más eficientes para la eliminación del monóxido de carbono es la oxidación catalítica, en la que el $\mathrm{CO}$ es convertido a $\mathrm{CO}_{2}$ :

$$
2 \mathrm{CO}+\mathrm{O}_{2} \rightarrow 2 \mathrm{CO}_{2}
$$

La hopcalita es uno de los catalizadores más empleados comercialmente desde hace años para la oxidación de $\mathrm{CO}$ a bajas temperaturas. Se trata de un óxido amorfo binario de $\mathrm{Mn}$ y $\mathrm{Cu}\left(\mathrm{CuMnO}_{\mathrm{x}}\right)$. Su uso se ha extendido ampliamente debido a su bajo coste y a su alta actividad. Se trata de un catalizador que permite la oxidación de $\mathrm{CO}$ incluso a temperatura ambiente. Se ha descrito que el óxido de cobre es poco activo para la oxidación de $\mathrm{CO}$, sin embargo, cuando es mezclado en proporciones adecuadas con el óxido de manganeso se consigue una alta actividad catalítica. No obstante, estos catalizadores sufren procesos de desactivación que pueden ser causados por dos factores. Por una parte, se ha descrito que la superficie de estos materiales puede ser saturada con carbonatos, lo que obstaculizaría la interacción de los centros activos con los reactivos. Por otra parte, las temperaturas superiores a $500{ }^{\circ} \mathrm{C}$ provocarían la transición de la fase amorfa a la fase cristalina de la hopcalita, la cual presenta una superficie específica mucho menor [70]. Asimismo, se ha descrito que la adición de algunos metales como $\mathrm{Au}, \mathrm{Ce}$ y $\mathrm{Co}$ en la hopcalita dan lugar a una mejora de la actividad de estos catalizadores. En el caso de la adición de $\mathrm{Au}$, se producen cambios electrónicos en la superficie de $\mathrm{CuMnO}_{\mathrm{x}}$, lo que provoca que la oxidación de $\mathrm{CO}$ ocurra más rápidamente que cuando sólo está presente la hopcalita [71]. La presencia de $\mathrm{Ce}$ en el catalizador CuMnOx también parece mejorar su actividad, lo que se ha relacionado con una mejora de la movilidad del oxígeno, proporcionada por el $\mathrm{CeO}_{2}$, así como con un aumento de las propiedades redox de la hopcalita [72]. Se ha descrito también el uso de catalizadores de hopcalita preparados con cobalto, los cuales presentan un área superficial mayor que la hopcalita de partida, resultando en un aumento de su actividad catalítica [70]. 
Por otro lado, el desarrollo de los convertidores catalíticos asociados a los coches puso de manifiesto las excelentes propiedades catalíticas de los metales nobles ( $\mathrm{Au}, \mathrm{Pt}, \mathrm{Pd}$ y Rh) en la oxidación catalítica de $\mathrm{CO}$, los cuales presentan una alta actividad catalítica a bajas temperaturas. Por ejemplo, Glaspell et al. [73] estudiaron la actividad de catalizadores de paladio soportados sobre distintos óxidos $\left(\mathrm{Al}_{2} \mathrm{O}_{3}, \mathrm{SiO}_{2}\right.$ y $\left.\mathrm{ZrO}_{2}\right)$, encontrando que la actividad catalítica dependía del soporte empleado. Los catalizadores preparados sobre $\mathrm{CeO}_{2}$ presentaban la mejor actividad catalítica, obteniendo un $100 \%$ de conversión a $108^{\circ} \mathrm{C}$, seguido por los catalizadores soportados sobre zirconia, y siendo los catalizadores de $\mathrm{SiO}_{2}$ los menos activos. Esta mayor actividad de los catalizadores preparados con $\mathrm{CeO}_{2} \mathrm{se}$ atribuye a la mayor área superficial de este óxido, lo que da lugar a una alta dispersión del Pd. Asimismo, la naturaleza del oxígeno superficial presente en estos óxidos se cree que tiene un efecto positivo en la actividad de los catalizadores en esta reacción. Un estudio similar fue realizado por Ligthart et al. [74] pero empleando $\mathrm{Rh}$ como fase activa y $\mathrm{CeO}_{2}, \mathrm{ZrO}_{2}, \mathrm{CeZrO}_{2}$ y $\mathrm{SiO}_{2}$ como soportes. Los resultados también mostraron que el soporte tiene una importante influencia en la dispersión del $\mathrm{Rh} \mathrm{y}$, por tanto, en la actividad catalítica, encontrando que esta aumenta según el orden $\mathrm{Rh} / \mathrm{SiO}_{2}<\mathrm{Rh} / \mathrm{ZrO}{ }_{2}<\mathrm{Rh} / \mathrm{CeZrO}_{2}$ $<\mathrm{Rh} / \mathrm{CeO}_{2}$.

Por otra parte, Bamwenda et al. [75] investigaron el empleo de catalizadores de platino y oro soportados sobre $\mathrm{TiO}_{2}$ preparados por diferentes métodos (deposición-precipitación, impregnación y deposición fotoquímica). Los resultados mostraron que la actividad de los catalizadores en la oxidación de CO es altamente dependiente del método de preparación en el caso de los catalizadores de $\mathrm{Au}$, mientras que no afecta a los catalizadores de Pt. El catalizador de Au preparado por deposición-precipitación fue más activo que el de Pt preparado por el mismo método. Sin embargo, los catalizadores preparados por los otros dos métodos fueron más activos cuando se empleó Pt en lugar de Au. No obstante, este tipo de catalizadores operan a temperaturas por debajo de los $100^{\circ} \mathrm{C}$, por lo que se desactivan al acumularse los carbonatos o bicarbonatos en la superficie del catalizador, los cuales no son descompuestos dadas las bajas temperaturas empleadas para la reacción [76]. 
Debido el alto coste de los catalizadores basados en metales nobles, los óxidos de metales de transición han surgido como una alternativa más económica. El empleo de catalizadores basados en $\mathrm{CuO}$ ha sido investigado por Liu et al. [77]. En este trabajo se comparó la actividad del $\mathrm{CuO}$ bulk, de nano-CuO, de $\mathrm{CeO}_{2}$ bulk y de un sistema $\mathrm{Cu}-\mathrm{Ce}-\mathrm{O}$. Los resultados mostraron que, a bajas temperaturas, no existía diferencia en la actividad de los catalizadores $\mathrm{CuO}$ con distinto tamaño de partículas, mientras que, a altas temperaturas, la actividad del nano-CuO disminuía considerablemente debido a la sinterización de las nanopartículas. Por otra parte, la actividad del $\mathrm{CeO}_{2}$ aumentaba drásticamente al incorporar cobre en el catalizador, obteniendo $100 \%$ de conversión a $100{ }^{\circ} \mathrm{C}$. Otro óxido muy usado como catalizador en esta reacción es el $\mathrm{Co}_{3} \mathrm{O}_{4}$. Xie et al. [78] prepararon catalizadores basados en nanorods de $\mathrm{Co}_{3} \mathrm{O}_{4}$ que presentaban un alta actividad catalítica en esta reacción a temperaturas tan bajas como $-77^{\circ} \mathrm{C}$, presentando además una alta estabilidad en corrientes de gases ricos en $\mathrm{H}_{2} \mathrm{O}$ y $\mathrm{CO}_{2}$ a $200-400{ }^{\circ} \mathrm{C}$. Biabani-Ravandi et al. [79] diseñaron catalizadores basados en óxidos mixtos de Fe y Co para la oxidación de CO. Los resultados obtenidos mostraron que la adición de cobalto a los óxidos de hierro provocaba un aumento en la actividad de estos catalizadores, obteniendo un $100 \%$ de conversión a temperaturas inferiores a $100{ }^{\circ} \mathrm{C}$, inhibiendo la desactivación de los catalizadores por la formación de carbonatos descrita para los catalizadores de óxidos de cobalto puros.

Un grupo especial de catalizadores empleados para la oxidación catalítica de CO son los basados en nanopartículas metálicas, los cuales han sido ampliamente investigados en los últimos años. Las nanopartículas metálicas se caracterizan por tener propiedades únicas que pueden ser aplicadas en diversas aplicaciones $y$, particularmente, en el campo de la catálisis. Numerosos estudios se han centrado en la síntesis y aplicación de nanomateriales basados en metales, en óxidos metálicos o en aleaciones, en procesos de control de la contaminación ambiental [80]. En ese sentido, Haruta et al. [81] describieron las propiedades catalíticas excepcionales de las nanopartículas de oro en la reacción de oxidación de CO. Desde ese momento, se han realizado numerosas investigaciones para el desarrollo de catalizadores activos en la oxidación de $\mathrm{CO}$ basados en 
nanopartículas de oro. En particular, los nanoclusters de oro protegidos por ligandos tiolatos $\left(\mathrm{Au}_{\mathrm{n}}(\mathrm{SR})_{\mathrm{m}}\right)$ han demostrado ser catalizadores que presentan muy buena actividad catalítica [82-84]. En general, la actividad catalítica de estas nanopartículas o nanoclusters depende de distintos factores como el estado de valencia del metal [85], el tamaño de la nanopartícula o del nanocluster [86,87], las condiciones de pretratamiento [88], los ligandos [89], y el soporte empleado [90,91]. Pollit et al. [92] investigaron la actividad catalítica de nanoclusters $\mathrm{Au}_{38}(\mathrm{SR})_{24}$ soportados sobre $\mathrm{CeO}_{2}$ en la oxidación de $\mathrm{CO}$. La mejor actividad la encontraron al pretratar las muestras a $250{ }^{\circ} \mathrm{C}$ con oxígeno, ya que en estas condiciones se produce la eliminación del $\mathrm{S}$ de los ligandos, lo que resulta en una mayor actividad en comparación con las muestras pretratadas a $150^{\circ} \mathrm{C}$, en las que el azufre no es eliminado por completo y produce el envenenamiento de los centros activos. A diferencia de esto, Li et al. [93] encontraron que la actividad de los catalizadores basados en $\mathrm{Au}_{36}(\mathrm{SR})_{24}$ no variaba en función de la temperatura empleada en el pretratamiento. Sin embargo, demostraron que existían diferencias catalíticas según el tamaño de los nanoclusters, siendo los nanoclusters $\mathrm{Au}_{38}(\mathrm{SR})_{24}$ más activos que los catalizadores basados en $\mathrm{Au}_{36}(\mathrm{SR})_{24}$. El efecto del soporte empleado en los catalizadores basados en nanoclusters $\mathrm{Au}_{25}(\mathrm{SR})_{18}$ fue investigado por Nie et al. [94]. Para ello, prepararon catalizadores con estos nanoclusters soportados sobre $\mathrm{CeO}_{2}, \mathrm{TiO}_{2}$ y $\mathrm{Fe}_{2} \mathrm{O}_{3}$, obteniendo un $60 \%$ de conversión a $160{ }^{\circ} \mathrm{C}$ con el catalizador soportado sobre $\mathrm{CeO}_{2}$, siendo necesario aumentar la temperatura hasta casi $200{ }^{\circ} \mathrm{C}$ para conseguir la misma conversión con el catalizador soportado sobre $\mathrm{Fe}_{2} \mathrm{O}_{3}$. El catalizador preparado con $\mathrm{TiO}_{2}$ resultó ser inactivo en la reacción en todo el rango de temperatura.

Las propiedades de los nanoclusters metálicos pueden ser modificadas mediante la adición de otros metales en su estructura [95], lo que implica también una modificación de las propiedades catalíticas. En el caso de los nanoclusters de oro $\left(\mathrm{Au}_{25}\right)$, se ha descrito la sustitución de un átomo de oro central por 16 metales distintos [96]. Tsukuda et al. [97] han demostrado que la introducción de un átomo de plata en la estructura del nanocluster $\mathrm{Au}_{25}$ da lugar a una estructura más estable, lo cual es importante para la aplicación catalítica de estos materiales. El efecto de la adición de otros metales a los nanoclusters de oro ha sido estudiado 
en la reacción de oxidación de $\mathrm{CO}$, encontrándose que para nanoclusters soportados sobre $\mathrm{CeO}_{2}$ la actividad catalítica sigue la tendencia $\mathrm{Cu}_{\mathrm{x}} \mathrm{Au}_{25-\mathrm{x}}(\mathrm{SR})_{18}$ $>\mathrm{Au}_{25}(\mathrm{SR})_{18}>\mathrm{Ag}_{\mathrm{x}} \mathrm{Au}_{25-\mathrm{x}}(\mathrm{SR})_{18}[98]$.

Asimismo, al igual que ocurre con las nanopartículas de oro, los catalizadores basados en nanopartículas de plata también han mostrado actividad catalítica significativa en la reacción de oxidación de CO [99]. Sin embargo, la estabilidad de estos catalizadores no es tan buena como la de los nanoclusters de oro. Yu et al. [100] encontraron una clara dependencia del tamaño de las nanopartículas en la actividad de catalizadores basados en nanopartículas de plata soportados sobre $\mathrm{SiO}_{2}$. En ese sentido, los resultados mostraron que los catalizadores con partículas con un tamaño entre 3 y $5 \mathrm{~nm}$ eran los más activos, alcanzando un $100 \%$ de conversión a $150{ }^{\circ} \mathrm{C}$. Por otra parte, Liu et al. [101] describieron que el empleo de $\mathrm{SiO}_{2}$ mesoestructurado como soporte para nanopartículas de plata daba lugar a un aumento sustancial de la actividad en la oxidación de $\mathrm{CO}$ en comparación con catalizadores de nanopartículas preparados con $\mathrm{SiO}_{2}$ convencional, obteniendo el $100 \%$ de conversión a temperatura ambiente.

Por último, cabe comentar que la reacción de oxidación catalítica de $\mathrm{CO}$ ha sido ampliamente usada como una reacción test, ya que se trata de una reacción en la que se obtiene un único producto, el $\mathrm{CO}_{2}$, el cual interacciona de una manera mucho más débil con la superficie de los catalizadores. Es por ello, que la oxidación de $\mathrm{CO}$ es una reacción excelente para el estudio de los mecanismos y de las interacciones reactivos-catalizador $[102,103]$.

\subsection{Química Fina}

La Química Fina es un área de la química que tiene como fin la síntesis de compuestos químicos complejos, con una alta pureza, producidos en cantidades limitadas (un volumen inferior a 1000 toneladas anuales) y cuyo precio es superior a $8 € / \mathrm{kg}$ [104]. Sin embargo, se trata de productos con un alto valor añadido, lo que justifica los altos costes de los procesos [105]. Por lo general, no se hace distinción entre los productos de química fina, que pueden ser tanto 
moléculas precursoras de otras moléculas, como productos finales tales como fármacos, pesticidas, fragancias, saborizantes, y otros similares [104]. Desde un punto de vista químico, estos productos son moléculas complejas multifuncionales, y consecuentemente, presentan una baja volatibilidad y una estabilidad térmica limitada. Esto implica que los procesos, generalmente, tienen lugar en fase líquida a presión atmosférica. Por otra parte, la fabricación de los productos de Química Fina precisa de síntesis con varias etapas (5-10 etapas para productos farmacéuticos y 3-7 para productos agroquímicos), dando lugar a grandes cantidades de productos indeseados.

Un indicador de la producción de subproductos es el factor E, que se define como la relación $\left(\mathrm{kg}_{\text {subproducto }} / \mathrm{kg}_{\text {producto }}\right)$. Como puede observarse en la Tabla 12, el factor E aumenta drásticamente en los procesos de Química Fina en comparación con el resto de procesos industriales [104].

Tabla 12. Factor $\mathbf{E}$ en las distintas industrias.

\begin{tabular}{|c|c|c|}
\hline Área industrial & $\frac{\text { Volumen de producción }}{\underline{\text { (toneladas/año) }}}$ & $\begin{array}{c}\underline{\text { Factor E }} \\
\underline{\left.\text { (kg subproducto } / \mathbf{k g}_{\text {producto }}\right)}\end{array}$ \\
\hline Refino de petróleo & $10^{6}-10^{8}$ & $\sim 0.1$ \\
\hline Química bulk & $10^{4}-10^{6}$ & $<1-5$ \\
\hline Química Fina & $10^{2}-10^{4}$ & $5-50$ \\
\hline Farmacéutica & $10-10^{2}$ & $>100$ \\
\hline
\end{tabular}

Todo lo descrito anteriormente hace que la Química Fina, por lo general, no cumpla los requisitos de sostenibilidad promovidos por la Química Verde. En ese sentido, el empleo de la catálisis en estos procesos puede contribuir a desarrollar métodos más sostenibles, mejorando los procesos de producción, y ayudando a eliminar o transformar los subproductos indeseados. A continuación se enumeran 
algunos casos en los que el empleo de la catálisis da lugar a una Química Fina más sostenible [104], bien sea por posibilitar nuevas reacciones como:

- Hidrogenación de compuestos aromáticos

- Metátesis de olefinas

- Reducción Rosenmund de cloruros de arilo

- Hidrogenación selectiva de alquinos a cis-olefinas

bien sea por permitir la combinación de varias transformaciones en una sola etapa:

- Alquilación reductiva de aminas con compuestos carbonilos

- Hidrogenación-acilación de nitroarenos a acilanilinas

- Alquilación directa de aminas con alcoholes mediante una secuencia deshidrogenación-condensación-hidrogenación

o bien sea por la sustitución de productos químicos tóxicos o problemáticos:

- Alquilación de aminas o aromáticos con alcoholes en lugar de haluros de alquilo (disminución de la producción de sales)

- Empleo de $\mathrm{H}_{2}$ en lugar de metales, hidruros de metal o sulfuros

- Empleo de $\mathrm{H}_{2} \mathrm{O}_{2}$ o $\mathrm{O}_{2}$ en lugar de óxidos metálicos o perácidos

- Sustitución de ácidos solubles por ácidos y bases sólidos

Entre todas estas reacciones, en esta tesis se va a estudiar el empleo de catalizadores para la semihidrogenación de alquinos a alquenos, por lo que la misma se describe con más detalle en el siguiente apartado. 


\subsubsection{Semihidrogenación de alquinos}

Entre los procesos catalíticos más comúnmente empleados en la industria, la hidrogenación selectiva de grupos funcionales es uno de los más importantes. En concreto, la semihidrogenación de alquinos a alquenos ha sido objeto de estudio en los últimos años dada su relevancia en las industrias de polímeros [106].

La hidrogenación de los alquinos al alqueno correspondiente ocurre según la Ecuación 15. Sin embargo, el alqueno puede ser fácilmente reducido al alcano (Ecuación 16), por lo que puede ser muy complicado parar la reacción en la formación del primero [104]. Por lo tanto, es necesario el desarrollo de catalizadores selectivos que impidan la sobrehidrogenación y/o la oligomerización de los alquinos.

$$
\begin{gathered}
\mathrm{HC} \equiv \mathrm{CH}+\mathrm{H}_{2} \longrightarrow \mathrm{CH}_{2}=\mathrm{CH}_{2} \quad \Delta \mathrm{H}^{\circ}=-41.9 \mathrm{kcal} \cdot \mathrm{m} \quad(15) \\
\mathrm{CH}_{2}=\mathrm{CH}_{2}+\mathrm{H}_{2} \longrightarrow \mathrm{CH}_{3} \mathrm{CH}_{3} \quad \Delta \mathrm{H}^{\circ}=-32.7 \mathrm{kcal} \cdot \mathbf{m}(16)
\end{gathered}
$$

Una de las reacciones de semihidrogenación de alquinos más investigadas es la del fenilacetileno a estireno, debido a su interés industrial. Esto se debe a que en el proceso de polimerización del estireno se requiere de un alimento puro con el fin de preservar el catalizador. La presencia de una pequeña cantidad de fenilacetileno en el alimento de la reacción podría desactivar el catalizador, por lo que es necesaria su reducción a menos de 10 ppm. Además, la reacción de semihidrogenación del fenilacetileno ocurre en condiciones relativamente suaves, por lo que se suele emplear como reacción modelo para la evaluación del diseño de reactores y la evaluación de catalizadores de hidrogenación [107], siendo esta reacción la que se va a estudiar en esta tesis.

En la bibliografía se han descrito numerosos catalizadores para la semihidrogenación selectiva de alquinos empleando diversos metales como paladio [108-110], iridio [111], rutenio [112,113], hierro [114] y níquel [115]. 
Sin embargo, el empleo de estos metales conlleva la aparición de problemas de selectividad, pues por lo general presentan una gran capacidad reductora, lo que da lugar a la sobrehidrogenación de los alquinos [106]. De hecho, algunos metales, como el paladio, son parcialmente envenenados antes de ser empleados, con el fin de evitar los problemas de selectividad debidos a la sobrehidrogenación de los alquinos. En ese sentido, últimamente se ha investigado el desarrollo de catalizadores con oro, ya que, por un lado, presentan una buena actividad catalítica en procesos de hidrogenación [116-118], y por otro, tienen una capacidad reductora inferior a la del resto de metales mencionados, lo que da lugar a una mejor selectividad. En concreto, destacan por su selectividad las nanopartículas de oro soportadas sobre óxidos metálicos $[119,120]$.

Los primeros resultados descritos con estos catalizadores fueron obtenidos por Bond et al. [121] en 1973, los cuales trabajaron con catalizadores basados en $\mathrm{Au} / \mathrm{SiO}_{2}$, que eran activos en la hidrogenación del penteno, del 1,3-butadieno y del 2-butino a $100{ }^{\circ} \mathrm{C}$, empleando únicamente un $0.01 \%$ en peso de oro. Okumura et al. [122] estudiaron también la hidrogenación del 1,3-butadieno con catalizadores de $\mathrm{Au} / \mathrm{Al}_{2} \mathrm{O}_{3}$ preparados por deposición-precipitación, obteniendo $100 \%$ de conversión a $175^{\circ} \mathrm{C}$ con una selectividad del $60 \%$ hacia el 1-buteno. Además, estos autores describieron que la actividad de estos catalizadores no era dependiente del tamaño de partícula ni del soporte empleado [122]. Esta independencia de la actividad catalítica con respecto al soporte está en concordancia con lo descrito por Li et al. [123], los cuales no observaron una influencia significante en la actividad catalítica de nanoclusters de oro soportados sobre $\mathrm{SiO}_{2}, \mathrm{Al}_{2} \mathrm{O}_{3}, \mathrm{CeO}_{2}$ y $\mathrm{TiO}_{2}$ en la semihidrogenación de alquinos terminales. Por otro parte, Fiorio et al. [118] sí que observaron diferencias en la actividad en función del soporte empleado, obteniendo la mejor actividad catalítica en la hidrogenación del fenilacetileno con nanopartículas de oro soportadas sobre $\mathrm{TiO}_{2}$ y $\mathrm{SiO}_{2}$, mientras que los catalizadores soportados sobre $\mathrm{CeO}_{2}$ fueron menos activos, y aquellos soportados sobre $\mathrm{Al}_{2} \mathrm{O}_{3}$ fueron menos selectivos 

La presente tesis trata sobre el desarrollo de catalizadores metálicos estructurados para su aplicación en reacciones de Química Sostenible. Por un lado, se estudia el empleo de estos catalizadores para el control de las emisiones de contaminantes atmosféricos y, por otra parte, se investiga el uso de los mismos en una reacción de interés en Química Fina, como es la reacción de semihidrogenación de alquinos a alquenos.

Por ello, el primer objetivo de esta tesis es la preparación de catalizadores Mn-Fe soportados sobre distintos materiales y su posterior aplicación en la reducción catalítica selectiva de los óxidos de nitrógeno empleando amoniaco como agente reductor. Se investigará la influencia en la actividad catalítica de diversos factores como el tipo de soporte empleado en la preparación de los catalizadores, la adición de agua al medio de reacción y el envejecimiento con vapor de agua a altas temperaturas. Los catalizadores serán caracterizados mediante el empleo de diversas técnicas con el fin de determinar las características que permitan obtener los mejores resultados, así como para correlacionar los resultados catalíticos con las propiedades físico-químicas de los catalizadores.

El segundo objetivo de esta tesis es el desarrollo de catalizadores basados en Ag y Ag-Au soportados sobre la zeolita ITQ-2 para su aplicación en la oxidación catalítica del monóxido de carbono. La preparación de estos catalizadores será optimizada mediante la investigación de las variables relacionadas con el catalizador que afectan a la actividad catalítica: el método de incorporación de la fase metálica, las condiciones de pretratamiento, las especies activas y la composición metálica. Estas variables serán investigadas mediante el empleo de técnicas de caracterización in situ y ex situ, y con el análisis de los resultados catalíticos obtenidos. Así mismo, se estudiará el mecanismo de reacción, la evolución de las especies metálicas durante los pretratamientos y la reacción, así como la reutilización de los catalizadores.

Por último, el tercer objetivo de esta tesis es el empleo de catalizadores basados en nanoclusters de oro soportados sobre diferentes materiales para la semihidrogenación del fenilacetileno a estireno. Se estudiará cómo afectan a la 
actividad catalítica los diferentes pretratamientos, el tamaño de los nanoclusters, el tipo de ligando de los nanoclusters y las propiedades ácido/base de los soportes. 
3. PROCEDIMIENTO EXPERIMENTAL 



\subsection{Materiales}

\subsubsection{Gases}

- Acetileno, $1 \%$ en etileno, Abelló Linde S.A. Gases técnicos.

- Aire sintético 5.0, $99.995 \%$, Abelló Linde S.A. Gases técnicos.

- Amoniaco, 3000 ppm en nitrógeno, Abelló Linde S.A. Gases técnicos.

- Hidrógeno 5.0, 99.999 \%, Abelló Linde S.A. Gases técnicos.

- Monóxido de carbono, 4 \% en nitrógeno, Abelló Linde S.A. Gases técnicos.

- Monóxido de nitrógeno, 3000 ppm en nitrógeno, Abelló Linde S.A. Gases técnicos.

- Nitrógeno 5.0, 99.999 \%, Abelló Linde S.A. Gases técnicos.

\subsubsection{Líquidos}

- 2,4-dimetilbencenotiol, $\mathrm{HSPhMe}_{2},>99 \%$ Sigma Aldrich.

- 2-feniletanotiol, $\mathrm{PhC}_{2} \mathrm{H}_{4} \mathrm{SH},>99 \%$ Sigma Aldrich.

- Acetonitrilo, ACN, $99.8 \%$, Sigma Aldrich.

- Agua miliQ, $\mathrm{H}_{2} \mathrm{O}$, Milipore.

- Amoniaco, $\mathrm{NH}_{3}, 99.98 \%$, Sigma Aldrich.

- Diclorometano, DCM, 99.8 \%. Sigma Aldrich.

- Etanol absoluto, $\mathrm{CH}_{3} \mathrm{CH}_{2} \mathrm{OH}$, Sigma Aldrich.

- Isopropóxido de titanio (IV), Ti[OCH( $\left.\left(\mathrm{CH}_{3}\right)_{2}\right]_{4}, 99.999 \%$, Sigma Aldrich.

- Metanol, $\mathrm{CH}_{3} \mathrm{OH}, 99.9$ \%, Panreac.

- Tethahidrofurano, THF, $99.9 \%$, Sigma Aldrich.

- Tolueno, $\mathrm{C}_{6} \mathrm{H}_{5} \mathrm{CH}_{3}, 99.9 \%$, Panreac.

\subsubsection{Sólidos}

- Ácido tetracloroáurico (III), $\mathrm{HAuCl}_{4} \cdot 3 \mathrm{H}_{2} \mathrm{O}, 99.9 \%$, Sigma Aldrich.

- Alúmina, $\gamma-\mathrm{Al}_{2} \mathrm{O}_{3}$, abcr $\mathrm{GmbH}$.

- Bromuro de tetrafenilfosfonio, $\mathrm{PPh}_{4} \mathrm{Br}, 97 \%$, Sigma Aldrich.

- Bromuro de tetraoctilamonio, TOAB, 99.9 \%, Sigma Aldrich. 
- Borohidruro de sodio, $\mathrm{NaBH}_{4}, 98 \%$, Sigma Aldrich.

- Carbonato de magnesio básico, $\left(\mathrm{MgCO}_{3}\right)_{4} \mathrm{Mg}(\mathrm{OH})_{2}$, Sigma Aldrich.

- Carburo de silicio, SiC, Fisher Scientific.

- Cloruro de hierro (II), $\mathrm{FeCl}_{2}, 98$ \%, Sigma Aldrich.

- Cloruro de manganeso (II), $\mathrm{MnCl}_{2} \cdot 4 \mathrm{H}_{2} \mathrm{O}, 99.99 \%$, Sigma Aldrich.

- Cloruro de zirconio (IV), $\mathrm{ZrCl}_{4}, 99.9$ \%, Sigma Aldrich.

- Copolímero tribloque poli(etilenglicol)-block-poli(propilenglicol)block-poli(etilenglicol), $\mathrm{PO}_{20} \mathrm{EO}_{70} \mathrm{PO}_{20}, \mathrm{M}_{\mathrm{n}} \sim 5,800$, Sigma Aldrich.

- Hidróxido de potasio, $\mathrm{KOH}, 85 \%$, Sigma Aldrich.

- Hidróxido de sodio, $\mathrm{NaOH}, 98$ \%, Sigma Aldrich.

- Nitrato de aluminio, $\mathrm{Al}\left(\mathrm{NO}_{3}\right)_{3} \cdot 9 \mathrm{H}_{2} \mathrm{O}, 98.5 \%$, Riedel-de Haën.

- Nitrato de magnesio, $\mathrm{Mg}\left(\mathrm{NO}_{3}\right)_{2} \cdot 6 \mathrm{H}_{2} \mathrm{O}, 99 \%$, Fluka.

- Nitrato de plata, $\mathrm{AgNO}_{3}, 99 \%$, Sigma Aldrich.

- Nitrato de sodio, $\mathrm{NaNO}_{3}, 99 \%$, Fluka.

- Trans-2[3-4-t-butil-fenil-2-metil-2-propenilideno]-malononitrilo, DCTB, $99 \%$, Sigma Aldrich.

- Trifluoroacetato de plata, $\mathrm{AgCF}_{3} \mathrm{COO}, 99 \%$, Sigma Aldrich.

- Zeolita BEA, Zeolyst.

- Zeolita FAU, Zeolyst.

\subsection{Preparación de los catalizadores}

En la reacción de reducción catalítica selectiva de $\mathrm{NO}_{\mathrm{x}}\left(\mathrm{SCR}-\mathrm{NO}_{\mathrm{x}}\right)$ se han utilizado catalizadores de manganeso y hierro soportados sobre óxidos metálicos, zeolitas y materiales mesoporosos. Algunos óxidos fueron sintetizados en el laboratorio $\left(\mathrm{TiO}_{2}\right.$ y $\left.\mathrm{MgO}\right)$ y el otro era comercial $\left(\gamma-\mathrm{Al}_{2} \mathrm{O}_{3}\right)$. Las zeolitas BEA y FAU eran comerciales, teniendo las primeras una relación $\mathrm{Si} / \mathrm{Al}$ de 12.5 y $19, \mathrm{y}$ las últimas de 6 y 30. Las zeolitas CHA tenían una relación Si/Al de 2 y de 10. La de relación 2 fue preparada en el laboratorio, y la de 10 fue suministrada por el Instituto de Tecnología Química. La zeolita ITQ-2 también fue suministrada por el ITQ, y se preparó en su forma pura sílice y con una relación $\mathrm{Si} / \mathrm{Al}$ de 10 según [124]. Los materiales mesoporosos empleados fueron MCM-41 y SBA-15, ambos sintetizados en el ITQ según [125] en su forma pura sílice y con relaciones 
$\mathrm{Si} / \mathrm{Al}$ de 11 y 15 , respectivamente. La fase metálica se ha incorporado a estos soportes mediante el método de impregnación a volumen de poro.

En la reacción de oxidación catalítica de $\mathrm{CO}$ se han empleado catalizadores de oro y/o plata. El soporte empleado ha sido la zeolita ITQ-2 pura sílice sintetizada en el Instituto de Tecnología Química según [124]. La fase metálica se ha incorporado mediante impregnación a volumen de poro, mediante intercambio iónico, o mediante la adición por el método de impregnación húmeda de nanoclusters metálicos de oro y/o plata sintetizados en el laboratorio.

En el caso de la reacción de hidrogenación de alquinos, los catalizadores utilizados consisten en nanoclusters metálicos de oro soportados sobre óxido de magnesio, hidrotalcita $\mathrm{Mg} / \mathrm{Al}$ o alúmina. $\mathrm{El} \mathrm{MgO}$ y la hidrotalcita fueron sintetizados en el laboratorio, y la alúmina era comercial. Los nanoclusters han sido soportados mediante impregnación húmeda.

En los apartados siguientes se describe con detalle el método de síntesis de los soportes y de los nanoclusters preparados en el laboratorio, así como los métodos empleados para añadir los metales al soporte.

\subsubsection{Síntesis de soportes}

En esta tesis se han utilizado como soportes de los catalizadores diversos óxidos metálicos, zeolitas, materiales mesoporosos e hidrotalcitas. En este apartado se describe la preparación de los soportes sintetizados en el laboratorio.

\subsubsection{Síntesis de óxidos de alta superficie específica}

Se prepararon óxidos metálicos de titanio y magnesio por distintos procedimientos con el fin de obtener un material con un área superficial mayor que la de los óxidos comerciales.

La síntesis del óxido de titanio (IV) se ha realizado según el procedimiento descrito en la bibliografía por Yu et al. [126]. Para ello, se disuelven $3 \mathrm{~g}$ de 
copolímero tribloque poli(etilenglicol)-block-poli(propilenglicol)-blockpoli(etilenglicol) $\left(\mathrm{PO}_{20} \mathrm{EO}_{70} \mathrm{PO}_{20}\right)$ junto con $0.03 \mathrm{~mol}$ de isopropóxido de titanio (IV) en $30 \mathrm{~mL}$ de etanol absoluto. Esta disolución se mantiene en agitación durante 30 minutos y seguidamente se añaden $40 \mathrm{~mL}$ de agua. Tras ello, se deja evaporar lentamente el agua y el etanol, y se obtiene el producto en forma de sólido. Por último, la muestra se calcina a $400{ }^{\circ} \mathrm{C}$ durante 3 horas con una velocidad de calentamiento de $5^{\circ} \mathrm{C} \cdot \mathrm{min}^{-1}$.

El óxido de magnesio se ha sintetizado siguiendo el método descrito en la bibliografía por Bartley et al. [127]. Para ello, $25 \mathrm{~g}$ de $\left(\mathrm{MgCO}_{3}\right)_{4} \mathrm{Mg}(\mathrm{OH})_{2}$ se suspenden en $750 \mathrm{~mL}$ de agua y se agita durante 30 minutos a $80{ }^{\circ} \mathrm{C}$. A continuación, se filtra el sólido, se seca a $90^{\circ} \mathrm{C}$ durante 24 horas y se calcina a $450{ }^{\circ} \mathrm{C}$ durante 2 horas.

\subsubsection{Síntesis de la hidrotalcita Mg/Al}

En este trabajo se ha empleado una hidrotalcita de $\mathrm{Mg} / \mathrm{Al}$ que ha sido sintetizada por el método de coprecipitación. Para realizar la síntesis, se preparan dos disoluciones acuosas, una ácida y otra básica. La disolución básica contiene $\mathrm{NaOH}$ y $\mathrm{NaNO}_{3}$, mientras que la ácida contiene nitrato de magnesio $\left[\mathrm{Mg}\left(\mathrm{NO}_{3}\right)_{2} \cdot 6 \mathrm{H}_{2} \mathrm{O}\right]$ y nitrato de aluminio $\left[\mathrm{Al}\left(\mathrm{NO}_{3}\right)_{3} \cdot 9 \mathrm{H}_{2} \mathrm{O}\right]$. Las cantidades de cada uno de los reactivos se ajustaron para obtener una relación molar $\mathrm{Mg} / \mathrm{Al}$ de 4. Las disoluciones preparadas se introducen en dos jeringuillas por separado, y mediante el empleo de una bomba perfusora, van siendo añadidas con una velocidad de $1 \mathrm{~mL} \cdot \mathrm{min}^{-1}$ a un vaso de precipitados, el cual tiene agitación continua. Este proceso se realiza a temperatura ambiente y a presión atmosférica. A continuación, se realiza el envejecimiento del gel resultante a $60^{\circ} \mathrm{C}$ durante 24 horas. Tras el proceso de envejecimiento, se filtra el sólido resultante y se realizan lavados con agua destilada hasta alcanzar un $\mathrm{pH}$ de 7 en el agua de lavado. Finalmente, el sólido se seca en la estufa a $100^{\circ} \mathrm{C}$ durante 24 horas. 


\subsubsection{Síntesis de la zeolita CHA}

Para preparar las zeolitas $\mathrm{CHA}$ con relación $\mathrm{Si} / \mathrm{Al}=2$, se sigue el procedimiento de síntesis hidrotermal publicado en la IZA (Asociación Internacional de Zeolitas) [128]. El material de partida es una zeolita FAU en forma amónica de relación $\mathrm{Si} / \mathrm{Al}=2.5(\mathrm{CBV}-500)$, la cual es calcinada a $550{ }^{\circ} \mathrm{C}$ durante 2 horas para obtener la forma ácida (HY). Por otro lado, se mezclan $198.2 \mathrm{~mL}$ de agua con $26.8 \mathrm{~mL}$ de una disolución de hidróxido potásico $(\mathrm{KOH})$ al $45 \%$ en peso. La disolución anterior se pasa a un bote de polipropileno y se añaden $25 \mathrm{~g}$ de la zeolita FAU calcinada, con el fin de obtener una mezcla con la siguiente composición: $0.17 \mathrm{Na}_{2} \mathrm{O}: 2 \mathrm{~K}_{2} \mathrm{O}: 1 \mathrm{Al}_{2} \mathrm{O}_{3}: 5.18 \mathrm{SiO}_{2}: 244 \mathrm{H}_{2} \mathrm{O}$. Se tapa el bote de polipropileno y se deja a $95{ }^{\circ} \mathrm{C}$ durante 96 horas en estático. Una vez transcurrido este tiempo, se filtra, en caliente, el sólido obtenido y se lava 2 veces con $500 \mathrm{~mL}$ de agua. Por último, la zeolita obtenida se seca durante 24 horas a $100{ }^{\circ} \mathrm{C}$.

\subsubsection{Síntesis de nanoclusters}

Los nanoclusters metálicos han sido preparados en el Instituto de Química de los Materiales en la Universidad Técnica de Viena (Austria). Se han sintetizado nanoclusters metálicos de oro y/o plata protegidos por ligandos tiolatos (SR). Estos nanoclusters presentan un núcleo estructurado compuesto por átomos del metal seleccionado, y que se encuentra estabilizado por una capa de oligómeros que consiste en enlaces covalentes entre el metal y el azufre llamados staple motif $\mathrm{u}$ oligómero $-\mathrm{S}(\mathrm{R})-\left(\mathrm{Au}-\mathrm{S}(\mathrm{R})^{-}\right)$. Asimismo, se han sintetizado nanoclusters monometálicos de oro protegidos con ligandos de tipo fosfina $\left(\mathrm{PPh}_{3}\right)$.

\subsubsection{Síntesis de nanoclusters $\mathrm{Au}_{25}\left(\mathrm{SC}_{2} \mathrm{H}_{4} \mathrm{Ph}\right)_{18}$}

Los nanoclusters monometálicos de 25 átomos de oro $\left(\mathrm{Au}_{25}\right)$ con ligandos de azufre han sido sintetizados siguiendo el proceso descrito previamente en la bibliografia [129]. Para ello, se disuelven $500 \mathrm{mg}(1.27 \mathrm{mmol})$ de ácido tetracloroáurico (III) $\left(\mathrm{HAuCl}_{4} \cdot 3 \mathrm{H}_{2} \mathrm{O}\right)$ en $50 \mathrm{~mL}$ de tetrahidrofurano (THF) y se mezclan con 1.2 equivalentes de bromuro de tetraoctilamonio (TOAB). La disolución resultante se mantiene en agitación durante 10 minutos. A 
continuación, se añade a lo anterior, gota a gota, 5 equivalentes del ligando, en este caso de 2-feniletanotiol $\left(\mathrm{PhC}_{2} \mathrm{H}_{4} \mathrm{SH}\right)$ y se mantiene en agitación hasta que la disolución se vuelve transparente. Una vez obtenida la disolución transparente, se añade rápidamente una disolución de 10 equivalentes de $\mathrm{NaBH}_{4}$ en $10 \mathrm{~mL}$ de agua fría y se deja en agitación durante 4 días. Una vez finalizada la reacción se evapora el disolvente en un rotavapor (a $40{ }^{\circ} \mathrm{C}$ y $180 \mathrm{mbar}$ ). El residuo obtenido se lava varias veces cambiando las proporciones de una mezcla etanol agua: 75/25, 85/15 y 90/10. El producto se extrae con THF y se filtra con filtros de jeringa. Por último, los nanoclusters son separados mediante cromatografía de exclusión por tamaño, empleando THF como eluyente. Toda la síntesis tiene lugar a temperatura ambiente y presión atmosférica.

\subsubsection{Síntesis de nanoclusters $\mathrm{Au}_{11}\left(\mathrm{PPh}_{3}\right)_{7} \mathrm{Br}_{3}$}

La síntesis de los nanoclusters de 11 átomos de oro $\left(\mathrm{Au}_{11}\right)$ con ligandos tipo fosfina se llevó a cabo según lo descrito en [130]. En primer lugar, $1.27 \mathrm{mmol}$ de $\mathrm{HAuCl}_{4} \cdot 3 \mathrm{H}_{2} \mathrm{O}$ y 1.2 equivalentes de TOAB se disuelven en $50 \mathrm{~mL}$ de THF. A continuación, se añaden 5 equivalentes de $\mathrm{PPh}_{3}$ y la disolución resultante se agita durante una hora. Tras ello, se disuelven 10 equivalentes de $\mathrm{NaBH}_{4}$ en $10 \mathrm{~mL}$ en agua fría, y esto se añade a la disolución anterior. Esta disolución se mantiene en agitación durante 48 horas dando lugar a un precipitado. Una vez transcurridas las 48 horas, se elimina el disolvente por evaporación, y el sólido se lava varias veces con una mezcla metanol:agua 1:1. Los subproductos son eliminados por extracción con THF, tolueno y por último con una mezcla 2:1 de hexano:etanol. Finalmente, los nanoclusters $\mathrm{Au}_{11}$ se extraen con diclorometano (DCM).

\subsubsection{Síntesis de nanoclusters $\operatorname{Ag}_{25}\left(\mathrm{SPhMe}_{2}\right)_{18}\left(\mathrm{PPh}_{4}\right)$}

Para la síntesis de nanoclusters de 25 átomos de plata $\left(\mathrm{Ag}_{25}\right)$ se sigue el procedimiento detallado por Joshi et al. [131]. El procedimiento se realiza bajo atmósfera inerte de nitrógeno. En un vial de vidrio, se disuelven $38 \mathrm{mg}$ de $\mathrm{AgNO}_{3}$ (0.22 mmol) en $2 \mathrm{~mL}$ de metanol mediante ultrasonidos. A continuación, se añaden $0.66 \mathrm{mmol}$ del ligando, en este caso 2,4-dimetilbencenotiol ( $\left.\mathrm{HSPhMe}_{2}\right)$, lo que da lugar a una disolución de color amarillo. Después, se enfría la mezcla 
con un baño de agua-hielo, se añaden $17 \mathrm{~mL}$ de DCM y se deja en agitación durante 20 minutos. Transcurrido este tiempo, se adiciona una disolución de 6 $\mathrm{mg}$ de bromuro de tetrafenilfosfonio $\left(\mathrm{PPh}_{4} \mathrm{Br}\right)$ en $0.5 \mathrm{~mL}$ de metanol $\mathrm{y}$, seguidamente, se añade gota a gota una disolución acuosa fría de $0.4 \mathrm{mmol}$ de $\mathrm{NaBH}_{4}$. Tras este último paso, la mezcla se deja en agitación durante 6 horas y posteriormente se deja envejeciendo en el congelador hasta el día siguiente. A continuación, se separa el sobrenadante de la mezcla mediante centrifugación y se concentra hasta unos $5 \mathrm{~mL}$ en el rotavapor. Tras esto, los nanoclusters sintetizados se precipitan con la adición de metanol y seguidamente se redisuelven en tolueno. Esta disolución que contiene los nanoclusters se filtra a través de filtros de jeringa y se somete a cromatografía de exclusión por tamaño para la purificación de los nanoclusters.

\subsubsection{Síntesis de nanoclusters $\operatorname{Ag}_{\mathrm{x}} \mathrm{Au}_{25-\mathrm{x}}\left(\mathrm{SC}_{2} \mathrm{H}_{4} \mathrm{Ph}\right)_{18}$}

La síntesis de los nanoclusters de 25 átomos con oro y plata $\left(\mathrm{Ag}_{\mathrm{x}} \mathrm{Au}_{25-\mathrm{x}}\right)$ se basa en una modificación del procedimiento descrito por Gottlieb at al [132]. La síntesis tiene lugar a temperatura ambiente y a presión atmosférica. En primer lugar, se disuelve $0.609 \mathrm{mmol}$ de $\mathrm{HAuCl}_{4} \cdot 3 \mathrm{H}_{2} \mathrm{O}$ en $50 \mathrm{~mL}$ de agua. A continuación, se añade $0.126 \mathrm{mmol}$ de trifluoroacetato de plata $\left(\mathrm{AgCF}_{3} \mathrm{COO}\right)$ y $0.859 \mathrm{mmol}$ del catalizador de transferencia de fase (TOAB) en $45 \mathrm{~mL}$ de THF. Esta disolución de color rojizo se mantiene en agitación durante 15 minutos. Luego, se añade $3.73 \mathrm{mmol}$ del ligando $\mathrm{PhC}_{2} \mathrm{H}_{4} \mathrm{SH}$ y se deja agitar otros 15 minutos. Tras ello, se disuelve el agente reductor $\mathrm{NaBH}_{4}(7.38 \mathrm{mmol})$ en $15 \mathrm{~mL}$ de agua fría e inmediatamente se añade a la disolución anterior, la cual se vuelve de color marrón. Se deja la mezcla en agitación durante 7 horas bajo atmósfera de nitrógeno y al finalizar la reacción, el disolvente es evaporado en rotavapor y el residuo se lava cinco veces consecutivas con metanol, separando por centrifugación el precipitado formado. A continuación, se añade acetonitrilo al precipitado formado, se agita bien y se separa el sobrenadante por centrifugación. Por último, esta disolución es llevada a sequedad en el rotavapor. 


\subsubsection{Modificaciones post-síntesis}

La incorporación de la fase metálica sobre los soportes se llevó a cabo mediante diferentes métodos. En este apartado se describe cada uno de ellos.

\subsubsection{Catalizadores preparados por impregnación}

El método de impregnación a volumen de poro consiste en disolver una sal precursora del metal deseado en la cantidad de agua necesaria para llenar todos los poros de los soportes. En la reacción $\mathrm{SCR}-\mathrm{NO}_{\mathrm{X}}$ se han preparado catalizadores bimetálicos de manganeso y hierro soportados sobre distintos soportes mediante este método. Los soportes empleados han sido varios óxidos metálicos $(\mathrm{MgO}$, $\mathrm{TiO}_{2}, \mathrm{Al}_{2} \mathrm{O}_{3}$ ), materiales microporosos como las zeolitas BEA, FAU, ITQ-2 y CHA, y materiales mesoporosos (MCM-41 y SBA-15). Las sales precursoras empleadas en este trabajo son el cloruro de manganeso (II) tetrahidratado $\left(\mathrm{MnCl}_{2} \cdot 4 \mathrm{H}_{2} \mathrm{O}\right)$ y el cloruro de hierro (II) $\left(\mathrm{FeCl}_{2}\right)$. La cantidad de sal precursora disuelta en agua ha de ser la necesaria para conseguir la cantidad de metal que se desee incorporar al soporte. Una vez se ha impregnado el soporte con la disolución del metal, se seca a $100{ }^{\circ} \mathrm{C}$ durante 24 horas y luego se calcina a 250 ${ }^{\circ} \mathrm{C}$ durante 1 hora y a $450{ }^{\circ} \mathrm{C}$ durante 2 horas.

Algunos catalizadores empleados en la oxidación de CO también han sido preparados por este método. El procedimiento seguido ha sido el mismo que el descrito más arriba. El soporte empleado en este caso ha sido la zeolita ITQ-2 y el metal introducido ha sido plata, empleando como sal precursora el nitrato de plata $\left(\mathrm{AgNO}_{3}\right)$.

Los nanoclusters empleados en la reacción de oxidación de $\mathrm{CO}$ y en la hidrogenación de alquinos también han sido incorporados al soporte mediante el método de impregnación Los soportes empleados han sido la zeolita ITQ-2 pura sílice, una hidrotalcita $\mathrm{Mg} / \mathrm{Al}$ y los óxidos $\mathrm{MgO}$ y $\mathrm{Al}_{2} \mathrm{O}_{3}$. Se han soportado tanto los nanoclusters monometálicos de $\mathrm{Ag}_{25}, \mathrm{Au}_{25}$ y $\mathrm{Au}_{11}$, como los nanoclusters bimetálicos $\mathrm{Ag}_{\mathrm{x}} \mathrm{Au}_{25-\mathrm{x}}$. Para soportar los nanoclusters, los soportes han sido suspendidos en una disolución de tolueno que contiene la cantidad de 
nanoclusters necesaria para obtener la cantidad de Ag, Au o AgAu deseada. Esta suspensión se mantiene en agitación durante 24 horas, y luego el catalizador es separado mediante centrifugación y decantación. Por último, las muestras se secan a $80^{\circ} \mathrm{C}$ durante 1 hora.

\subsubsection{Catalizadores preparados por intercambio iónico}

Algunos catalizadores empleados en la reacción de oxidación de CO han sido preparados siguiendo el procedimiento de intercambio iónico. Como soporte se ha empleado la zeolita ITQ-2 con una relación $\mathrm{Si} / \mathrm{Al}=10$. Para realizar el intercambio iónico, se prepara una disolución acuosa con la cantidad necesaria de $\mathrm{AgNO}_{3}$. Sobre esta disolución se añade la zeolita, con una relación zeolita/agua $=0.01 \mathrm{~g} / \mathrm{mL}$ y se deja en agitación durante 24 horas. El recipiente donde se realiza el intercambio se cubre con papel aluminio al completo para evitar la reducción de la plata por la luz durante el proceso. Una vez finalizado el periodo de intercambio, se separa la zeolita de la disolución mediante filtración a vacío, se lava con abundante agua y se seca a $100^{\circ} \mathrm{C}$ durante toda la noche. Por último, los catalizadores son calcinados a $250{ }^{\circ} \mathrm{C}$ durante 1 hora y a $450{ }^{\circ} \mathrm{C}$ durante 2 horas.

\subsection{Técnicas de caracterización}

En esta tesis se han utilizado distintas técnicas de caracterización disponibles en la Universitat Politècnica de València o en la Universidad Técnica de Viena, las cuales son descritas a continuación:

\subsubsection{Análisis químico}

El análisis químico de las muestras empleadas en esta tesis se ha llevado a cabo mediante la espectrometría de emisión atómica de plasma acoplado inductivamente (ICP-AES). El ICP-AES es una técnica ampliamente utilizada para el análisis de materiales inorgánicos. Esta técnica se basa en determinar la intensidad de la radiación emitida cuando los electrones de la capa interna se 
relajan desde el estado excitado al estado fundamental. La radiación emitida tiene una longitud de onda característica para cada elemento, y su intensidad es proporcional a la concentración del elemento medido en la muestra.

Los átomos de la muestra son excitados por un plasma de argón a altas temperaturas (8000-10000 K). Las muestras se midieron en un equipo Varian 715-ES. Previamente al análisis, las muestras han de ser disgregadas con una disolución 1:1 $\mathrm{HF} / \mathrm{HNO}_{3}$ en agua.

\subsubsection{Análisis textural: adsorción volumétrica de nitrógeno}

Mediante esta técnica de caracterización se pueden determinar las propiedades texturales de los materiales: la superficie específica, el volumen de poro y la distribución del tamaño de poro de la muestra estudiada. La técnica se basa en la obtención de isotermas de adsorción/desorción de nitrógeno a una temperatura de $-196{ }^{\circ} \mathrm{C}$ (temperatura del $\mathrm{N}_{2}$ líquido). Las medidas se realizaron en un equipo Micrometrics ASAP 2000.

Para la determinación de las superficie específica, las isotermas se ajustaron al modelo Brunauer-Emmet-Telle (BET) [133]. Este modelo se basa en las siguientes hipótesis:

- La superficie de los materiales es uniforme y no porosa

- No existen interacciones laterales entre las moléculas absorbidas

- Las moléculas del gas se adsorben en capas sucesivas

Estas hipótesis hacen que la ecuación de BET sea más una herramienta para comparar las áreas de distintos materiales que para obtener el área real de un adsorbente. Cuando se trabaja en un rango de presiones relativas $\left(\mathrm{P} / \mathrm{P}_{0}\right)$ determinado, generalmente entre 0.05 y 0.33 , la ecuación de BET puede emplearse en su forma lineal (Ecuación 17): 


$$
\frac{\mathrm{P}}{\mathrm{x} \cdot\left(\mathrm{P}_{0}-\mathrm{P}\right)}=\frac{1}{\mathrm{x}_{\mathrm{m}} \cdot \mathrm{C}}+\frac{(\mathrm{C}-1)}{\mathrm{x}_{\mathrm{m}} \cdot \mathrm{C}} \cdot \frac{\mathrm{P}}{\mathrm{P}_{0}}
$$

donde:

P: presión de equilibrio

$\mathrm{P}_{0}$ : presión de saturación

C: constante relacionada con el equilibrio de adsorción

$\mathrm{x}$ : número de moléculas adsorbidas por gramo de adsorbente a una presión $\mathrm{P}$

$\mathrm{x}_{\mathrm{m}}$ : número de moléculas de adsorbato que forman una monocapa por gramo de adsorbente

Al representar $\frac{\mathrm{P}}{\mathrm{x} \cdot\left(\mathrm{P}_{0}-\mathrm{P}\right)}$ frente $\mathrm{a} \frac{\mathrm{P}}{\mathrm{P}_{0}}$, se obtiene una recta con cuya pendiente $\mathrm{y}$ ordenada en el origen puede calcularse los valores de $\mathrm{x}_{\mathrm{m}} \mathrm{y}$ de $\mathrm{C}$. El valor de $\mathrm{C}$ ha de ser positivo, ya que la adsorción presenta una naturaleza exotérmica intrínseca. Por lo tanto, si se obtiene un valor negativo de $\mathrm{C}$, significa que el rango de $\mathrm{P} / \mathrm{P}_{0}$ elegido para linealizar la ecuación no es el idóneo.

Lo que se obtiene realmente durante los análisis es el volumen adsorbido de $\mathrm{N}_{2}$ (V) a una presión P. De esta manera, x (número de moléculas adsorbidas) se obtendrá a partir de la ecuación de los gases ideales (Ecuación 18), en donde $\mathrm{N}$ es el número de Avogadro (6.022 $10^{23}$ moléculas $\left./ \mathrm{mol}\right)$.

$$
\mathrm{P} \cdot \mathrm{V}=\frac{\mathrm{x} \cdot \mathrm{R} \cdot \mathrm{T}}{\mathrm{N}}
$$

Al obtener $\mathrm{x}_{\mathrm{m}}$, el área superficial del adsorbente puede calcularse conociendo el área que ocupa cada molécula del adsorbato $\left(\mathrm{A}_{\mathrm{m}}\right)$ sobre la superficie del adsorbente en las condiciones de medida. En este caso, el valor de $\mathrm{A}_{\mathrm{m}}$ para el $\mathrm{N}_{2}$ 
en las condiciones del análisis es de $10.2 \cdot 10^{-20} \mathrm{~m}^{2} /$ molécula. Por lo tanto, la superficie específica $\left(\mathrm{S}_{\mathrm{BET}}\right)$ se expresa como se muestra en la Ecuación 19:

$$
\mathrm{S}_{\mathrm{BET}}=\mathrm{x}_{\mathrm{m}} \cdot \mathrm{A}_{\mathrm{m}}
$$

\subsubsection{Difracción de rayos $X$}

La difracción de rayos $\mathrm{X}$ (DRX) es una técnica muy versátil para analizar compuestos cristalinos. La información obtenida incluye el tipo de fase cristalina, estructura, grado de cristalinidad, tamaño y orientación de los cristales, etc.

Esta técnica de caracterización se basa en la interacción entre la estructura cristalina de un sólido y una fuente de rayos $\mathrm{X}$. Cuando el haz de rayos $\mathrm{X}$ incide en la superficie del cristal en un ángulo $\theta$, parte de los rayos son dispersados por la primera capa de átomos y la otra parte penetra hasta la segunda capa de átomos, donde, parte del haz es dispersado por los átomos de esta capa, mientras que otra parte penetra de nuevo, dispersándose otra parte del haz, y así sucesivamente con el resto de planos cristalográficos. Si los haces dispersos no están en fase, se producirán interferencias destructivas y se anularán entre sí. Sin embargo, si el haz sale en fase, se producirá una interferencia constructiva, lo que provocará la difracción, y entonces se podrá detectar el haz. Cuando se cumple la ley de Bragg (Ecuación 20), es cuando se produce la difracción de rayos X.

$$
\mathrm{n} \cdot \lambda=2 \cdot \mathrm{d} \cdot \operatorname{sen} \theta
$$

Los términos de la ecuación corresponden a:

n: número entero que representa el orden de difracción

$\lambda$ : longitud de onda de los rayos $\mathrm{X}$

d: distancia interplanar 
$\theta$ : ángulo entre los rayos incidentes y los planos de dispersión

El patrón de difracción se obtiene variando el ángulo de incidencia de los rayos $\mathrm{X}$.

La técnica de DRX se emplea en esta tesis para determinar las distintas fases cristalinas de las muestras sintetizadas. Las medidas han sido realizadas en un difractómetro CUBIX de PANalytical equipado con un detector PANalytical $\mathrm{X}$ 'Celerator. Se usó radiación de rayos $\mathrm{X}$ de $\mathrm{Cu} \mathrm{K} \alpha\left(\lambda_{1}=1.5406 \AA, \lambda_{2}=1.5444\right.$ $\AA, \mathrm{I}_{2} / \mathrm{I}_{1}=0.5$ ), y un voltaje e intensidad de tubo de $45 \mathrm{kV}$ y $40 \mathrm{~mA}$ respectivamente.

Para las medidas de zeolitas sin fase metálica introducida se utilizó una rendija de divergencia variable con un área de muestra irradiada de $5 \mathrm{~mm}$ y el rango de

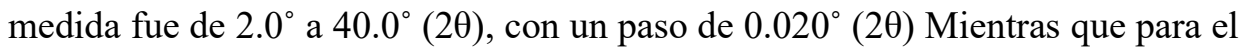
resto de muestras, así como para zeolitas que contenían metales se utilizó una rendija de divergencia variable con un área de muestra irradiada de $2.5 \mathrm{~mm}$, siendo el rango de medida de $2.0^{\circ}$ a $90.0^{\circ}(2 \theta)$, con un paso de $0.040^{\circ}(2 \theta)$. En ambos casos, el tiempo de medida fue de 35 segundos por paso, y la medida se realizó a $298 \mathrm{~K}$, rotando la muestra durante la misma a 0.5 revoluciones por segundo.

\subsubsection{Espectroscopía UV-Visible}

La espectroscopia ultravioleta-visible se basa en el análisis de la interacción de las moléculas de la muestra con la radiación UV-visible (longitud de onda entre 190 y $800 \mathrm{~nm}$ ) emitida por una fuente de radiación.

La absorción de la radiación UV-Vis hace que los electrones pasen a un estado excitado. Los electrones que se excitan al absorber radiación de esta frecuencia suelen ser electrones de enlace de las moléculas, por lo que el espectrograma de absorción puede relacionarse con los diferentes tipos de enlaces presentes en la 
muestra. Por tanto, la espectroscopia de absorción UV-Vis puede utilizarse para identificar los grupos funcionales presentes en la molécula. Para realizar las medidas de absorción se emplea un espectrómetro UV-Vis, el cual mide la intensidad de la luz que ha atravesado una muestra (I), y la compara con la luz con la que se ha irradiado la muestra $\left(\mathrm{I}_{0}\right)$. La relación $\mathrm{I} / \mathrm{I}_{0}$ se denomina transmitancia y se expresa en porcentaje. La absorbancia está relacionada con la transmitancia según la Ecuación 21:

$$
A=-\log (T)
$$

Esta técnica ha sido empleada para caracterizar los nanoclusters sintetizados de oro y/o plata en disolución. Los nanoclusters han sido disueltos en $\mathrm{CH}_{2} \mathrm{Cl}$ y se han obtenido sus espectros de absorción con un equipo Perkin ElmerLambda 750 UV-Vis de la TU-Wien.

Las muestras que se encuentran en estado sólido se analizan mediante la técnica de reflectancia difusa (UV-Vis DRS). En este caso, lo que se mide es la reflectancia difusa de la radiación UV-Vis tras interaccionar con el sólido. La reflectancia difusa se define como la proporción de radiación incidente reflejada por la muestra en todas las direcciones. El espectro obtenido generalmente se obtiene como un porcentaje de reflectancia frente a la longitud de onda, fijando la reflectancia obtenida por una muestra de referencia que no absorbe luz en el rango de longitud de onda utilizado como $100 \%$ de reflectancia. Las mediciones se realizaron en un equipo Varian Cary 5000 en la UPV. Esta técnica permite obtener información sobre el estado de oxidación y de coordinación de los metales presentes en las muestras.

\subsubsection{Espectroscopía de absorción de rayos $\mathrm{X}$}

La espectroscopía de absorción de rayos X (XAS) es una técnica que permite determinar la estructura y la configuración electrónica de los materiales. Esta técnica consiste en la excitación de un electrón de un nivel interno mediante la absorción de un fotón procedente de rayos X. Cuando el electrón tiene la energía 
necesaria, es expulsado al infinito con una energía cinética equivalente a la diferencia energética entre el rayo X incidente y la energía de enlace del electrón excitado. Esta energía se conoce como borde de absorción o absorption edge, que se identifica con un incremento pronunciado en la señal de absorción, y que se encuentra tabulada para cada elemento en función de la capa electrónica a la que pertenezca el electrón.

En los espectros de absorción de rayos $\mathrm{X}$ pueden diferenciarse dos regiones:

1) Región XANES (X-Ray Absorption Near Edge Structure): esta región está comprendida desde el borde de absorción hasta unos $50 \mathrm{eV}$ por encima del mismo. Esta zona del espectro informa sobre la configuración electrónica y sobre la geometría local alrededor del átomo que es excitado.

2) Región EXAFS (Extended X-Ray Absorption Fine Structure): se trata de la región comprendida desde unos de $50 \mathrm{eV}$ por encima del borde de absorción hasta unos $1000 \mathrm{eV}$ por encima del mismo. Esta región aporta datos sobre el número y naturaleza de los átomos vecinos, la longitud de enlace entre el átomo excitado y los átomos del entorno, permitiendo además obtener información cualitativa sobre el tamaño y forma de las nanopartículas.

Para poder realizar las medidas de XAS es necesaria una fuente de luz sincrotrón. En un sincrotrón, los electrones se encuentran acelerados por fuertes campos magnéticos a una velocidad cercana a la de la luz y girando en un anillo. Este anillo contiene secciones rectas y curvas, por lo que cuando se cambia la trayectoria de los electrones, se produce la generación de los rayos X. Las medidas XAS de este trabajo han sido realizadas en la fuente de radiación sincrotrón ALBA en Cerdanyola del Vallès (Barcelona, España). En concreto, fueron realizadas en la línea de espectroscopía de absorción de rayos X CLÆSS (BeamLine 22). 
Esta técnica se ha utilizado para caracterizar los catalizadores basados en nanoclusters de oro y/o plata soportados sobre zeolita ITQ-2. Las medidas se realizaron en modo de fluorescencia (Ag K-edge y Au $L_{3}$-edge) en una celda de reacción multipropósito desarrollada por el Instituto de Tecnología Química en colaboración con el sincrotrón ALBA [134], la cual permite realizar estudios in situ. Las muestras fueron pretratadas en la celda a $150^{\circ} \mathrm{C}$ durante 30 minutos con una atmósfera oxidativa $\left(5 \% \mathrm{O}_{2}\right.$ en $\mathrm{He}$, flujo total: $\left.45 \mathrm{~mL} \cdot \mathrm{min}^{-1}\right)$ o reductora $\left(5 \% \mathrm{H}_{2}\right.$ en $\mathrm{He}$, flujo total: $\left.45 \mathrm{~mL} \cdot \mathrm{min}^{-1}\right)$. Después del pretratamiento, las muestras se enfriaron hasta llegar a temperatura ambiente con un flujo de $40 \mathrm{~mL} \cdot \mathrm{min}^{-1} \mathrm{de}$ He. A continuación, se introdujo la mezcla de reacción $\left(1.7 \% \mathrm{CO}, 3.3 \% \mathrm{O}_{2}\right.$ en He con un flujo total de $45 \mathrm{~mL} \cdot \mathrm{min}^{-1}$ ) y se fue aumentando la temperatura con una rampa de calentamiento de $5{ }^{\circ} \mathrm{C} \cdot \mathrm{min}^{-1}$ hasta $150{ }^{\circ} \mathrm{C}$, se mantuvo durante 30 minutos y se continuó aumentando hasta $400{ }^{\circ} \mathrm{C}$. Después de 30 minutos a $400{ }^{\circ} \mathrm{C}$, se volvió a enfriar la muestra hasta temperatura ambiente en $\mathrm{He}$ (flujo: $45 \mathrm{~mL} \cdot \mathrm{min}^{-1}$ ). Los espectros de EXAFS se obtuvieron a $40{ }^{\circ} \mathrm{C}$ en flujo de He antes de pretratar la muestra, después del pretratamiento de la muestra, y después de reacción.

Los datos obtenidos en las medidas fueron tratados con el programa Artemis [135] el cual emplea el código FEFF8 [136].

\subsubsection{Espectroscopía infrarroja de reflectancia difusa por transformada de Fourier}

La espectroscopía infrarroja de reflectancia difusa por transformada de Fourier (DRIFTS) es una técnica que emplea una fuente de radiación infrarroja y que permite realizar estudios in situ de los materiales y de los posibles adsorbatos presentes en las muestras.

Cuando incide la radiación infrarroja sobre una muestra, el haz incidente puede interaccionar de diferentes maneras con la materia. Por un lado, la radiación puede ser reflejada por la muestra sin que se produzca ninguna interacción con la materia. Por otro lado, el haz puede sufrir múltiples reflexiones (reflexión 
especular) al incidir sobre la superficie de la muestra. También puede ocurrir que el haz penetre en la muestra y sea dispersado por la matriz de ésta. Esto último es lo que se conoce por reflectancia difusa y es el fenómeno que es medido durante la caracterización por DRIFTS. Los equipos empleados han de contar con componentes ópticos que permitan discriminar la reflexión especular.

La técnica DRIFTS ha sido empleada en este trabajo para la caracterización de las muestras con nanoclusters de oro y/o plata soportados en zeolita. Las medidas se han realizado en la TU-Wien en un espectrómetro Bruker Vertex 70 acoplado a un detector de telururo de mercurio-cadmio (MCT) que se encuentra refrigerado por $\mathrm{N}_{2}$ líquido durante todo el análisis. La celda donde se coloca la muestra es de acero inoxidable (Pike) y cuenta con una ventana de $\mathrm{CaF}_{2}$ la cual no absorbe radiación IR y presenta un bajo índice de refracción. La celda también cuenta con un horno que permite controlar la temperatura de la muestra durante los experimentos.

Las muestras analizadas por esta técnica fueron pretratadas con $\mathrm{O}_{2}\left(5 \% \mathrm{O}_{2}\right.$ en He, flujo: $\left.47.5 \mathrm{~mL} \cdot \mathrm{min}^{-1}\right)$ o con $\mathrm{H}_{2}\left(5 \% \mathrm{H}_{2}\right.$ en $\mathrm{He}$, flujo: $\left.47.5 \mathrm{~mL} \cdot \mathrm{min}^{-1}\right)$ a $150{ }^{\circ} \mathrm{C}$ durante 40 minutos. Una vez terminado el pretratamiento, se enfrió hasta llegar a temperatura ambiente y se cambiaron los gases a la mezcla de reacción $\left(\mathrm{CO}: \mathrm{O}_{2}\right.$ 1:2 en $\mathrm{He}$, flujo total: $\left.50 \mathrm{~mL} \cdot \mathrm{min}^{-1}\right)$. La reacción se llevó a cabo aumentando la temperatura hasta $150{ }^{\circ} \mathrm{C}$. Tras permanecer $30 \mathrm{~min}$ a $150{ }^{\circ} \mathrm{C}$ se continuó aumentando la temperatura hasta llegar a $400{ }^{\circ} \mathrm{C}$, se mantuvo esta temperatura otros 30 minutos y finalmente se volvió a enfriar a temperatura ambiente. Los espectros DRIFTS fueron adquiridos durante todo el experimento obteniendo una media de 256 scans para conseguir una adecuada relación señal/ruido.

\subsubsection{Espectroscopía de infrarrojo de transmisión con piridina como molécula sonda}

La espectroscopía de infrarrojo de transmisión empleando piridina como molécula sonda permite la determinación de los centros ácidos de los materiales. 
Esta técnica se basa en la interacción de la piridina, la cual es una molécula fuertemente básica, con los distintos centros ácidos. Esta interacción es distinta según la naturaleza de los centros ácidos, por lo que el empleo de esta técnica permite discriminar entre centros ácidos Lewis y centros ácidos Brönsted.

Cuando la piridina interacciona con un centro ácido Lewis, se coordina al centro ácido al donar un par de electrones al átomo metálico, lo que genera una banda en el espectro de infrarrojos a $1450 \mathrm{~cm}^{-1}$. Por otra parte, cuando la piridina es adsorbida en un centro ácido Brönsted se generan iones piridinio, los cuales presentan una banda característica a $1550 \mathrm{~cm}^{-1}$ en el espectro infrarrojo.

Las medidas se realizaron en un espectrofotómetro FTIR Nicolet 710. Para realizar los análisis, las muestras han de prepararse en forma de pastilla autoconsistente $(10-15 \mathrm{mg})$. Estas pastillas son pretratadas a $400{ }^{\circ} \mathrm{C}$ a vacío durante toda la noche, y a continuación, son saturadas con vapor de piridina (650 $\mathrm{Pa})$ a temperatura ambiente, eliminando el exceso mediante vacío. Tras esto, se lleva a cabo la desorción, para lo cual se va aumentando la temperatura hasta 150 ${ }^{\circ} \mathrm{C}, 250{ }^{\circ} \mathrm{C}$ y $350^{\circ} \mathrm{C}$ mientras se adquieren los espectros correspondientes.

\subsubsection{Espectroscopía fotoelectrónica de rayos $\mathrm{X}$}

La espectroscopía fotoelectrónica de rayos X (XPS) es una técnica de caracterización que permite determinar y cuantificar los elementos que están presentes en la superficie de una muestra. Asimismo, aporta información sobre el estado de oxidación y de coordinación de cada elemento. El análisis XPS se basa en irradiar una muestra a vacío con fotones del rango de energía de los rayos X. Al incidir estos fotones sobre la superficie del material, los átomos que la conforman emiten electrones debido al denominado efecto fotoeléctrico. Los electrones emitidos salen con una determinada energía cinética cumpliendo la Ecuación 22:

$$
\mathrm{E}_{\mathrm{k}}=\mathrm{h} v-\mathrm{E}_{\mathrm{B}}
$$


en donde:

$$
\begin{aligned}
& \mathrm{E}_{\mathrm{k}} \text { : energía cinética de los electrones emitidos } \\
& \mathrm{h} v \text { : energía de los fotones } \\
& \mathrm{E}_{\mathrm{B}} \text { : energía de enlace del electrón en el átomo }
\end{aligned}
$$

La energía de enlace es característica a cada elemento, por lo que la identificación y cuantificación de los elementos que componen la superficie del sólido puede determinarse mediante el análisis de la energía cinética de los electrones que son emitidos.

Las medidas realizadas en esta tesis se han realizado en un equipo que permite trabajar a presiones cercanas a la atmosférica (NAP-XPS). Los análisis de XPS se realizaron en la TU-Wien en un sistema NAP-XPS in situ SPECS GmbH equipado con un analizador hemiesférico Phoiboos 150 NAP y con una fuente de rayos X XR 50 MF. Los espectros fueron adquiridos con radiación monocromática $\mathrm{Al} \mathrm{K} \alpha$ y los datos fueron analizados con el programa CasaXPS.

\subsubsection{Espectroscopía de resonancia magnética nuclear}

La espectroscopía de resonancia magnética nuclear (RMN) es una técnica ampliamente utilizada para la elucidación estructural de materiales. La RMN se basa en el análisis de la interacción entre un campo magnético externo y los momentos nucleares de átomos cuyo momento magnético nuclear es distinto de cero $\left({ }^{1} \mathrm{H},{ }^{13} \mathrm{C},{ }^{14} \mathrm{~N},{ }^{19} \mathrm{~F},{ }^{27} \mathrm{Al},{ }^{29} \mathrm{Si},{ }^{31} \mathrm{P}\right.$, entre otros).

En el caso de las muestras sólidas, como las estudiadas en esta tesis, los átomos presentan baja movilidad, lo que causa un ensanchamiento de las señales que dificulta su interpretación. Estos ensanchamientos son producidos por diversas interacciones anisótropas (interacciones dipolares y cuadrupolares, anisotropía del desplazamiento químico, etc.). Para evitar esto, se emplea la RMN con giro al ángulo mágico (MAS) que consiste en colocar la muestra con un ángulo de $54.7^{\circ}$ con respecto al eje en el que está orientado el campo magnético externo. 
Con esto, se consigue anular la contribución de las interacciones que producen los ensanchamientos de la señal.

La técnica RMN se ha empleado en esta tesis para estudiar el entorno de los ligandos con fósforo presentes en los nanoclusters $\mathrm{Au}_{11}$. Los espectros de RMN $\mathrm{de}^{31} \mathrm{P}$ de las muestras se realizaron mediante la técnica de giro al ángulo mágico en un equipo Bruker Avance III HD de $400 \mathrm{MHz}$. Los espectros se registraron en una sonda de $4 \mathrm{~mm}$ a una velocidad de giro de $10 \mathrm{kHz}$, utilizado un pulso de $\pi / 2$ de $4.5 \mu$ s con desacoplamiento de ${ }^{1} \mathrm{H}$ durante el tiempo adquisición. Los espectros se referenciaron respecto a una muestra de $\mathrm{H}_{3} \mathrm{PO}_{4}(0 \mathrm{ppm})$.

\subsubsection{Espectrometría de masas por desorción/ionización láser asistida por matriz}

La espectrometría de masas por desorción/ionización láser asistida por matriz (MALDI) es una técnica que permite la determinación de moléculas en un amplio rango de masas moleculares. Durante los análisis, la muestra se mezcla con un exceso de una matriz de naturaleza orgánica, consiguiendo luego que cristalicen ambas. La muestra es sometida a pulsos de láser cortos en alto vacío. Estos pulsos provocan que la energía absorbida por la matriz transfiera un protón a la muestra, dando lugar a especias cargadas. El calor provocado por la irradiación hace que las especies iónicas pasen de fase sólida a fase gas. A continuación, se aplica un campo eléctrico y los iones generados son acelerados y conducidos a un analizador de tiempo de vuelo (TOF). El analizador TOF separa los iones de la muestra en función de la relación masa/carga $(\mathrm{m} / \mathrm{z})$ y mide el tiempo que tardan desde que se produce la aceleración de los iones hasta que impactan en un detector. El detector que recibe el impacto recoge la información necesaria para generar el espectro de masas de los compuestos analizados.

La técnica MALDI-TOF se empleó en este trabajo para conocer la composición de los nanoclusters de oro y/o plata tras sus síntesis. Los análisis se llevaron a cabo en un espectrómetro de masas de tiempo de vuelo Shimadzu. La matriz orgánica empleada es el compuesto trans-2[3-4-t-butil-fenil-2-metil-2- 
propenilideno]-malononitrilo (DCTB). Los espectros de masas fueron generados con la media de 300-600 pulsos de láser no seleccionados e individuales $(\lambda=337$ $\mathrm{nm}$ a $50 \mathrm{~Hz}$ ).

\subsubsection{Reducción a temperatura programada}

La reducción a temperatura programada (TPR) es una técnica que se emplea para el estudio de la reducibilidad de óxidos metálicos y de las fases metálicas soportadas en otros materiales. Asimismo, mediante esta técnica se puede obtener información sobre el grado y el tipo de interacción entre los metales y el soporte. La técnica de TPR consiste en hacer pasar una corriente gaseosa reductora de $\mathrm{H}_{2}$ en $\mathrm{He}$ (o Ar) a través de la muestra, a la vez que la temperatura se va incrementando. Durante este proceso, la concentración de $\mathrm{H}_{2}$ irá disminuyendo al ser consumido en la reacción de reducción, lo que genera un cambio en la conductividad térmica de la corriente gaseosa. Esta variación de la conductividad térmica se registra en un detector de conductividad térmica (TCD), y su representación en función del tiempo y la temperatura proporciona el perfil característico de reducibilidad de los metales presentes en la muestra.

Los experimentos de TPR se llevaron a cabo en un equipo TPD/TPR Autochem 2910 acoplado a un TCD. Antes de los análisis, las muestras fueron pretratadas en flujo de Ar por $1 \mathrm{~h}$ a temperatura ambiente. Durante el análisis, la composición de la corriente gaseosa reductora es de $\mathrm{H}_{2} / \operatorname{Ar}\left(10 \%\right.$ vol $\left.\mathrm{H}_{2}\right)$ y la temperatura se incrementa desde temperatura ambiente hasta $600-800{ }^{\circ} \mathrm{C}$.

\subsubsection{Microscopía electrónica}

Un microscopio electrónico es un microscopio que utiliza un haz de electrones para crear una imagen de la muestra en estudio. La interacción de los electrones incidentes con la muestra produce una serie de fenómenos: electrones secundarios, electrones retrodispersados, electrones transmitidos, rayos $\mathrm{X}$, electrones Auger, catodoluminiscencia e incluso electrones absorbidos por la propia muestra. La detección de estas señales proporciona distinta información 
sobre la muestra. Para la obtención de esta información se hace uso de distintos detectores y microscopios electrónicos.

En esta tesis se ha empleado la microscopía electrónica de transmisión de barrido con detector de electrones de alto ángulo en campo oscuro (STEM-HAADF). En la técnica STEM, el haz de electrones realiza un barrido a lo largo de la muestra y los electrones que se detectan son aquellos que atraviesan la muestra y que son dispersados. Al no tratarse de un haz fijo sobre una única zona de la muestra, el daño causado en la muestra por la radiación es mucho menor. En el caso particular de STEM-HAADF, el detector de electrones se encuentra colocado de manera que solamente detecta los electrones dispersados incoherentemente. Esto implica que este detector sea muy sensible a los cambios de los números atómicos $(\mathrm{Z})$ entre los distintos elementos que contenga la muestra, lo que permite observar contrastes de fases cuando la muestra tiene más de un elemento químico.

Asimismo, se empleó la espectroscopía de energía dispersiva de rayos X (EDX) como técnica para determinar la composición elemental de las muestras. Al bombardear la muestra con el haz de electrones, se puede producir un ion excitado que más tarde se relaja a su estado inicial. Esta relajación se produce por la transferencia de un electrón a una capa interior desde un orbital exterior, lo que produce la emisión de rayos $\mathrm{X}$. La energía de los rayos $\mathrm{X}$ emitidos es característica de cada elemento, por lo que de esta manera se puede determinar cualitativa y cuantitativamente los elementos que componen la muestra.

Las muestras que se han analizado mediante esta técnica son los catalizadores preparados con nanoclusters de oro y/o plata soportados sobre ITQ-2. Los análisis se realizaron en la TU-Wien empleando un microscopio electrónico $200 \mathrm{kV}$ FEI Tecnai F20 S-TWIN. La energía de resolución fue $\leq 1 \mathrm{eV}$, el ángulo de semiconvergencia $\sim 8 \mathrm{mrad}$, el ángulo de semi-colección $\sim 15 \mathrm{mrad}$, y la resolución espacial del orden de $0.5 \mathrm{~nm}$. 


\subsection{Ensayos catalíticos}

En esta tesis se ha trabajado con tres reacciones distintas: la reducción catalítica selectiva de óxidos de nitrógeno, la oxidación catalítica de monóxido de carbono y la semihidrogenación de alquinos.

\subsubsection{Reacción de reducción catalítica selectiva de NOx}

Esta reacción se basa en la reducción catalítica selectiva de los $\mathrm{NO}_{\mathrm{x}}$ empleando amoniaco como agente reductor de acuerdo con las reacciones descritas en las Ecuaciones 11, 12 y 13. Para llevar a cabo estos estudios se emplea el sistema descrito a continuación.

\section{a) Sistema de reacción}

Los ensayos catalíticos han sido llevados a cabo en un reactor continuo de cuarzo, de lecho fijo y a presión atmosférica. El reactor es de forma tubular y mide $53 \mathrm{~cm}$ de longitud y $22 \mathrm{~mm}$ de diámetro interno. En su interior, contiene una placa porosa sobre la que se deposita el catalizador. Para conseguir un reparto uniforme del calor y evitar problemas de gradientes de temperatura en el reactor, el catalizador es diluido con carburo de silicio. El reactor se encuentra albergado en un horno cilíndrico cuya temperatura es controlada por un controlador PID. La temperatura es medida por un termopar de tipo-K colocado dentro del reactor.

Los gases son introducidos en el sistema mediante llaves todo-nada y los caudales son regulados con caudalímetros másicos de la marca Bruker. Una vez mezclados los gases del alimento, estos se dirigen a una llave de tres vías que permite hacer pasar la mezcla a través del reactor o llevarla directamente a los detectores. Tras el reactor hay dos llaves para llevar la corriente de gases hacia los analizadores o directamente hacia venteo.

En las reacciones en las que se quiere añadir vapor de agua como reactivo, los gases se saturan al pasar por un borboteador lleno de agua a través del cual fluyen 
los mismos. En la Figura 9 se muestra un esquema del sistema de reacción empleado.

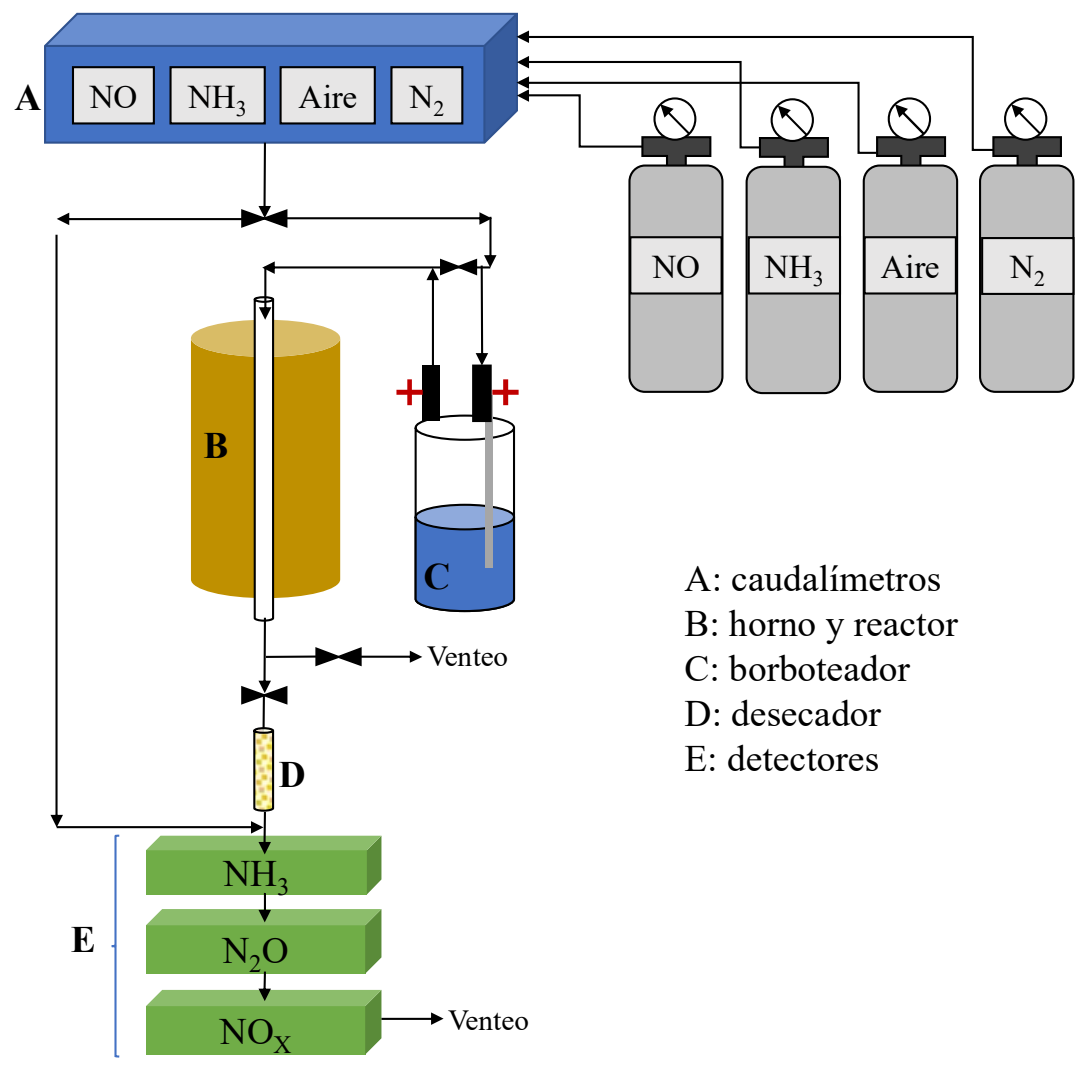

Figura 9. Esquema del sistema de reacción.

\section{b) Sistema de análisis}

El sistema de reacción consta de tres detectores conectados en serie para monitorizar en continuo la concentración de $\mathrm{NH}_{3}, \mathrm{~N}_{2} \mathrm{O}$ y $\mathrm{NO}_{\mathrm{X}}$ en el transcurso de la reacción. Todos ellos muestran directamente la concentración de estos gases en sus respectivas pantallas. 
Para la monitorización del amoniaco, se utilizó el detector EXM400 de Tethys Instruments, cuyo funcionamiento está basado en la espectroscopía UV. Para el correcto funcionamiento, ha de realizarse en primer lugar un blanco que consiste en medir la emisión de una lámpara de xenón en presencia de un gas que no presente absorción, nitrógeno en este caso, tomándose este valor como referencia para la absorción cero. Luego, a medida que el amoniaco circula en la celda del detector, el analizador mide la luz transmitida para determinar el espectro de absorción y calcular la concentración de amoníaco, en base a la ley de LambertBeer.

Para la monitorización de $\mathrm{NO}_{\mathrm{x}}$, se utilizó un detector de tipo $42 \mathrm{C}$ de Thermo Electron Corporation, que es un detector de quimioluminiscencia. Se basa en la reacción del monóxido de nitrógeno y el ozono para producir dióxido de nitrógeno y oxígeno (Ecuación 23). En esta reacción, algunas moléculas de $\mathrm{NO}_{2}$ se encuentran en estado excitado, y cuando vuelven al estado fundamental emiten un fotón (Ecuación 24) que es detectado en el tubo fotomultiplicador, por lo que la concentración de NO puede ser relacionada con la emisión de fotones.

$$
\begin{gathered}
\mathrm{NO}+\mathrm{O}_{3} \rightarrow \mathrm{NO}_{2}^{*}+\mathrm{O}_{2} \\
\mathrm{NO}_{2}^{*} \rightarrow \mathrm{NO}_{2}+\mathrm{hv}
\end{gathered}
$$

Además, el equipo permite determinar la concentración total de $\mathrm{NO}_{\mathrm{x}}(\mathrm{NO}+$ $\mathrm{NO}_{2}$ ). Para poder realizar esta medida, es necesario reducir el $\mathrm{NO}_{2}$ a $\mathrm{NO}$ (Ecuación 25) en el convertidor catalítico antes de que se produzca la reacción con ozono (Ecuación 23).

$$
2 \mathrm{NO}_{2} \rightarrow 2 \mathrm{NO}+\mathrm{O}_{2}
$$


El ozono necesario para las mediciones del detector es generado en el propio equipo. Para ello una corriente de aire se expone a radiación UV (Ecuación 26). El aire empleado ha de estar seco, por lo que a la entrada del equipo se encuentra un desecador.

$$
3 \mathrm{O}_{2}+\mathrm{hv} \rightarrow 2 \mathrm{O}_{3}
$$

El $\mathrm{N}_{2} \mathrm{O}$ es detectado con un equipo ServoPro 4000 Series de la marca Servomex. El funcionamiento de este detector se basa en la espectroscopía infrarroja, empleando un sensor GFx 1210 Series que permite determinar la concentración de óxido nitroso en la corriente gaseosa a analizar.

\section{c) Descripción de los experimentos}

Para realizar la reacción de reducción catalítica selectiva de $\mathrm{NO}_{\mathrm{X}}$ se introducen en el reactor $400 \mathrm{mg}$ de catalizador diluido con $\sim 8 \mathrm{~g}$ de $\mathrm{SiC}$. El catalizador es previamente tamizado con un tamaño de partícula de 0.4-0.6 mm, evitando de esta manera la formación de caminos preferenciales en el paso de los gases y la obturación de la placa porosa del reactor. Una vez cargado el reactor, se pasa una corriente de $\mathrm{N}_{2}$ a $600 \mathrm{~mL} \cdot \mathrm{min}^{-1}$ a $550{ }^{\circ} \mathrm{C}$ durante 30 minutos. Tras activar el catalizador, se enfría a temperatura ambiente en la misma corriente de $\mathrm{N}_{2}$ para comenzar la reacción. En ese momento, se introduce la muestra de reacción cuya composición es la siguiente: $500 \mathrm{ppm}$ de $\mathrm{NO}, 500 \mathrm{ppm}$ de $\mathrm{NH}_{3}, 4 \% \mathrm{O}_{2}$ y $\mathrm{N}_{2}$ como gas balance con un caudal total de $600 \mathrm{~mL} \cdot \mathrm{min}^{-1}$. A continuación, se va aumentando la temperatura en intervalos de $50{ }^{\circ} \mathrm{C}$ hasta alcanzar los $550-600^{\circ} \mathrm{C}$, analizando en todo momento la composición de los gases de salida. Al acabar la reacción, se vuelve a enfriar y se purgan con $\mathrm{N}_{2}$ las líneas del equipo para evitar que queden reactivos o productos de la reacción.

La conversión de $\mathrm{NO}_{\mathrm{X}}$ fue calculada para cada temperatura según la Ecuación 27: 


$$
\% \text { conversión } \mathrm{NO}_{\mathrm{X}}=\frac{\left[\mathrm{NO}_{\mathrm{X}}\right]_{\text {in }}-\left[\mathrm{NO}_{\mathrm{X}}\right]_{\text {out }}}{\left[\mathrm{NO}_{\mathrm{X}}\right]_{\text {in }}} \cdot 100
$$

en donde el subíndice in hace referencia a la concentración de $\mathrm{NO}_{\mathrm{x}}$ del alimento y out a la concentración de $\mathrm{NO}_{\mathrm{x}}$ detectada en cada temperatura.

Por otro lado, la selectividad a $\mathrm{N}_{2} \mathrm{O}$ se calculó según la Ecuación 28:

$$
\% \text { selectividad a } \mathrm{N}_{2} \mathrm{O}=\frac{\left[\mathrm{N}_{2} \mathrm{O}\right]_{\text {out }} \cdot 2}{\left[\mathrm{NH}_{3}\right]_{\text {in }}+\left[\mathrm{NO}_{\mathrm{X}}\right]_{\text {in }}-\left[\mathrm{NH}_{3}\right]_{\text {out }}-\left[\mathrm{NO}_{\mathrm{X}}\right]_{\text {out }}} \cdot 100
$$

\subsubsection{Reacción de oxidación catalítica de CO}

Esta reacción consiste en la oxidación catalítica de $\mathrm{CO}$ en presencia de $\mathrm{O}_{2}$.

\section{a) Sistema de reacción}

El sistema de reacción empleado para la reacción de oxidación catalítica de CO es el descrito en el apartado 3.4.1., con la diferencia de que los gases de entrada son $\mathrm{CO}$, aire y nitrógeno.

\section{b) Sistema de análisis}

Durante la reacción catalítica de oxidación de $\mathrm{CO}$ se emplea un detector que analiza la cantidad de $\mathrm{CO}_{2}$ formada durante la reacción. El detector empleado es el ServoPro 4000 Series de la marca Servomex explicado en el apartado 3.4.1., cuyo funcionamiento se basa en la espectroscopía infrarroja, y que contiene un sensor para la determinación de la concentración de $\mathrm{CO}_{2}$. 


\section{c) Descripción de los experimentos}

Para esta reacción, el reactor se carga con $250 \mathrm{mg}$ de catalizador con un tamaño de partícula de 0.4-0.6 mm diluido en $\sim 8 \mathrm{~g}$ de $\mathrm{SiC}$. El catalizador es pretratado antes de comenzar la reacción en un flujo de $\mathrm{O}_{2}$ o de $\mathrm{H}_{2}$ a $150{ }^{\circ} \mathrm{C}$ con un caudal de $500 \mathrm{~mL} \cdot \mathrm{min}^{-1}$ durante 1 hora. Una vez finalizado el pretratamiento, el reactor se enfría a temperatura ambiente en flujo de $\mathrm{N}_{2}$. A continuación, se introduce el alimento de la reacción que consiste en $0.5 \% \mathrm{CO}, 4 \% \mathrm{O}_{2}$ y $\mathrm{N}_{2}$ como gas balance. Para realizar la reacción, la temperatura se va aumentando desde $100{ }^{\circ} \mathrm{C}$ hasta 550-600 ${ }^{\circ} \mathrm{C}$ en intervalos de $50^{\circ} \mathrm{C}$, y se analiza la concentración de $\mathrm{CO}_{2}$ a la salida de los gases. Una vez terminada la reacción, se enfría el reactor y se purga con $\mathrm{N}_{2}$.

La conversión de CO fue calculada para cada temperatura según la Ecuación 29:

$$
\% \text { conversión } \mathrm{CO}=\frac{\left[\mathrm{CO}_{2}\right]_{\text {out }}}{[\mathrm{CO}]_{\text {in }}} \cdot 100
$$

en donde el subíndice in hace referencia a la concentración de $\mathrm{CO}$ del alimento y out a la concentración de $\mathrm{CO}_{2}$ detectada en cada temperatura.

\subsubsection{Reacción de semihidrogenación de alquinos}

Esta reacción se basa en la semihidrogenación del fenilacetileno para obtener estireno en presencia de piridina. La reacción se realizó en fase líquida tal y como se describe a continuación.

\section{a) Sistema de reacción}

En este caso se emplea un reactor de vidrio de $8 \mathrm{~mL}$ que consta de un manómetro que permite la presurización del sistema. El reactor tiene dos llaves todo-nada que permiten la entrada y salida de gas. En el interior del reactor se coloca un agitador magnético para conseguir la homogeneidad de la muestra durante la reacción. El reactor se coloca sobre un soporte metálico encima de una placa 
agitadora/calefactora para mantener la temperatura deseada, así como la agitación. En la Figura 10 puede observarse un esquema del sistema de reacción empleado en esta reacción.

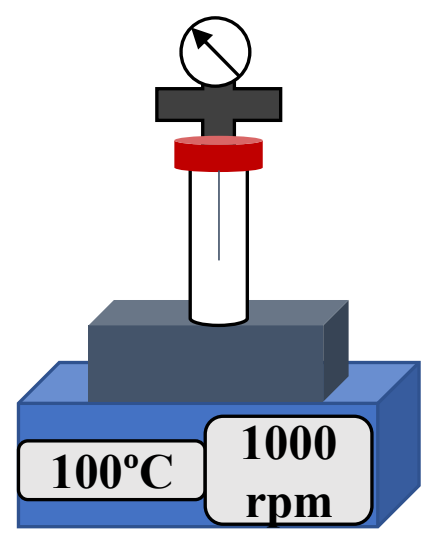

Figura 10. Esquema del sistema de reacción de la semihidrogenación de alquinos.

\section{b) Sistema de análisis}

Los productos de reacción (estireno, etilbenceno, y fenilacetileno en caso de que no se consuma por completo) fueron analizados por cromatografía de gases, empleando un cromatógrafo Varian CP-3800. Para la separación de los gases se emplea una columna HP-5 de 25 metros de longitud $(0.25 \mathrm{~mm}$ de diámetro interno y $0.25 \mu \mathrm{m}$ de grosor de fase activa). Los productos fueron detectados con un detector de ionización de llama (FID).

Los factores de respuesta relativos, los cuales permiten el cálculo de las áreas corregidas de los productos, fueron determinados mediante una calibración hecha con diferentes mezclas ternarias. A partir de los valores de las áreas corregidas $\left(A c_{j}\right)$, se obtuvieron la fracción másica $\left(\mathrm{w}_{\mathrm{j}}\right)$, la conversión $(\mathrm{X})$ y la selectividad $\left(\mathrm{S}_{\mathrm{j}}\right)$ según las siguientes ecuaciones: 


$$
\begin{gathered}
w_{j}(\%)=\frac{A c_{j}}{\sum_{j}^{3} A c_{j}} \cdot 100 \\
X(\%)=100-w_{F A} \\
S_{j}(\%)=\frac{w_{j}}{X} \cdot 100
\end{gathered}
$$

en donde $\mathrm{w}_{\mathrm{FA}}$ es la fracción másica del fenilacetileno al final de la reacción.

\section{c) Descripción de los experimentos}

El reactor se cargó con $100 \mathrm{mg}$ de catalizador y se introdujo el alimento: $0.1 \mathrm{mmol}$ de fenilacetileno y $0.2 \mathrm{mmol}$ de piridina diluidos en $1 \mathrm{~mL}$ de disolvente (etanol:agua 10:1 V/V). Una vez cerrado el reactor, se purgó el aire del interior introduciendo 2 veces 10 bares de hidrógeno. A continuación, se colocó el reactor en la placa agitadora/calefactora ajustando la agitación a $1000 \mathrm{rpm}$ y la temperatura a $100^{\circ} \mathrm{C}$. Una vez alcanzada $\operatorname{los} 100{ }^{\circ} \mathrm{C}$, se ajustó la presión final a 10 bares con hidrógeno. El tiempo de reacción fue de 20 horas. Al finalizar, se separó el catalizador mediante filtración y se analizaron las muestras. 
4. REDUCCIÓN CATALÍTICA SELECTIVA DE ÓXIDOS DE NITRÓGENO CON AMONIACO 

En este capítulo se describe el estudio realizado sobre la eliminación de óxidos de nitrógeno mediante la reducción catalítica selectiva con amoniaco empleando catalizadores bimetálicos de manganeso y hierro. Este tipo de catalizadores han sido estudiados con el fin de encontrar alternativas más económicas y menos contaminantes que los actuales catalizadores basados en zeolitas con $\mathrm{Cu}$ o en óxidos de vanadio/tungsteno, y utilizados comercialmente para el control de las emisiones de $\mathrm{NO}_{\mathrm{X}}$ procedentes de fuentes móviles y estacionarias.

El uso de catalizadores bimetálicos basados en $\mathrm{Mn}$ y Fe ha sido descrito como una posible alternativa al uso de los catalizadores comerciales previamente comentados [53,61-64,137-142]. Sin embargo, la actividad de estos catalizadores bimetálicos parece depender de numerosas variables como el tipo de soporte [137], el método de incorporación de la fase metálica y las condiciones de reacción, haciendo difícil determinar las características necesarias para tener un catalizador activo en esta reacción.

Se ha realizado un estudio de la actividad de diferentes catalizadores conteniendo un $4 \%$ de Mn y un $2 \%$ de $\mathrm{Fe}$ (\% en peso) en la reacción de reducción catalítica selectiva de $\mathrm{NO}_{\mathrm{x}}$. Para ello, se han preparado distintos catalizadores de $\mathrm{Mn}-\mathrm{Fe}$ soportados sobre:

- Zeolitas con distinta estructura (CHA, ITQ-2, BEA, y FAU) y diferente relación $\mathrm{Si} / \mathrm{Al}$

- Materiales mesoporosos con diferente topología (MCM-41 y SBA-15) y diferente relación $\mathrm{Si} / \mathrm{Al}$

- Óxidos metálicos con distinta área superficial y diferentes propiedades ácido/base $\left(\mathrm{MgO}, \mathrm{TiO}_{2}, \mathrm{Al}_{2} \mathrm{O}_{3}\right)$ 


\subsection{Catalizadores Mn-Fe soportados sobre zeolitas}

En este estudio se emplearon cuatro zeolitas con diferente topología y distinta relación Si/Al. Estas zeolitas fueron:

- Faujasita (FAU) con relación $\mathrm{Si} / \mathrm{Al}=6$ y 30

- Beta (BEA) con relación $\mathrm{Si} / \mathrm{Al}=12.5$ y 19

- Chabazita (CHA) con relación $\mathrm{Si} / \mathrm{Al}=2$ y 10

- ITQ-2 con relación $\mathrm{Si} / \mathrm{Al}=10$ y $\infty$ (pura sílice)

La zeolita con estructura tipo faujasita (FAU) (Figura 11A) se caracteriza por tener grandes cavidades y presenta una celda unidad compuesta por dos tipos de unidades de construcción secundaria: dobles anillos de 6 miembros (d6r) y cajas tipo sodalita (sod) (Figura 11B), alternándose ambas en las tres direcciones del espacio. La zeolita FAU es una zeolita con canales tridimensionales interconectados con aperturas de 12 miembros (7.4 x $7.4 \AA$ ) (Figura 11C) y con tamaño de poro grande. Se trata de una zeolita con una densidad de red de $12.7 \mathrm{~T} \cdot 1000 \AA^{-3}[143]$.

A)

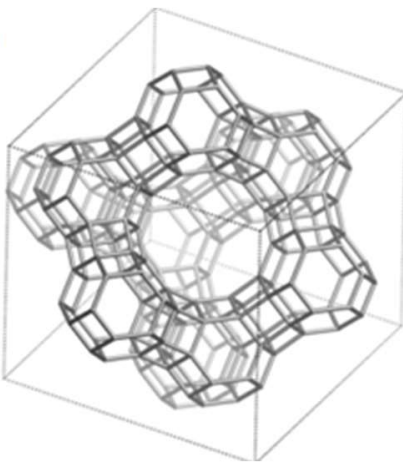

B)

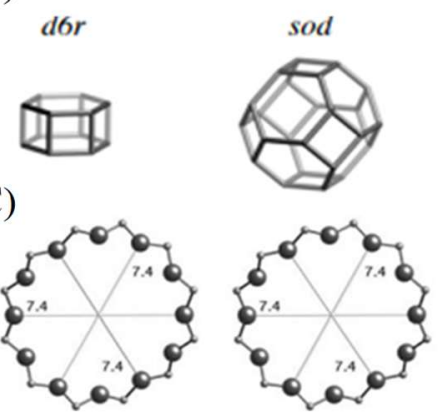

Figura 11. A) Estructura tipo faujasita. B) Unidades de construcción secundaria. C) Vista transversal de los canales de 12 miembros [143]. 
Las zeolitas FAU empleadas en este trabajo fueron suministradas por Zeolyst International, y sus especificaciones se muestran en la Tabla 13:

Tabla 13. Especificaciones de las zeolitas FAU comerciales.

\begin{tabular}{cccc}
\hline Zeolita & $\begin{array}{c}\text { Si/Al } \\
\text { (relación molar) }\end{array}$ & $\begin{array}{c}\text { Área superficial } \\
\left(\mathbf{m}^{\mathbf{2}} \cdot \mathbf{g}^{-1}\right)\end{array}$ & Cocatión \\
\hline $\begin{array}{c}\text { CBV 712 } \\
\text { (FAU6) }\end{array}$ & 6 & 780 & $\mathrm{NH}_{4}^{+}$ \\
\hline $\begin{array}{c}\text { CBV 760 } \\
\text { (FAU30) }\end{array}$ & 30 & 720 & $\mathrm{H}^{+}$ \\
\hline
\end{tabular}

La zeolita chabazita (CHA) (Figura 12A) presenta dos tipos de unidades de construcción secundaria en la celda unidad: dobles anillos de 6 miembros (d6r) y cajas tipo chabazita (cha) (Figura 12B), las cuales comprenden seis anillos de 8 miembros ( 3.8 x $3.8 \AA$ ) (Figura 12C) y una supercavidad central elipsoidal (6.7 $\mathrm{x} 10 \AA$ ). Por lo tanto, se trata de una zeolita de poro pequeño que tiene una densidad de red de $14.5 \mathrm{~T} \cdot 1000 \AA^{-3}[143]$.

A)

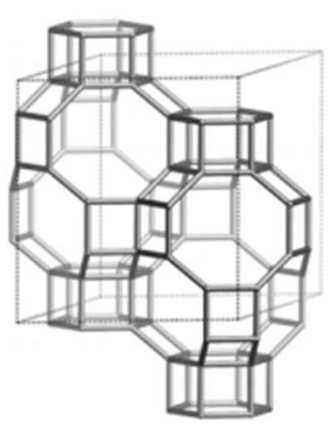

B)

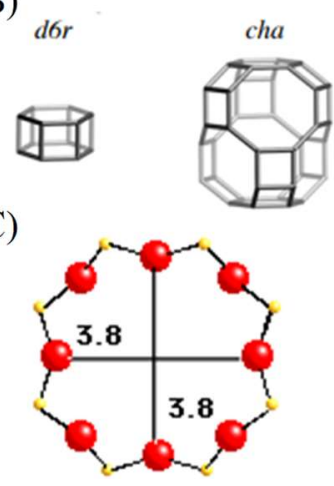

Figura 12. A) Estructura tipo CHA. B) Unidades de construcción secundaria d6r y cha. C) Vista transversal de los canales de 8 miembros [143]. 
Las zeolitas CHA empleadas en este trabajo fueron sintetizadas en el ITQ con dos relaciones $\mathrm{Si} / \mathrm{Al}$ ( 2 y 10$)$ y sus difractogramas aparecen en la Figura 13. En estos difractogramas se observan los picos característicos de la zeolita CHA [128], lo que confirma la correcta preparación de las zeolitas durante la síntesis.

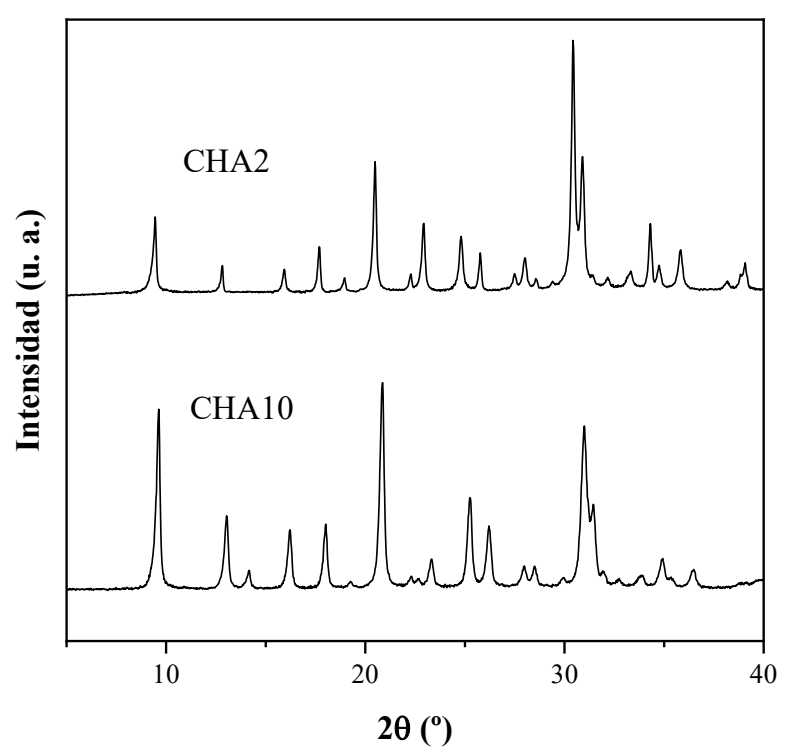

Figura 13. Difractogramas de rayos de las zeolitas $\mathrm{CHA}(\mathrm{Si} / \mathrm{Al}=2$ y 10).

La composición química de las zeolitas CHA sintetizadas y sus áreas superficiales se muestran en la Tabla 14:

Tabla 14. Composición química y áreas superficiales de las zeolitas CHA.

\begin{tabular}{ccccc} 
Zeolita & $\begin{array}{c}\text { Si/Al } \\
\text { (relación molar) }\end{array}$ & $\begin{array}{c}\text { \% Na } \\
\text { (en peso) }\end{array}$ & $\begin{array}{c}\text { \% K } \\
(\text { en peso) }\end{array}$ & $\begin{array}{c}\text { Área superficial } \\
\left(\mathbf{m}^{\mathbf{2}} \cdot \mathbf{g}^{-1}\right)\end{array}$ \\
\hline CHA10 & 10.4 & 2.0 & -- & 604 \\
\hline CHA2 & 2.2 & -- & 15.2 & -- \\
\hline
\end{tabular}


La zeolita beta (BEA) está formada por dos polimorfos con distintas simetrías (monoclínica y tetragonal) (Figura 14A). Ambos polimorfos presentan un sistema tridimensional de canales de 12 miembros interconectados (7.6 x $6.4 \AA$ y $5.6 \mathrm{x}$ $5.6 \AA$ ) (Figura 14B). En el cruce de los canales existen cavidades cuyas dimensiones varían entre 0.9-1 nm [143,144]. A diferencia de la faujasita, este tipo de zeolita no presenta supercavidades.

A)

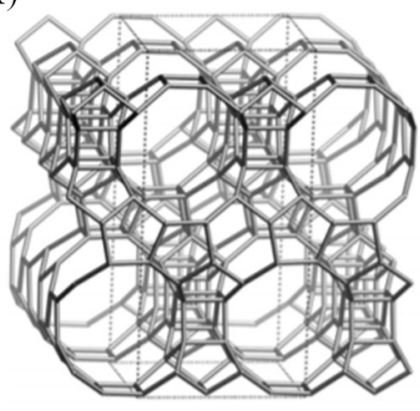

B)

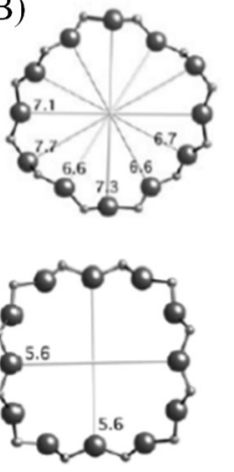

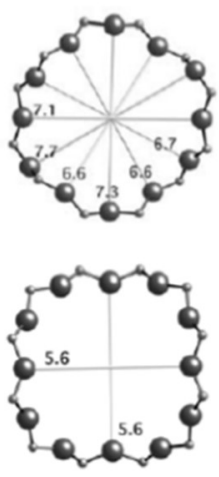

Figura 14. A) Estructura tipo BEA. B) Vista transversal de los canales de 12 miembros [143].

Las diferentes zeolitas BEA empleadas en esta tesis fueron suministradas por Zeolyst International y sus especificaciones se muestran en Tabla 15.

Tabla 15. Especificaciones de las zeolitas BEA.

\begin{tabular}{cccc}
\hline Zeolita & $\begin{array}{c}\text { Si/Al } \\
\text { (relación molar) }\end{array}$ & $\begin{array}{c}\text { Área superficial } \\
\left(\mathbf{m}^{2} \cdot \mathbf{g}^{-1}\right)\end{array}$ & Cocatión \\
\hline $\begin{array}{c}\text { CP814E } \\
\text { (BEA12.5) }\end{array}$ & 12.5 & 680 & $\mathrm{NH}_{4}^{+}$ \\
\hline $\begin{array}{c}\text { CP814C } \\
\text { (BEA19) }\end{array}$ & 19.0 & 710 & $\mathrm{NH}_{4}^{+}$ \\
\hline
\end{tabular}


La zeolita ITQ-2 es una zeolita deslaminada descubierta y sintetizada por primera vez en el Instituto de Tecnología Química [145]. Esta zeolita se obtiene tras el hinchamiento y posterior deslaminado de un precursor laminar tipo MWW (la zeolita MCM-22) como se observa en la Figura 15.

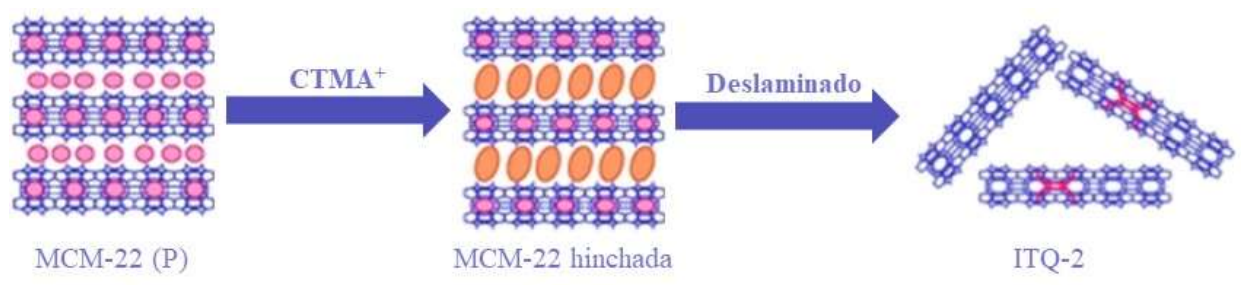

Figura 15. Esquema de la síntesis de la zeolita ITQ-2 [146].

El proceso de deslaminación da lugar a una zeolita con elevada área superficial $\left(>600 \mathrm{~m}^{2} \cdot \mathrm{g}^{-1}\right)$ consistente en láminas de unos $2.5 \mathrm{~nm}$ de espesor. Estas láminas se encuentran ordenadas mediante una distribución hexagonal de "copas". Estas "copas" consisten en una apertura formada por un anillo de $12 \mathrm{MR}$, y se unen a la copa contraria por la base a través de un doble anillo de $6 \mathrm{MR}$ en forma de prisma hexagonal. El espacio interlaminar está formado por canales sinusoidales de anillos de 10 MR (Figura 16).

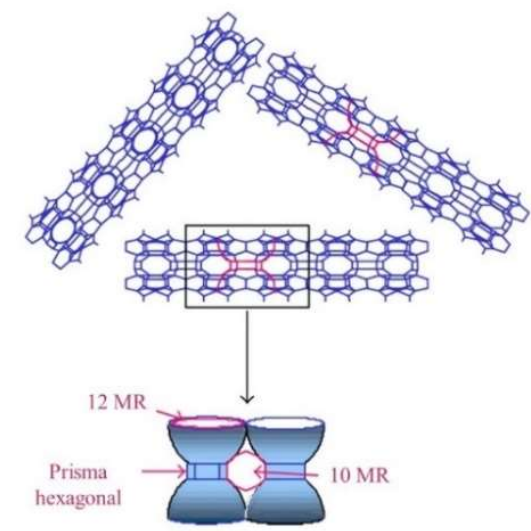

Figura 16. Estructura de la zeolita ITQ-2 [146]. 
En este estudio se ha empleado una zeolita ITQ-2 en su forma pura sílice (ITQ2_PS) y otra con relación Si/Al de 10 (ITQ-2_Al), ambas sintetizadas en el Instituto de Tecnología Química. Los difractogramas de rayos $\mathrm{X}$ de ambas zeolitas se muestran en la Figura 17, en donde se observan los picos característicos de este material, los cuales coinciden con los de las láminas del precursor laminar empleado en la síntesis de estas zeolitas [146].

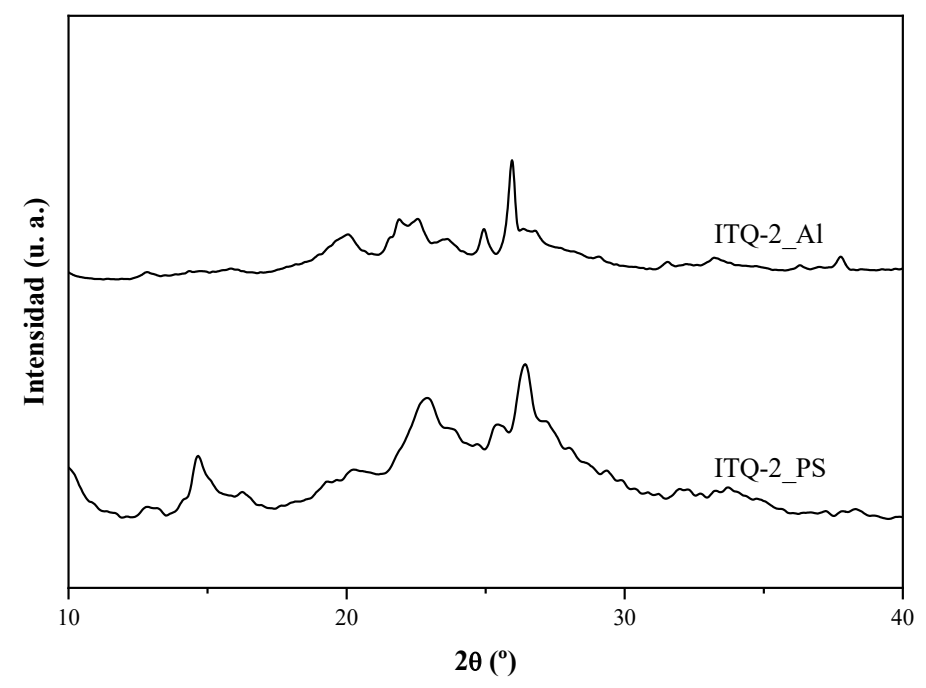

Figura 17. Difractogramas de $\operatorname{rayos} \mathrm{X}$ de las zeolitas $\mathrm{ITQ}$-2 $(\mathrm{Si} / \mathrm{Al}=\infty \mathrm{y} \mathbf{1 0})$.

Las propiedades físico-químicas de las zeolitas ITQ-2 empleadas en este estudio se muestran en la Tabla 16:

Tabla 16. Propiedades físico-químicas de las zeolitas ITQ-2.

\begin{tabular}{ccc}
\hline Zeolita & $\begin{array}{c}\text { Si/Al } \\
\text { (relación molar) }\end{array}$ & $\begin{array}{c}\text { Área superficial } \\
\left(\mathbf{m}^{\mathbf{2}} \cdot \mathbf{g}^{-1}\right)\end{array}$ \\
\hline ITQ-2_PS & $\infty$ & 722 \\
\hline ITQ-2_Al & 10.4 & 504
\end{tabular}


Estas zeolitas fueron impregnadas a volumen de poro con sales precursoras de Mn y Fe para obtener catalizadores con un $4 \%$ de Mn y un $2 \%$ de Fe (\% en peso). La composición química de los catalizadores, así como sus propiedades texturales se muestran en la Tabla 17.

Tabla 17. Composición química y área superficial de los catalizadores preparados con zeolitas.

\begin{tabular}{ccccc}
\hline Catalizador & $\begin{array}{c}\text { \% Mn } \\
\text { (en peso) }\end{array}$ & $\begin{array}{c}\text { \% Fe } \\
(\text { en peso })\end{array}$ & $\begin{array}{c}\text { Si/Al } \\
\text { (relación molar) }\end{array}$ & $\begin{array}{c}\text { Área } \\
\text { superficial } \\
\left(\mathbf{m}^{2} \cdot \mathbf{g}^{-1}\right)\end{array}$ \\
\hline Mn-Fe/FAU6 & 4.3 & 1.8 & 6 & 541 \\
\hline Mn-Fe/FAU30 & 4.7 & 2.1 & 30 & 616 \\
\hline Mn-Fe/CHA2 & 3.8 & 1.9 & 2.2 & -- \\
\hline Mn-Fe/CHA10 & 4.3 & 2.1 & 10.4 & 517 \\
\hline Mn-Fe/BEA12.5 & 4.9 & 2.0 & 12.5 & 516 \\
\hline Mn-Fe/BEA19 & 4.6 & 2.3 & 19 & 521 \\
\hline Mn-Fe/ITQ-2_PS & 4.8 & 2.2 & $\infty$ & 585 \\
\hline Mn-Fe/ITQ-2_Al & 4.5 & 2.2 & 10.2 & 458 \\
\hline
\end{tabular}

Los resultados obtenidos muestran que en todos los casos el contenido final de Mn y de Fe ha sido próximo al valor deseado (4 \% de Mn y $2 \%$ de Fe). Asimismo, en todos los catalizadores se produce una ligera disminución del área superficial tras la incorporación de las sales metálicas (Tablas 13, 14, 15 y 16), debido probablemente a una obturación parcial de los poros de las zeolitas tras depositar la sal metálica. Sin embargo, en todos los catalizadores las áreas superficiales obtenidas son muy elevadas $\left(>450 \mathrm{~m}^{2} \cdot \mathrm{g}^{-1}\right)$. Los materiales fueron caracterizados por DRX y los resultados se muestran en la Figura 18. 

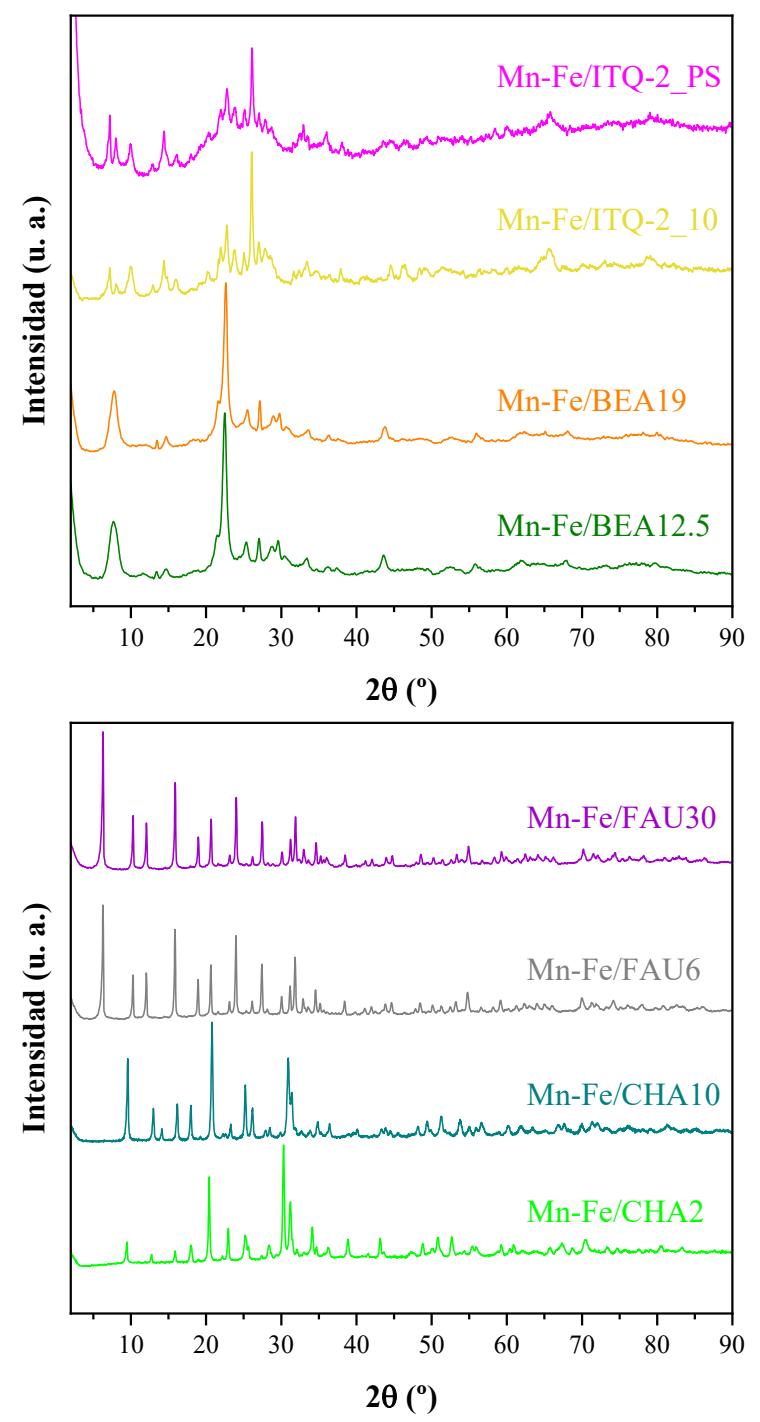

Figura 18. Difractograma de rayos $\mathrm{X}$ de los catalizadores soportados sobre las zeolitas ITQ-2, BEA, CHA y FAU con distinta relación Si/Al.

En todos los casos, los difractogramas de rayos $\mathrm{X}$ de las zeolitas tras la impregnación muestran únicamente los picos característicos de cada una de las 
estructuras zeolíticas, sin aparecer ningún pico asociado al manganeso o al hierro, lo que indica una buena dispersión de los metales soportados.

\subsubsection{Catalizadores Mn-Fe sobre la zeolita FAU}

Se prepararon dos catalizadores de $\mathrm{Mn}$ y Fe soportados sobre dos zeolitas FAU comerciales con distintas relaciones Si/Al (6 y 30). Los resultados de actividad catalítica a distinta temperatura en la reacción $\mathrm{SCR}-\mathrm{NO}_{\mathrm{x}}$ se muestran en la Figura 19.

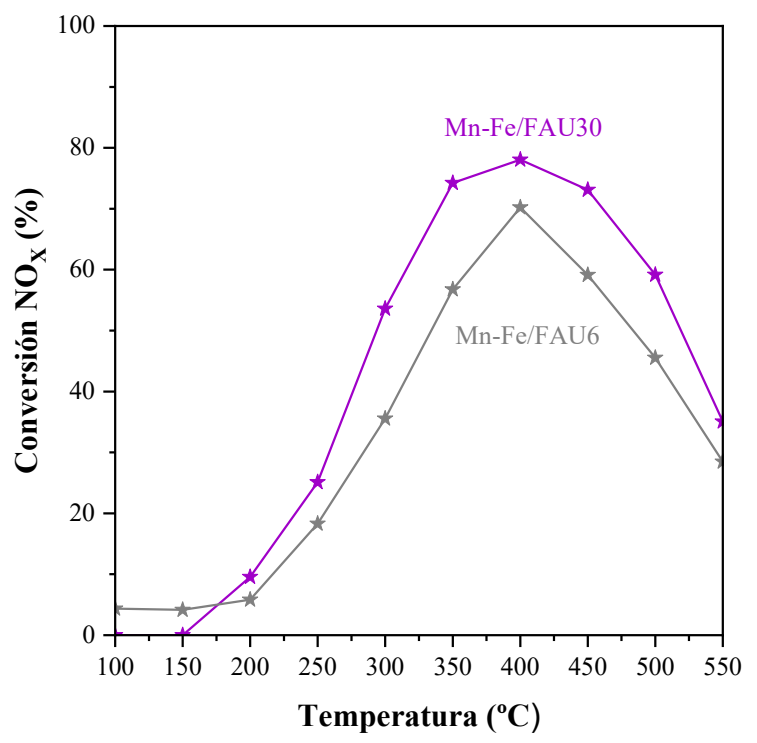

Figura 19. Actividad de los catalizadores Mn-Fe preparados con la zeolita FAU a distintas temperaturas. (500 ppm NO, $500 \mathrm{ppm} \mathrm{NH}_{3}, 4 \% \mathrm{O}_{2}$ y resto $\mathrm{N}_{2}$, masa $a_{\text {cat }}: 400 \mathrm{mg}$, Q: $\left.600 \mathrm{~mL} \cdot \mathrm{min}^{-1}\right)$.

Como se observa en la Figura 19, la actividad catalítica no es apreciable hasta que se alcanzan los $200{ }^{\circ} \mathrm{C}$. A partir de esa temperatura, la conversión va aumentando hasta alcanzar un máximo a $400{ }^{\circ} \mathrm{C}$, comenzando a bajar de nuevo a partir de esta temperatura. La formación de $\mathrm{N}_{2} \mathrm{O}$ es despreciable en todo el rango de temperatura, siendo la selectividad a $\mathrm{N}_{2}$ en el máximo de conversión $\left(400{ }^{\circ} \mathrm{C}\right)$ 
del $92 \%$ para el catalizador Mn-Fe/FAU6 y del $94 \%$ para el catalizador Mn$\mathrm{Fe} / \mathrm{FAU} 30$.

Comparando la actividad de ambos catalizadores, se observa que tienen un comportamiento similar en todo el rango de temperatura. Sin embargo, la actividad del catalizador preparado sobre la zeolita FAU30 es mayor en todo este rango, alcanzando una conversión máxima del $78 \%$ a $400{ }^{\circ} \mathrm{C}$, mientras que la del catalizador Mn-Fe/FAU6 es del $70 \%$ a la misma temperatura. Estas diferencias parecen indicar que hay una influencia de la relación Si/Al en la actividad de los catalizadores. En general, los catalizadores de zeolitas con un mayor contenido de aluminio (menor relación $\mathrm{Si} / \mathrm{Al}$ ) presentan un mayor número de centros ácidos, aunque la fortaleza de estos centros es menor que la de los centros presentes en zeolitas con una mayor relación Si/A1. Por ello, los resultados obtenidos parecen indicar que, la presencia de estos centros ácidos más fuertes y aislados favorecen la actividad catalítica. Se ha descrito que, en los catalizadores con Mn [58], una elevada acidez superficial beneficia a la actividad catalítica, al favorecer la adsorción del amoniaco. Sin embargo, los resultados obtenidos con esta zeolita indican que no es tan importante tener un elevado número de centros ácidos como el tener un número suficiente de los mismos con una elevada fuerza ácida, que es lo que ocurre al aumentar la relación $\mathrm{Si} / \mathrm{Al}$ en las zeolitas.

\subsubsection{Catalizadores Mn-Fe sobre la zeolita CHA}

La zeolita CHA ha sido sintetizada en el laboratorio con dos relaciones $\mathrm{Si} / \mathrm{Al}$ diferentes: 2 y 10 y, sobre la misma, se ha incorporado un $4 \%$ de Mn y un $2 \%$ de $\mathrm{Fe}$ en peso. Los resultados de actividad catalítica obtenidos con los catalizadores preparados se muestran en la Figura 20: 


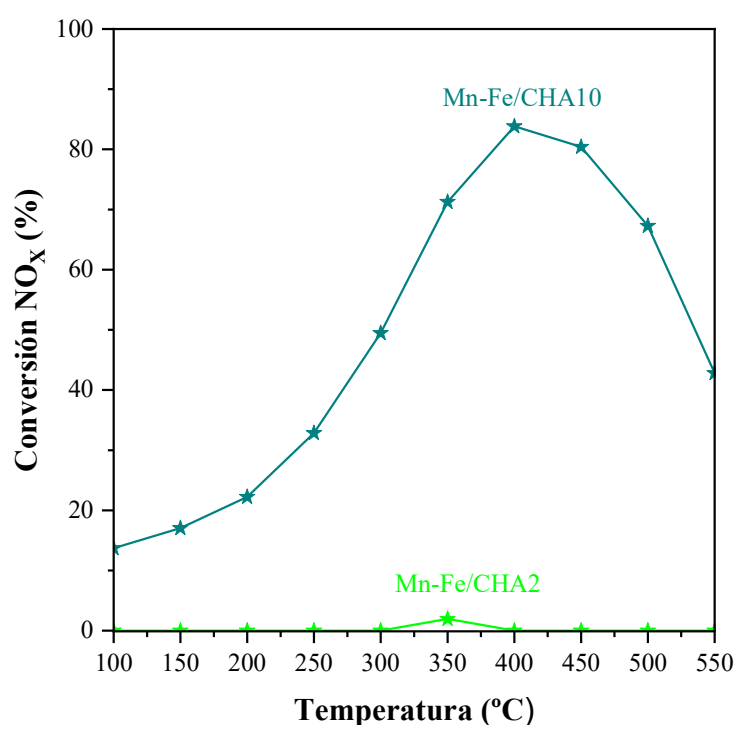

Figura 20. Actividad de los catalizadores Mn-Fe preparados con la zeolita CHA a distintas temperaturas. $\left(500 \mathrm{ppm} \mathrm{NO}, 500 \mathrm{ppm} \mathrm{NH}_{3}, 4 \% \mathrm{O}_{2}\right.$ y resto $\mathrm{N}_{2}$, masacat: $400 \mathrm{mg}$, Q: $\left.600 \mathrm{~mL} \cdot \mathrm{min}^{-1}\right)$.

Los resultados catalíticos muestran que el catalizador preparado sobre la zeolita $\mathrm{CHA}$ con $\mathrm{Si} / \mathrm{Al}=10$ presenta una buena actividad catalítica en un amplio rango de temperaturas. La actividad se inicia a partir de los $100{ }^{\circ} \mathrm{C}$, alcanzando un máximo de conversión a $400{ }^{\circ} \mathrm{C}(84 \%$ de conversión), tras el cual la actividad disminuye al seguir aumentando la temperatura. La selectividad a $\mathrm{N}_{2}$ es del $98 \%$ a la temperatura de máxima conversión. Sin embargo, el catalizador preparado con la zeolita sintetizada con una relación $\mathrm{Si} / \mathrm{Al}=2$ no presenta actividad catalítica significativa en todo el rango de temperatura de la reacción. Esto último puede relacionarse con que esta zeolita, debido a su proceso de síntesis, tiene un alto contenido en $\mathrm{K}$ ( $15.2 \%$ en peso) (Tabla 14), el cual tiene un radio iónico relativamente grande $(\mathrm{r}=0.133 \mathrm{~nm})$. El catión $\mathrm{K}^{+}$es el catión que compensa la carga de la zeolita y, por tanto, está uniformemente distribuido en toda la estructura zeolítica. Dado que la zeolita CHA es una zeolita de poro pequeño, el alto contenido de cationes $\mathrm{K}^{+}$bloquea los poros de la misma. De hecho, la medida del área BET de este material daría un valor de $17.9 \mathrm{~m}^{2} \cdot \mathrm{g}^{-1}$, debido a que el 
bloqueo de los poros impide que el $\mathrm{N}_{2}$ pueda entrar a través de los poros de la zeolita al realizar las medidas de área BET [147]. Esto mismo puede ocurrir con los gases del alimento de la reacción, que debido al bloqueo de los poros no pueden difundir a través de la zeolita, lo que explica que no se produzca actividad catalítica alguna con este catalizador. Además, la relación Si/Al de esta zeolita es extremadamente baja, es decir, tiene un contenido muy elevado de aluminio, con lo que los centros ácidos del catalizador pese a ser muy numerosos, son muy débiles, lo que dificultaría la adsorción del amoniaco. Esto, unido a los problemas de difusividad de los gases explicaría la inactividad de este catalizador.

\subsubsection{Catalizadores Mn-Fe sobre la zeolita BEA}

Las zeolitas BEA empleadas son dos zeolitas comerciales, suministradas por Zeolyst International y con dos relaciones $\mathrm{Si} / \mathrm{Al}$ diferentes (12.5 y 19). Como en los casos anteriores, se han preparado catalizadores bimetálicos de Mn y Fe con ambas zeolitas (Tabla 17) y se ha estudiado sus actividades catalíticas. Los resultados se muestran en la Figura 21, observándose que, al igual que ocurría con la zeolita FAU, la conversión empieza a ser importante a partir de $200{ }^{\circ} \mathrm{C}$, alcanzándose la máxima actividad a $400{ }^{\circ} \mathrm{C}$. A partir de esta temperatura, disminuye la conversión obtenida. 


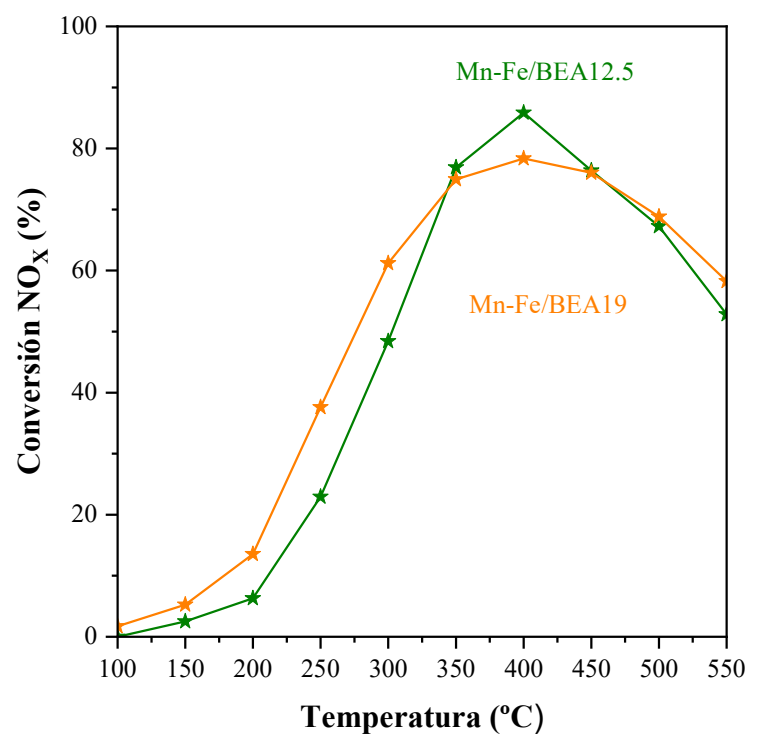

Figura 21. Influencia de la relación $\mathrm{Si} / \mathrm{Al}$ en los catalizadores $\mathrm{Mn}-\mathrm{Fe}$ preparados con la

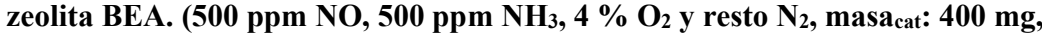
Q: $\left.600 \mathrm{~mL} \cdot \mathrm{min}^{-1}\right)$.

En este caso, la actividad de ambas zeolitas con distinta relación $\mathrm{Si} / \mathrm{Al}$ es bastante similar, siendo más activa la zeolita de relación $\mathrm{Si} / \mathrm{Al}=19$ a bajas temperaturas, mientras que entre 350 y $450{ }^{\circ} \mathrm{C}$, la zeolita de relación $\mathrm{Si} / \mathrm{Al}=12.5$ es ligeramente más activa, alcanzando una conversión máxima del $86 \%$ a $400{ }^{\circ} \mathrm{C}$. En ambos casos, la selectividad a $\mathrm{N}_{2}$ fue muy alta, manteniéndose por encima del $90 \%$ en todo el rango de temperatura.

La similar actividad catalítica de ambas zeolitas puede relacionarse con un contenido en aluminio bajo y relativamente similar en ambas zeolitas $(2.9 \%$ en peso para la zeolita de relación $\mathrm{Si} / \mathrm{Al}=12.5$ y $1.9 \%$ en peso para la de relación 19), lo que resultaría en la presencia de centros ácidos de similares características. 


\subsubsection{Catalizadores Mn-Fe sobre la zeolita ITQ-2}

Las zeolitas ITQ-2 utilizadas en este estudio eran una zeolita en forma pura sílice y otra con relación Si/Al de 10.5, ambas sintetizadas en el Instituto de Tecnología Química. Sobre estas zeolitas se ha soportado un $4 \%$ de Mn y un $2 \%$ de Fe y se ha estudiado su actividad catalítica en un amplio rango de temperatura (Figura 22).

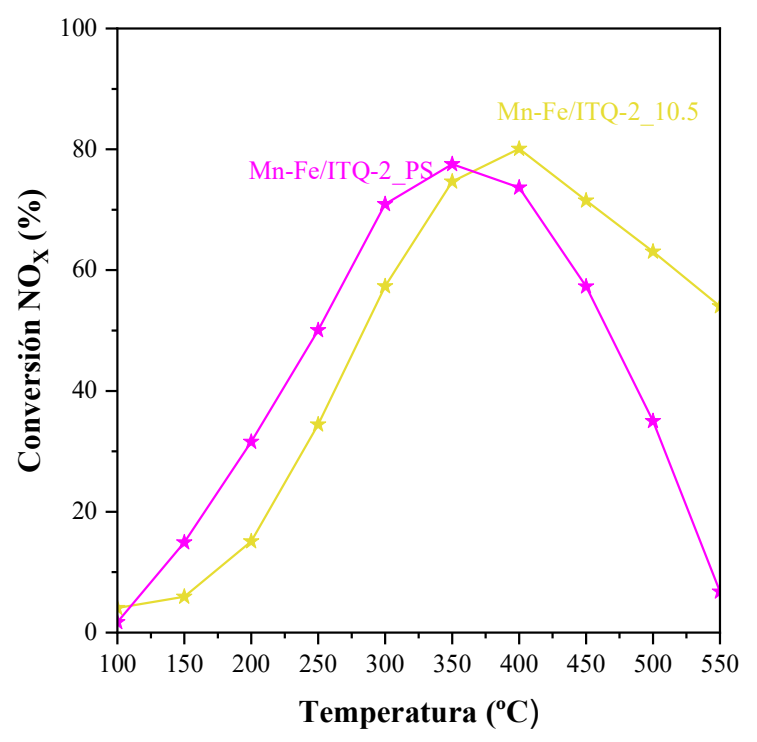

Figura 22. Actividad catalítica de los catalizadores Mn-Fe preparados sobre las zeolitas

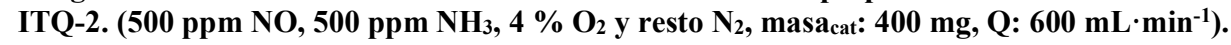

Como se observa en la gráfica de la Figura 22, en ambos catalizadores la actividad comienza a ser significativa a partir de $150{ }^{\circ} \mathrm{C}$. Sin embargo, en este caso se observa un desplazamiento del pico del máximo de actividad hacia menores temperaturas en el catalizador que no contiene aluminio.

El catalizador Mn-Fe soportado sobre la zeolita pura sílice es más activo a bajas temperaturas, alcanzando un máximo de conversión del $78 \%$ a $350{ }^{\circ} \mathrm{C}$, 
temperatura a la cual comienza a disminuir la conversión. El catalizador preparado con la zeolita con relación $\mathrm{Si} / \mathrm{Al}=10.5$ es más activo a temperaturas mayores, con un máximo de conversión a $400{ }^{\circ} \mathrm{C}$ de un $80 \%$, ligeramente superior al máximo obtenido con la zeolita pura sílice. La formación de $\mathrm{N}_{2} \mathrm{O}$ en ambos catalizadores es mínima, presentando selectividades a $\mathrm{N}_{2}$ superiores al 90 $\%$ en toda la reacción.

Se observa de nuevo una influencia de la relación $\mathrm{Si} / \mathrm{Al}$ en la actividad de los catalizadores, que a su vez podría relacionarse con la distinta acidez que presentan las zeolitas ITQ-2 empleadas. Para investigar esto, se realizó un experimento de adsorción-desorción de piridina seguido por espectroscopía infrarroja. Como puede verse en la Figura 23, la piridina se adsorbe en el catalizador que contiene aluminio a través de los centros Lewis (bandas situadas a $1448 \mathrm{~cm}^{-1}$ ) y Brönsted (bandas alrededor de $1544 \mathrm{~cm}^{-1}$ ). Sin embargo, el catalizador preparado con la zeolita pura sílice parece que presenta únicamente centros Lewis. Además, el área de estas bandas es mucho menor, indicando un menor número de centros ácidos en este catalizador. Los centros ácidos presentes en este catalizador son más débiles que los presentes en el catalizador preparado con la zeolita ITQ-2 con aluminio, ya que en el primero, al aumentar la temperatura, desaparecen más rápidamente las bandas correspondientes a la interacción de la piridina con los centros ácidos [148]. Esto podría explicar la menor actividad a temperaturas altas del catalizador pura sílice, ya que la adsorción del amoniaco en estos centros más débiles se vería desfavorecida a estas temperaturas. 


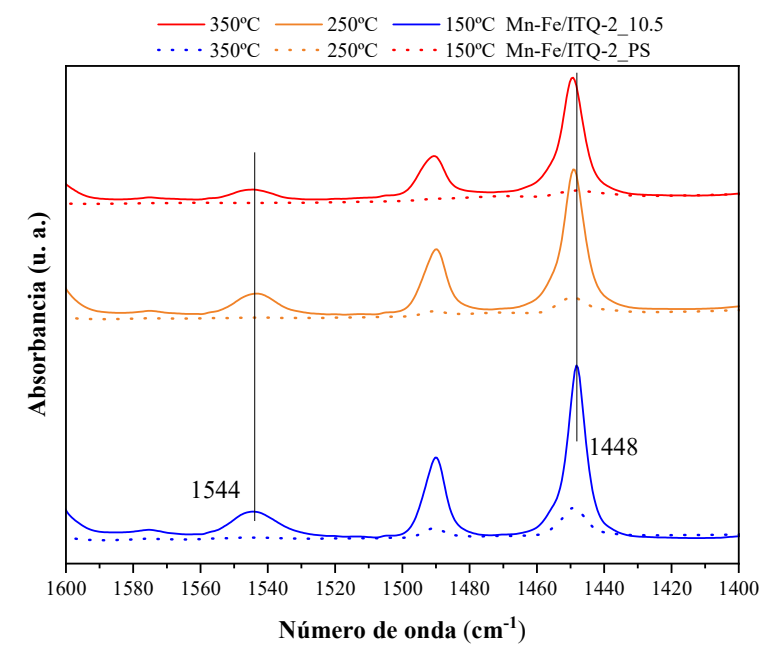

Figura 23. Espectro IR de desorción de piridina a $150{ }^{\circ} \mathrm{C}, 250{ }^{\circ} \mathrm{C}$ y $350{ }^{\circ} \mathrm{C}$ de los catalizadores Mn-Fe/ITQ-2_10.5 y Mn-Fe/ITQ-2_PS.

\subsubsection{Comparación de los resultados obtenidos con los catalizadores Mn-Fe soportados sobre las distintas zeolitas}

Los resultados obtenidos muestran que el tipo de estructura zeolítica, pero sobre todo la relación $\mathrm{Si} / \mathrm{Al}$ de las zeolitas juegan un papel importante en la actividad catalítica de los catalizadores de Mn-Fe soportados sobre zeolitas. En la Figura 24 se comparan los resultados obtenidos con los catalizadores preparados con las distintas zeolitas.

Esta comparación se hace con los catalizadores que han mostrado la máxima conversión para cada una las diferentes zeolitas empleadas, esto es los catalizadores Mn-Fe soportados sobre las zeolitas CHA10, ITQ-2_10.5, FAU30 y BEA12.5. 


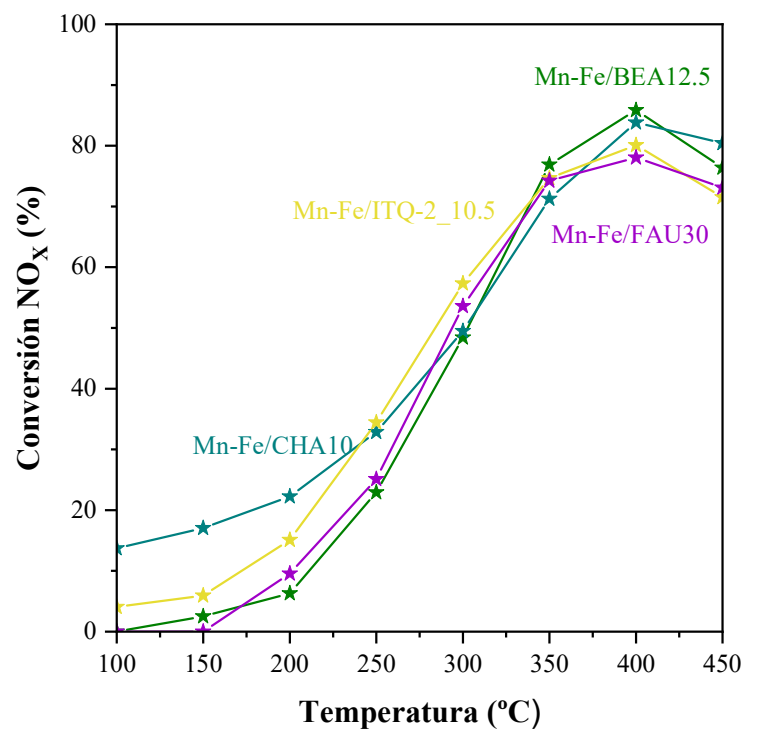

Figura 24. Actividad catalítica de los catalizadores Mn-Fe preparados sobre distintas zeolitas. (500 ppm NO, $500 \mathrm{ppm} \mathrm{NH}, 4 \% \mathrm{O}_{2}$ y resto $\mathrm{N}_{2}$, masacat: $400 \mathrm{mg}$, Q: $600 \mathrm{~mL} \cdot \mathrm{min}^{-1}$ ).

Como se observa en la Figura 24, los resultados obtenidos son bastantes similares, observándose las principales diferencias a bajas temperaturas y en los picos de máxima conversión. A excepción del catalizador Mn-Fe/CHA10, el resto de los catalizadores no tienen actividad significativa hasta los $200^{\circ} \mathrm{C}$, alcanzando la máxima actividad a $400{ }^{\circ} \mathrm{C}$. A partir de esta temperatura, la actividad disminuye en todos los catalizadores. Estos resultados indicarían que los catalizadores más interesantes serían los soportados en la zeolita CHA10, por su actividad a bajas temperaturas, y los soportados en la zeolita BEA12.5, por su actividad a altas temperaturas.

Estudios previos han determinado que cuando se utilizan catalizadores con cobre, las zeolitas con menor tamaño de poro son las que mejor actividad presentan en la reacción SCR-NO $\mathrm{X}_{\mathrm{X}}$ a bajas temperaturas [149]. Esto estaría en concordancia con los resultados obtenidos con los catalizadores de $\mathrm{Mn}-\mathrm{Fe}$, aunque las diferencias observadas entre los distintos tipos de zeolitas no son tan notables, 
siendo mucho más importante la cantidad de aluminio presente en la zeolita que su topología. En este sentido, los resultados obtenidos indican que las zeolitas más activas son aquellas que tienen un número suficiente de centros ácidos fuertes y aislados, con relaciones $\mathrm{Si} / \mathrm{Al}$ altas (superiores a 10). La presencia de estos centros, junto con la elevada área superficial parece determinar la actividad de los catalizadores, siendo menor la influencia de la topología de las zeolitas.

\subsection{Catalizadores Mn-Fe soportados sobre materiales mesoporosos}

La actividad de los catalizadores $\mathrm{Mn}-\mathrm{Fe}$ soportados sobre materiales mesoporosos en la reducción catalítica selectiva de los $\mathrm{NO}_{\mathrm{x}}$ con amoniaco se ha estudiado con los materiales mesoestructurados SBA-15 y MCM-41 (Figura 25), los cuales han sido sintetizados en el Instituto de Tecnología Química. Estos materiales han sido empleados tanto en su forma pura sílice, como con la incorporación de aluminio en sus estructuras (Al-MCM-41 y Al-SBA-15). La principal diferencia entre estos dos materiales mesoporosos es la forma de los poros, los cuales son hexagonales en el caso del MCM-41 y circulares en el material SBA-15 (Figura 25). Además, los tamaños de los poros son mayores y las paredes son más gruesas en el material SBA-15 que en el mesoporoso MCM41. [125,150].

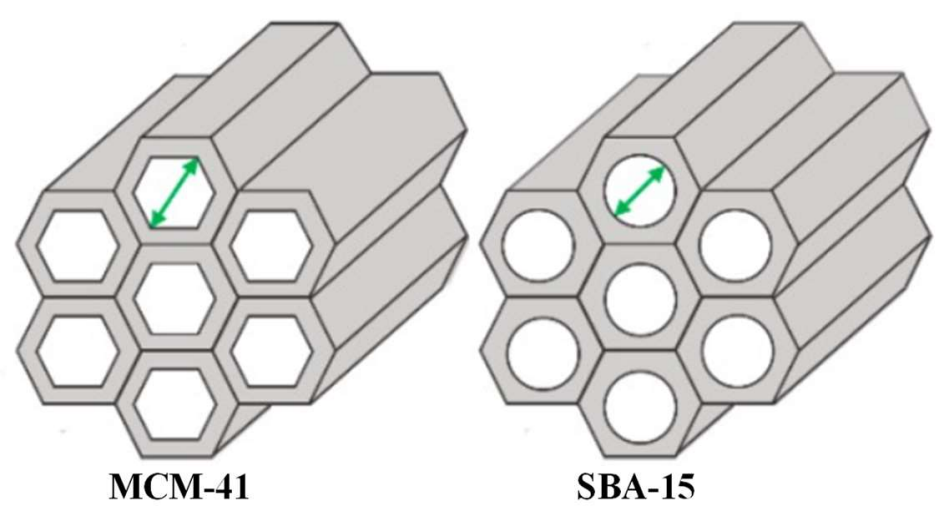

Figura 25. Estructura de los materiales mesoporosos MCM-41 y SBA-15 [151]. 
La relación $\mathrm{Si} / \mathrm{Al}$ y el área superficial de los materiales mesoporosos empleados en el estudio se muestran en la Tabla 18.

Tabla 18. Composición química y área superficial de los materiales mesoporosos MCM-41 y SBA-15.

\begin{tabular}{ccc} 
Material & $\begin{array}{c}\text { Si/Al } \\
\text { (relación molar) }\end{array}$ & $\begin{array}{c}\text { Área superficial } \\
\left(\mathbf{m}^{\mathbf{2}} \cdot \mathbf{g}^{-1}\right)\end{array}$ \\
\hline SBA-15 & $\infty$ & 904 \\
\hline Al-SBA-15 & 15.5 & 967 \\
\hline MCM-41 & $\infty$ & 924 \\
\hline Al-MCM-41 & 11.3 & 909 \\
\hline
\end{tabular}

Tal y como se observa, el área superficial de estos materiales es muy elevada, siendo incluso superior a las áreas de las zeolitas estudias en el apartado anterior.

Sobre estos soportes se impregnaron las sales precursoras de manganeso y hierro, y tras su calcinación se determinaron las propiedades texturales y la composición química de estos materiales (Tabla 19).

Tabla 19. Propiedades texturales y composición química de los catalizadores preparados con materiales mesoporosos.

\begin{tabular}{ccccc}
\hline Catalizador & $\begin{array}{c}\text { \% Mn } \\
\text { (en peso) }\end{array}$ & $\begin{array}{c}\text { \% Fe } \\
\text { (en peso) }\end{array}$ & $\begin{array}{c}\text { Si/Al } \\
\text { (relación molar) }\end{array}$ & $\begin{array}{c}\text { Área } \\
\text { superficial } \\
\left(\mathbf{m}^{\mathbf{2}} \cdot \mathbf{g}^{-1}\right)\end{array}$ \\
\hline Mn-Fe/SBA-15 & 4.9 & 2.0 & $\infty$ & 476 \\
\hline Mn-Fe/Al-SBA-15 & 3.9 & 2.1 & 15.5 & 712 \\
\hline Mn-Fe/MCM-41 & 4.4 & 2.1 & $\infty$ & 523 \\
\hline Mn-Fe/Al-MCM-41 & 4.8 & 1.7 & 11.3 & 710 \\
\hline
\end{tabular}


En la tabla anterior, lo que más llama la atención es la caída del área superficial de los catalizadores soportados sobre los materiales sin aluminio en comparación con las áreas de los soportes originales (Tabla 18). Esta disminución del área superficial es menos significativa en el caso de los materiales mesoporosos que contienen Al en su estructura. Se ha descrito [152] que, los materiales mesoporosos que no contienen aluminio, al ponerse en contacto con agua pueden sufrir una degradación parcial de su estructura debido a la hidrólisis de los silicatos. Como en la preparación de los catalizadores las sales precursoras se añaden en una disolución acuosa, se puede producir esta hidrólisis parcial y afectar al área superficial del catalizador, lo que explicaría la pronunciada disminución de las áreas observada. No obstante, todos los catalizadores presentan un área superficial superior a $500 \mathrm{~m}^{2} \cdot \mathrm{g}^{-1}$, siendo estas áreas similares a la de los catalizadores soportados sobre zeolitas.

La actividad catalítica de los catalizadores Mn-Fe soportados sobre los materiales mesoporosos SBA-15 y MCM-41 pura sílice aparece en la Figura 26. Tal y como puede observarse, la actividad de ambos catalizadores es bastante diferente. Así, el catalizador preparado sobre SBA-15 comienza a mostrar actividad catalítica a $150{ }^{\circ} \mathrm{C}$, mientras que es necesario llegar hasta $250{ }^{\circ} \mathrm{C}$ para que el catalizador de MCM-41 empiece a ser activo. Además, el catalizador soportado sobre SBA-15 alcanza un máximo de conversión del $50 \%$, mientras que el catalizador de MCM41 sólo llega a un $30 \%$ como valor máximo. Estos valores de conversión son considerablemente más bajos que los obtenidos con los catalizadores zeolíticos. La formación de $\mathrm{N}_{2} \mathrm{O}$ con estos catalizadores es ligeramente superior a la de los catalizadores basados en zeolitas, obteniéndose una selectividad a $\mathrm{N}_{2}$ del $84 \%$ y del $88 \%$ para MCM-41 y SBA-15, respectivamente, en el punto de máxima conversión. 


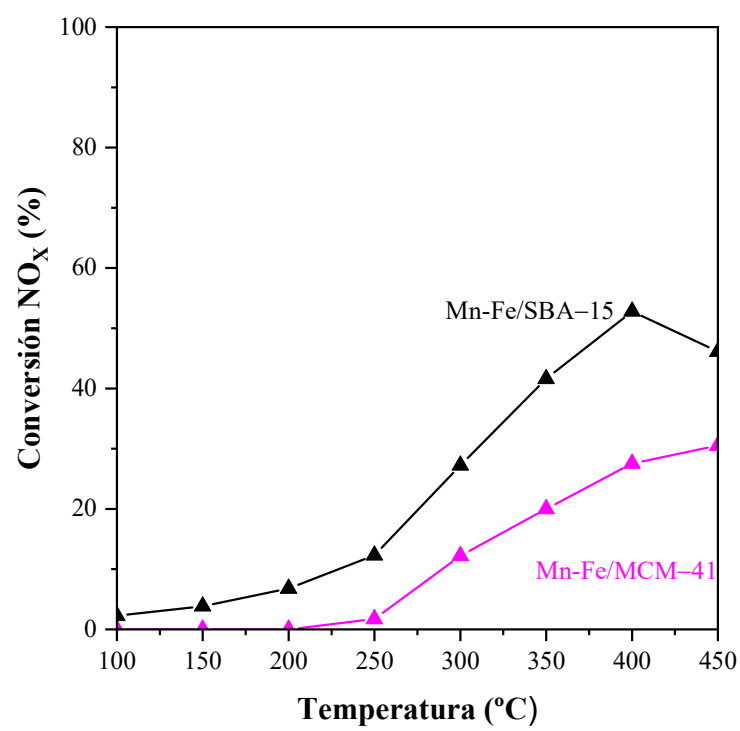

Figura 26. Actividad catalítica de los catalizadores Mn-Fe preparados con materiales mesoporosos. (500 ppm NO, $500 \mathrm{ppm} \mathrm{NH}_{3}, 4 \% \mathrm{O}_{2}$ y resto $\mathrm{N}_{2}$, masacat: $400 \mathrm{mg}$, Q: $\left.600 \mathrm{~mL} \cdot \mathrm{min}^{-1}\right)$.

Las diferencias entre los resultados obtenidos entre ambos catalizadores han sido atribuidas por algunos investigadores a sus diferentes tamaños de sus poros y a sus distintos canales. Los poros del MCM-41 son más pequeños que los de las SBA-15, y esto podría relacionarse con la menor actividad del catalizador de MCM-41 [153], lo que podría dificultar la difusión de los reactivos y productos. Sin embargo, los tamaños de estos poros son mucho mayores que los de las zeolitas, las cuales no presentan problemas difusionales. Es por ello por lo que, probablemente, sean otras características, como la topología de los canales, o la ausencia de centros ácidos, o la dispersión de los metales lo que explica los diferentes resultados obtenidos.

Para evitar los problemas de estabilidad de los materiales mesoporosos en presencia de agua [154], se preparó de nuevo el catalizador Mn-Fe/MCM-41 por impregnación a volumen de poro, pero empleando etanol en lugar de agua para 
disolver las sales precursoras. En este caso, el área superficial del catalizador tras la impregnación es de $920 \mathrm{~m}^{2} \cdot \mathrm{g}^{-1}$, es decir, prácticamente igual a la del material de partida (Tabla 18). Los resultados de la actividad catalítica se muestran en la Figura 27.

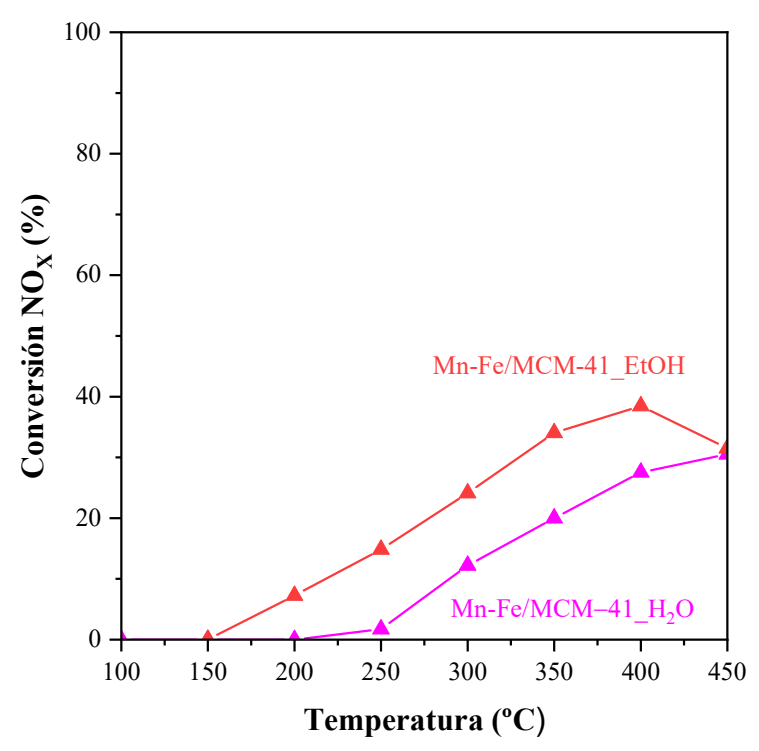

Figura 27. Influencia del disolvente en la impregnación de los materiales mesoporosos. (500 ppm NO, 500 ppm $\mathrm{NH}_{3}, 4 \% \mathrm{O}_{2}$ y resto $\mathrm{N}_{2}$, masacat: $400 \mathrm{mg}$, Q: $600 \mathrm{~mL} \cdot \mathrm{min}^{-1}$ ).

Como se observa, se ha obtenido una mejor actividad catalítica al preparar el catalizador con etanol, obteniendo un $38 \%$ de conversión a $400{ }^{\circ} \mathrm{C}$, y presentando una actividad significativa en un rango más amplio de temperatura (desde $\left.175^{\circ} \mathrm{C}\right)$.

En este tipo de catalizadores se estudió también la influencia de la presencia de aluminio en la red de los materiales mesoporosos en la actividad catalítica. Para ello, se ha estudiado la actividad de catalizadores Mn-Fe preparados con los mismos materiales mesoporosos, pero conteniendo Al en sus estructuras 
(Al-MCM-41 y Al-SBA-15). Tal y como se observa en la Tabla 19, la presencia de aluminio en red confiere una mayor estabilidad al soporte, ya que no se produce una disminución tan acentuada del área superficial al impregnar el material original con la disolución acuosa de las sales precursoras de Mn y Fe. Además, la presencia de aluminio en la red del material le aportaría centros ácidos fuertes y aislados, que se ha visto con las zeolitas que eran necesarios para obtener una mayor actividad catalítica.

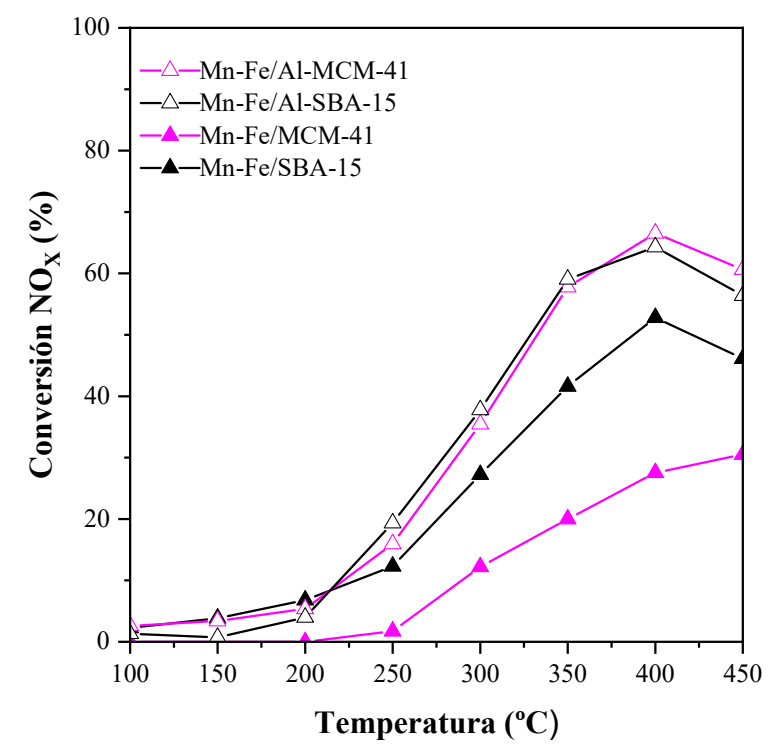

Figura 28. Influencia de la adición de $\mathrm{Al}$ a los soportes mesoporosos en la actividad de los catalizadores Mn-Fe. $\left(500 \mathrm{ppm} \mathrm{NO}, 500 \mathrm{ppm} \mathrm{NH}, 4 \% \mathrm{O}_{2}\right.$ y resto $\mathrm{N}_{2}$, masacat: $400 \mathrm{mg}$, Q: $\left.600 \mathrm{~mL} \cdot \mathrm{min}^{-1}\right)$.

Como se observa en la Figura 28, la adición de aluminio en la estructura de los materiales mesoporosos tiene un efecto muy positivo en la actividad catalítica de ambos catalizadores. Esta mejora es más notable para el catalizador menos activo (el que estaba soportado sobre MCM-41). Cuando este material mesoporoso posee aluminio en red, el catalizador Mn-Fe/Al-MCM-41 comienza a presentar 
actividad a $150{ }^{\circ} \mathrm{C}$, a diferencia del material sin aluminio que había que llegar hasta $250^{\circ} \mathrm{C}$. Asimismo, tras la adición del aluminio, se alcanza un máximo de conversión del $67 \%$ a $400{ }^{\circ} \mathrm{C}$, conversión mucho mayor que la obtenida con el material sin $\mathrm{Al}$, que era del $31 \%$ a $450{ }^{\circ} \mathrm{C}$. Este efecto también se da con el otro material mesoporoso estudiado (SBA-15), observándose un aumento de actividad a partir de $200{ }^{\circ} \mathrm{C}$, y consiguiendo, en este caso, unos resultados similares a los obtenidos con el material MCM-41 que contiene Al.

Estos resultados podrían relacionarse con el hecho de que los catalizadores que contienen $\mathrm{Al}$, tienen un área superficial considerablemente mayor a la de los catalizadores pura sílice, lo que permitiría una mejor dispersión de las fases metálicas y, por lo tanto, una mejor actividad catalítica. Asimismo, la introducción de Al provoca una modificación de la acidez de los soportes $[155,156]$, dando lugar a la aparición de centros ácidos Lewis y Brönsted, con una fuerza ácida media [157]. Tal y como se ha visto con las zeolitas, este aumento de la acidez es beneficioso para la reacción $\mathrm{SCR}-\mathrm{NO}_{\mathrm{x}}$, pues aumenta la capacidad de adsorción de amoniaco sobre la superficie del catalizador [158], lo que explicaría el aumento de la actividad catalítica de los catalizadores tras la incorporación de aluminio en la estructura de los materiales mesoporosos. Este resultado parece indicar, de nuevo, que tal y como se observa con los catalizadores Mn-Fe sobre zeolitas, la topología del soporte no es tan importante como lo son otros factores, tales como la presencia de centros ácidos fuertes y aislados, y la estabilidad de los materiales.

Sin embargo, la baja estabilidad de los materiales mesoporosos en presencia de agua desaconsejarían el empleo de los mismos en esta reacción ya que, en los gases a tratar normalmente, junto a los $\mathrm{NO}_{\mathrm{x}}$, siempre aparece agua, que afectaría a la estabilidad del material.

\subsection{Catalizadores Mn-Fe soportados sobre óxidos metálicos}

El último grupo de soportes utilizados para los catalizadores Mn-Fe fueron los óxidos metálicos. En concreto, se emplearon como soportes: 
- $\boldsymbol{\gamma}-\mathbf{A l}_{2} \mathbf{O}_{3}$ suministrado por abcr $\mathrm{GmbH}$

- $\mathrm{TiO}_{2}$. Se usaron dos tipos, un óxido comercial de baja área superficial suministrado por Sigma Aldrich, y otro sintetizado en el laboratorio con alta área superficial

- MgO, sintetizado en el laboratorio para conseguir un óxido con alta área superficial

Las propiedades texturales de los óxidos empleados se muestran en la Tabla 20.

Tabla 20. Propiedades texturales de los óxidos metálicos utilizados.

\begin{tabular}{cc}
\hline Óxido & $\begin{array}{c}\text { Área superficial BET } \\
\left(\mathbf{m}^{2} \cdot \mathbf{g}^{-1}\right)\end{array}$ \\
\hline $\mathrm{TiO}_{2}$ _comercial & 9 \\
\hline $\mathrm{TiO}_{2}$ síntesis & 154 \\
\hline $\mathrm{MgO} \_$síntesis & 171 \\
\hline$\gamma-\mathrm{Al}_{2} \mathbf{O}_{3}$ & 212 \\
\hline
\end{tabular}

Como se observa en la Tabla 20, el área superficial del $\mathrm{TiO}_{2}$ sintetizado en el laboratorio es significativamente mayor que la de su análogo comercial. El MgO también se ha sintetizado en el laboratorio y se ha obtenido un área superficial alta. $\mathrm{El} \gamma-\mathrm{Al}_{2} \mathrm{O}_{3}$ es el único óxido que se ha empleado en su forma comercial, pues el mismo presenta un área superficial elevada.

En la Figura 29 se han representado los difractogramas de rayos X de los óxidos que han sido sintetizados en el laboratorio. 


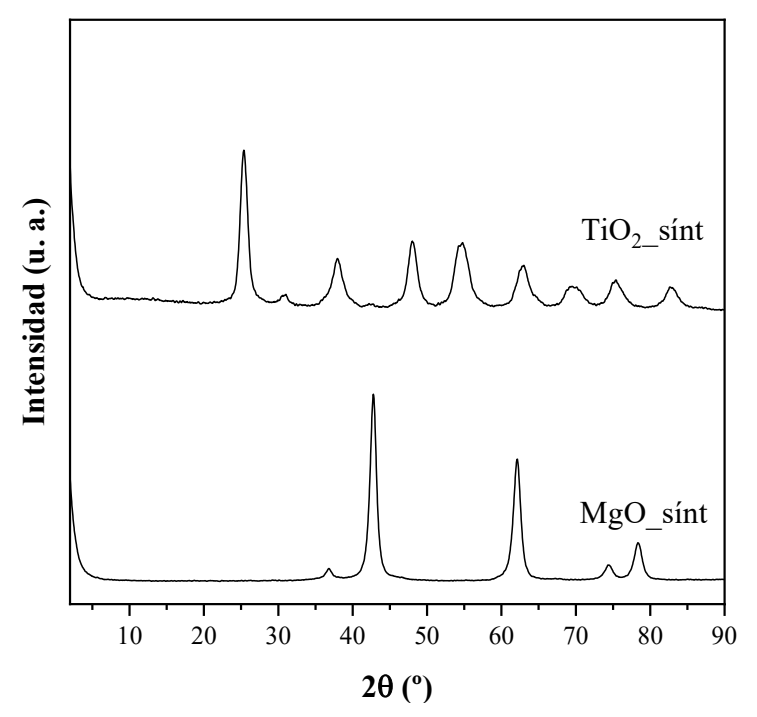

Figura 29. Difractogramas de rayos $\mathrm{X}$ de los óxidos metálicos sintetizados.

El difractograma del $\mathrm{TiO}_{2}$ presenta las reflexiones características de la fase anatasa del $\mathrm{TiO}_{2}$ (Centro Internacional de Datos de Difracción, ICDD, No. 211272), mientras que el difractograma del $\mathrm{MgO}$ se corresponde con la fase cúbica de este óxido (ICDD, No. 45-0946).

Estos óxidos fueron impregnados con sales precursoras de Mn y de Fe para obtener un contenido metálico de $4 \%$ de Mn y de $2 \%$ de Fe (en peso). La composición química de los catalizadores y sus áreas superficiales se muestran en la Tabla 21. 
Tabla 21. Composición química y área superficial de los catalizadores Mn-Fe preparados con óxidos metálicos como soportes.

\begin{tabular}{|c|c|c|c|}
\hline Catalizador & $\begin{array}{c}\text { \% Mn } \\
\text { (en peso) }\end{array}$ & $\begin{array}{c}\% \mathrm{Fe} \\
\text { (en peso) }\end{array}$ & $\begin{array}{l}\text { Área superficial } \\
\qquad\left(\mathrm{m}^{2} \cdot \mathrm{g}^{-1}\right)\end{array}$ \\
\hline Mn-Fe/TiO2_síntesis & 4.89 & 2.27 & 120 \\
\hline $\mathrm{Mn}-\mathrm{Fe} / \mathrm{TiO}_{2}$ _comercial & 4.15 & 2.21 & 8 \\
\hline Mn-Fe/MgO_síntesis & 4.11 & 1.83 & 132 \\
\hline $\mathrm{Mn}-\mathrm{Fe} / \gamma-\mathrm{Al}_{2} \mathrm{O}_{3}$ & 3.42 & 1.95 & 188 \\
\hline
\end{tabular}

Como se observa, en todos los casos se obtuvo una cantidad de Mn y Fe próxima a la deseada. El área de los catalizadores es menor a la de los respectivos soportes, aunque esta área, a excepción del catalizador de $\mathrm{TiO}_{2}$ comercial, sigue siendo elevada. Esta disminución en el área es debida al bloqueo de los poros al incorporar, mediante impregnación a volumen de poro, la fase metálica.

En la Figura 30 se muestran los difractogramas de algunos catalizadores tras su preparación. En todos los casos, los difractogramas muestran únicamente los picos característicos de los respectivos soportes, sin aparecer ningún pico adicional correspondiente a la fase metálica, lo que indica una alta dispersión de los metales incorporados. 


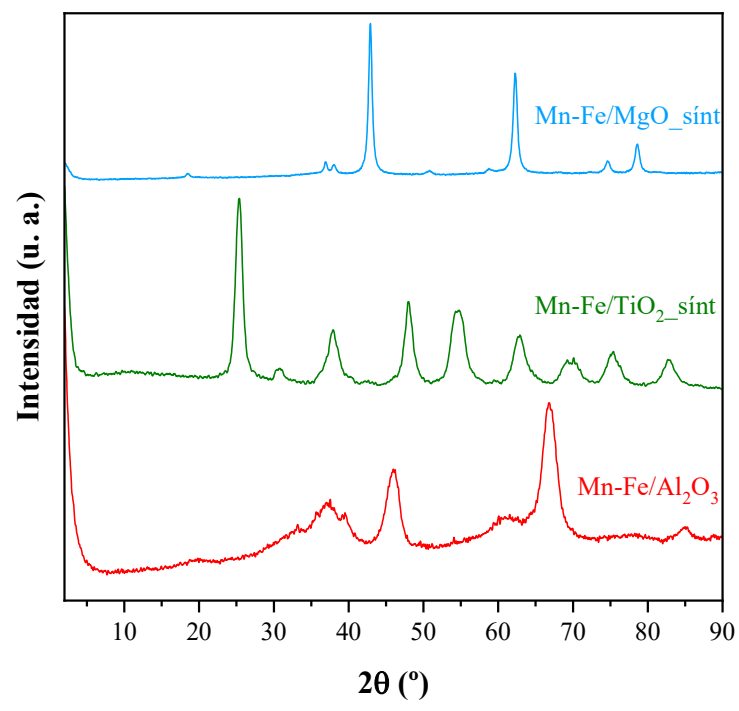

Figura 30. Difractogramas de rayos X de los catalizadores Mn-Fe soportados sobre óxidos metálicos.

Los resultados de la actividad catalítica de los distintos catalizadores $\mathrm{Mn}-\mathrm{Fe}$ preparados se muestran en la Figura 31. Al comparar la actividad de los catalizadores bimetálicos soportados sobre los distintos óxidos, se observa que tanto el catalizador preparado con $\mathrm{TiO}_{2}$ de alta superficie, como con $\gamma-\mathrm{Al}_{2} \mathrm{O}_{3}$, presentan una actividad catalítica significativa en todo el rango de temperaturas, alcanzando ambos un máximo de conversión del $80 \%$ a $300{ }^{\circ} \mathrm{C}$, temperatura a partir de la cual disminuye la actividad catalítica. La selectividad a $\mathrm{N}_{2}$ en este punto de máxima conversión es del $86 \%$ para el catalizador preparado con $\mathrm{TiO}_{2}$ y del $81 \%$ para la alúmina. Por el contrario, el catalizador preparado con el óxido de magnesio presenta una actividad muy baja, a pesar de su alta área superficial. Esta actividad es aún menor para el catalizador soportado sobre el $\mathrm{TiO}_{2}$ comercial, el cual tiene un área específica extremadamente baja $\left(8 \mathrm{~m}^{2} \cdot \mathrm{g}^{-1}\right.$ frente a $120 \mathrm{~m}^{2} \cdot \mathrm{g}^{-1}$ que presenta el $\mathrm{TiO}_{2}$ de síntesis). La baja actividad de este último se relaciona con la baja área superficial del material, que produciría una mala dispersión de los metales sobre el soporte $[159,160]$, dando lugar a una menor actividad catalítica. Por el contrario, el $\mathrm{TiO}_{2}$ sintetizado en el laboratorio, al 
presentar un área mucho mayor que el comercial, permite una mejor dispersión de los metales resultando en una mayor actividad catalítica.

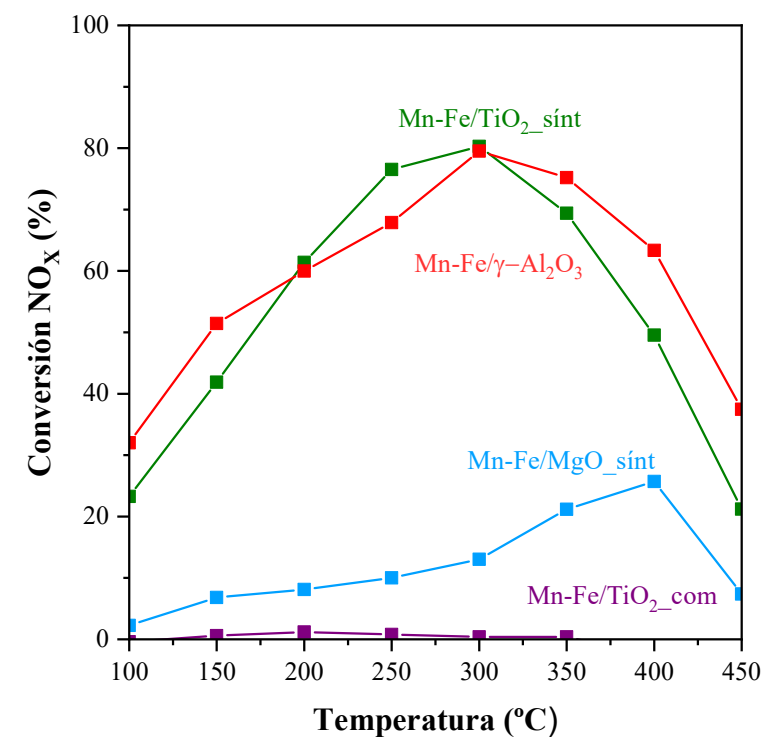

Figura 31. Actividad catalítica de los catalizadores Mn-Fe soportados sobre los distintos

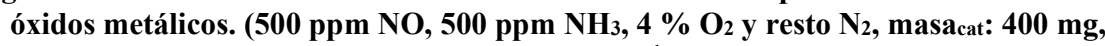
Q: $\left.600 \mathrm{~mL} \cdot \mathrm{min}^{-1}\right)$.

Por otro lado, la baja actividad del catalizador soportado sobre $\mathrm{MgO}$ (con área superficial de $132 \mathrm{~m}^{2} \cdot \mathrm{g}^{-1}$ ) parece indicar la existencia de otros factores intrínsecos al soporte que afectan a la actividad catalítica, además del área superficial. Estos factores se pueden relacionar con la acidez del soporte. Haciendo un análisis de la acidez de los óxidos metálicos empleados según la escala de electronegatividad de Sanderson [161], se obtiene que el MgO tiene un valor asignado de 2.066, típico de óxidos básicos, mientras que por otro lado, tanto la alúmina como el $\mathrm{TiO}_{2}$ tienen valores correspondientes a óxidos ácidos $(2.28$ y 3.046, respectivamente). Estos datos evidencian, como ya se vio con el resto de soportes empleados (zeolitas y materiales mesoporosos), que la acidez del soporte es 
necesaria para obtener una elevada actividad catalítica. Tal y como se ha discutido anteriormente, esto puede relacionarse con una mejor adsorción del amoniaco en la superficie del catalizador, lo cual es un paso clave en la reacción SCR-NOX con amoniaco $[162,163]$.

Las propiedades redox de estos materiales y el tipo de óxidos formados han sido investigados mediante estudios de reducción a temperatura programada (TPR), y los resultados se muestran en la Figura 32.

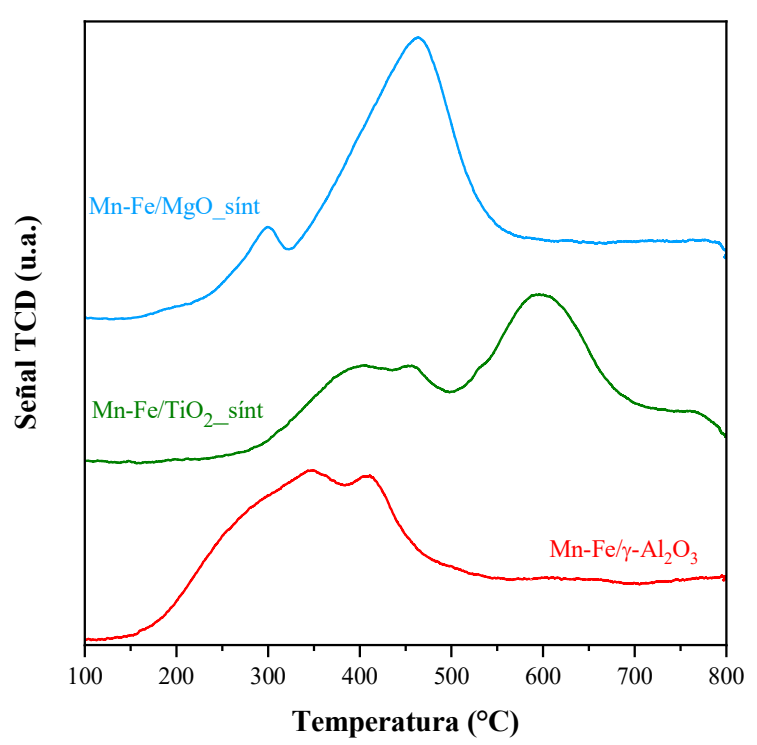

Figura 32. Perfiles de TPR de los catalizadores $\mathrm{Mn}$-Fe soportados sobre $\mathrm{MgO}, \mathrm{Al}_{2} \mathrm{O}_{3}$ y $\mathrm{TiO}_{2}$.

Los termogramas muestran diferentes picos relacionados con la reducción de las especies de hierro y de manganeso. La asignación de estos picos es complicada debido a que la reducción de los óxidos de Mn ocurre de manera secuencial, pues el $\mathrm{MnO}_{2}$ se reduce a $\mathrm{Mn}_{2} \mathrm{O}_{3}$, este a $\mathrm{Mn}_{3} \mathrm{O}_{4}$ y finalmente a $\mathrm{MnO}$, superponiéndose los diferentes picos [164-166]. Según lo descrito en la bibliografía [167-169], el 
pico a más bajas temperaturas se corresponde con la reducción de $\mathrm{MnO}_{2} / \mathrm{Mn}_{2} \mathrm{O}_{3}$ a $\mathrm{Mn}_{3} \mathrm{O}_{4}$ y el segundo pico se corresponde con la reducción de $\mathrm{Mn}_{3} \mathrm{O}_{4}$ a $\mathrm{MnO}$. Sin embargo, la superposición de los picos indicaría que los óxidos de manganeso formados sobre los distintos soportes no son fases puras, sino que son sistemas no estequiométricos $[64,140,159]$. Además, algunos picos de reducción de las especies de manganeso coinciden con los de la reducción de las especies de hierro, lo que indicaría la formación de óxidos mixtos Mn-Fe [52]. Por último, la comparación de los distintos perfiles de TPR muestra que las especies metálicas presentes en el catalizador con mayor área superficial, es decir, el soportado sobre alúmina, son reducidas a temperaturas más bajas que las presentes en los otros soportes, sugiriendo que este catalizador presenta mejores propiedades redox, lo que explicaría la mayor actividad del mismo a temperaturas más bajas.

De esta manera, estos resultados indican que para obtener una actividad óptima con catalizadores $\mathrm{Mn}-\mathrm{Fe}$ soportados sobre óxidos metálicos, es necesario que el soporte aporte acidez, alta área superficial y propiedades redox. Todo ello contribuye a una mejor dispersión de los metales en la superficie del catalizador y favorece la adsorción y reacción de los reactivos.

\subsection{Estabilidad de los catalizadores}

Los resultados anteriores han mostrado que los catalizadores Mn-Fe más activos en la reacción SCR-NO ${ }_{x}$ eran los soportados sobre las zeolitas BEA y CHA con alta relación $\mathrm{Si} / \mathrm{Al}$, así como sobre el óxido de Ti de alta área superficial y la alúmina. Con estos materiales se estudió la estabilidad de los catalizadores en presencia de vapor de agua, dado que esta molécula está presente en todos los procesos de generación de óxidos de nitrógeno.

En general, se ha descrito que el agua tiene un efecto negativo produciendo una desactivación parcial del catalizador, bien por existir una competencia entre las moléculas de agua y las de amoniaco y $\mathrm{NO}_{\mathrm{x}}$ por ser adsorbidas en los centros activos de los catalizadores [170], o bien por producirse una sinterización del metal que se encuentra inicialmente disperso en el catalizador [171]. 
En la Figura 33 se muestran los resultados obtenidos con los catalizadores Mn-Fe soportados sobre las zeolitas CHA y BEA cuando se añade un $2.5 \%$ de agua al alimento de la reacción.
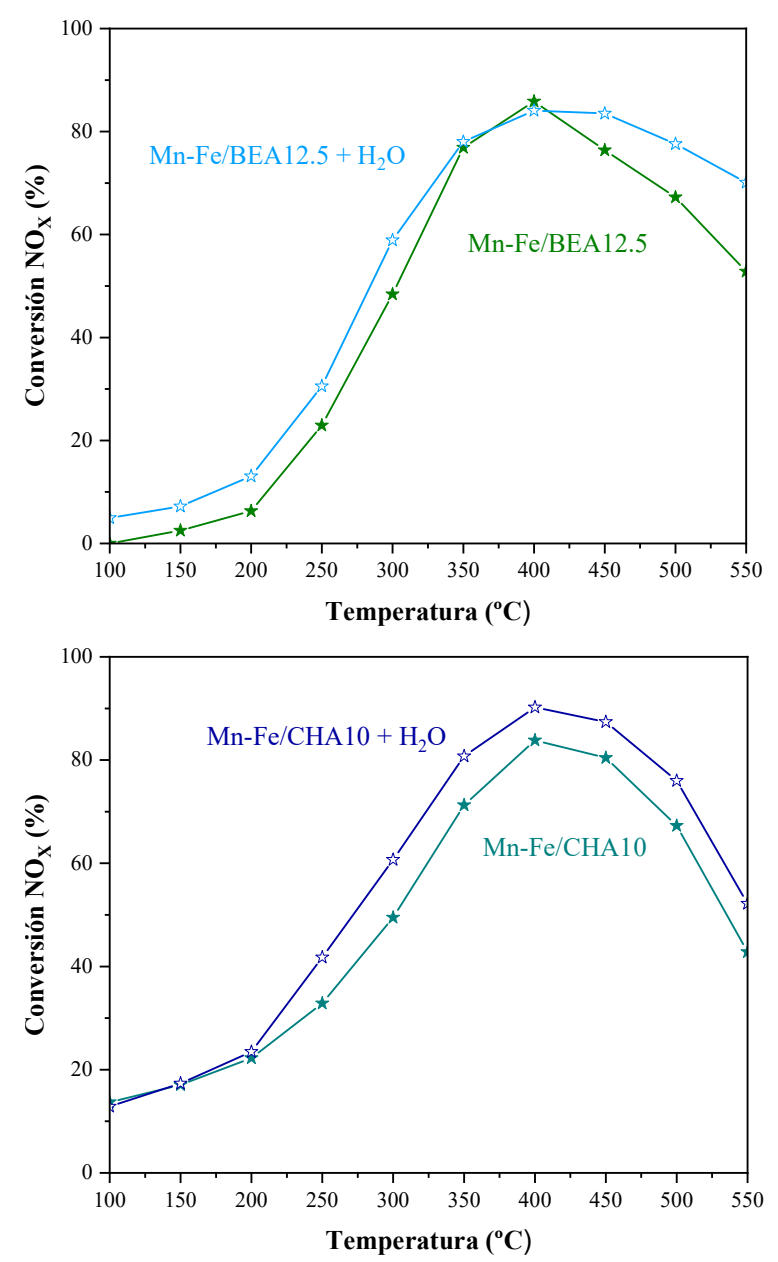

Figura 33. Influencia de la adición de agua ( $2.5 \%$ ) en la actividad de los catalizadores MnFe soportados sobre la zeolita BEA12.5 (arriba) y sobre la zeolita CHA10 (abajo). (500 ppm $\mathrm{NO}, 500 \mathrm{ppm} \mathrm{NH}_{3}, 4 \% \mathrm{O}_{2}$ y resto $\mathrm{N}_{2}$, masa cat: $\left._{400} \mathrm{mg}, Q: 600 \mathrm{~mL} \cdot \mathrm{min}^{-1}\right)$. 
Los resultados obtenidos son muy interesantes, ya que muestran que la adición de agua en el alimento de la reacción no desactiva los catalizadores preparados sobre las zeolitas, manteniéndose tanto la conversión como la selectividad hacia $\mathrm{N}_{2}$ obtenidas, lo que parece indicar que los centros activos de los catalizadores no se ven afectados por la presencia de agua.

Se estudió, también, el efecto de la presencia de agua en la actividad del catalizador de Mn y Fe soportado sobre alúmina, y los resultados se muestran en la Figura 34.

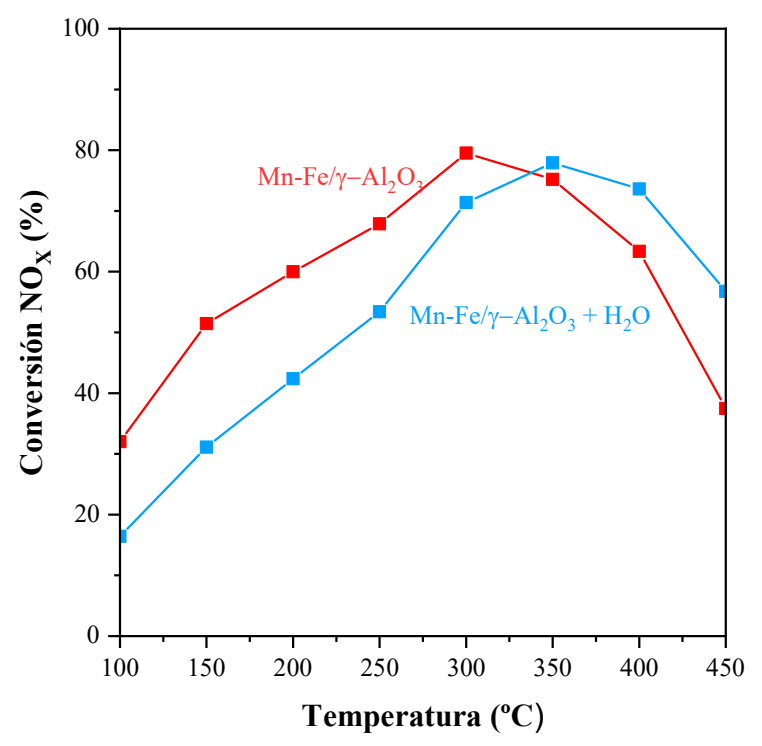

Figura 34. Influencia de la presencia del agua en la actividad el catalizador Mn-Fe soportado sobre alúmina. $\left(500 \mathrm{ppm} \mathrm{NO,500} \mathrm{ppm} \mathrm{NH}_{3}, 4 \% \mathrm{O}_{2}\right.$ y resto $\mathrm{N}_{2}$, masa at: $400 \mathrm{mg}$, Q: $\left.600 \mathrm{~mL} \cdot \mathrm{min}^{-1}\right)$.

Tal y como se aprecia en la Figura 34, la adición de agua a la reacción, a diferencia de lo que ocurre con las zeolitas, da lugar a una disminución en la actividad catalítica del catalizador a bajas temperaturas, además de a un 
desplazamiento del pico de máxima conversión, que se obtiene en este caso a $350{ }^{\circ} \mathrm{C}$, frente a los $300{ }^{\circ} \mathrm{C}$ que era la temperatura de máxima actividad en ausencia de agua. Esto parecería indicar que se produce una modificación de las especies activas de este catalizador en presencia de agua. Por otro lado, la selectividad hacia nitrógeno no se ve modificada por la presencia de esta molécula.

Estos resultados muestran que estos catalizadores, especialmente los soportados en zeolitas, son efectivos para la eliminación de $\mathrm{NO}_{\mathrm{x}}$ procedentes de fuentes estacionarias o móviles mediante su reducción catalítica selectiva con amoniaco en presencia de vapor de agua.

Sin embargo, estos experimentos no informan de la estabilidad del catalizador a largo plazo (por ejemplo, un catalizador de un coche debería ser activo al menos durante $100000 \mathrm{~km}$ ). Para poder obtener esta información, es necesario someter al catalizador a un proceso acelerado de envejecimiento mediante un tratamiento hidrotérmico. Este tratamiento consiste en poner el catalizador en contacto con vapor de agua a altas temperaturas. Para ello, los catalizadores que mejores resultados han mostrado han sido sometidos al tratamiento hidrotérmico especificado en la Figura 35, y se ha estudiado su posterior actividad catalítica. 


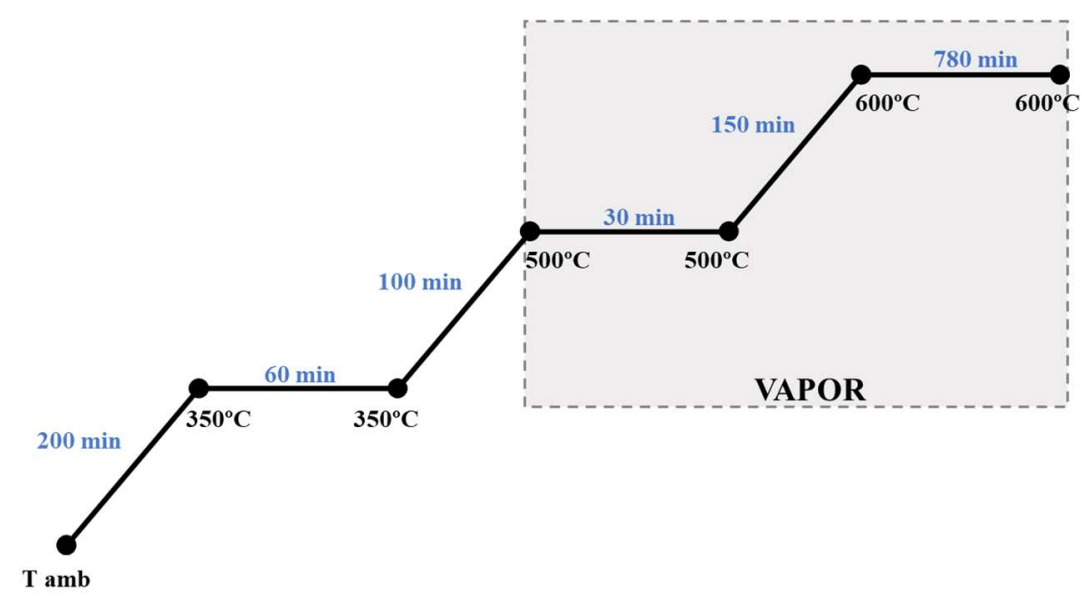

Figura 35. Condiciones del tratamiento hidrotérmico.

En la Figura 36 se muestran los resultados obtenidos con el catalizador Mn-Fe preparado con la zeolita BEA12.5. Como se observa, la actividad del catalizador tras el tratamiento hidrotérmico disminuye significativamente a temperaturas inferiores a $400{ }^{\circ} \mathrm{C}$, desplazándose la máxima actividad a temperaturas superiores a $500{ }^{\circ} \mathrm{C}$. La selectividad a $\mathrm{N}_{2}$ se mantiene por encima del $90 \%$, mientras que la conversión de $\mathrm{NO}_{\mathrm{x}}$ baja desde un $86 \%$ que presenta la muestra fresca a $400{ }^{\circ} \mathrm{C}$ a un $66 \%$ a $500{ }^{\circ} \mathrm{C}$. Esta disminución de la actividad puede deberse a que el tratamiento hidrotérmico afecta a la estructura de la zeolita, pues provoca un proceso de desaluminización, modificando la acidez de la zeolita y provocando una pérdida de cristalinidad o incluso la condensación de silanoles [172]. Esto, a su vez, puede afectar a la dispersión del manganeso y del hierro situados en la superficie de la zeolita. 


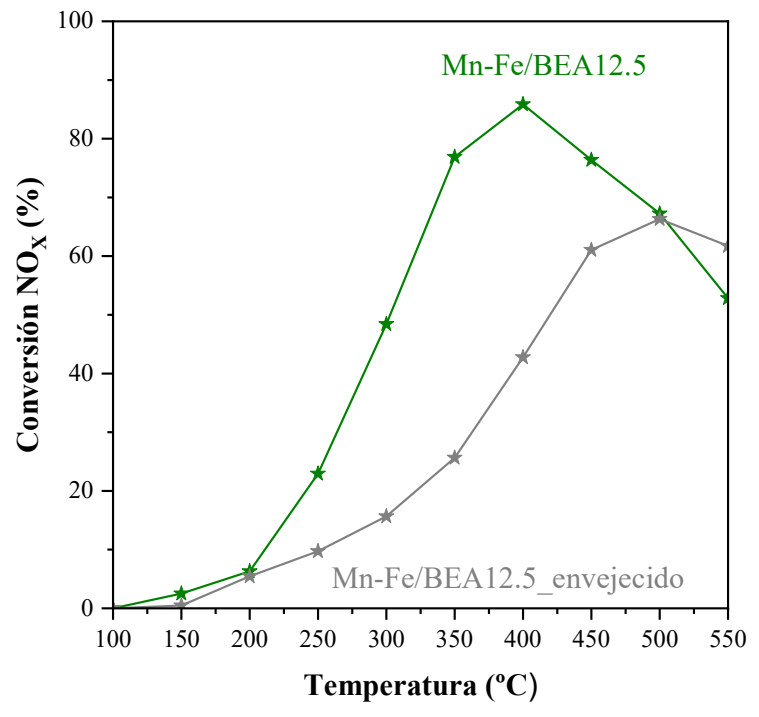

Figura 36. Influencia del tratamiento hidrotérmico en la actividad del catalizador MnFe/BEA12.5. (500 ppm NO, 500 ppm $\mathrm{NH}_{3}, 4 \% \mathrm{O}_{2}$ y resto $\mathrm{N}_{2}$, masacat: $400 \mathrm{mg}$, Q: $\left.600 \mathrm{~mL} \cdot \mathrm{min}^{-1}\right)$.

Este catalizador se ha analizado por difracción de rayos $\mathrm{X}$ tras el tratamiento hidrotérmico y los difractogramas se muestran en la Figura 37. 


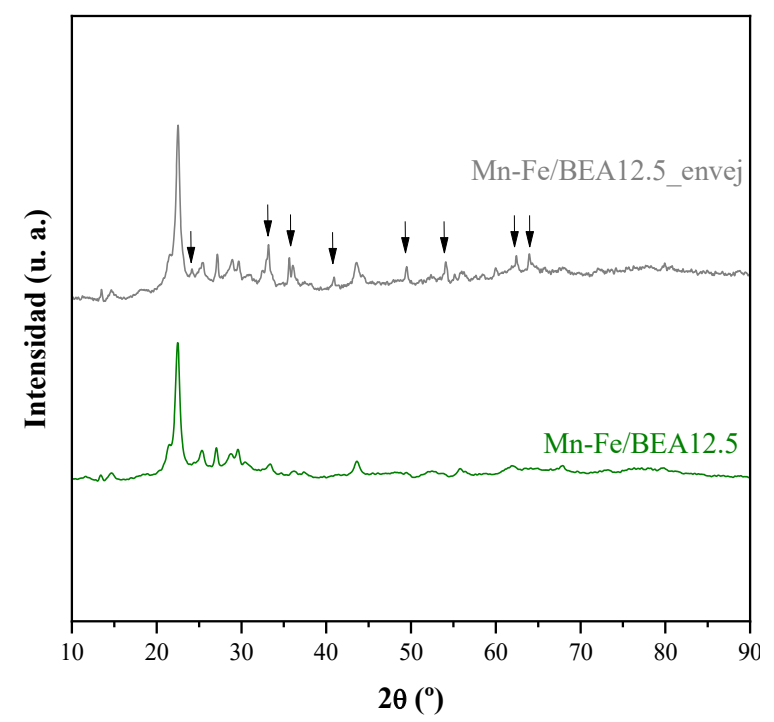

Figura 37. Difractograma de rayos $\mathrm{X}$ de los catalizadores Mn-Fe preparados sobre la zeolita BEA12.5, antes y después el tratamiento hidrotérmico.

El difractograma del catalizador tras el tratamiento hidrotérmico muestra la presencia de picos adicionales que se corresponden con los picos de $\mathrm{Fe}_{2} \mathrm{O}_{3}$. Esto indicaría que se ha producido una sinterización de los metales tras este tratamiento, lo que explicaría la disminución de la actividad observada. Asimismo, el área superficial de este material disminuye tras someterlo a vapor de agua a altas temperaturas, pasando de $516 \mathrm{~m}^{2} \cdot \mathrm{g}^{-1}$ a $404 \mathrm{~m}^{2} \cdot \mathrm{g}^{-1}$, lo que indicaría una baja estabilidad hidrotérmica de la zeolita.

Este mismo estudio fue realizado con el catalizador Mn-Fe soportado sobre la zeolita CHA10, obteniendo los resultados que se muestran en la Figura 38. 


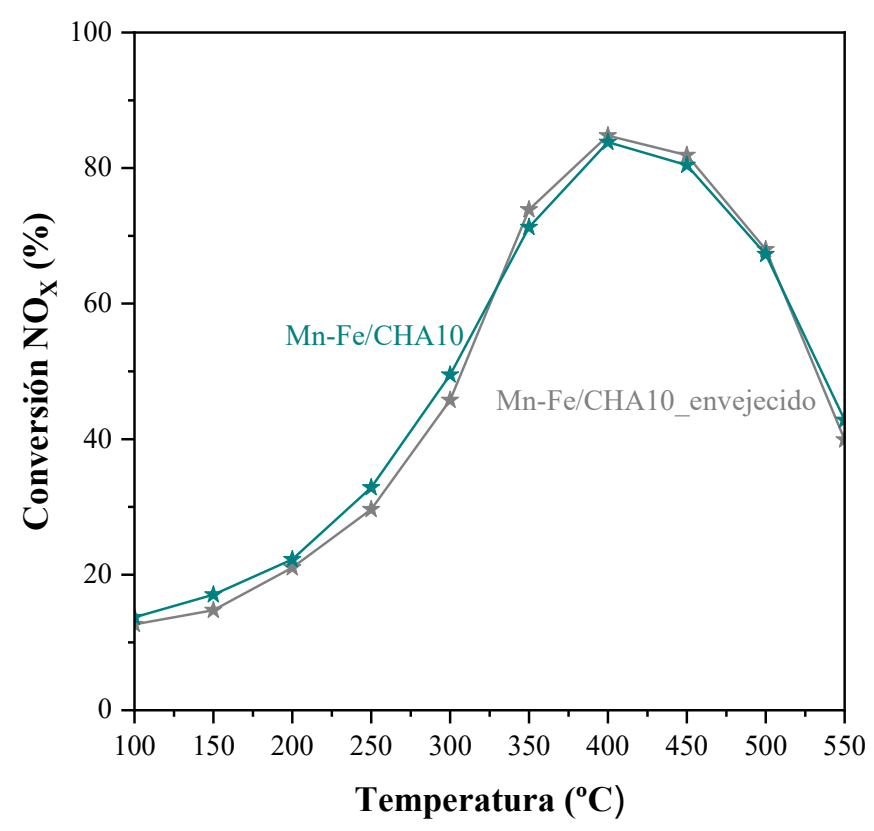

Figura 38. Influencia del tratamiento hidrotérmico en la actividad del catalizador MnFe/CHA10. (500 ppm NO, 500 ppm $\mathrm{NH}_{3}, 4 \% \mathrm{O}_{2}$ y resto $\mathrm{N}_{2}$, masacat: $400 \mathrm{mg}$, Q: $\left.600 \mathrm{~mL} \cdot \mathrm{min}^{-1}\right)$.

En este catalizador, la actividad y la selectividad a $\mathrm{N}_{2}$ son idénticas antes y después del tratamiento hidrotérmico, lo que indicaría una gran estabilidad de este tipo de catalizador. La estabilidad hidrotérmica de la zeolita CHA ha sido ampliamente investigada en catalizadores basados en cobre y en hierro [173,174], encontrándose que los poros de tamaño pequeño, presentes en estas zeolitas, estabilizan los centros activos, impidiendo que se agreguen los metales y preservando la estructura zeolítica. 


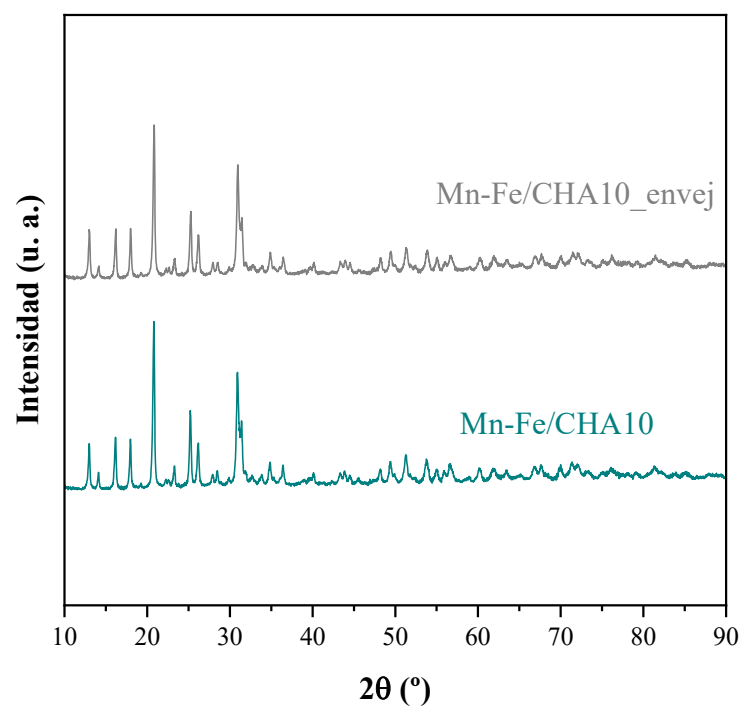

Figura 39. Difractogramas de rayos $X$ del catalizador Mn-Fe/CHA10 antes y después del tratamiento hidrotérmico.

Esta estabilidad se pone de manifiesto al comparar los difractogramas de los catalizadores antes y después del tratamiento hidrotérmico (Figura 39), observándose que estos son idénticos, e indicando que los metales no han sinterizado durante el proceso hidrotermal. Además, el área de este catalizador es prácticamente igual después del tratamiento hidrotérmico en comparación con el catalizador fresco $\left(502 \mathrm{~m}^{2} \cdot \mathrm{g}^{-1}\right.$ frente a $517 \mathrm{~m}^{2} \cdot \mathrm{g}^{-1}$ del catalizador fresco). Todo esto confirma la estabilidad hidrotérmica de estas muestras y explicaría la idéntica actividad encontrada después del tratamiento hidrotérmico en comparación con el catalizador fresco.

La influencia del tratamiento de envejecimiento sobre la actividad de los catalizadores de Mn y Fe fue también estudiada con los catalizadores soportados sobre alúmina y sobre titania de alta área superficial. Los resultados se muestran en la Figura 40. 

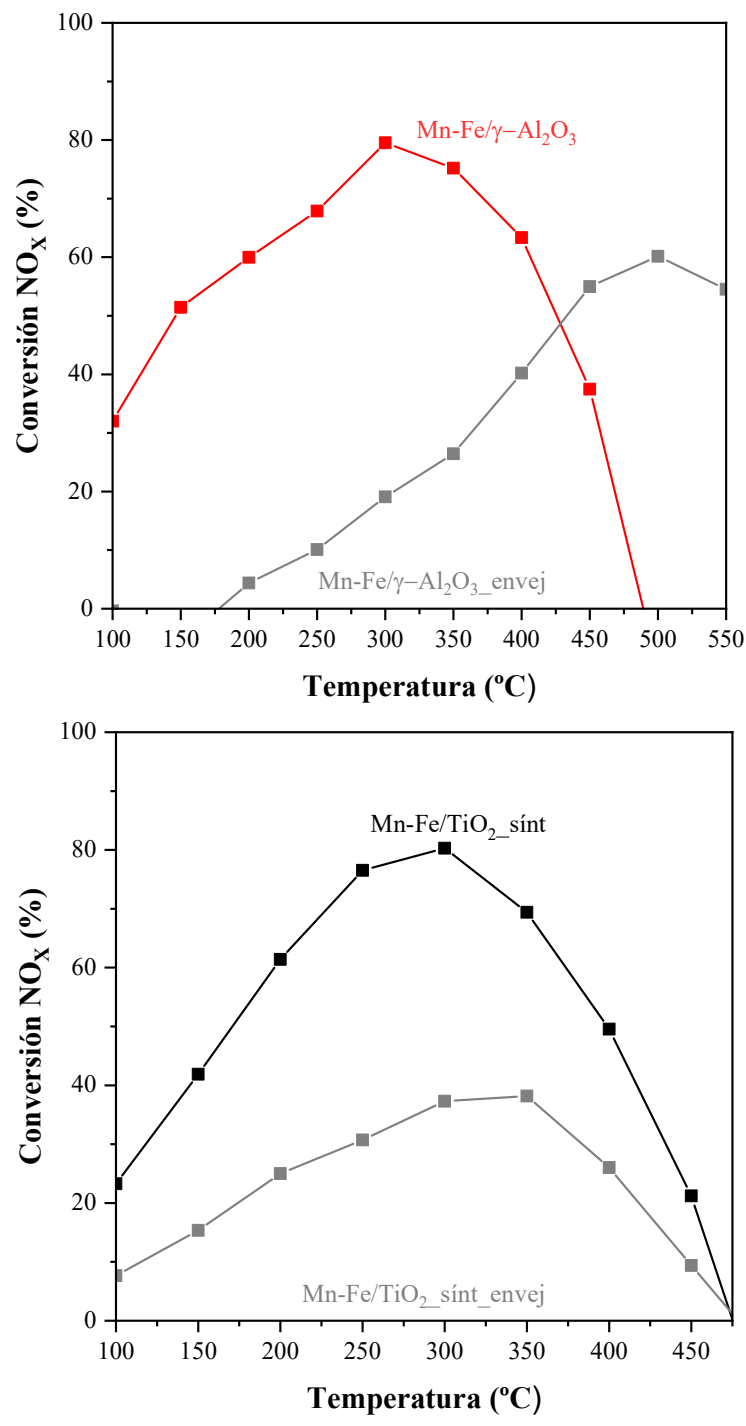

Figura 40. Influencia del tratamiento hidrotérmico en la actividad de los catalizadores MnFe sobre alúmina (arriba) y sobre titania (abajo). (500 ppm NO, $500 \mathrm{ppm} \mathrm{NH}, 4 \% \mathrm{O}_{2}$ y resto $\mathrm{N}_{2}$, masacat: $400 \mathrm{mg}$, Q: $\left.600 \mathrm{~mL} \cdot \mathrm{min}^{-1}\right)$. 
En este caso, y tal y como se observó con la zeolita BEA12.5, tras el tratamiento hidrotérmico, el catalizador sólo presenta actividad catalítica significativa a temperaturas más altas, alcanzándose el máximo de conversión a $500{ }^{\circ} \mathrm{C}$ para el catalizador soportado sobre alúmina. Asimismo, la conversión máxima de este catalizador disminuye desde el $80 \%$ a $300{ }^{\circ} \mathrm{C}$ hasta el $60 \%$ a $500{ }^{\circ} \mathrm{C}$. Por otra parte, la selectividad a $\mathrm{N}_{2}$ se mantiene con valores por encima del $85 \%$. Resultados aún peores se obtienen tras someter al tratamiento hidrotérmico al catalizador bimetálico preparado sobre titania. Para este catalizador, se observa una abrupta disminución de la actividad catalítica y un desplazamiento del máximo de conversión a una temperatura mayor. Además, la selectividad de este catalizador a $\mathrm{N}_{2}$ disminuye hasta un $54 \%$ en el punto de máxima conversión. La desactivación de este último catalizador se debe a la gran disminución de su área superficial que pasa de tener inicialmente $120 \mathrm{~m}^{2} \cdot \mathrm{g}^{-1}$, a tener $30 \mathrm{~m}^{2} \cdot \mathrm{g}^{-1}$ tras el tratamiento hidrotérmico.

Al analizar estos catalizadores por difracción de rayos X (Figura 41), se observa en ambos casos cambios en su estructura después del tratamiento hidrotérmico. En el caso del catalizador preparado sobre alúmina, se observa la aparición de dos picos adicionales a $2 \theta=44.6$ y 82 , que se corresponden con picos característicos del Fe, lo que indica que los metales han sinterizado durante el tratamiento con vapor, disminuyendo su dispersión. En el caso del catalizador preparado con $\mathrm{TiO}_{2}$, además se observa que los picos característicos del soporte se vuelven más definidos, indicando una disminución del área superficial [126]. Asimismo, se observa que en el soporte se ha producido un cambio parcial de fase de anatasa a rutilo, apareciendo además los picos característicos de óxidos de $\mathrm{Mn}$ y de Fe [175], lo que indicaría que se produce una sinterización de las fases metálicas en la superficie de los catalizadores, que se traduce en una brusca disminución de la actividad catalítica, siendo mucho más acusada en este catalizador que en la alúmina. 

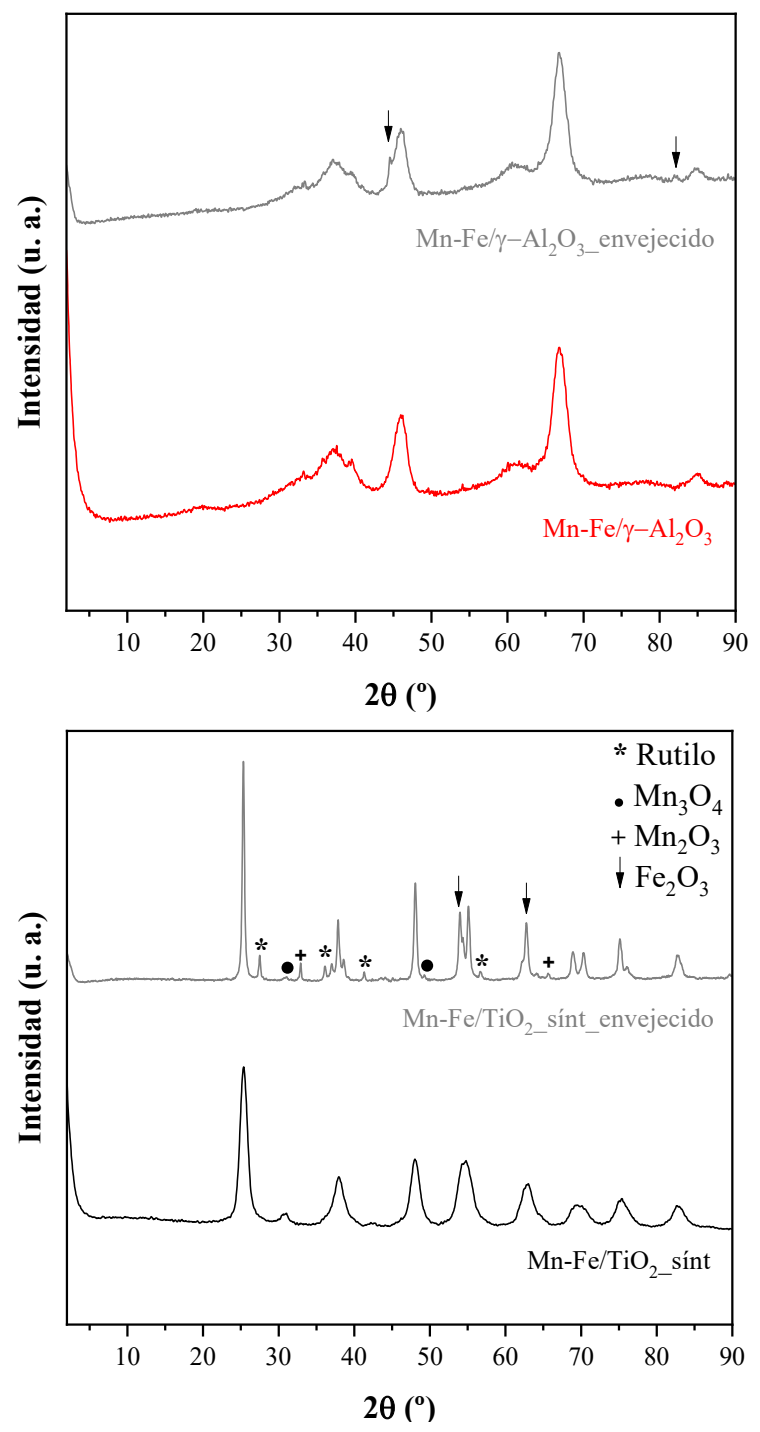

Figura 41. Difractograma de rayos $X$ de los catalizadores Mn-Fe soportados sobre alúmina (arriba) y titania (abajo), antes y después del tratamiento hidrotérmico. 


\subsection{Conclusiones parciales}

El estudio realizado con los catalizadores $\mathrm{Mn}-\mathrm{Fe}$ soportados sobre diversos materiales indica que, para tener catalizadores activos en la reacción de reducción catalítica selectiva de $\mathrm{NO}_{\mathrm{X}}$ con amoniaco, es necesario el uso de soportes con un área superficial elevada y que presenten centros ácidos. En este sentido, los mejores resultados a temperaturas superiores a $300-350{ }^{\circ} \mathrm{C}$ se han obtenidos con la zeolita $\mathrm{BEA}$ con relación $\mathrm{Si} / \mathrm{Al}=12.5$, con la zeolita $\mathrm{CHA}$ de relación $\mathrm{Si} / \mathrm{Al}=$ 10 y con la zeolita ITQ-2 con relación $\mathrm{Si} / \mathrm{Al}=10$. Por el contrario, para temperaturas inferiores a $300{ }^{\circ} \mathrm{C}$, los mejores resultados se obtienen con los catalizadores soportados sobre óxidos ácidos de alta área superficial como $\mathrm{TiO}_{2}$ y alúmina.

Estos materiales, especialmente los catalizadores soportados en zeolitas, son activos en presencia de agua, mientras que se descarta el empleo de materiales mesoporosos como MCM-41 o SBA-15, debido a su tendencia a hidrolizar en presencia de esta molécula.

Sin embargo, los estudios de estabilidad hidrotérmica indicarían que únicamente los catalizadores Mn-Fe soportados sobre la zeolita CHA con relación $\mathrm{Si} / \mathrm{Al}$ de 10 son estables tras ser sometidos a un proceso acelerado de envejecimiento. El resto de los catalizadores, tras un tratamiento hidrotérmico, presentan una disminución de su actividad, especialmente a bajas temperaturas debido, principalmente, a la sinterización de la fase metálica sobre la superficie de los soportes y a la alteración de sus estructuras. Es por ello que, el catalizador más adecuado y que podría tener un uso comercial es el Mn-Fe soportado sobre zeolita tipo CHA. 
5. OXIDACIÓN CATALÍTICA DE MONÓXIDO DE CARBONO 

El principal objetivo de esta tesis es el desarrollo de catalizadores metálicos estructurados para reacciones de Química Sostenible. En este capítulo se va a estudiar una reacción de gran interés desde el punto de vista medioambiental como es la reacción de oxidación catalítica de $\mathrm{CO}$ para obtener $\mathrm{CO}_{2}$ de acuerdo con la reacción:

$$
2 \mathrm{CO}+\mathrm{O}_{2} \rightarrow 2 \mathrm{CO}_{2}
$$

Los catalizadores que se van a utilizar son catalizadores de oro y/o plata soportados sobre la zeolita ITQ-2. La zeolita ITQ-2 ha sido preparada en su forma pura sílice y con una relación $\mathrm{Si} / \mathrm{Al}$ de 10 , y sus principales características han sido descritas en el apartado 4.1.

La actividad catalítica de estos materiales ha sido estudiada en el rango de temperaturas en el cual suele ser emitido este contaminante. Estas emisiones proceden, básicamente, de procesos de combustión incompleta, en donde los gases formados suelen salir por la chimenea con una temperatura comprendida entre los $100 \mathrm{y} \operatorname{los} 500^{\circ} \mathrm{C}$, y con una concentración de CO inferior al $1 \%$.

\subsection{Catalizadores de Ag/ITQ-2}

Se prepararon distintos catalizadores basados en plata soportados sobre la zeolita ITQ-2, en los que la plata fue incorporada a la zeolita mediante distintos métodos:

- En forma de nanoclusters de plata

- Por intercambio iónico

- Por impregnación a volumen de poro

En todos los catalizadores, el contenido metálico de plata fue del $1 \%$ en peso, y los catalizadores fueron sometidos a distintos pretratamientos, estudiando su actividad en la reacción de oxidación catalítica de CO. 
Se escogió una zeolita como soporte por su elevada área superficial, sus propiedades de intercambio iónico, su morfología, y por la posibilidad de ser preparadas con distinta composición química.

\subsubsection{Nanoclusters de plata sobre ITQ-2}

Los nanoclusters metálicos se han preparado en colaboración con la Universidad Técnica de Viena y se han sintetizado con diferentes ligandos, tamaño y composición. Se considera que un nanocluster es una agrupación de átomos (entre 1 y 100 átomos), con un tamaño menor a $2 \mathrm{~nm}$ y sus propiedades fisicoquímicas están directamente relacionadas con su estructura y su composición atómica. A esta escala, las partículas presentan un efecto de confinamiento cuántico, lo que hace que exhiban diferentes propiedades en comparación con el estado bulk (Figura 42) [176].

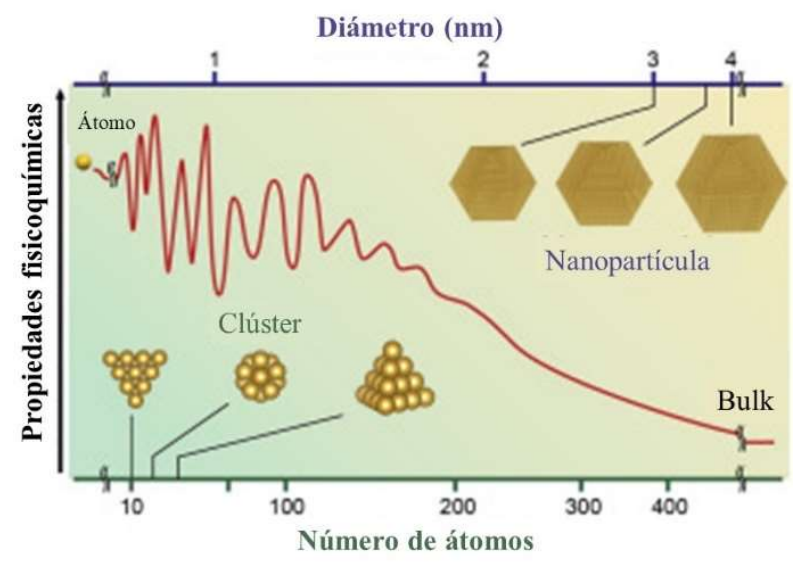

Figura 42. Comparación entre átomo, clúster, nanopartícula y bulk [176].

Estos materiales presentan propiedades específicas como transiciones electrónicas HOMO-LUMO diferentes, diversas cargas, fotoluminiscencia, magnetismo e incluso propiedades redox o quirales. Esto hace que estos 
materiales sean un campo de investigación emergente para un amplio abanico de aplicaciones como la nanoelectrónica, la óptica, la biomedicina y la catálisis [84].

Los nanoclusters protegidos por ligandos tiolatos (SR) [176-178] han sido los más estudiados en los últimos años dada su alta estabilidad, sus propiedades fisicoquímicas y su buena actividad catalítica. Asimismo, la posibilidad de controlar su tamaño con precisión permite obtener nanoclusters con una estructura bien definida por un número preciso de átomos, lo que les hace ideales para estudios fundamentales.

Se prepararon nanoclusters de 25 átomos de plata empleando tioles como ligandos, siendo su composición $\mathrm{Ag}_{25}\left(\mathrm{SPhMe}_{3}\right)_{18} \mathrm{PPh}_{4}$. La pureza de los nanoclusters sintetizados fue confirmada por espectroscopía UV-Vis.

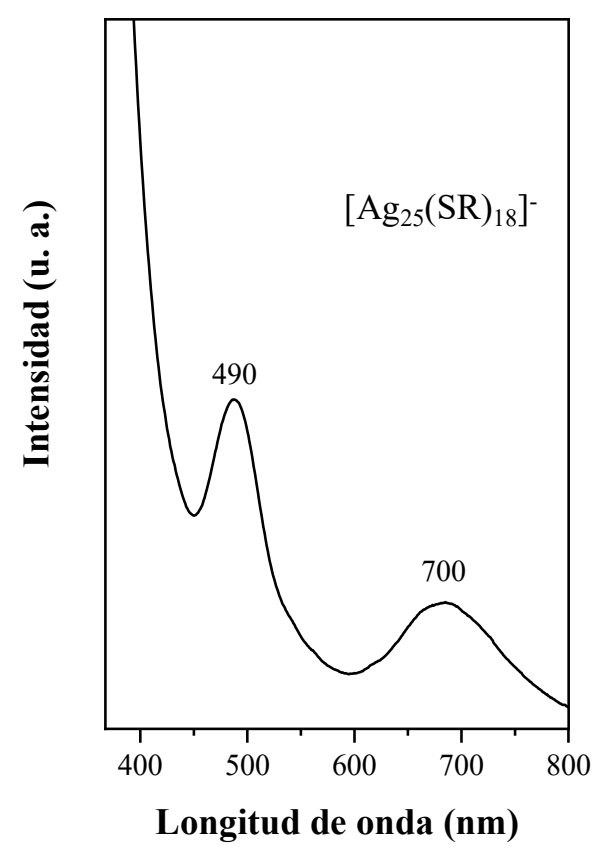

Figura 43. Espectro UV-Vis de los nanoclusters $\operatorname{Ag}_{25}\left(\mathrm{SPhMe}_{3}\right)_{18} \mathrm{PPh}_{4}$ en disolución. 
La Figura 43 muestra el espectro UV-Vis de los nanoclusters de plata tras su síntesis. El espectro de absorción muestra dos bandas diferenciadas a 490 y $700 \mathrm{~nm}$, características de los nanoclusters de plata y que se deben a transiciones electrónicas entre los diferentes orbitales moleculares [131].

Estos nanoclusters fueron soportados sobre una zeolita ITQ-2 en su forma pura sílice teniendo una cantidad final de plata del $1 \%$ (en peso). En la Tabla 22 se muestra la composición química y el área superficial de este catalizador.

Tabla 22. Propiedades físico-químicas del catalizador $\mathbf{A g}_{25} / \mathrm{ITQ-2}$

\begin{tabular}{ccc}
\hline Catalizador & $\begin{array}{c}\% \mathrm{Ag} \\
\text { (en peso) }\end{array}$ & $\begin{array}{c}\text { Área superficial BET } \\
\left(\mathbf{m}^{2} \cdot \mathbf{g}^{-1}\right)\end{array}$ \\
\hline $\mathbf{A g}_{25} / \mathrm{ITQ} \mathbf{2}$ & 1.4 & 465 \\
\hline
\end{tabular}

En la Figura 44 se han representado los difractogramas de rayos $\mathrm{X}$ de la zeolita ITQ-2 y del catalizador con los nanoclusters de plata soportados ( $\left.\mathrm{Ag}_{25} / \mathrm{ITQ}-2\right)$. Tal y como se observa, la zeolita ITQ-2 presenta los picos característicos de este material [146], sin haber ninguna diferencia entre este difractograma y el de la zeolita que contiene los nanoclusters de $\mathrm{Ag}$ soportados. Esto indica que la estructura zeolítica no se ha visto alterada durante el proceso de preparación del catalizador, y que existe una buena dispersión de la fase metálica sobre la superficie de la zeolita. 


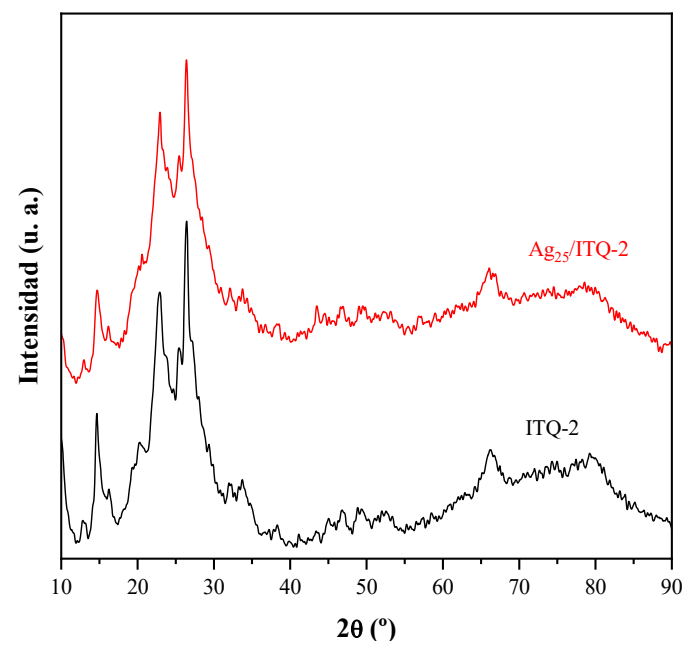

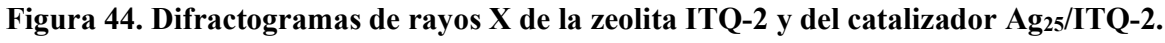

La actividad catalítica en la reacción de oxidación de los nanoclusters de Ag soportados sobre la zeolita ITQ-2 se estudió con las muestras activadas con $\mathrm{H}_{2}$, pues se ha descrito que son las especies metálicas [179] las más activas para esta reacción. La activación se realizó inicialmente a $150^{\circ} \mathrm{C}$ para evitar la destrucción de los ligandos. Los resultados se muestran en la Figura 45, comparándose con los obtenidos en una oxidación térmica. Como se observa, la adición del catalizador consigue disminuir la temperatura necesaria para oxidar el $\mathrm{CO}$, pasando de un $\mathrm{T}_{50}$ (temperatura a la cual se alcanza el $50 \%$ de conversión) de $650{ }^{\circ} \mathrm{C}$ para la oxidación térmica, a un $\mathrm{T}_{50}$ de $575^{\circ} \mathrm{C}$ para la oxidación catalítica. Sin embargo, estos resultados son peores que los descritos cuando se utilizan otros catalizadores de plata para esta reacción [180]. 


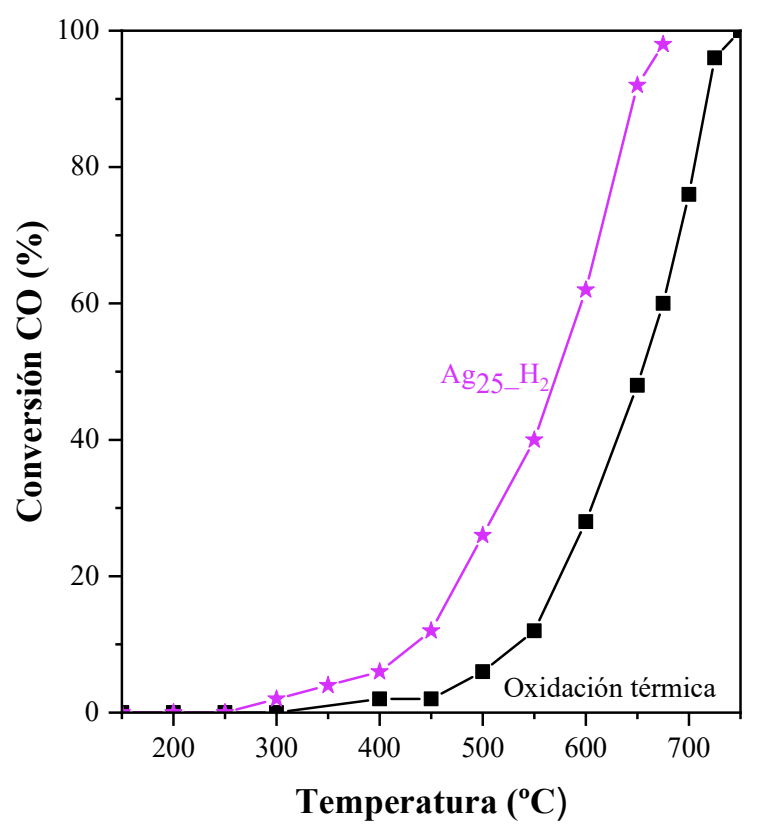

Figura 45. Actividad catalítica en la oxidación de $\mathrm{CO}$ del catalizador Ag25/ITQ-2 tras ser pretratado con $\mathrm{H}_{2}\left(\mathrm{Ag}_{25} \mathrm{H}_{2}\right)\left(0.5 \% \mathrm{CO}, 4 \% \mathrm{O}_{2}\right.$, resto $\mathrm{N}_{2}$, masa cat: $250 \mathrm{mg}$, $\left.\mathrm{Q}: 500 \mathrm{~mL} \cdot \mathrm{min}^{-1}\right)$ y resultado de la oxidación térmica.

Para entender los motivos de esta baja actividad catalítica, el catalizador fue caracterizado por diferentes técnicas y sometido a diversos ciclos de activación/reacción.

La espectroscopía DRS UV-Vis ha mostrado en estudios previos [181-185] ser una técnica espectroscópica que permite discriminar entre las distintas especies de plata. Estas especies de plata que pueden estar presentes en el catalizador son: $\mathrm{Ag}^{+}$, con bandas entre $\sim 200$ y $250 \mathrm{~nm}$; clusters de plata con carga parcial positiva, $\mathrm{Ag}_{\mathrm{n}}^{\delta+}$, cuyas bandas características se encuentran entre $\sim 250$ y $370 \mathrm{~nm}$; y por último plata en su estado metálico, $\mathrm{Ag}^{0}$, con bandas entre $\sim 340$ y $675 \mathrm{~nm}$.

Los espectros de la muestra fresca y de la muestra activada con $\mathrm{H}_{2}$ a $150{ }^{\circ} \mathrm{C}$ aparecen en la Figura 46. En ambos casos, aparecen principalmente bandas por 
debajo de los $300 \mathrm{~nm}$, correspondientes a las especies de plata catiónica [181185] y bandas a $370 \mathrm{~nm}$ características de los clusters con carga parcial positiva. Esto confirma que, pese a la activación del catalizador con $\mathrm{H}_{2}$ a $150^{\circ} \mathrm{C}$, no se han formado nanopartículas de plata metálica, lo que se podría relacionar con la baja actividad obtenida.

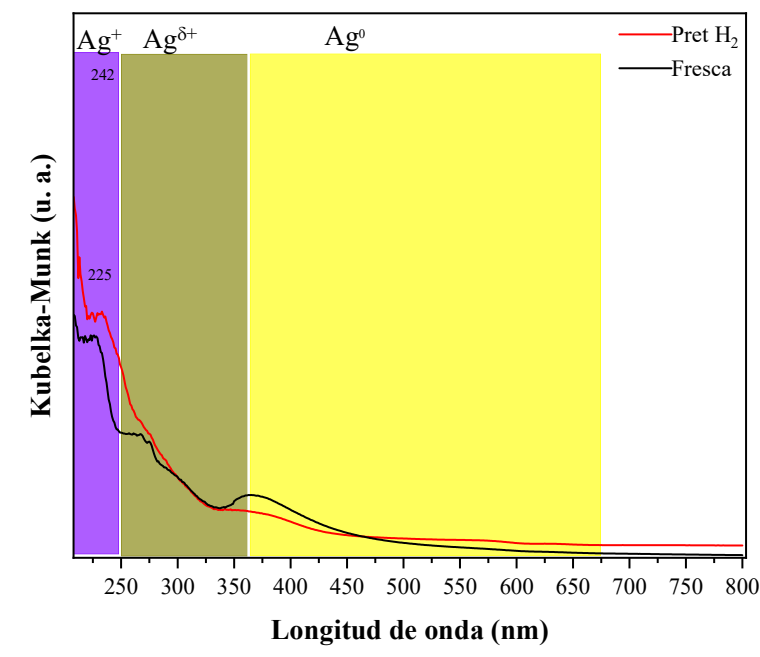

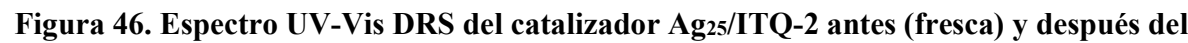
pretratamiento con $\mathrm{H}_{2}$.

Para estudiar la evolución de las especies de plata durante los pretratamientos y durante la reacción, la misma muestra fue sometida a ciclos sucesivos de activación/reacción (Tabla 23). 
Tabla 23. Reacciones y tratamientos sucesivos realizados al catalizador Ag25/ITQ-2.

\begin{tabular}{|c|c|}
\hline Reacción & Tratamiento/Reacción \\
\hline $\mathbf{R} 1$ & Activación con $\mathrm{H}_{2}\left(150^{\circ}\right)$ y reacción $\left(\mathrm{CO}+\mathrm{O}_{2}\right.$ hasta $\left.650^{\circ} \mathrm{C}\right)$ \\
\hline $\mathbf{R} 2$ & Catalizador usado en (1) y reacción $\left(\mathrm{CO}+\mathrm{O}_{2}\right.$ hasta $\left.600^{\circ} \mathrm{C}\right)$ \\
\hline $\mathbf{R} 3$ & $\begin{array}{l}\text { Catalizador usado en }(2) \text {, reactivado con } \mathrm{H}_{2}\left(150^{\circ} \mathrm{C}\right) \text { y reacción } \\
\qquad\left(\mathrm{CO}+\mathrm{O}_{2} \text { hasta } 400^{\circ} \mathrm{C}\right)\end{array}$ \\
\hline R 4 & $\begin{array}{l}\text { Catalizador usado en }(3) \text {, reactivado con } \mathrm{H}_{2}\left(150^{\circ} \mathrm{C}\right) \text { y reacción } \\
\qquad\left(\mathrm{CO}+\mathrm{O}_{2} \text { hasta } 400^{\circ} \mathrm{C}\right)\end{array}$ \\
\hline
\end{tabular}

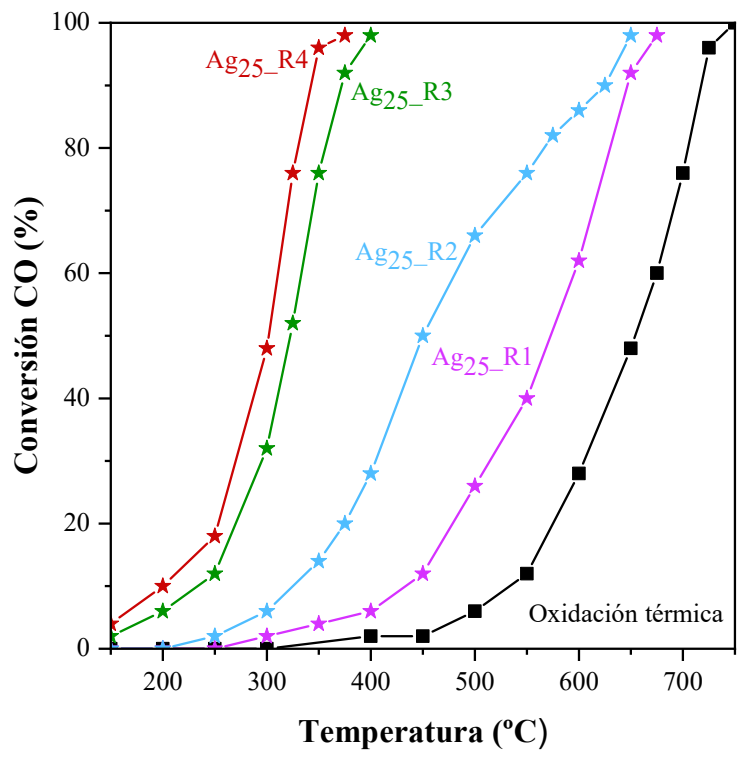

Figura 47. Actividad catalítica del catalizador $\mathrm{Ag}_{25} / \mathrm{ITQ}-2$ tras reacciones sucesivas (ver Tabla 23). (0.5\% CO, $4 \% \mathrm{O}_{2}$, resto $\mathrm{N}_{2}$, masacat: $\left.250 \mathrm{mg}, \mathrm{Q}: 500 \mathrm{~mL} \cdot \mathrm{min}^{-1}\right)$.

Los resultados catalíticos de estos experimentos se muestran en la Figura 47 y se comparan con los resultados de la oxidación térmica. Como puede observarse, si 
tras la primera reacción se utiliza el mismo catalizador para una segunda reacción (Figura 47, $\mathrm{Ag}_{25}$ R2), la actividad aumenta pasando de un $\mathrm{T}_{50}$ de $575^{\circ} \mathrm{C}$ a un $\mathrm{T}_{50}$ de $450^{\circ} \mathrm{C}$. Estos resultados pueden relacionarse con la destrucción de los ligandos tiolatos que se empieza a producir a temperaturas superiores a $150{ }^{\circ} \mathrm{C}$. Hay que tener en cuenta que el catalizador en la primera reacción alcanza $\operatorname{los} 650^{\circ} \mathrm{C}$, y a esta temperatura y en presencia de oxígeno, los ligandos de los nanoclusters son parcialmente destruidos, dando lugar a la formación de nanopartículas de plata metálica. De hecho, si tras esta segunda reacción se reactiva el mismo catalizador con $\mathrm{H}_{2}$ y se somete a una tercera reacción en la que los ligandos estarán ya completamente destruidos, la actividad sigue incrementando, y alcanza un $\mathrm{T}_{50}$ de $325{ }^{\circ} \mathrm{C}$ (Figura 47, $\mathrm{Ag}_{25}$ R3). Una cuarta reacción con el mismo catalizador (Figura 47, $\mathrm{Ag}_{25} \mathrm{R} 4$ ) ya sólo induce a una ligera mejoría de la actividad catalítica $\left(\mathrm{T}_{50}=310^{\circ} \mathrm{C}\right)$, pues la mayoría de la plata estará ya como plata metálica.

Tal como se ha comentado, el aumento de la actividad en los sucesivos ciclos de activación/reacción se puede relacionar con la destrucción de los ligandos, y con la formación de nanopartículas de Ag metálica que serían las especias activas en esta reacción. Estas especies únicamente pueden formarse tras la eliminación de los ligandos de los nanoclusters, lo que se ve favorecido por las altas temperaturas, pero sobre todo por la atmósfera oxidante de la reacción. De hecho, si se compara la actividad del catalizador pretratado con $\mathrm{H}_{2}$ o con $\mathrm{O}_{2}$, se observa que cuando el catalizador es activado con una atmósfera oxidante, se obtiene una actividad catalítica significativamente mayor (Figura 48). 


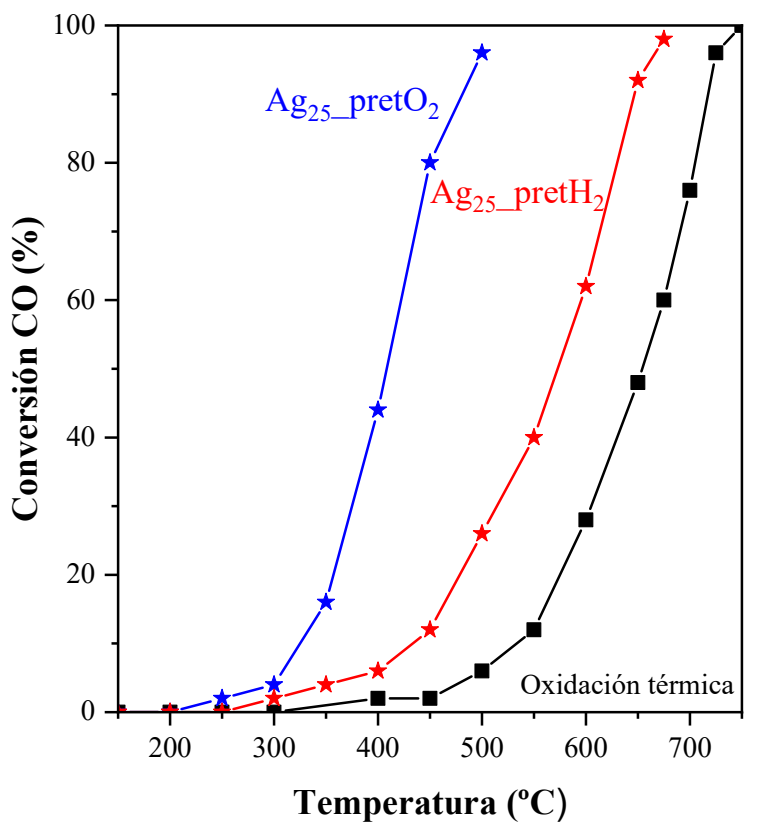

Figura 48. Actividad catalítica en la oxidación de CO del catalizador Ag25/ITQ-2 tras ser pretratado con $\mathrm{H}_{2}$ y con $\mathrm{O}_{2} .\left(0.5 \% \mathrm{CO}, 4 \% \mathrm{O}_{2}\right.$, resto $\mathrm{N}_{2}$, masacat: $250 \mathrm{mg}$, Q:500 $\left.\mathrm{mL} \cdot \mathrm{min}^{-1}\right)$.

Esta hipótesis fue corroborada con estudios de XAS in situ realizados en el Sincrotrón ALBA. La Figura 49 muestra los espectros XANES antes y después de los dos pretratamientos, y durante la reacción de oxidación de $\mathrm{CO}$ a distintas temperaturas. La figura también muestra los espectros de la plata metálica empleada como referencia para las especies $\mathrm{Ag}^{0}$. 


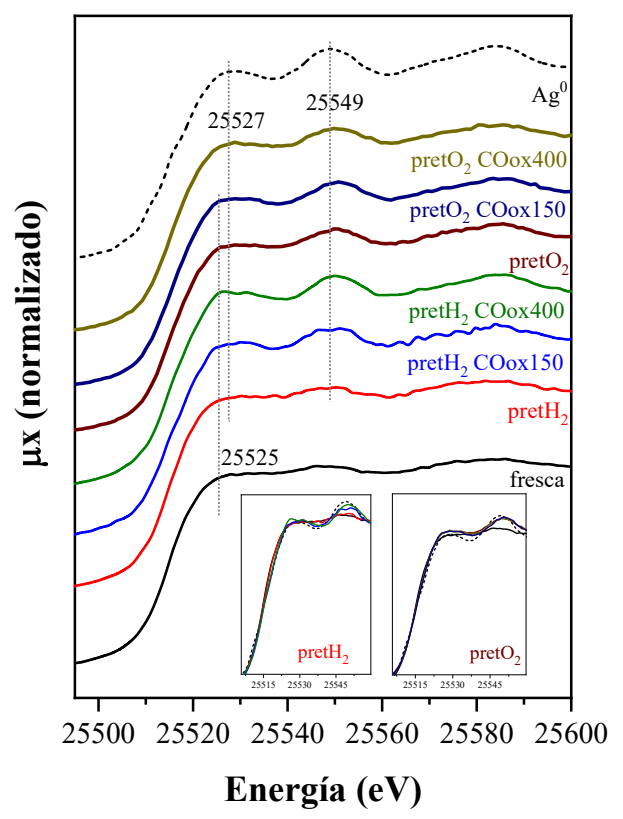

Figura 49. Espectro XANES normalizado en el borde $K$ de la plata del catalizador $\mathrm{Ag}_{25} / \mathrm{ITQ}$-2 antes (fresca) y después de los pretratamientos con $\mathrm{H}_{2}\left(\right.$ pretH $\left._{2}\right)$ y $\mathrm{O}_{2}$ (pretO $\mathrm{p}_{2}$ ), y durante la reacción de oxidación de $\mathrm{CO}$ a diferentes temperaturas (COox150 o 400).

Tal y como se observa en la Figura 49, la muestra fresca presenta un salto de absorción a energías ligeramente más altas que el de la plata metálica, así como un ensanchamiento del primer pico después del salto. Estos resultados son los característicos de los nanoclusters de plata [186,187], lo que indica que los nanoclusters se han sintetizado correctamente $y$ que se encuentran adecuadamente soportados sobre la zeolita ITQ-2. Tras el pretratamiento con $\mathrm{O}_{2}$ y después de reacción, aparece un pequeño pico alrededor de $25.550 \mathrm{keV}$ característico de la plata metálica $[89,186,188,189]$. Estas muestras presentan además un desplazamiento del borde de absorción hacia energía mayores, así como una disminución de la intensidad de la línea blanca, lo que podría estar relacionado con la eliminación de los ligandos tiolatos unido a un aumento del estado metálico de la plata en los nanoclusters. 
Por el contrario, se observa que en el caso de la muestra pretratada con $\mathrm{H}_{2}$, no hay desplazamientos en la energía entre la muestra fresca y la muestra después del pretratamiento, lo que indica que no se produce alteración en la estructura de los nanoclusters y que se mantiene el estado de oxidación con carga parcial positiva. Después de reacción, la muestra que había sido pretratada en $\mathrm{H}_{2}$ presenta un espectro ligeramente desplazado a mayores energías junto con picos más definidos sobre $25.550 \mathrm{keV}$, mostrando un espectro más parecido al patrón de la plata metálica, e indicando que, durante la reacción, se ha producido una modificación en los nanoclusters, probablemente debido a la eliminación de los ligandos.

Con el fin de obtener más información sobre la estructura de los nanoclusters, así como sobre su estabilidad en las condiciones de reacción, se realizaron análisis EXAFS de los catalizadores Ag $_{25} / \mathrm{ITQ}-2$. La Figura 50 y la Tabla 24 muestran los resultados de los estudios EXAFS realizados con este catalizador monometálico.

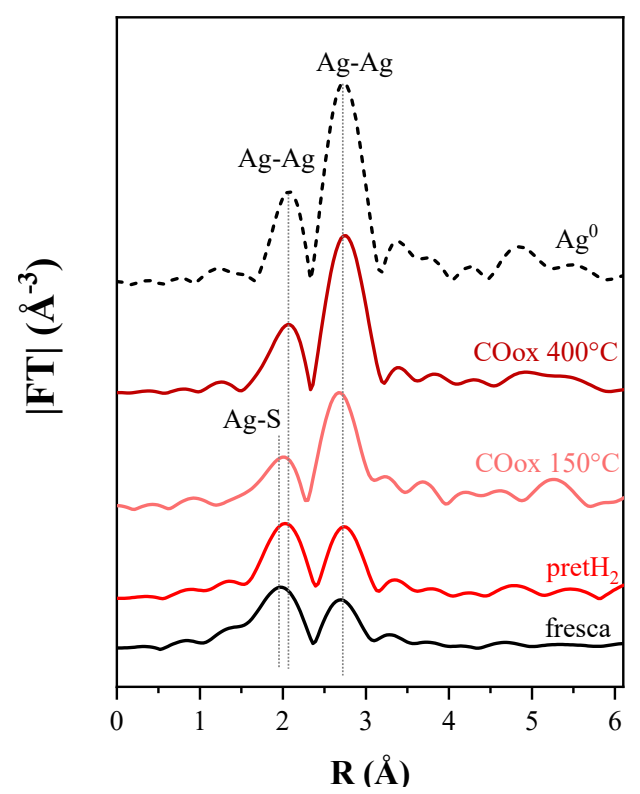

Figura 50. Transformada de Fourier (FT) de la señal EXAFS del catalizador Ag Ag/ITQ-2 $^{2}$ fresco, pretratado con $\mathrm{H}_{2}$ y en condiciones de reacción a 150 y $450{ }^{\circ} \mathrm{C}$. 
Tabla 24. Resumen de los parámetros optimizados de los datos de EXAFS del catalizador $\mathrm{Ag}_{25} / \mathrm{ITQ}$-2.

\begin{tabular}{|c|c|c|c|c|c|c|}
\hline Muestra & Enlace & $\mathrm{CN}$ & $\mathbf{R}(\AA ̊)$ & $\sigma^{2}\left(\AA^{2}\right)$ & $\begin{array}{l}\Delta E_{0} \\
(e V)\end{array}$ & $\mathbf{R}_{\text {factor }}$ \\
\hline $\mathbf{A g}^{0}$ & $\mathrm{Ag}-\mathrm{Ag}$ & 12 & $\begin{array}{c}2.862 \pm \\
0.004\end{array}$ & $\begin{array}{c}0.0096 \pm \\
0.0006\end{array}$ & $\begin{array}{c}1.9 \pm \\
0.4\end{array}$ & 0.0036 \\
\hline \multirow{4}{*}{ Fresca $^{a}$} & Ag-S & $1.5 \pm$ & $2.433 \pm$ & \multirow{4}{*}{$\begin{array}{c}0.0098 \pm \\
0.0026\end{array}$} & \multirow{4}{*}{$\begin{array}{c}2.5 \pm \\
1.7\end{array}$} & \multirow{4}{*}{0.0260} \\
\hline & & 0.3 & 0.022 & & & \\
\hline & $\mathrm{Ag}-\mathrm{Ag}$ & $2.5 \pm$ & $2.856 \pm$ & & & \\
\hline & & 0.6 & 0.019 & & & \\
\hline \multirow{3}{*}{$\operatorname{pretH}_{2}{ }^{a}$} & $\mathrm{Ag}-\mathrm{S}$ & $1.7 \pm$ & $2.491 \pm$ & \multirow{3}{*}{$\begin{array}{c}0.0101 \pm \\
0.0023\end{array}$} & \multirow{3}{*}{$\begin{array}{c}3.1 \pm \\
1.6\end{array}$} & \multirow{3}{*}{0.0262} \\
\hline & & 0.3 & 0.023 & & & \\
\hline & $\mathrm{Ag}-\mathrm{Ag}$ & $\begin{array}{c}4.0 \pm \\
0.8\end{array}$ & $\begin{array}{c}2.876 \pm \\
0.017\end{array}$ & & & \\
\hline $\mathrm{H}_{2} \mathrm{COOx} 400^{b}$ & $\mathrm{Ag}-\mathrm{Ag}$ & $\begin{array}{c}8.6 \pm \\
0.4\end{array}$ & $\begin{array}{c}2.861 \pm \\
0.004\end{array}$ & $\begin{array}{c}0.0093 \pm \\
0.0007\end{array}$ & $\begin{array}{c}2.6 \pm \\
0.4\end{array}$ & 0.0020 \\
\hline
\end{tabular}

$\mathrm{CN}=$ número de coordinación; $\mathrm{R}=$ distancia interatómica; $\sigma^{2}=$ factor de desorden térmico y estático; $\Delta \mathbf{E}_{0}=$ variación de potencial; $R_{\text {factor }}=$ error del ajuste

${ }^{\text {a}}$ Ajuste realizado en $\Delta \mathrm{R}=\mathbf{1 . 5 - 3 . 2} \AA \AA$ de los parámetros de la señal EXAFS en el intervalo $\Delta \mathrm{k}$ $=2.0-10.0 \AA^{-1}$

${ }^{\text {b}}$ Ajuste realizado en $\Delta \mathrm{R}=1.8-3.2 \AA$ de los parámetros de la señal EXAFS en el intervalo $\Delta \mathrm{k}$ $=2.0-9.0 \AA^{-1}$

Como puede observarse, el pretratamiento con $\mathrm{H}_{2}$ no da lugar a cambios significativos en los catalizadores $\mathrm{Ag}_{25} / \mathrm{ITQ}-2$ (Figura 50), lo que confirma la estabilidad de la estructura de los nanoclusters en estas condiciones. Esto indicaría que durante este pretratamiento no se produce la eliminación de los ligandos tiolatos, lo que se refleja en el alto número de coordinación para Ag-S de la Tabla 24. Sin embargo, durante la reacción se eliminan prácticamente la totalidad de los ligandos tiolatos, ya que la muestra después de reacción no presenta enlaces Ag-S. Asimismo, la reacción produce un cambio en el número de coordinación de Ag-Ag pasando de 4.0 a 8.6, aunque las distancias de enlace 
Ag-Ag siguen siendo las mismas que antes de la reacción (Tabla 24), lo que indicaría que pese la destrucción de los ligandos, no se produce una agregación de las especies de plata.

Todos estos resultados se pueden correlacionar con los resultados de la actividad catalítica y con los estudios de UV-Vis DRS. En la muestra fresca, los nanoclusters de $\mathrm{Ag}$ se encuentran con carga parcial positiva y protegidos por los ligandos. Estas características no varían tras la activación con $\mathrm{H}_{2}$ a $150{ }^{\circ} \mathrm{C}$, lo que hace que los reactivos no puedan alcanzar los centros activos que serían las nanopartículas de $\mathrm{Ag}^{0}$, resultando en una baja actividad (Figura 47, $\mathrm{Ag}_{25} \mathrm{R} 1$ ). Sin embargo, al aumentar la temperatura y en presencia de oxígeno, los ligandos se destruyen y se forman nanopartículas de plata accesibles, provocando un aumento sustancial de la actividad catalítica (Figura 47, $\mathrm{Ag}_{25}$ R2). Una posterior reducción del catalizador aumenta el carácter metálico de estos centros, aumentando en el mismo sentido la actividad del catalizador (Figura 47, $\mathrm{Ag}_{25} \mathrm{R} 3$ ). Es decir, la muestra fresca evoluciona hacia la formación de plata metálica durante la oxidación de $\mathrm{CO}$, especialmente cuando la muestra es llevada a altas temperaturas, lo que permite explicar el aumento de la actividad observado en los ciclos sucesivos de activación/reacción.

\subsubsection{Otros catalizadores de Ag/ITQ-2}

Los resultados obtenidos en el apartado anterior muestran que es necesaria la destrucción de los ligandos y la formación de nanopartículas de plata metálica para tener catalizadores de plata activos en esta reacción. En este apartado se analiza la actividad catalítica de otros catalizadores de plata soportados sobre la zeolita ITQ-2, pero en los que la plata se ha incorporado de manera distinta: por impregnación a volumen de poro $\left(\mathrm{Ag}_{\mathrm{imp}}\right)$ a partir de una sal precursora de plata $\left(\mathrm{AgNO}_{3}\right)$ y su posterior calcinación a $450{ }^{\circ} \mathrm{C}$ o por intercambio iónico $\left(\mathrm{Ag}_{\text {int }}\right)$. En todos ellos, la cantidad de plata es la misma que en el apartado anterior $(1 \%$ en peso), y los catalizadores han sido activados con aire a $150^{\circ} \mathrm{C}$. 
Los resultados de actividad catalítica de estos catalizadores se muestran en la Figura 51, en donde también se ha incluido los resultados de la oxidación térmica y de la muestra con los nanoclusters de $\mathrm{Ag}$ soportados sobre la zeolita $\left(\mathrm{Ag}_{25}\right)$.

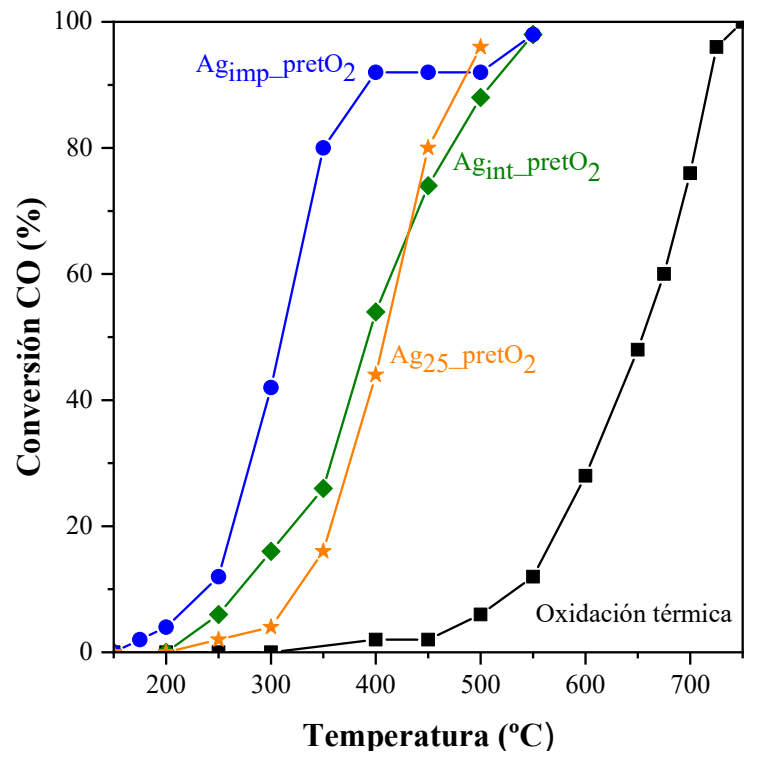

Figura 51. Influencia del método de preparación de los catalizadores en la actividad catalítica. $\left(0.5 \% \mathrm{CO}, 4 \% \mathrm{O}_{2}\right.$, resto $\mathrm{N}_{2}$, masa $\left.{ }_{\text {cat: }} 250 \mathrm{mg}, \mathrm{Q:500} \mathrm{mL} \cdot \mathrm{min}^{-1}\right)$.

Como se observa en la gráfica, la mejor actividad catalítica se obtiene con el catalizador preparado por impregnación a volumen de poro, con un $\mathrm{T}_{50}$ de $310^{\circ} \mathrm{C}$, mientras que los catalizadores preparados incorporando los nanoclusters de plata al soporte y con la plata añadida por intercambio iónico presentan una actividad menor, siendo esta muy similar entre ambos catalizadores.

Las muestras fueron caracterizadas por UV-Vis DRS, antes y después del pretratamiento de activación con oxígeno, y los espectros obtenidos se muestran en la Figura 52. 


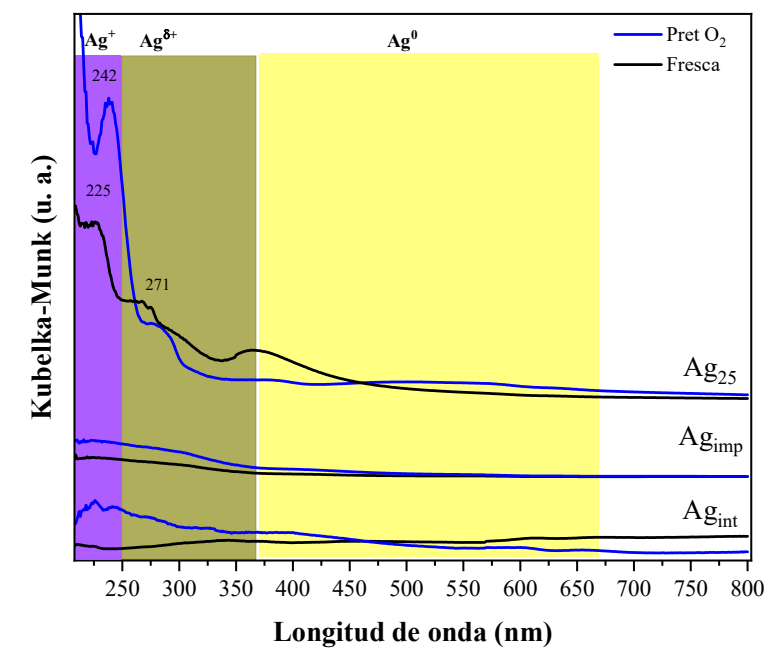

Figura 52. Espectro UV-Vis DRS de las muestras $\mathbf{A g}_{25} / \mathbf{I T Q - 2 ,} \mathbf{A g}_{\text {inp }} / \mathrm{ITQ-2}$ y $\mathbf{A g}_{\text {int }} / \mathbf{I T Q - 2}$ antes (fresca) y después del pretratamiento con $\mathrm{O}_{2}$.

Como puede observarse, en los catalizadores preparados por intercambio iónico $\left(A g_{i n t}\right)$ y con los nanoclusters de plata soportados $\left(\mathrm{Ag}_{25}\right)$ se observan principalmente bandas por debajo de los $325 \mathrm{~nm}$, las cuales no aparecen en las muestras preparadas por impregnación $\left(\mathrm{Ag}_{\mathrm{imp}}\right)$. Estas bandas corresponden a especies catiónicas de plata [181-185], tal y como se ha descrito anteriormente. Esto indicaría que estas son las especies predominantes en estos catalizadores. No obstante, y tal como han confirmado los experimentos de XAS en el caso de los catalizadores con nanoclusters de plata, no se puede excluir la presencia de plata metálica en estas muestras, pues la resolución del espectro no es suficiente para identificar la presencia de estas especies. Esta hipótesis está reforzada por los resultados catalíticos pues, si tal como se ha comprobado, la actividad catalítica en esta reacción se debe únicamente a las especies de plata metálica, estas especies deben estar presentes en los catalizadores, aunque no se observen por espectroscopía UV-Vis. Por tanto, parece que la técnica UV-Vis DRS no es suficientemente sensible como para detectar tan bajas concentraciones de 
partículas metálicas [182], mientras que, el estudio de la actividad de estos catalizadores en la reacción de oxidación catalítica de $\mathrm{CO}$ sí que permitiría discernir las especies de plata presentes en los catalizadores.

\subsubsection{La reacción de oxidación de CO como reacción test para determinar especies de plata}

Los resultados descritos anteriormente indican que la reacción de oxidación de CO puede emplearse como reacción test para determinar las especies de plata presentes en catalizadores con bajo contenido en este metal. Los resultados muestran que esta reacción puede aportar más información sobre la naturaleza de estas especies que técnicas convencionales como la espectroscopía UV-Vis. Para comprobar esto, se prepararon varios catalizadores con plata, la cual fue incorporada mediante el método de impregnación a volumen de poro, y estos fueron sometidos a distintos pretratamientos, estudiando su actividad catalítica. Los pretratamientos realizados fueron:

- Pretratamiento con $\mathrm{H}_{2}$

- Pretratamiento con $\mathrm{O}_{2}$ :

- Tras el cual el catalizador es mantenido en oscuridad

- Tras el cual el catalizador es expuesto a la luz

El estudio de la influencia de la exposición a la luz se hizo únicamente con el catalizador oxidado pues se ha descrito que la luz reduce las especies de plata oxidadas que se forman tras impregnar el catalizador con una sal precursora y someterlo a un proceso de oxidación [190,191]. Los resultados obtenidos se muestran en la Figura 53, en los cuales se compara la actividad catalítica de estos catalizadores con la reacción de oxidación térmica. 


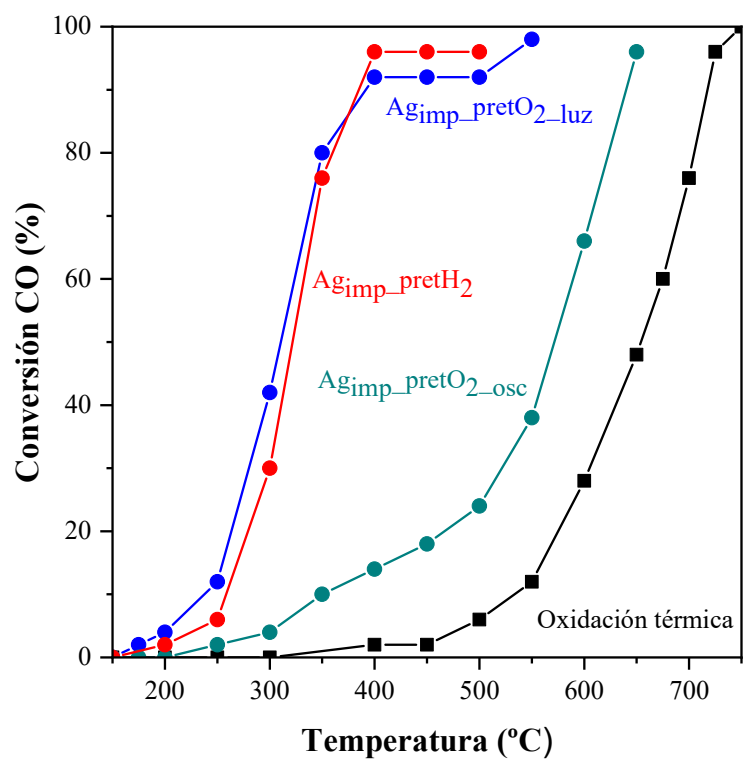

Figura 53. Influencia del pretratamiento en la actividad catalítica de catalizadores de plata preparados por impregnación a volumen de poro. $\left(0.5 \% \mathrm{CO}, 4 \% \mathrm{O}_{2}\right.$, resto $\mathrm{N}_{2}$, masacat: $\left.250 \mathrm{mg}, \mathrm{Q}: 500 \mathrm{~mL} \cdot \mathrm{min}^{-1}\right)$.

Como puede observarse, se obtienen resultados catalíticos diferentes en función del pretratamiento empleado. Las diferencias más importantes se dan con los catalizadores pretratados con oxígeno, en función de si la muestra ha sido protegida de la luz o no, obteniéndose una actividad considerablemente peor cuando sobre la muestra no ha incidido la luz ( $\mathrm{Ag}_{\text {imp_pretO }}$ 2 osc $\left._{2}\right)$. Por otro lado, los mejores resultados de actividad catalítica se obtienen cuando la muestra se pretrata en atmósfera de hidrógeno $\left(\mathrm{Ag}_{\text {imp__p }} \mathrm{pret}_{2}\right)$ o cuando la muestra se pretrata con oxígeno e incide la luz sobre la misma $\left(\mathrm{Ag}_{\text {imp__petO }}\right.$ prluz $\left._{2}\right)$. Como se observa, los resultados obtenidos con la muestra pretratada con oxígeno y mantenida en la oscuridad coinciden con los de la muestra con nanoclusters de plata con ligandos y que presenta carga parcial positiva (Figura 47, $\mathrm{Ag}_{25} \mathrm{R} 1$ ), mientras que los obtenidos con la muestra tratada con $\mathrm{H}_{2} \mathrm{u} \mathrm{O}_{2}$ en presencia de luz coinciden con los de la muestra con nanoclusters de Ag tras cuatro reacciones sucesivas 
(Figura 47, $\mathrm{Ag}_{25} \mathrm{R} 4$ ), en la que se han formado las nanopartículas de $\mathrm{Ag}^{0}$. Este resultado indicaría, nuevamente, que la presencia de especies de plata reducida es necesaria para catalizar la oxidación de CO.

Las muestras sometidas a los distintos pretratamientos fueron estudiadas por espectroscopía UV-Vis DRS, y los espectros obtenidos se muestran en la Figura 54.

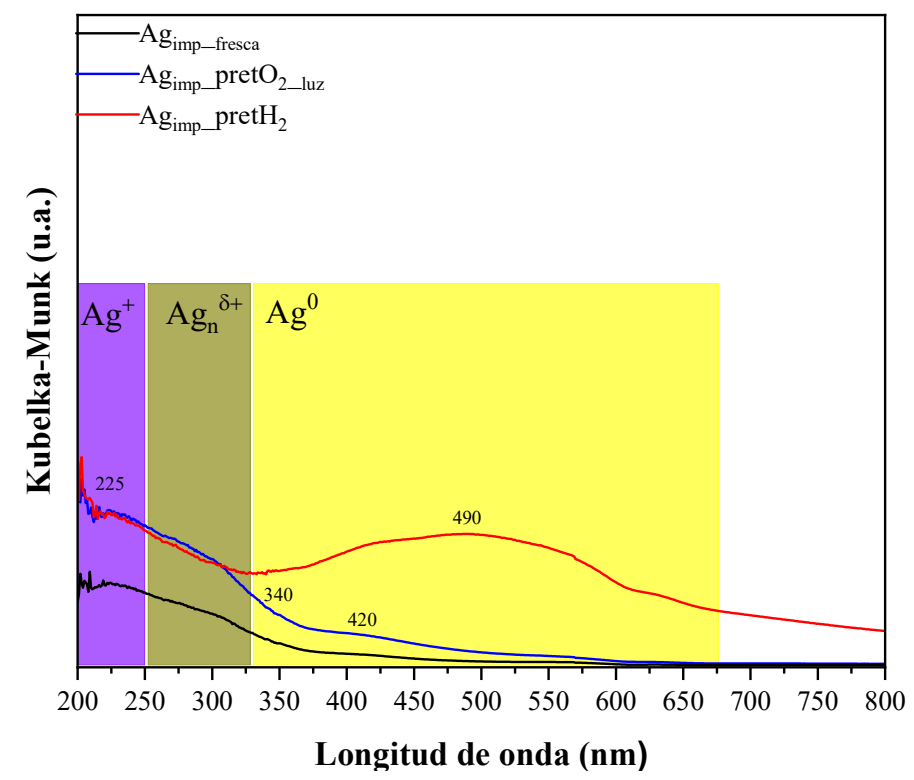

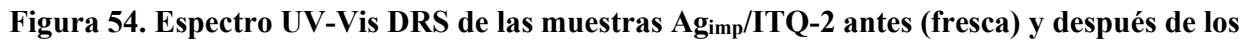
distintos pretratamientos.

Al tratar la muestra con $\left.\mathrm{H}_{2}\left(\mathrm{Ag}_{\text {imp__pret }}\right)_{2}\right)$, se observa la aparición de una banda pronunciada centrada en $490 \mathrm{~nm}$, la cual se corresponde con las especies de plata metálica. El catalizador pretratado con $\mathrm{O}_{2}$ y sobre el cual ha incidido la luz también presenta bandas correspondientes a $\mathrm{Ag}^{0}$ a $340 \mathrm{~nm}$ y a $420 \mathrm{~nm}$. Estos resultados confirman que, las especies de plata catiónicas han sido reducidas casi 
en su totalidad a plata metálica por efecto del tratamiento con hidrógeno o por la incidencia de la luz. Esta capacidad reductora de la luz sobre la plata ha sido descrita previamente $[190,191]$, y ocurre con la mayor parte de óxidos de plata.

Estos resultados ponen de manifiesto que la reacción de oxidación catalítica de $\mathrm{CO}$ puede ser una reacción test para determinar la presencia de especies de $\mathrm{Ag}^{0}$ en los catalizadores, pues estas son las especies activas en la reacción, mientras que la presencia de especies cargadas resulta en una baja actividad catalítica. Teniendo en cuenta esta consideración, se puede afirmar que las especies catiónicas presentes en el catalizador preparado con intercambio iónico y el preparado con nanoclusters soportados son más estables que las que se forman al preparar el catalizador por impregnación a volumen de poro, ya que en los primeros son necesarios tratamientos térmicos para conseguir la formación de nanopartículas $\mathrm{Ag}^{0}$ y obtener la máxima actividad catalítica, mientras que en los últimos, con la mera presencia de la luz, se produce la reducción de la plata, obteniéndose desde el principio una elevada actividad catalítica.

\subsubsection{Conclusiones parciales}

Los resultados obtenidos muestran que los diferentes métodos de preparación empleados para la incorporación de plata a la zeolita ITQ-2, así como los distintos pretratamientos de las muestras, conducen a una diferente configuración de las especies de plata en la superficie de la zeolita ITQ-2. Estas especies se pueden identificar con la reacción de oxidación de $\mathrm{CO}$, ya que las especies activas son los centros de plata metálica, mientras que la plata catiónica no cataliza la reacción. Se ha visto que la plata metálica se forma por autorreducción al incidir la luz en las muestras preparadas por impregnación a volumen de poro, mientras que son necesarios tratamientos térmicos para su formación en los catalizadores preparados por intercambio iónico y, sobre todo, en los preparados a partir de nanoclusters soportados. En este último caso, se ha comprobado que es necesaria, además, la eliminación del ligando para conseguir la formación de las especies activas. 


\subsection{Catalizadores bimetálicos $\operatorname{Ag}_{\mathrm{x}} \mathbf{A u}_{25-\mathrm{x}} / \mathrm{ITQ}$-2}

El dopaje de los nanoclusters $\mathrm{Au}_{\mathrm{n}}(\mathrm{SR})_{\mathrm{m}}$ con otros metales [84,95,192] como $\mathrm{Ag}$, $\mathrm{Hg}, \mathrm{Cd}, \mathrm{Pd}, \mathrm{Pt}$ o $\mathrm{Cu}$ permite modificar o introducir nuevas propiedades en los mismos, tales como una mayor estabilidad o reactividad. Estas modificaciones se producen al alterar la composición atómica y, por lo tanto, la coordinación de los nanoclusters, lo que da lugar a una diferente configuración electrónica. En este apartado se estudia el empleo de catalizadores bimetálicos basados en nanoclusters de oro dopados con átomos de plata y soportados sobre la zeolita de ITQ-2 en la reacción de oxidación catalítica de CO.

Para realizar este estudio se prepararon nanoclusters bimetálicos AgAu en los que se sustituyó algunos de los átomos de oro (entre 6 y 8 ) presentes en nanoclusters de 25 átomos (con una estructura similar a la de la Figura 55), por átomos de plata, para así obtener nanoclusters bimetálicos $\operatorname{Ag}_{x} \mathrm{Au}_{25-\mathrm{x}}(\mathrm{SR})_{18}$, donde $\mathrm{SR}$ representa el ligando tiol $\left(\mathrm{SC}_{2} \mathrm{H}_{4} \mathrm{Ph}\right)$.

Los materiales fueron preparados en la Universidad Técnica de Viena, y han sido analizados por diversas técnicas in situ y/o ex situ de caracterización. Su estabilidad y actividad catalítica se han evaluado tras diferentes pretratamientos, buscando determinar cuál es el papel de las diferentes especies activas y su evolución dinámica durante esta reacción.

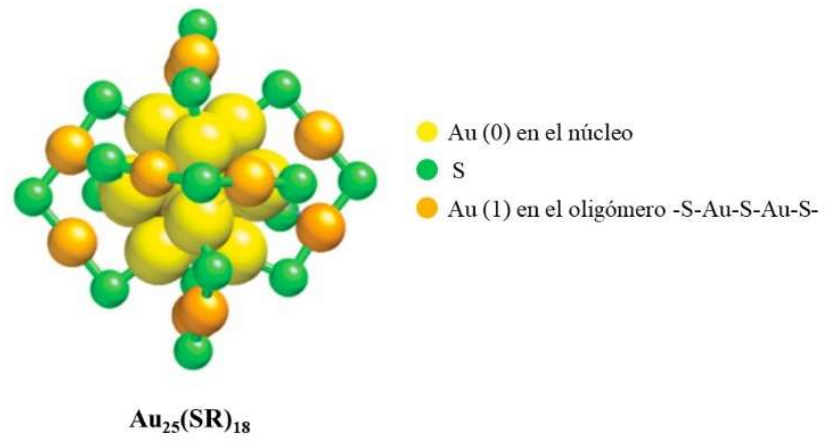

Figura 55. Esquema de la estructura de los nanoclusters $\operatorname{Au}_{n}(\mathrm{SR})_{\mathrm{m}}[91]$. 
La espectrometría de masas por desorción/ionización láser asistida por matriz (MALDI) y la espectroscopía UV-Vis permitieron comprobar que los nanoclusters habían sido preparados adecuadamente. El espectro UV-Vis de los nanoclusters bimetálicos $\mathrm{Ag}_{\mathrm{x}} \mathrm{Au}_{25-\mathrm{x}}$ se muestra en la Figura 56, donde se observan las bandas a 475, 520, y $673 \mathrm{~nm}$ características de este tipo de nanoclusters bimetálicos [95].

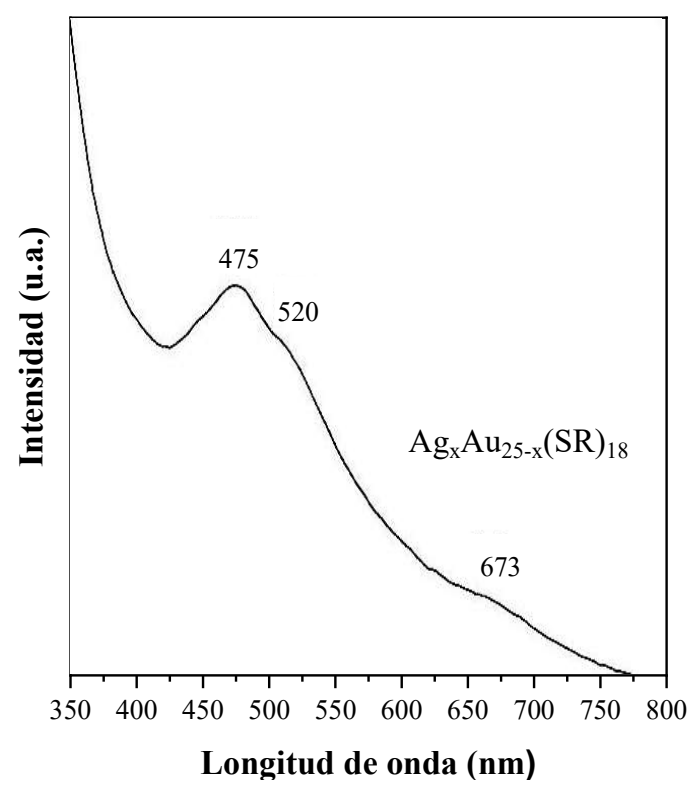

Figura 56.Espectro UV-Vis de los nanoclusters $\operatorname{Ag}_{\mathrm{x}} \mathrm{Au}_{25-\mathrm{x}}$ en disolución.

La composición exacta de los nanoclusters $\mathrm{Ag}_{\mathrm{x}} \mathrm{Au}_{25-\mathrm{x}}$ sintetizados fue identificada por espectrometría MALDI y los resultados se muestran en la Figura 57, en donde se observa una estrecha distribución de átomos de plata (entre 6 y 8 átomos) introducidos en la estructura de los nanoclusters. 


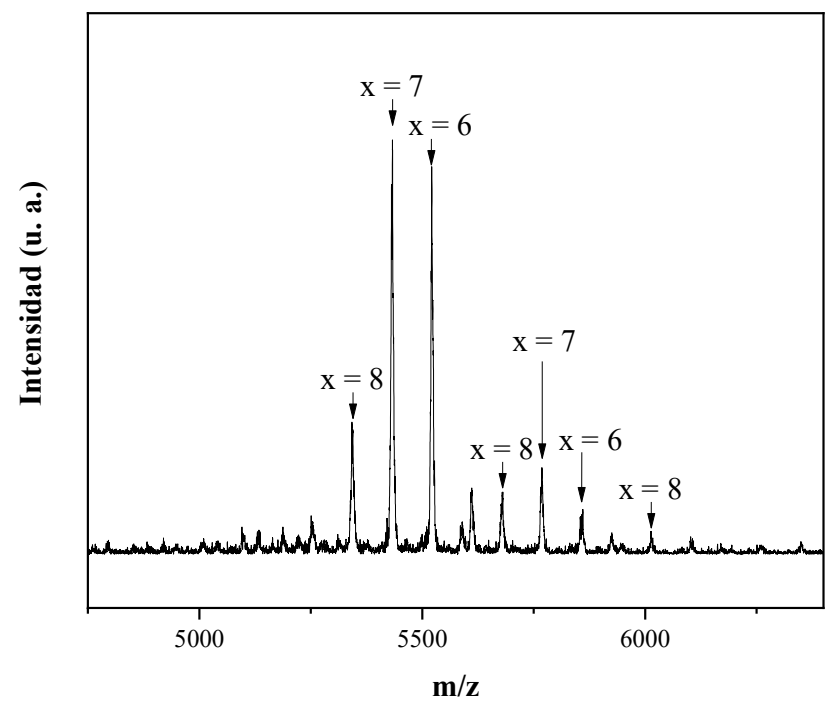

Figura 57. Espectro MALDI de los nanoclusters bimetálicos $\operatorname{Ag}_{\mathrm{x}} \mathrm{Au}$ 25-x.

\subsubsection{Actividad catalítica}

La actividad de los catalizadores preparados fue estudiada en la reacción de oxidación catalítica de $\mathrm{CO}$ tras someterlos a distintos pretratamientos, ya que, como ha sido descrito para los nanoclusters de plata en el apartado 5.1., el pretratamiento del catalizador puede producir modificaciones en las especies activas y/o la eliminación (parcial) de los ligandos tiolato presentes en el catalizador. Esto puede afectar a la actividad catalítica de los materiales. Por ello, se ha estudiado el efecto del pretratamiento de los catalizadores $\mathrm{Ag}_{\mathrm{x}} \mathrm{Au}_{25-\mathrm{x}} / \mathrm{ITQ}-2$ en presencia de aire $\left(\right.$ pretO$\left._{2}\right)$ o de hidrógeno $\left(\operatorname{pretH}_{2}\right)$. La Figura 58 muestra los resultados obtenidos después de ambos pretratamientos, comparando su actividad con la de un proceso de oxidación térmica. 


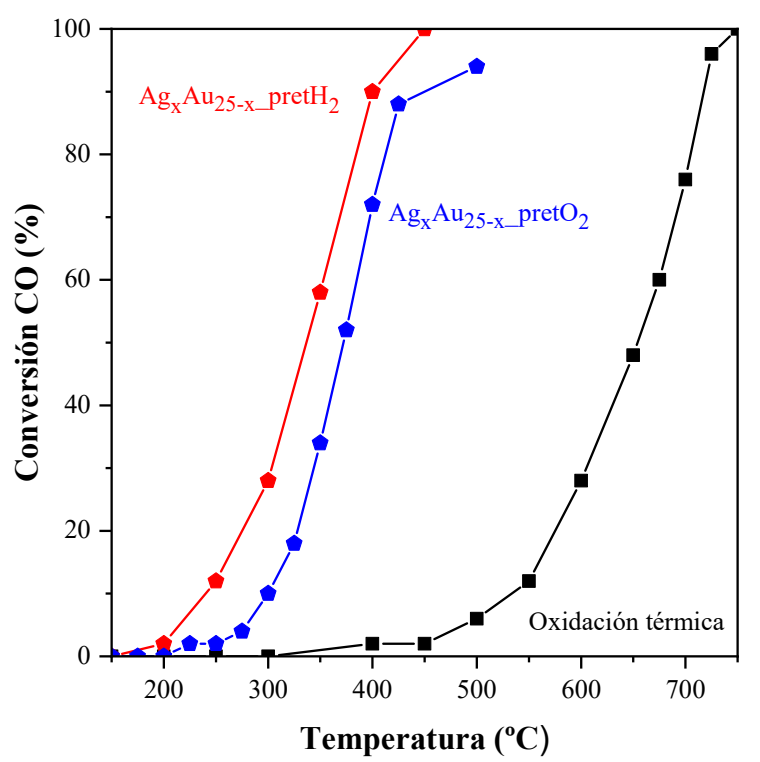

Figura 58. Influencia del pretratamiento en la actividad del catalizador $\mathbf{A g}_{\mathrm{x}} \mathbf{A u}_{25-\mathrm{x}} / \mathrm{ITQ}$-2. $\left(0.5 \% \mathrm{CO}, 4 \% \mathrm{O}_{2}\right.$, resto $\mathrm{N}_{2}$, masacat: $\left.250 \mathrm{mg}, \mathrm{Q}: 500 \mathrm{~mL} \cdot \mathrm{min}^{-1}\right)$.

Como puede observarse, los catalizadores son activos en la reacción de oxidación catalítica de CO después de ambos pretratamientos, obteniéndose una alta conversión a temperaturas muy inferiores de las necesarias para la reacción sin catalizar. Los resultados también muestran que el catalizador pretratado con hidrógeno es más activo que el pretratado con oxígeno, siendo las diferencias más pronunciadas, sobre todo, en el rango de temperaturas más bajas. Estos resultados son diferentes a los obtenidos en el apartado 5.1.1. con los nanoclusters de Ag, y sugieren que los nanoclusters bimetálicos evolucionan de distinta manera al ser sometidos a estos pretratamientos, lo que será discutido en los apartados posteriores.

La actividad de estos catalizadores bimetálicos fue también comparada con la de los catalizadores monometálicos pretratados con $\mathrm{H}_{2}$. Como puede observarse (Figura 59), los mejores resultados se obtienen con el catalizador que contiene los nanoclusters bimetálicos $\mathrm{Ag}_{\mathrm{x}} \mathrm{Au}_{25-\mathrm{x}}$, el cual presenta actividad a partir de 
$200^{\circ} \mathrm{C}$. Para el catalizador con los nanoclusters de $\mathrm{Au}$, es necesario alcanzar los $300{ }^{\circ} \mathrm{C}$ para observar una actividad significativa. Por último, son necesarias temperaturas superiores a $400{ }^{\circ} \mathrm{C}$ para obtener actividad con el catalizador que contiene los nanoclusters de Ag. Todos estos resultados indican que existe un efecto sinérgico positivo de los centros Ag-Au presentes en los catalizadores bimetálicos, y que las especies formadas son diferentes y más activas que las formadas en los catalizadores con nanoclusters mono metálicos.

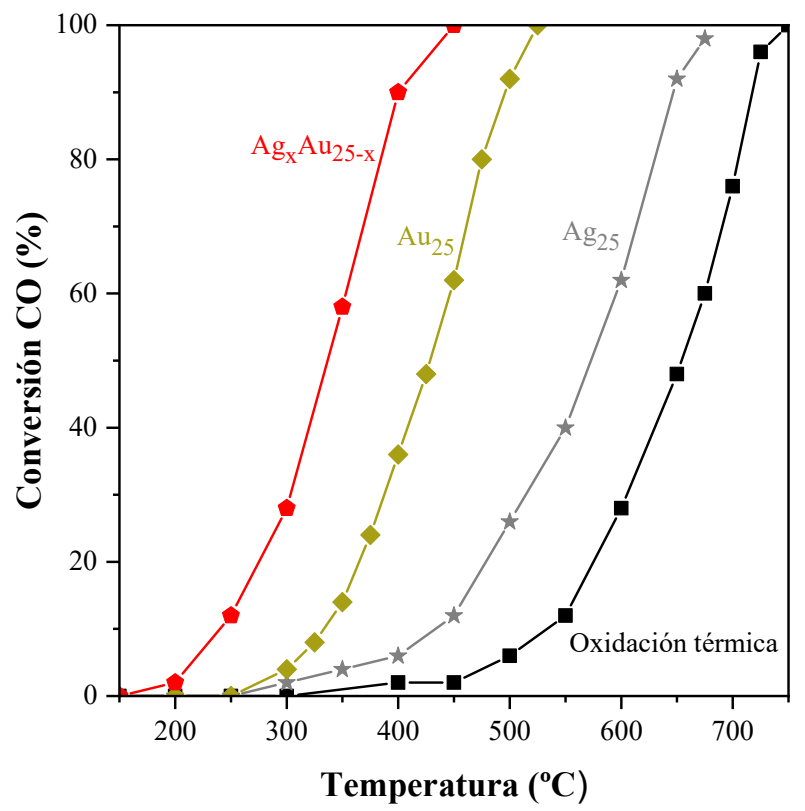

Figura 59. Actividad catalítica de los nanoclusters bi- y monometálicos soportados sobre ITQ-2 y activados con $\mathrm{H}_{2} .\left(0.5 \% \mathrm{CO}, 4 \% \mathrm{O}_{2}\right.$, resto $\mathrm{N}_{2}$, masacat: $\left.250 \mathrm{mg}, \mathrm{Q}: 500 \mathrm{~mL} \cdot \mathrm{min}^{-1}\right)$.

Tan importante como la actividad en el rango de temperatura en el que se debe tratar este contaminante en chimeneas $\left(100^{\circ} \mathrm{C}-500^{\circ} \mathrm{C}\right)$, es su estabilidad. Por ello, en la Figura 60 se muestran los resultados catalíticos de una reacción en la cual la temperatura se mantuvo constante durante varias horas. 


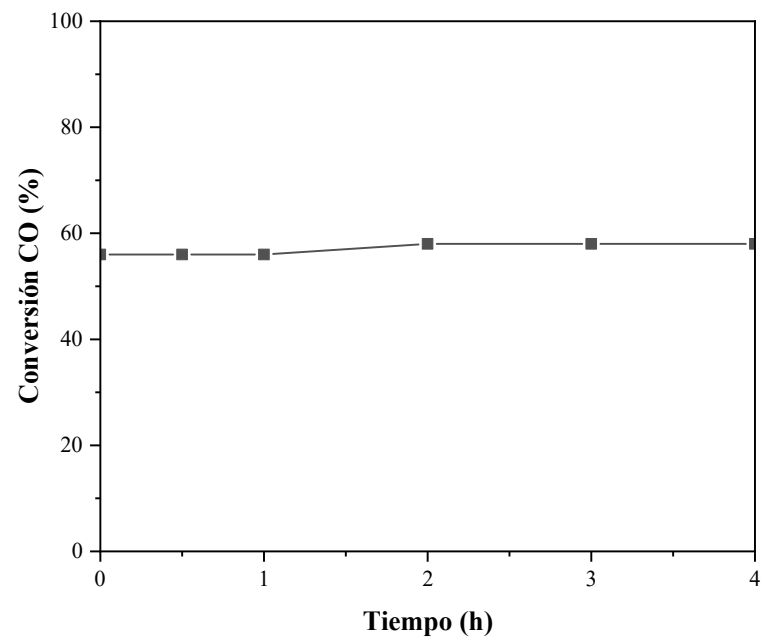

Figura 60. Actividad catalítica del catalizador $\mathbf{A g}_{\mathrm{x}} \mathrm{Au}$ 25-x/ITQ-2 después del pretratamiento con $\mathrm{H}_{2}$ en la oxidación de $\mathrm{CO}$ a $350{ }^{\circ} \mathrm{C} .\left(0.5 \% \mathrm{CO}, 4 \% \mathrm{O}_{2}\right.$, resto $\mathrm{N}_{2}$, masa aat: $250 \mathrm{mg}$, Q:500 $\left.\mathrm{mL} \cdot \mathrm{min}^{-1}\right)$.

Como puede observarse, la reacción se mantuvo durante 4 horas a $350{ }^{\circ} \mathrm{C}$ y la conversión fue estable al $60 \%$ en todo momento, coincidiendo con el valor alcanzado en el experimento mostrado en la Figura 58, y sin que se produjese la desactivación del catalizador, lo que es indicativo de su elevada estabilidad. Esta estabilidad fue también comprobada sometiendo al catalizador a reacciones consecutivas a diferentes temperaturas y empleando la misma muestra. Esto se realizó tanto con el catalizador pretratado con $\mathrm{H}_{2}\left(\mathrm{pretH}_{2}\right)$ como con el catalizador pretratado con $\mathrm{O}_{2}\left(\right.$ pretO$\left._{2}\right)$. Los resultados obtenidos se muestran en la Figura 61 . 

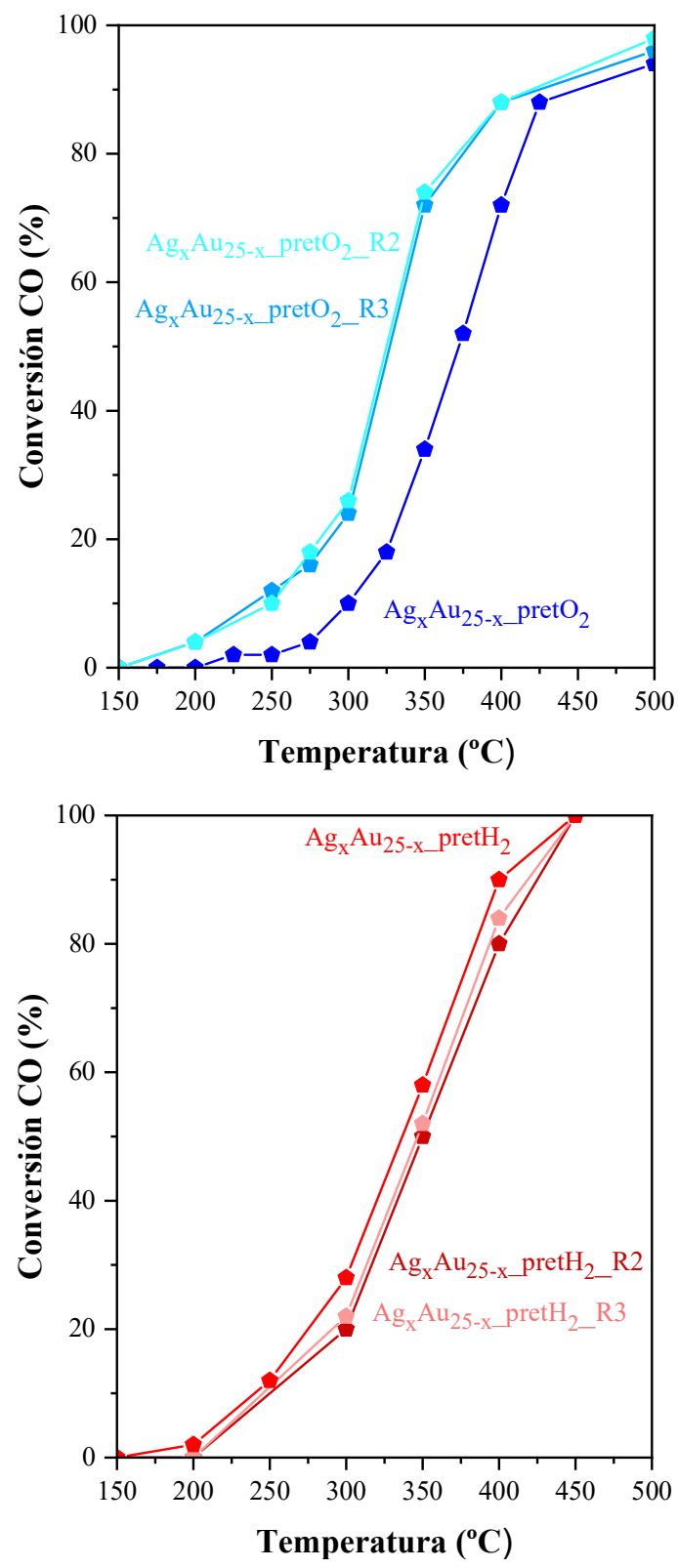

Figura 61. Actividad de los catalizadores $\mathrm{Ag}_{\mathrm{x}} \mathrm{Au}_{25-\mathrm{x}} / \mathrm{ITQ} \mathrm{I} 2$ tras los diferentes pretratamientos en reacciones consecutivas. $\left(0.5 \% \mathrm{CO}, 4 \% \mathrm{O}_{2}\right.$, resto $\mathrm{N}_{2}$, masacat: $250 \mathrm{mg}$, Q:500 $\mathbf{~ L L} \cdot$ min $\left.^{-1}\right)$. 
Los resultados confirman que el catalizador pretratado con hidrógeno (abajo) es altamente estable pues se obtienen resultados similares de actividad catalítica en las reacciones sucesivas (R2 y R3). Por otro lado, el catalizador pretratado con $\mathrm{O}_{2}$ (arriba) presenta una mayor actividad catalítica después de una primera reacción, lo que sugiere que las especies inicialmente presentes en el catalizador evolucionan durante la reacción hacia la formación de especies más activas. Estas nuevas especies formadas son más estables que las primeras ya que la actividad catalítica se mantiene igual durante una segunda y una tercera reacción consecutivas (R2 y R3). Además, se puede observar que el catalizador pretratado con $\mathrm{O}_{2}$, después de la primera reacción, presenta una actividad igual a la del catalizador pretratado con $\mathrm{H}_{2}$, lo que indica que las especies formadas después de reacción son las mismas en ambos casos. Para poder determinar la naturaleza de estas especies, los catalizadores fueron caracterizados por diferentes técnicas, tal como se describe en el apartado siguiente.

\subsubsection{Caracterización de los catalizadores $\operatorname{Ag}_{\mathrm{x}} \mathrm{Au} 25-\mathrm{x} / \mathrm{ITQ}$-2}

Los catalizadores fueron analizados antes, durante y después de los pretratamientos y las reacciones por diversas técnicas ex situ: UV-Vis DRS, NAP-XPS, XAS, TPR y microscopía electrónica, y con técnicas in situ tales como DRIFTS y XAS. Este estudio se realizó con el fin de determinar la naturaleza de las especies activas de los catalizadores y su evolución durante la reacción, buscando correlacionar estas propiedades con las diferentes actividades catalíticas obtenidas.

\section{- UV-Vis DRS:}

Los espectros UV-Vis de las muestras fresca, pretratada con $\mathrm{H}_{2}$, pretratada con $\mathrm{O}_{2}$ y tras la reacción (_R1) aparecen en la Figura 62. 


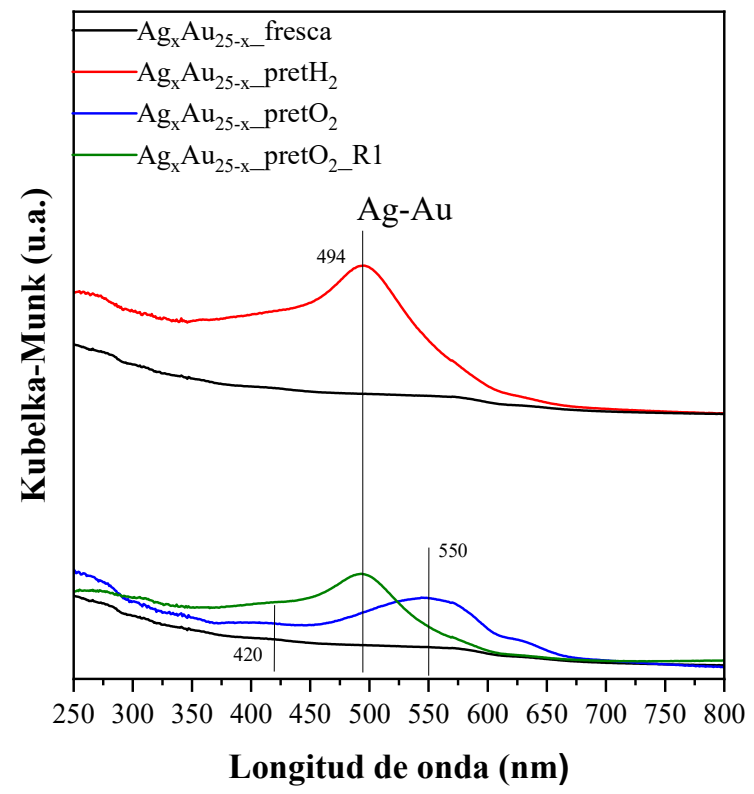

Figura 62. Espectro UV-Vis DRS del catalizador $\operatorname{Ag}_{\mathrm{x}} \mathrm{Au} \mathbf{u}_{25-\mathrm{x}} / \mathrm{ITQ}$-2 antes (fresca), tras los distintos tratamientos ( pretH $_{2}$ y pretO $\left.\mathrm{O}_{2}\right)$ y tras reacción $(\mathrm{R} 1)$.

Tal y como se observa, tras el pretratamiento con $\mathrm{O}_{2}$, aparecen dos bandas a 420 y a $550 \mathrm{~nm}$ correspondientes a los plasmones de resonancia de la plata y del oro, respectivamente [193]. Por contra, la muestra pretratada con $\mathrm{H}_{2}$ presenta una única banda centrada en $494 \mathrm{~nm}$ que es característica de las aleaciones $\mathrm{Ag}-\mathrm{Au}$ [194-196]. Esto sugiere que la mayor actividad catalítica mostrada inicialmente por el catalizador $\mathrm{Ag}_{\mathrm{x}} \mathrm{Au}_{25-\mathrm{x}} / \mathrm{ITQ}-2$ tras ser pretratado con $\mathrm{H}_{2}$ se debe a la presencia de centros activos formados por aleaciones $\mathrm{Ag}-\mathrm{Au}$, que se generan durante el pretratamiento reductivo. Estas especies también aparecen en la muestra pretratada con $\mathrm{O}_{2}$ tras una primera reacción (R1), como lo indica la banda a $494 \mathrm{~nm}$, que es igual a la mostrada por la muestra pretratada con $\mathrm{H}_{2}$. Esto explicaría el aumento de actividad que presenta el catalizador $\mathrm{Ag}_{\mathrm{x}} \mathrm{Au}_{25-\mathrm{x}} / \mathrm{ITQ}-2$ pretratado con $\mathrm{O}_{2}$ en el segundo ciclo de reacción (Figura 61), ya que parece que la aleación $\mathrm{Ag}-\mathrm{Au}$ se forma tanto durante el pretratamiento con $\mathrm{H}_{2}$, como durante 
la reacción de oxidación catalítica de $\mathrm{CO}$, probablemente por las altas temperaturas alcanzadas en el transcurso de la misma.

\section{- NAP-XPS:}

Los catalizadores con nanoclusters bimetálicos también fueron analizados por NAP-XPS. Los resultados se muestran en la Figura 63.
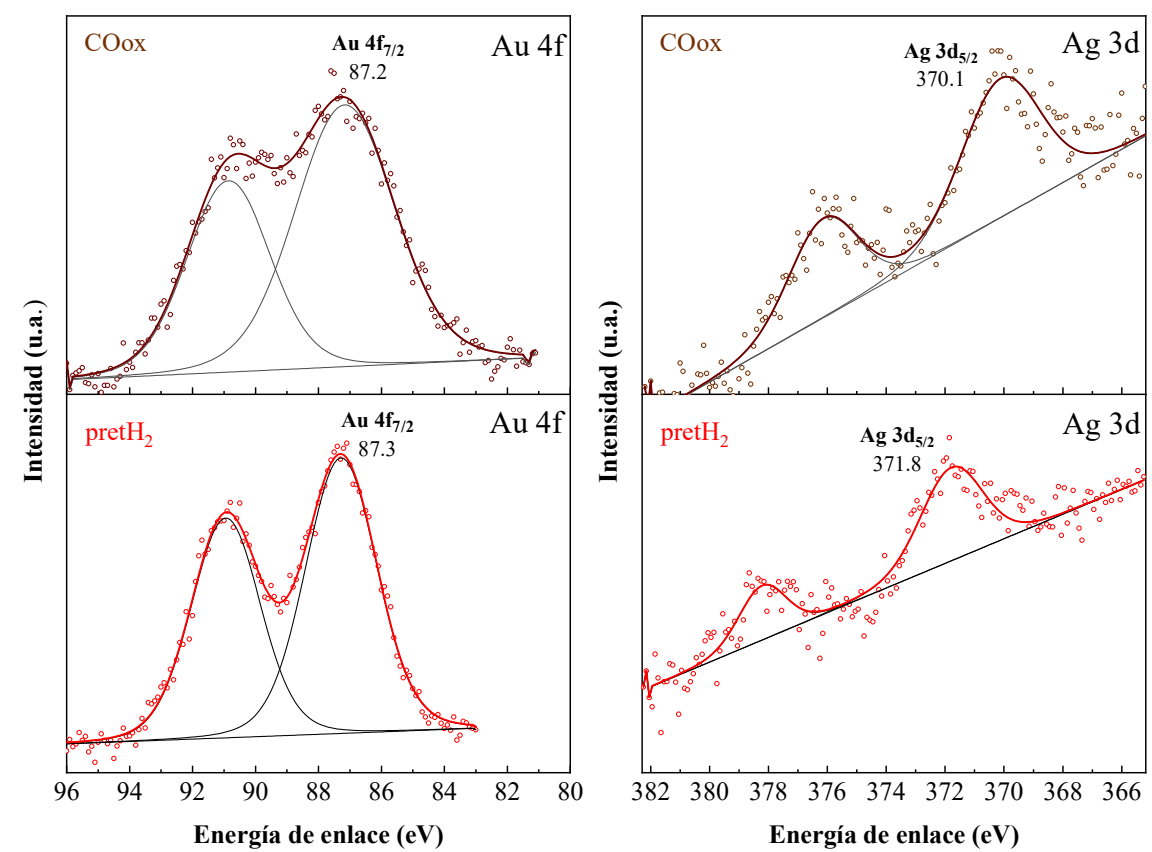

Figura 63. Espectro NAP-XPS del catalizador $\operatorname{Ag}_{\mathrm{x}} \mathrm{Au}_{25-\mathrm{x}} / \mathrm{ITQ}$-2: después del pretratamiento con $\mathrm{H}_{2}$ (abajo) y después de la reacción de oxidación de $\mathrm{CO}$ (arriba).

El espectro de los catalizadores con nanoclusters bimetálicos después del pretratamiento muestra un pico para $\mathrm{Ag} 3 \mathrm{~d}_{5 / 2}$ a $371.8 \mathrm{eV}$ y un pico para $\mathrm{Au} 4 \mathrm{f}_{7 / 2}$ a $87.3 \mathrm{eV}$. El primer pico es atribuido a los átomos de plata en los nanoclusters de oro. La energía de enlace relativamente alta de esta señal puede ser causada 
por la transferencia de carga parcial del oro a la plata, así como por la existencia de nanoclusters que dan lugar a energías de enlace más altas [197,198]. La alta energía de enlace observada para la señal del oro es causada por el llamado efecto de tamaño [199], ya que cuanto más pequeños son los nanoclusters, más altas son las energías de enlace. La relación $\mathrm{Au} / \mathrm{Ag}$ se calculó en base al área de estos picos y se obtuvo un valor $\mathrm{Au} / \mathrm{Ag}=2.4$.

Después de la reacción, se observan algunos cambios en los espectros NAP-XPS. En primer lugar, la señal $\mathrm{Ag} 3 \mathrm{~d}_{5 / 2}$ se ha desplazado hacia energías de enlace menores (de 371.8 a $370.1 \mathrm{eV}$ ), mientras que la señal de $\mathrm{Au} 4 \mathrm{f}_{7 / 2}$ sólo se desplaza $0.1 \mathrm{eV}$. Asimismo, la relación $\mathrm{Au} / \mathrm{Ag}$ cambia a un valor de 1.3, lo que también se aprecia en los espectros en los que aumenta la señal de $\mathrm{Ag}$ y disminuye la señal de $\mathrm{Au}$. Estos resultados indican que se ha producido la migración de átomos de plata hacia la superficie del catalizador, así como un cambio parcial de la carga de la Ag [197]. Esto confirmaría el enriquecimiento con plata de la superficie de los nanoclusters durante la reacción.

Los resultados también descartan la oxidación de los átomos de plata, ya que esto daría lugar a diferentes energías de enlace de las obtenidas, por lo que se puede afirmar que no hay especies de óxido de plata en la muestra.

\section{- Microscopía electrónica:}

El catalizador $\mathrm{Ag}_{\mathrm{x}} \mathrm{Au}_{25-\mathrm{X}} / \mathrm{ITQ}-2$ fue analizado por TEM-EDX así como por STEM-HAADF. En la Figura 64 se muestran las imágenes obtenidas del catalizador bimetálico antes (fresca) y después de la reacción para los distintos pretratamientos. 

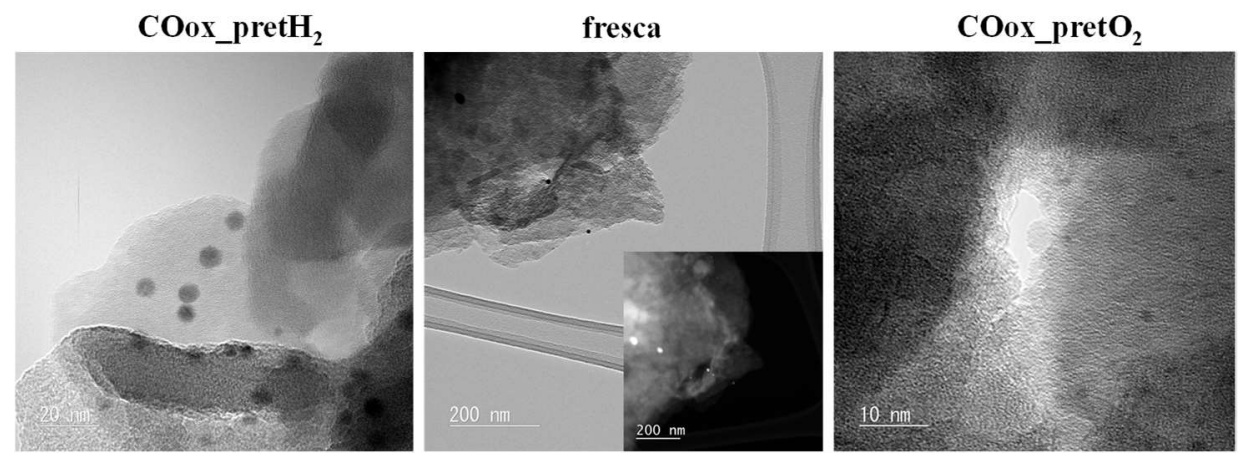

Figura 64. Imágenes STEM-HAADF del catalizador AgxAu25-x/ITQ-2 antes (centro) y después de la oxidación $\mathrm{CO}$ con pretratamiento previo de $\mathrm{O}_{2}$ (derecha) y de $\mathrm{H}_{2}$ (izquierda).

Para el caso del catalizador sin ningún pretratamiento (fresca), se observan partículas con un tamaño de $1.5 \pm 0.3 \mathrm{~nm}$, produciéndose un ligero aumento de su tamaño después de reacción $(1.7-2.0 \pm 0.5 \mathrm{~nm})$. Los resultados, además, muestran en todos los casos una distribución de tamaño de partícula muy homogénea.

Los análisis EDX al centrar el haz sobre los distintos nanoclusters se muestran en la Figura 65. Los resultados muestran que no hay segregación de las partículas e indican claramente que los nanoclusters son homogéneos. 

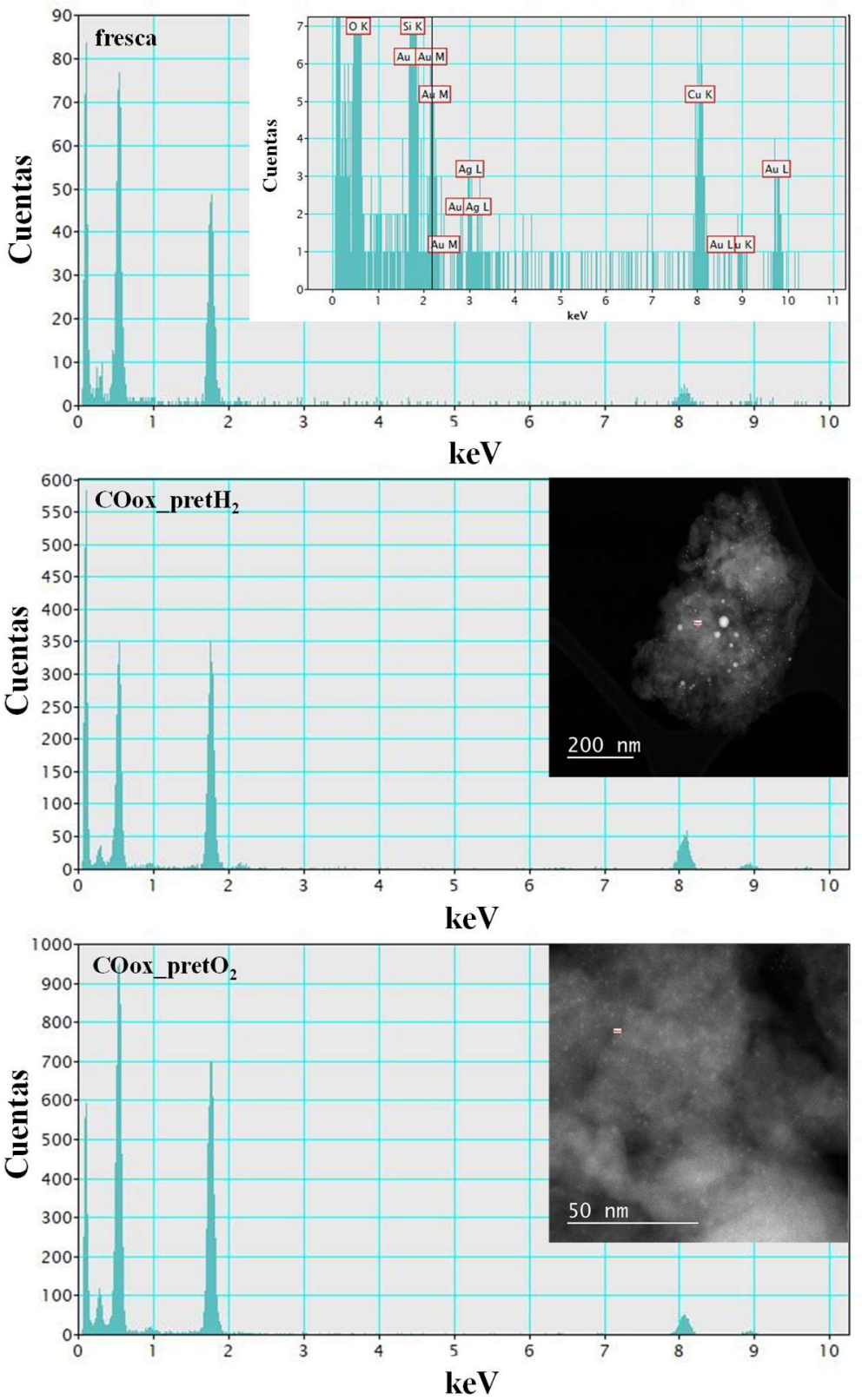

Figura 65. Análisis EDX en TEM-HAADF del catalizador con nanoclusters bimetálicos antes (fresca) y después de la oxidación de $\mathrm{CO}$ tras los pretratamientos con $\mathrm{H}_{2}$ y $\mathrm{O}_{2}$. 


\section{- TPR:}

Los catalizadores preparados con nanoclusters fueron analizados por reducción a temperatura programada para estudiar las interacciones inicialmente existentes entre los metales. Para una mejor interpretación de los resultados, se analizaron tanto los catalizadores bimetálicos como los catalizadores monometálicos de $\mathrm{Ag}$ y de Au. Los resultados se muestran en la Figura 66.

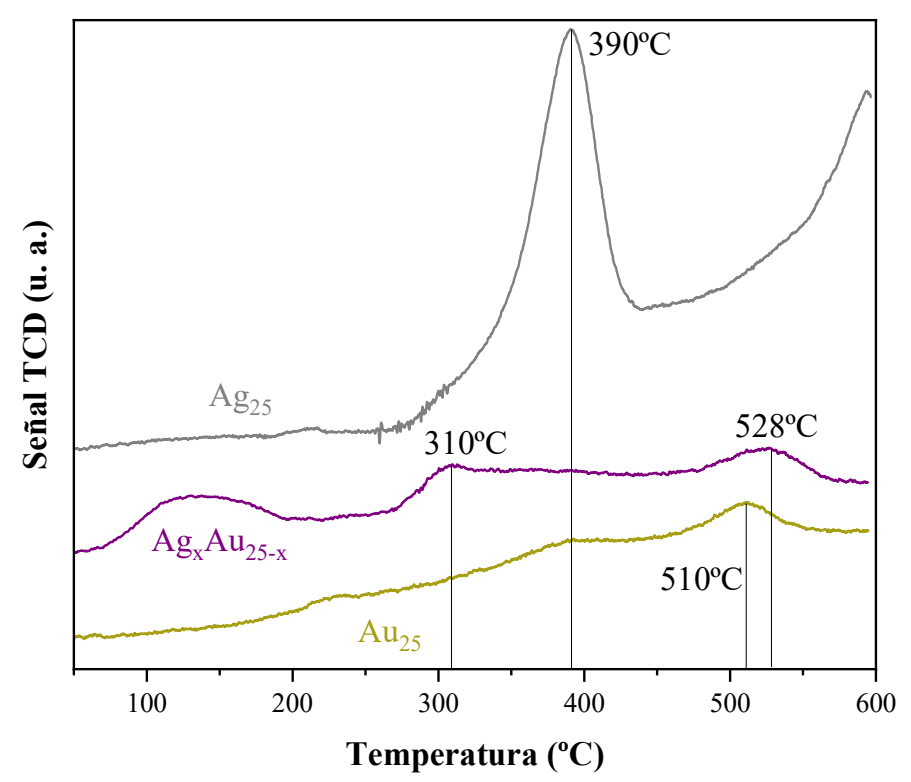

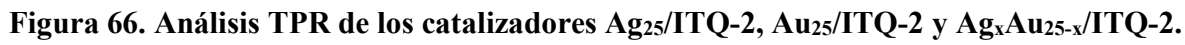

Como se observa en el termograma, el consumo de hidrógeno es mucho mayor para el catalizador de plata que para los catalizadores que contienen oro, lo que indica que la mayor parte de las especies metálicas en los catalizadores $A_{25} \mathrm{y}$ $\mathrm{Ag}_{\mathrm{x}} \mathrm{Au}_{25-\mathrm{x}}$ se encuentran en su forma reducida. Por contra, parece que las especies del catalizador de Ag se encuentran parcialmente oxidadas, siendo necesario llegar hasta $390{ }^{\circ} \mathrm{C}$ para que se reduzcan. Además, se observa que el catalizador 
monometálico de oro presenta un pequeño pico a $510{ }^{\circ} \mathrm{C}$, mientras que el catalizador bimetálico tiene dos picos, uno a $310{ }^{\circ} \mathrm{C}$ y otro a más altas temperaturas $\left(528^{\circ} \mathrm{C}\right)$. Este pico a mayor temperatura coincide con el presente en el perfil de reducción del catalizador $\mathrm{Au}_{25} / \mathrm{ITQ}-2$. Sin embargo, el pico a $310{ }^{\circ} \mathrm{C}$ aparece claramente a temperaturas más bajas que el observado para el catalizador $\mathrm{Ag}_{25} / \mathrm{ITQ}$-2. Esto indica que la reducción de la plata ha sido modificada por la presencia de $\mathrm{Au}$ en el catalizador bimetálico, lográndose una reducción a temperatura mucho menor. Estos resultados claramente muestran la existencia de una fuerte interacción entre los átomos de $\mathrm{Ag}$ y de $\mathrm{Au}$ en los nanoclusters bimetálicos.

\section{- DRIFTS in situ:}

Para seguir la evolución de los nanoclusters bimetálicos soportados sobre la zeolita ITQ-2 tanto durante los pretratamientos como durante la reacción de oxidación catalítica de $\mathrm{CO}$, se utilizó la espectroscopía infrarroja de reflectancia difusa por transformada de Fourier (DRIFTS) in situ. La Figura 67 muestra la evolución del espectro infrarrojo en las condiciones de reacción, desde temperatura ambiente hasta $400{ }^{\circ} \mathrm{C}$.

El comienzo de la actividad catalítica se identifica con la presencia de las bandas de la fase gas de $\mathrm{CO}_{2}\left(2400-2300 \mathrm{~cm}^{-1}\right)$, que aparecen a partir de $200{ }^{\circ} \mathrm{C}$ y que se hacen más pronunciadas a altas temperaturas. Simultáneamente, la banda correspondiente a la fase gas de CO $\left(2200-2100 \mathrm{~cm}^{-1}\right)$ disminuye. En estas mismas regiones, aparecen las posibles bandas correspondientes a las vibraciones del CO sobre el oro [92,200] y sobre la plata [182,201-203], lo que dificulta la asignación de las bandas debido a su solapamiento. 

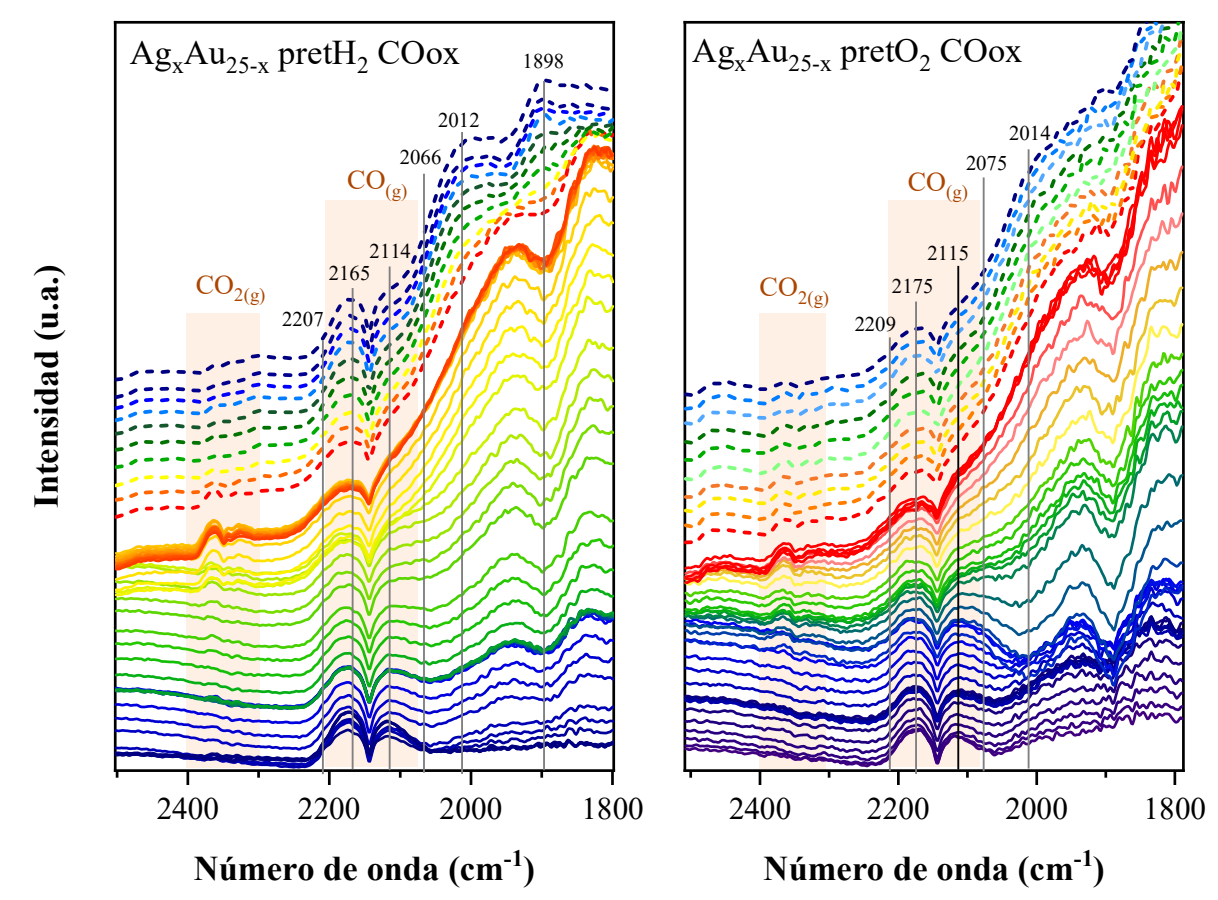

Figura 67. Análisis DRIFTS in situ del catalizador $\operatorname{Ag}_{\mathrm{x}} \mathrm{Au}_{25-\mathrm{x}} / \mathrm{ITQ}$-2 después de los distintos pretratamientos (pretH $\mathrm{y}_{2}$ pretO$_{2}$ ), y durante la oxidación de $\mathrm{CO}$, desde temperatura ambiente (azul) hasta $400{ }^{\circ} \mathrm{C}$ (rojo). Enfriamiento en condiciones de reacción (líneas discontinuas) desde $400{ }^{\circ} \mathrm{C}$ (rojo) hasta temperatura ambiente (azul).

La evolución de los espectros durante la reacción de oxidación de CO es bastante similar tras los dos pretratamientos empleados con la muestra. En ambos casos, se observa la aparición de una pequeña banda sobre 2207-2209 $\mathrm{cm}^{-1}$, la cual se corresponde con las vibraciones $\mathrm{CO}-\mathrm{Ag}^{+}\left(\sim 2160-2190 \mathrm{~cm}^{-1}\right)$ [182,201-203]. Estas mismas bandas también pueden ser debidas a las vibraciones $\mathrm{CO}-\mathrm{Au}^{+}$ $\left(\sim 2175 \mathrm{~cm}^{-1}\right)$ desplazadas hacia valores más altos de número de onda debido a la interacción Ag-Au. Esto indicaría la formación de aleaciones Ag-Au [202,204], en concordancia con los resultados de UV-Vis DRS y de TPR. Este proceso de aleación se inicia cuando, al aumentar la temperatura de la reacción, los ligandos son destruidos parcialmente. Tras esto, los átomos de plata que están localizados en el núcleo de los nanoclusters y rodeados por los oligómeros $[\mathrm{S}(\mathrm{R})-\mathrm{Au}]_{2}-\mathrm{S}(\mathrm{R})$, 
se alean con el oro, formándose nanopartículas de oro enriquecidas con átomos de plata en su superficie [205-207].

Por otro lado, también se observa que, aunque la evolución de los espectros tras los diferentes pretratamientos es bastante similar, aparecen diferencias entre ellos, principalmente en la banda situada alrededor de $2070 \mathrm{~cm}^{-1}$, la cual se corresponde con las vibraciones $\mathrm{CO}-\mathrm{Au}^{0}$. Esta banda es pronunciada en el catalizador pretratado con oxígeno, sobre todo a temperaturas alrededor de los $250{ }^{\circ} \mathrm{C}$ (espectro verde de la Figura 67), mientras que en el caso del catalizador pretratado con hidrógeno dicha banda es casi imperceptible. Esto indicaría que en el catalizador pretratado con $\mathrm{H}_{2}$, el $\mathrm{CO}$ se adsorbe sobre los centros $\mathrm{Ag}-\mathrm{Au}$, mientras que, en el catalizador oxidado, lo hace tanto sobre estos centros como sobre los centros $\mathrm{Au}^{0}$.

Se realizaron también estudios DRIFTS in situ con los catalizadores preparados con nanoclusters monometálicos de oro y de plata. En la Figura 68 se muestran los espectros obtenidos durante la oxidación de $\mathrm{CO}$ con los catalizadores $\mathrm{Au}_{25} / \mathrm{ITQ}-2$ y Ag $25 / \mathrm{ITQ}-2$ tras ser pretratados con hidrógeno. 

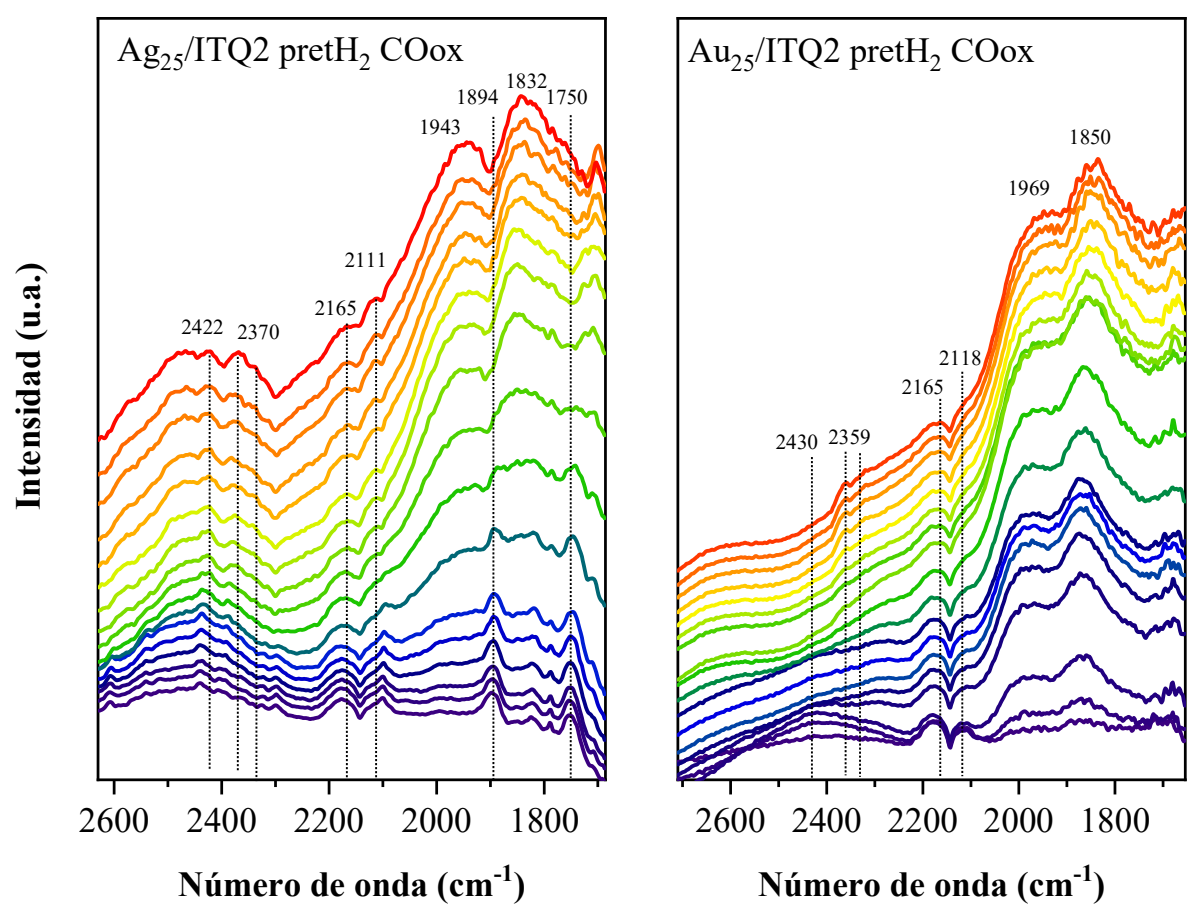

Figura 68. DRIFTS in situ de los catalizadores Au $25 /$ ITQ-2 (derecha) y Ag25/ITQ-2 (izquierda) pretratados con $\mathrm{H}_{2}$ durante la oxidación de $\mathrm{CO}$, desde temperatura ambiente (azul) hasta $400{ }^{\circ} \mathrm{C}$ (rojo).

Comparando los espectros de los nanoclusters bimetálicos (Figura 67) con los de los nanocluster monometálicos (Figura 68), se observa que las principales bandas características del CO adsorbido en la plata $\left(2160-2190 \mathrm{~cm}^{-1}\right)$ y en el oro (2120$2110 \mathrm{~cm}^{-1}$ ) están presentes en los nanoclusters de $\mathrm{Ag}$ y de $\mathrm{Au}$, respectivamente. Sin embargo, estas bandas no se encuentran en el espectro de los nanoclusters bimetálicos, indicando claramente que los centros de adsorción de $\mathrm{CO}$ en los catalizadores con nanoclusters bimetálicos son diferentes a los de los nanoclusters monometálicos. La presencia de diferentes centros activos se puede relacionar con la distinta actividad catalítica de los catalizadores mono- y bimetálicos (Figura 59). 


\section{- XAS in situ:}

Estos catalizadores también fueron analizados por XAS in situ en el sincrotrón ALBA, con el fin de seguir la evolución de los nanoclusters durante el pretratamiento y durante la reacción de oxidación catalítica de CO. En la Figura 69 se muestran los espectros XANES obtenidos.

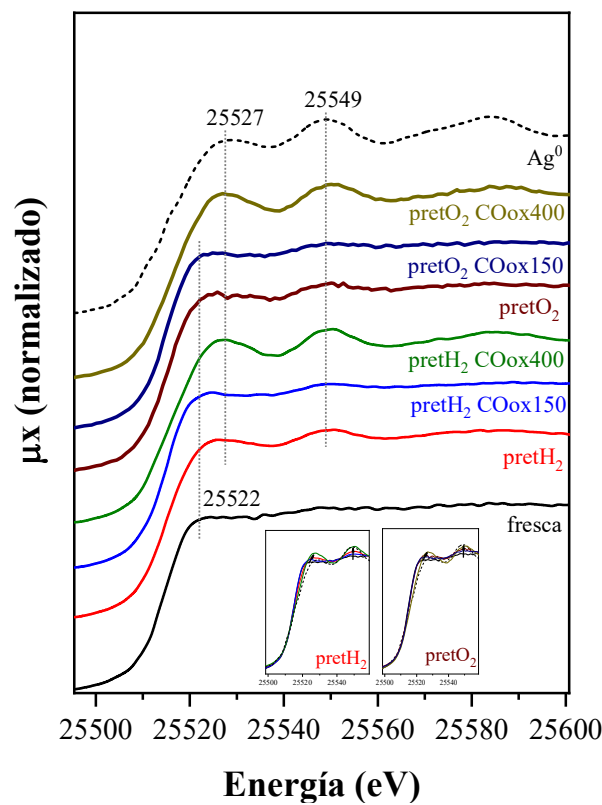

Figura 69. Espectro XANES normalizado en el borde $\mathrm{K}$ de la plata del catalizador $\mathbf{A g}_{\mathrm{x}} \mathrm{Au} 25$ х/ITQ-2 después de los pretratamientos y durante la oxidación de CO.

El análisis de los espectros se hizo sólo en el borde de la plata, pues los datos obtenidos en el borde del oro no fueron lo suficientemente precisos debido a problemas experimentales durante las medidas. Por ello, esta discusión se centra en lo que ocurre con los átomos de Ag presentes en el catalizador bimetálico.

El análisis de los espectros muestra, en primer lugar, la presencia de un borde de absorción ligeramente más intenso en el catalizador sin pretratar (fresca) que en 
el patrón de referencia de la plata metálica. Además, se observa un estrechamiento de las oscilaciones después del salto de absorción. Esto mismo se observaba también con el catalizador monometálico $\mathrm{Ag}_{25} / \mathrm{ITQ}$-2 (Figura 49), y se atribuía a la formación de los nanoclusters de Ag [187,208,209], en concreto, a la presencia de enlaces Ag-S [209-212]. Esto implicaría la existencia de especies de plata parcialmente cargadas.

Los pretratamientos de los nanoclusters bimetálicos a $150{ }^{\circ} \mathrm{C}$ con $\mathrm{O}_{2}$ o $\mathrm{H}_{2}$ no parecen afectar a la distribución de la plata en la estructura inicial del nanocluster, ya que los espectros XANES de las muestras, tras ambos pretratamientos, son muy similares. Sin embargo, durante la reacción de oxidación de CO sí que se observan cambios significativos. Como puede observarse, se produce un desplazamiento del espectro a energías mayores, así como la aparición de picos más definidos sobre $25.549 \mathrm{keV}$, obteniendo espectros más similares al del patrón de referencia de la plata metálica. Esto ocurre tanto en la muestra pretratada con oxígeno como en la pretratada con hidrógeno, e indica que se ha producido un aumento del carácter metálico de los nanoclusters durante el transcurso de la reacción. Este hecho puede ser relacionado con la eliminación completa de los ligandos tiolatos, que se produce a partir de $\operatorname{los} 150{ }^{\circ} \mathrm{C}$ [91,92], al igual que ocurría con los nanoclusters monometálicos de plata. La aleación entre el oro y la plata en el transcurso de la reacción a $400{ }^{\circ} \mathrm{C}$ se hace evidente por la presencia de oscilaciones desplazadas en las funciones $\chi(\mathrm{k})$ del catalizador bimetálico en comparación con la referencia de la plata metálica (Figura 70). Estos desplazamientos en el espacio-k, así como el comportamiento antifase (oscilaciones a $\sim 6 \AA^{-1}$ ), indican claramente la aleación entre los metales [213]. 


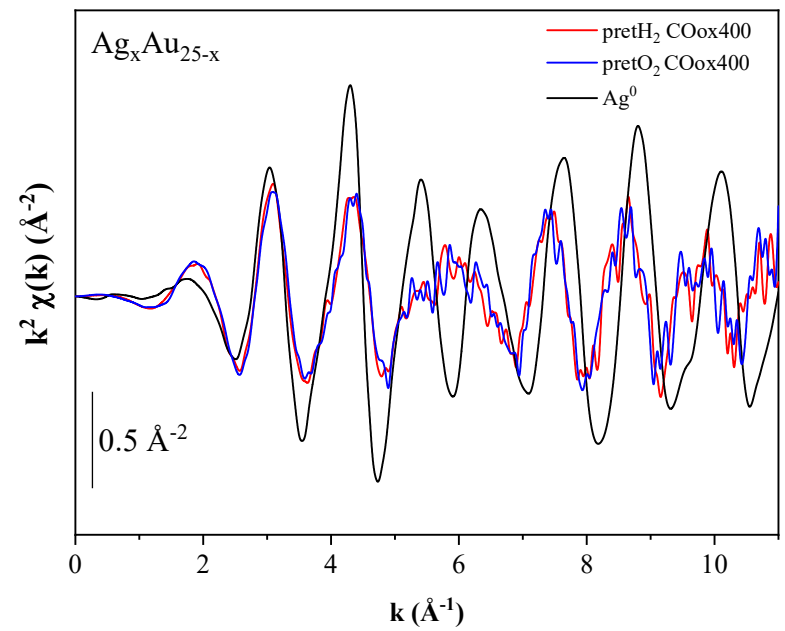

Figura 70. Función $\chi(k)$ con peso $\mathrm{k} 2 \mathrm{de} \mathrm{Ag}^{0}$ (referencia) y de las muestras $\operatorname{Ag}_{\mathrm{x}} \mathrm{Au}_{25-\mathrm{x}} / \mathrm{ITQ2}$ pretratadas con $\mathrm{H}_{2}$ y con $\mathrm{O}_{2}$ y durante la oxidación catalítica de $\mathrm{CO}$ a $400{ }^{\circ} \mathrm{C}$.

Una información más detallada del entorno de los átomos y de la estructura de los nanoclusters se puede obtener por el estudio EXAFS de las muestras. La Figura 71 y la Tabla 25 muestran los resultados del análisis EXAFS del catalizador bimetálico $\mathrm{Ag}_{\mathrm{x}} \mathrm{Au}_{25-\mathrm{x}} / \mathrm{ITQ}$-2.

El análisis de los resultados muestra que, tras ambos pretratamientos, se forman enlaces $\mathrm{Ag}-\mathrm{Au}$ y enlaces $\mathrm{Ag}-\mathrm{S}$, mientras que no se observa ningún enlace $\mathrm{Ag}$ $\mathrm{Ag}$, lo que indica que los átomos de plata se encuentran dispersos en la estructura del nanocluster. Esta distribución metálica inicial se ve modificada durante la oxidación de $\mathrm{CO}$, ya que después de reacción, los enlaces Ag-S desaparecen y aparecen enlaces Ag-Ag (Tabla 25). Además, se observa que independientemente del pretratamiento empleado, los catalizadores después de la reacción presentan una configuración superficial muy similar con valores casi idénticos del número de coordinación Ag-Au, así como de las distancias de enlace (Tabla 25).

Todo lo anterior indica que las condiciones de reacción conducen a una evolución similar de la distribución atómica de los nanoclusters bimetálicos, dando lugar a 
la formación de aleaciones $\mathrm{Ag}-\mathrm{Au}$, aunque aún están presentes algunos centros Ag-Ag.
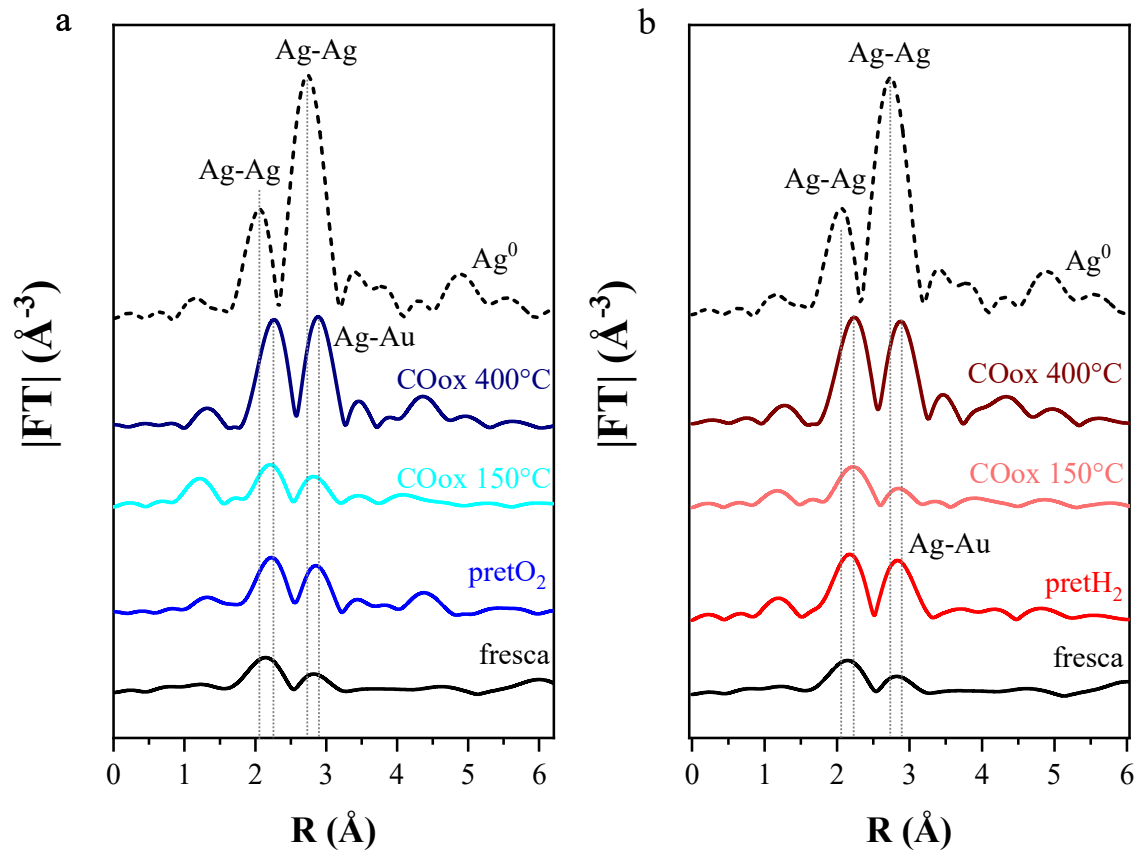

Figura 71. Transformada de Fourier (FT) de la señal EXAFS del catalizador $\mathbf{A g}_{\mathrm{x}} \mathrm{Au}_{25-\mathrm{x}} / \mathbf{I T Q}$ 2 tras el pretratamiento con $\mathrm{O}_{2}$ (a) y con $\mathrm{H}_{2}$ (b). 
Tabla 25. Resumen de los parámetros optimizados de los datos de EXAFS del catalizador $\mathbf{A g}_{\mathrm{x}} \mathrm{Au}_{25-\mathrm{x}} /$ ITQ-2 $^{\mathrm{a}}$.

\begin{tabular}{|c|c|c|c|c|c|c|}
\hline Muestra & Enlace & $\mathbf{C N}$ & $\mathbf{R}(\AA)$ & $\sigma^{2}\left(\AA^{2}\right)$ & $\begin{array}{l}\Delta E_{0} \\
(e V)\end{array}$ & $\mathbf{R}_{\text {factor }}$ \\
\hline \multirow{2}{*}{$\mathbf{A g}^{0}$} & $\mathrm{Ag}-\mathrm{Ag}$ & 12 & & $0.0096 \pm$ & $1.9 \pm$ & 0.0036 \\
\hline & & & 0.004 & 0.0006 & 0.4 & \\
\hline \multirow{4}{*}{ Fresca $^{b}$} & Ag-S & $0.5 \pm$ & $2.484 \pm$ & \multirow{4}{*}{$0.0094^{b}$} & & \multirow{4}{*}{0.0103} \\
\hline & & 0.1 & 0.037 & & $-0.8 \pm$ & \\
\hline & $\mathrm{Ag}-\mathrm{Au}$ & $2.5 \pm$ & $2.802 \pm$ & & 1.8 & \\
\hline & & 0.4 & 0.024 & & & \\
\hline \multirow{4}{*}{ pretO$_{2}$} & Ag-S & $0.6 \pm$ & $2.570 \pm$ & \multirow{4}{*}{$0.0094^{\mathrm{b}}$} & $-0.7 \pm$ & \multirow[t]{4}{*}{0.0421} \\
\hline & & 0.4 & 0.075 & & 2.1 & \\
\hline & $\mathrm{Ag}-\mathrm{Au}$ & $5.0 \pm$ & $2.800 \pm$ & & & \\
\hline & & 0.9 & 0.023 & & & \\
\hline \multirow{4}{*}{$\operatorname{pretO}_{2} \mathrm{COox} 400$} & $\mathrm{Ag}-\mathrm{Ag}$ & $2.0 \pm$ & $2.868 \pm$ & \multirow{4}{*}{$\begin{array}{c}0.0107 \pm \\
0.0074\end{array}$} & $2.5 \pm$ & \multirow[t]{4}{*}{0.0060} \\
\hline & & 0.3 & 0.025 & & 0.6 & \\
\hline & $\mathrm{Ag}-\mathrm{Au}$ & $7.1 \pm$ & $2.858 \pm$ & & & \\
\hline & & 0.7 & 0.008 & & & \\
\hline \multirow{4}{*}{$\operatorname{pretH}_{2}$} & Ag-S & $0.9 \pm$ & $2.545 \pm$ & \multirow[t]{4}{*}{$0.0094^{b}$} & $-1.3 \pm$ & \multirow[t]{4}{*}{0.0644} \\
\hline & & 0.4 & 0.046 & & 2.2 & \\
\hline & $\mathrm{Ag}-\mathrm{Au}$ & $5.6 \pm$ & $2.786 \pm$ & & & \\
\hline & & 0.9 & 0.020 & & & \\
\hline \multirow{3}{*}{$\operatorname{pretH}_{2} \mathrm{COox} 400$} & $\mathrm{Ag}-\mathrm{Ag}$ & $2.1 \pm$ & $2.864 \pm$ & \multirow{3}{*}{$\begin{array}{c}0.0090 \pm \\
0.0017\end{array}$} & $2.1 \pm$ & \multirow[t]{3}{*}{0.0037} \\
\hline & & 0.3 & 0.022 & & 0.5 & \\
\hline & $\mathrm{Ag}-\mathrm{Au}$ & $\begin{array}{c}7.2 \pm \\
0.7\end{array}$ & $\begin{array}{c}2.858 \pm \\
0.008\end{array}$ & & & \\
\hline
\end{tabular}

$\mathrm{CN}=$ número de coordinación; $\mathrm{R}=$ distancia interatómica; $\sigma^{2}=$ factor de desorden térmico $y$ estático; $\Delta \mathrm{E}_{0}=$ variación de potencial; $R_{\text {factor }}=$ error del ajuste

${ }^{\text {a }}$ Ajuste realizado en $\Delta \mathrm{R}=\mathbf{1 . 6 - 3 . 2} \AA$ de los parámetros de la señal EXAFS en el intervalo $\Delta \mathrm{k}=\mathbf{2 . 0 - 1 0 . 0} \AA^{-1} .{ }^{\mathrm{b}} \sigma 2$ fue fijado para ser igual en las muestras pretratadas, lo que disminuye los valores de error. 


\subsubsection{Evolución dinámica de los nanoclusters $\operatorname{Ag}_{x} A u_{25-x}$ durante la reacción de oxidación catalítica de $\mathrm{CO}$}

Los resultados discutidos en los dos apartados previos han permitido determinar la evolución de los nanoclusters bimetálicos durante la reacción de oxidación catalítica de $\mathrm{CO}$ y durante los diferentes pretratamientos, indicando que, tal y como se vio con el estudio de los catalizadores de plata, la reacción de oxidación de $\mathrm{CO}$ puede ser empleada como reacción test para analizar la naturaleza de las especies catalíticas.

Los principales resultados obtenidos en el apartado 5.2.1, en el que se discutía la actividad catalítica de estos materiales fueron: i) los nanoclusters bimetálicos soportados sobre la zeolita ITQ-2 tienen una mejor actividad catalítica que los nanoclusters monometálicos (Figura 59); ii) se obtiene una actividad diferente en función del pretratamiento empleado (Figura 58); y iii) estos catalizadores son estables y activos durante varias reacciones consecutivas (Figura 61).

Estos resultados pueden relacionarse con los estudios de caracterización discutidos en el apartado 5.2.2. Así, la mayor actividad de los catalizadores bimetálicos, si se compara con los monometálicos, se puede explicar por la presencia de centros diferentes en ambos catalizadores. Esto ha sido evidenciado por diversas técnicas de caracterización. Los experimentos DRIFTS in situ sugieren que los centros de adsorción de $\mathrm{CO}$ en los catalizadores bimetálicos son nanopartículas $\mathrm{Ag}-\mathrm{Au}$ aleadas. Esto fue confirmado mediante los análisis EXAFS in situ, los cuales mostraron también la presencia de enlaces Ag-Au en las muestras pretratadas. Los resultados de TPR también muestran la existencia de una fuerte interacción entre el oro y la plata en los nanoclusters bimetálicos al observarse un desplazamiento en los picos de la plata a una menor temperatura de reducción. Los estudios de XPS y de microscopía electrónica también han confirmado la formación de aleaciones homogéneas de Ag-Au sin encapsulación de los nanoclusters. Además, en los espectros de XPS no existe evidencia de la formación de óxidos de plata, por lo que se puede descartar la formación de 
interacciones metal-oxígeno en los catalizadores, a diferencia de lo descrito por otros autores [214-216].

Todos estos resultados muestras que los centros $\mathrm{Ag}-\mathrm{Au}$ son los centros

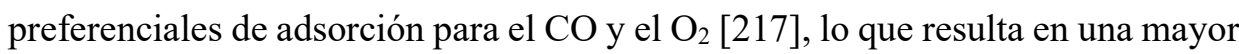
actividad catalítica de los catalizadores bimetálicos en comparación con los nanoclusters monometálicos soportados sobre la zeolita ITQ-2.

Los resultados también ponen en evidencia que los diferentes tipos de pretratamiento afectan a la evolución de la estructura de los nanoclusters bimetálicos, lo que se refleja en diferentes actividades catalíticas. Estos cambios en la estructura se deben a diferentes disposiciones de los átomos de plata en los nanoclusters en función del pretratamiento empleado. Se ha descrito que una atmósfera reductiva provoca la migración de la plata hacia la superficie de las nanopartículas, lo que no ocurre con un pretratamiento oxidativo [217]. Esto resulta en un mayor número de centros $\mathrm{Ag}-\mathrm{Au}$ en la superficie de los nanoclusters, tal y como se observó en los espectros de XPS, los cuales estarían accesibles para interaccionar con los reactivos. Estudios previos han mostrado que la coadsorción del $\mathrm{CO}$ y del $\mathrm{O}_{2}$ en centros $\mathrm{Ag}$-Au es más fuerte que en centros monometálicos de Au o Ag [217,218]. Por lo tanto, el mayor número de centros bimetálicos accesibles formados durante el pretratamiento reductivo darían lugar a una mayor actividad, lo que es consistente con los resultados catalíticos obtenidos a bajas temperaturas, en donde el catalizador bimetálico pretratado con $\mathrm{H}_{2}$ tiene una actividad mayor que el pretratado con $\mathrm{O}_{2}$. Los experimentos in situ DRIFTS confirman esta hipótesis ya que muestran que los nanoclusters bimetálicos pretratados con $\mathrm{O}_{2}$ forman adsorbatos $\mathrm{CO}-\mathrm{Au}^{0}$ a temperatura de reacción media $\left(250^{\circ} \mathrm{C}\right)$, que no fueron observados en la muestra pretratada con $\mathrm{H}_{2}$, indicando que la adsorción de $\mathrm{CO}$ en este catalizador se produce en centros $\mathrm{Ag}-\mathrm{Au}$, resultando en una mayor actividad catalítica.

En cuanto a la estabilidad de los catalizadores en reacciones sucesivas, se ha observado que la actividad catalítica de los nanoclusters bimetálicos pretratados con $\mathrm{H}_{2}$ fue la misma tras tres reacciones. Sin embargo, el catalizador pretratado 
con oxígeno mostró una actividad mayor después de una primera reacción, obteniendo en la segunda reacción los mismos resultados catalíticos que los obtenidos con el catalizador tras el pretratamiento con $\mathrm{H}_{2}$, y manteniendo la actividad catalítica en la tercera reacción. Estos resultados se pueden explicar con los resultados obtenidos en los estudios EXAFS de los catalizadores después de los dos pretratamientos y después de la reacción (pretH ${ }_{2} \mathrm{COox} 400$ y pretO $_{2} \mathrm{COox} 400$ ). En la Tabla 25 se observa que se obtienen los mismos números de coordinación Ag-Au después de la oxidación de CO para ambos catalizadores (7.1 y 7.2), aunque hayan sido pretratados previamente en atmósferas distintas. Esto indica una evolución dinámica del catalizador durante la reacción, que da lugar a la completa eliminación de los ligandos durante la misma, y a la formación de nanopartículas Ag-Au accesibles, independientemente del pretratamiento aplicado previamente.

\subsubsection{Conclusiones parciales}

La principal conclusión de este apartado es que los nanoclusters bimetálicos soportados sobre la zeolita ITQ-2 son activos para la oxidación del CO, y que los mismos evolucionan durante el pretratamiento y durante la reacción. Esta evolución pasa por la eliminación de los ligandos y la formación de centros bimetálicos $\mathrm{Ag}-\mathrm{Au}$, que presentan una mayor actividad catalítica en la oxidación de CO que los centros monometálicos.

Se observa que, un pretratamiento reductivo produce un mayor grado de aleación Ag-Au que un pretratamiento oxidativo. Esto, a su vez, facilita la coadsorción del $\mathrm{CO}$ y del $\mathrm{O}_{2}$, lo que explica la mayor actividad catalítica a bajas temperaturas observada para el catalizador pretratado con $\mathrm{H}_{2}$. No obstante, a pesar de estas diferencias iniciales, los nanoclusters activados con los diferentes pretratamientos evolucionan de la misma manera y forman especies similares durante la reacción. Estas especies son nanopartículas Ag-Au aleadas, las cuales son muy activas, apareciendo también, en menor medida, algunos centros Ag-Ag, cuya actividad es mucho menor. 
Los resultados han mostrado que estos catalizadores son muy estables pues, después de varias reacciones consecutivas, se obtiene la misma actividad catalítica, independientemente del pretratamiento inicial, lo que indica que las especies formadas durante la reacción son muy estables, previniendo la desactivación del catalizador.

En definitiva, los resultados obtenidos han mostrado que la reacción de oxidación catalítica de $\mathrm{CO}$ es una herramienta muy útil para analizar la evolución de los nanoclusters metálicos, lo cual es un factor fundamental en el diseño de catalizadores activos. 

6. SEMIHIDROGENACIÓN DE ALQUINOS 

Este capítulo de la tesis estudia la reacción de hidrogenación de alquinos a alquenos empleando catalizadores basados en nanoclusters de oro. En concreto, se ha estudiado la hidrogenación del fenilacetileno en presencia de piridina para obtener el alqueno correspondiente, el estireno, evitando la producción del alcano (etilbenceno), el cual carece de interés comercial. Para ello, los nanoclusters de oro han sido soportados sobre diferentes materiales con distintas propiedades ácido-base.

\subsection{Caracterización de los catalizadores}

Los catalizadores empleados en esta reacción se han preparado soportando nanoclusters de oro sobre dos óxidos metálicos $\left(\mathrm{MgO}\right.$ y $\left.\mathrm{Al}_{2} \mathrm{O}_{3}\right)$ y sobre una hidrotalcita (HT) con relación $\mathrm{Mg} / \mathrm{Al}$ de 4 .

El $\mathrm{MgO}$ ha sido sintetizado en el laboratorio para obtener un óxido con una elevada área superficial; la alúmina empleada era comercial, suministrada por abcr $\mathrm{GmbH}$; y la hidrotalcita de $\mathrm{Mg}$ y $\mathrm{Al}$ también fue sintetizada en el laboratorio por el método de coprecipitación. Las propiedades texturales de estos soportes empleados se muestran en la Tabla 26.

Tabla 26. Propiedades texturales de los materiales empleados como soportes.

\begin{tabular}{cc}
\hline Soporte & $\begin{array}{c}\text { Área superficial BET } \\
\left(\mathbf{m}^{2} \cdot \mathbf{g}^{-1}\right)\end{array}$ \\
\hline $\begin{array}{c}\text { Hidrotalcita } \\
(\mathrm{Mg} / \mathrm{Al}=4)\end{array}$ & 224 \\
\hline $\mathrm{MgO}$ _síntesis & 171 \\
\hline$\gamma-\mathrm{Al}_{2} \mathrm{O}_{3}$ & 212 \\
\hline
\end{tabular}

Estos materiales fueron caracterizados por difracción de rayos X (Figura 72). Tal y como puede observarse, los difractogramas de rayos $\mathrm{X}$ de los distintos soportes muestran los picos característicos de cada uno de los materiales: picos asignados 
al $\mathrm{MgO}$ a $2 \theta=37.0,43,62.9,74.4$ y $78.5^{\circ}$; los picos asignados a la fase de la $\gamma$ $\mathrm{Al}_{2} \mathrm{O}_{3}$ a $2 \theta=37.5,39.5,45.9,61.0$ y $66.9^{\circ}$; y los picos de la hidrotalcita (HT) a $2 \theta=11.2,22.7,34.4,38.4,45.5,46.7,60.1,61.8$ y $65.3^{\circ}$.

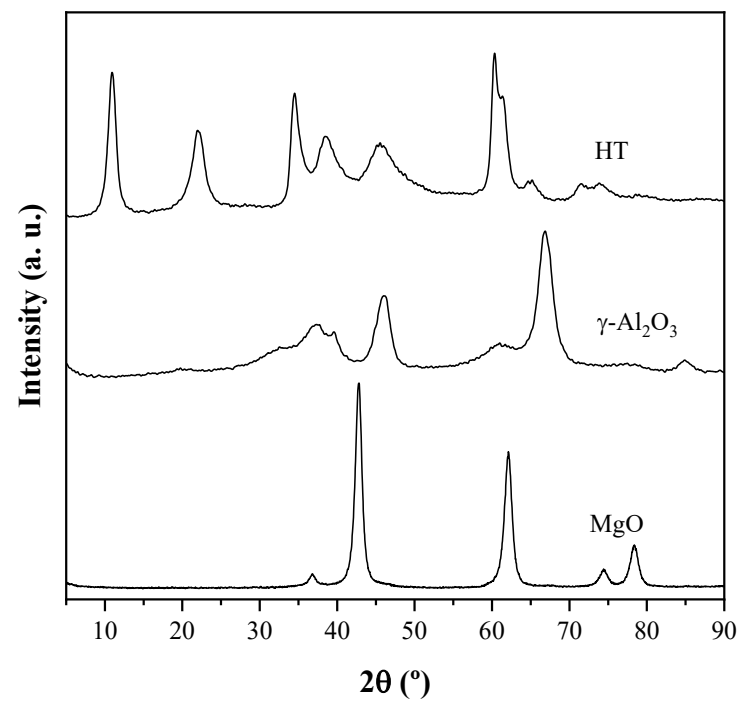

Figura 72. Difractograma de rayos X de los soportes empleados.

Los nanoclusters empleados fueron nanoclusters de oro de dos tamaños diferentes (25 y 11 átomos de oro) y con distintos ligandos (tiol y fosfina), cuyas composiciones eran: $\mathrm{Au}_{25}\left(\mathrm{SC}_{2} \mathrm{H}_{4} \mathrm{Ph}\right)_{18},\left(\mathrm{Au}_{25}\right.$ para simplificar $)$ y $\mathrm{Au}_{11}\left(\mathrm{PPh}_{3}\right)_{7} \mathrm{Br}_{3}$, $\left(\mathrm{Au}_{11}\right)$. Los espectros $\mathrm{UV}-\mathrm{V}$ is de los nanoclusters puros disueltos en $\mathrm{CH}_{2} \mathrm{Cl}_{2}$ (Figura 73) muestran las bandas características de estos nanoclusters (a $422 \mathrm{~nm}$ para los nanoclusters $\mathrm{Au}_{11}$ y a 399, 447 y $686 \mathrm{~nm}$ para los nanoclusters $\mathrm{Au}_{25}$ ), lo que confirma su correcta síntesis [91,130]. 


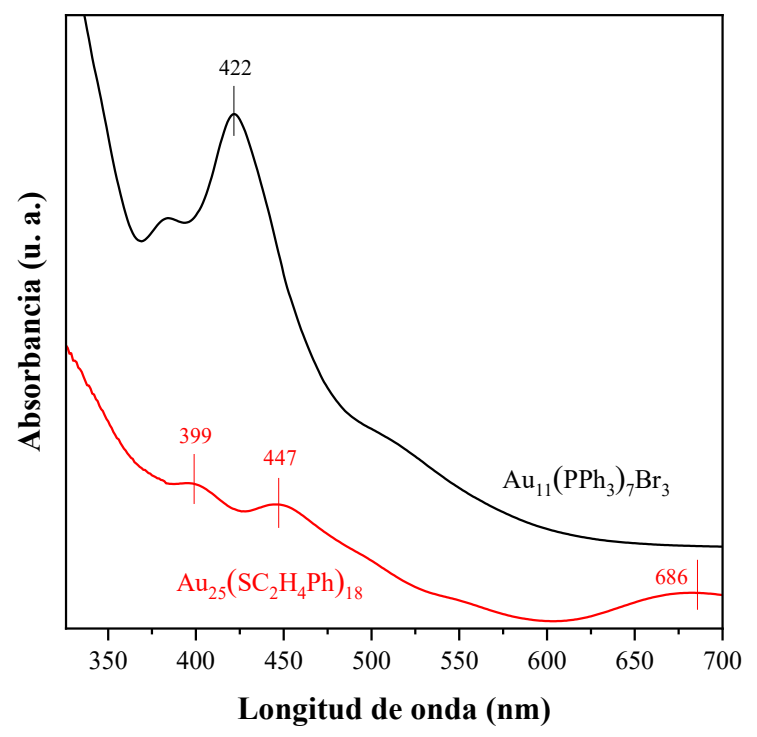

Figura 73. Espectros UV-Vis de los nanoclusters sintetizados.

Asimismo, los catalizadores con nanoclusters de 11 átomos de oro que contienen ligando de tipo fosfinas y soportados sobre $\mathrm{MgO}$ y $\mathrm{Al}_{2} \mathrm{O}_{3}$ fueron analizados por resonancia magnética nuclear de ${ }^{31} \mathrm{P}$ (Figura 74). Los espectros RMN de ${ }^{31} \mathrm{P}$ muestran una señal alrededor de $50 \mathrm{ppm}$ en ambos soportes, la cual es característica de este tipo de nanoclusters [219], indicando que los nanoclusters se han sintetizado correctamente y que mantienen su estructura tras el soporte sobre ambos óxidos. 


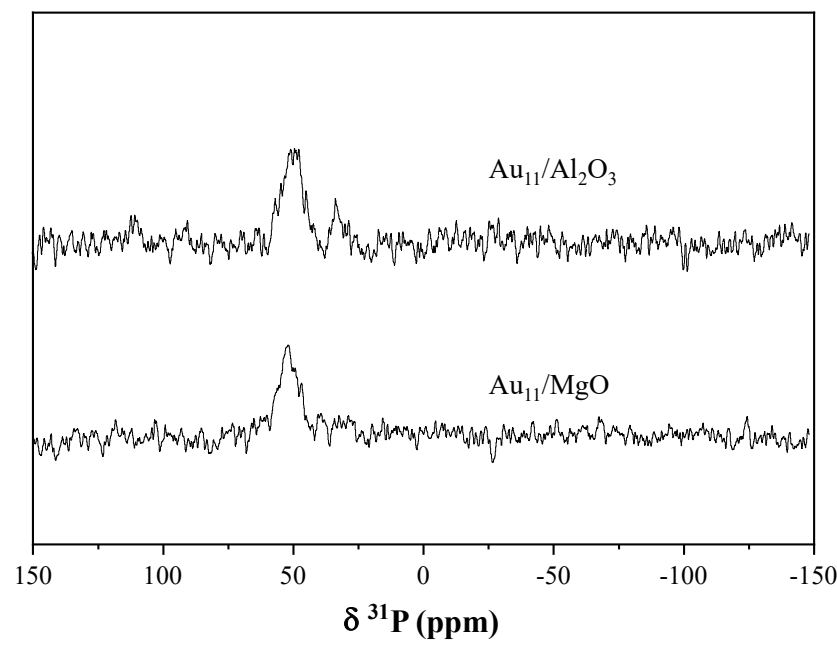

Figura 74. Espectros de RMN de ${ }^{31} \mathrm{P}$ de los catalizadores $\mathrm{Au} \mathrm{u}_{11} / \mathrm{MgO}$ y $\mathrm{Au}_{11} / \mathrm{Al}_{2} \mathrm{O}_{3}$.

El contenido metálico de los catalizadores y sus propiedades texturales se muestran en la Tabla 27. Todos los catalizadores presentan un área superficial superior a $100 \mathrm{~m}^{2} \cdot \mathrm{g}^{-1}$, siendo ésta ligeramente inferior a la de los soportes originales (Tabla 26).

Tabla 27. Propiedades físico-químicas de los catalizadores.

\begin{tabular}{ccc}
\hline Catalizador & $\begin{array}{c}\text { \% Au } \\
\text { (en peso) }\end{array}$ & $\begin{array}{c}\text { Área superficial } \\
\left(\mathbf{m}^{\mathbf{2}} \cdot \mathbf{g}^{-\mathbf{1}}\right)\end{array}$ \\
\hline $\mathbf{A u} 25 / \mathbf{H T}$ & 0.06 & 198 \\
\hline $\mathbf{A u} \mathbf{u}_{25} / \mathbf{M g O}$ & 0.19 & 121 \\
\hline $\mathbf{A u} \mathbf{u}_{25} / \mathbf{A l}_{2} \mathbf{O}_{3}$ & 0.17 & 202 \\
\hline $\mathbf{A u} \mathbf{u}_{11} / \mathbf{M g O}$ & 0.30 & 107 \\
\hline $\mathbf{A u} \mathbf{u}_{11} / \mathbf{A l}_{2} \mathbf{O}_{3}$ & 0.44 & 199 \\
\hline
\end{tabular}




\subsection{Resultados catalíticos}

Como ya se ha mencionado, el producto de interés en esta reacción es el alqueno resultante de la semihidrogenación del alquino, evitando la producción del alcano correspondiente. Para ello, se han estudiado distintas variables que pueden afectar al desarrollo de la reacción, así como a la selectividad. Estas variables son: propiedades ácido/base de los soportes, tamaño de nanoclusters, ligandos de los nanoclusters y condiciones de pretratamiento.

En primer lugar, se estudió la influencia en la actividad catalítica de las propiedades ácido/base del soporte, así como del número de átomos de oro en los nanoclusters. Para ello, se estudió la actividad de los catalizadores preparados con los dos tipos de nanoclusters, de 11 o 25 átomos de oro $\left(\mathrm{Au}_{25} \mathrm{y} \mathrm{Au}_{11}\right)$, soportados sobre $\mathrm{MgO}$ y sobre $\mathrm{Al}_{2} \mathrm{O}_{3}$ La Figura 75 muestra la actividad catalítica de estos catalizadores en la hidrogenación del fenilacetileno en presencia de piridina, y la selectividad a estireno (producto deseado) y a etilbenceno (subproducto).

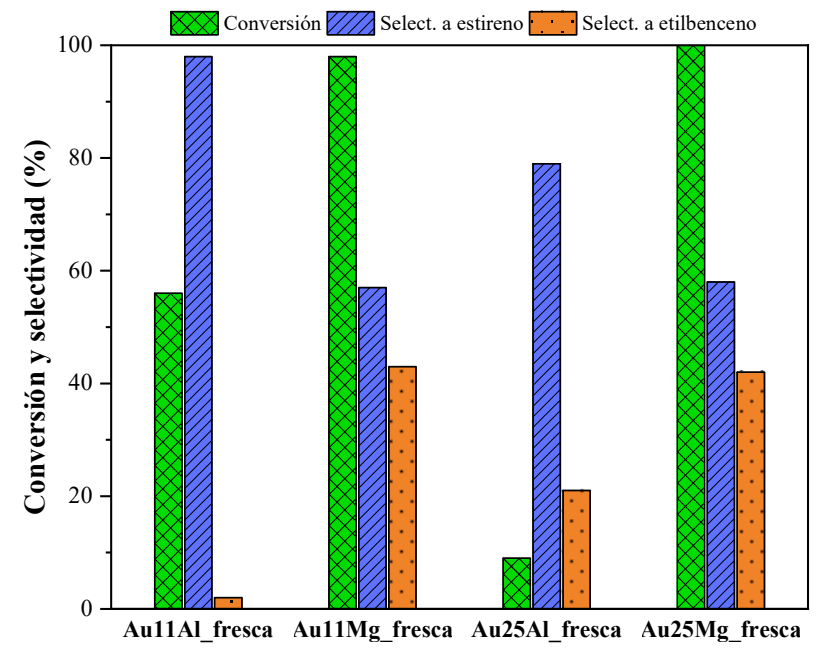

Figura 75. Influencia del tipo de soporte y del tamaño de los nanoclusters en la actividad y selectividad. (0.1 g. de catalizador, $0.1 \mathrm{mmol}$ de fenilacetileno y $0.2 \mathrm{mmol}$ de piridina, 20 horas, $100{ }^{\circ} \mathrm{C}, 10$ bar de $\mathrm{H}_{2}$ ). 
Los resultados muestran que hay un claro efecto del soporte sobre la actividad catalítica, siendo los catalizadores soportados sobre $\mathrm{MgO}$ los que presentan una mayor actividad. Como puede observarse, los dos catalizadores preparados sobre $\mathrm{MgO}$ dan lugar a una conversión casi completa del fenilacetileno, mientras que los catalizadores soportados sobre $\mathrm{Al}_{2} \mathrm{O}_{3}$ presentan una menor actividad.

Por otra parte, en el caso de los catalizadores de $\mathrm{MgO}$, no se observan diferencias en la conversión final obtenida, independientemente del tamaño de nanoclusters, mientras que en el caso de los catalizadores de alúmina sí que se observa distinta actividad en función del número de átomos de oro. Así, con el catalizador $\mathrm{Au}_{11} / \mathrm{Al}_{2} \mathrm{O}_{3}$ se obtiene una conversión de casi el $60 \%$ mientras que con el catalizador $\mathrm{Au}_{25} / \mathrm{Al}_{2} \mathrm{O}_{3}$ sólo se alcanza un $9 \%$ de conversión. Estos resultados parecen indicar que existe una influencia de la acidez/basicidad del soporte y del tipo de nanoclusters en la actividad de los catalizadores.

No obstante, los nanoclusters no sólo se diferencian en el número de átomos de oro que contienen, sino que también difieren en el tipo de ligando con el que han sido sintetizados. Los nanoclusters $\mathrm{Au}_{25}$ tienen un ligando tiolato $\left(\mathrm{SC}_{2} \mathrm{H}_{4} \mathrm{Ph}\right)_{18}$, mientras que los nanoclusters $\mathrm{Au}_{11}$ tienen un ligando de tipo fosfina $\left(\mathrm{PPh}_{3}\right)$. En este sentido, Wan et al. [220] encontraron recientemente diferencias en la actividad obtenida para la semihidrogenación de alquinos en función del tipo de ligando que presentan los nanoclusters de oro $\left[\mathrm{Au}_{38}\left(\mathrm{~L}_{20} \mathrm{Ph}_{3} \mathrm{P}_{4}\right]^{2+}\right.$, según el ligando fuese un alquinilo o un tiolato soportados sobre $\mathrm{TiO}_{2}$. En este estudio se mostró que, al igual que con los catalizadores de alúmina mostrados en la Figura 75, los nanoclusters $\mathrm{Au}_{38}$ con ligandos tiolatos exhibieron una menor actividad que los nanoclusters con ligandos alquinilos. Sin embargo, resultados diferentes han sido descritos por Jin et al. [123], quienes no apreciaron influencia alguna del tipo de ligando en los catalizadores preparados con nanoclusters $\mathrm{Au}_{25}\left(\mathrm{SCH}_{4} \mathrm{Ph}\right)_{18}$ y $\mathrm{Au}_{25}\left(\mathrm{PPh}_{3}\right)_{10}(\mathrm{CCPh})_{5} \mathrm{Br}_{2}$ sobre $\mathrm{TiO}_{2}$, como ocurre con las muestras de $\mathrm{MgO}$ mostradas en la Figura 75.

Además de esto, ha de tenerse en cuenta que los ligandos pueden ser parcialmente degradados durante la reacción debido a las condiciones de presión y temperatura 
de la misma, haciendo que los nanoclusters evolucionen hacia la formación de nanopartículas de oro. Por ello, y con el fin de investigar mejor el papel de los soportes en la actividad catalítica, los catalizadores fueron pretratados térmicamente antes de la reacción, de tal manera que los ligandos eran destruidos antes de iniciarse la reacción.

La influencia de los pretratamientos térmicos en la actividad de los catalizadores fue investigada primeramente con las muestras preparadas con nanoclusters $\mathrm{Au}_{11}$ sobre $\mathrm{Al}_{2} \mathrm{O}_{3}$. Para ello, los catalizadores fueron sometidos a un pretratamiento térmico a $300{ }^{\circ} \mathrm{C}$ con dos atmósferas distintas: oxidativa (con oxígeno) y reductora (con hidrógeno). Los resultados de la Figura 76 muestran que la actividad de los catalizadores que han sido pretratados (_red y _oxi) es casi el doble que la de la muestra fresca, tanto en el caso del pretratamiento con oxígeno como con el pretratamiento con hidrógeno. Sin embargo, este aumento de actividad va ligado a una disminución de la selectividad, obteniéndose una selectividad a estireno del $33 \%$ con el pretratamiento reductivo y únicamente del $2 \%$ con el pretratamiento oxidativo. 


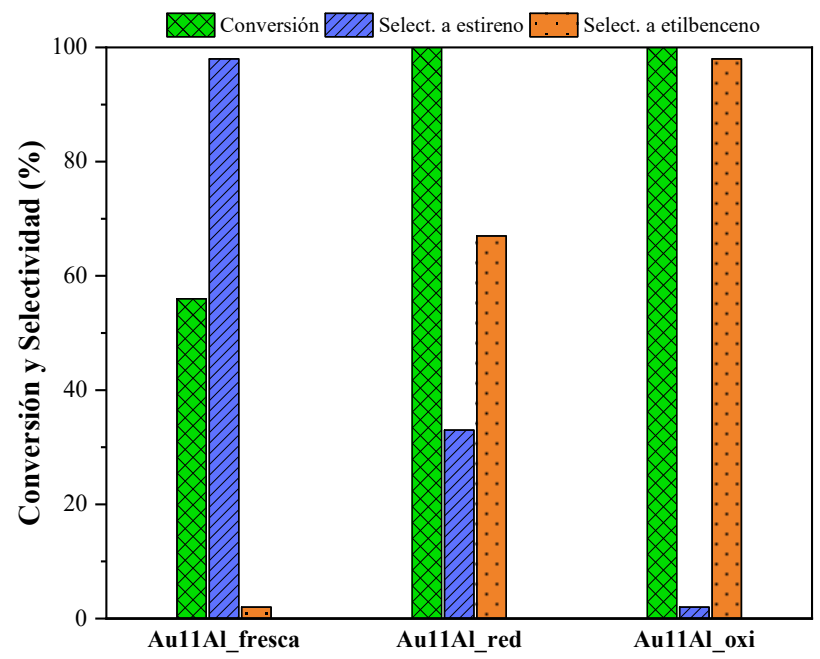

Figura 76. Influencia del pretratamiento en la actividad de los catalizadores preparados sobre alúmina. ( $0.1 \mathrm{~g}$. de catalizador, $0.1 \mathrm{mmol}$ de fenilacetileno y $0.2 \mathrm{mmol}$ de piridina, 20 horas, $100{ }^{\circ} \mathrm{C}, 10$ bar de $\mathrm{H}_{2}$ ).

Estos resultados catalíticos pueden ser correlacionados con los cambios que ocurren en los nanoclusters durante los pretratamientos. En los procesos de activación de los catalizadores se eliminan, al menos parcialmente, los ligandos de los nanoclusters, permitiendo así una mejor interacción de los reactivos con los centros activos, es decir, los enlaces triples de los alquinos interaccionan directamente con la superficie del nanoclusters de oro. Es por ello que cabría esperar una mayor conversión. Este mismo efecto del pretratamiento ya fue descrito en el capítulo 4, en donde se emplearon nanoclusters como catalizadores para la oxidación catalítica de CO. Para analizar estos resultados se estudió la evolución de los nanoclusters de oro durante los pretratamientos por espectroscopía UV-Vis. Se han comparado los espectros UV-Vis de los nanoclusters puros en disolución que aparece en la Figura 73, con los espectros UV-Vis de los nanoclusters soportados sobre alúmina y después de cada pretratamiento Figura 77. 


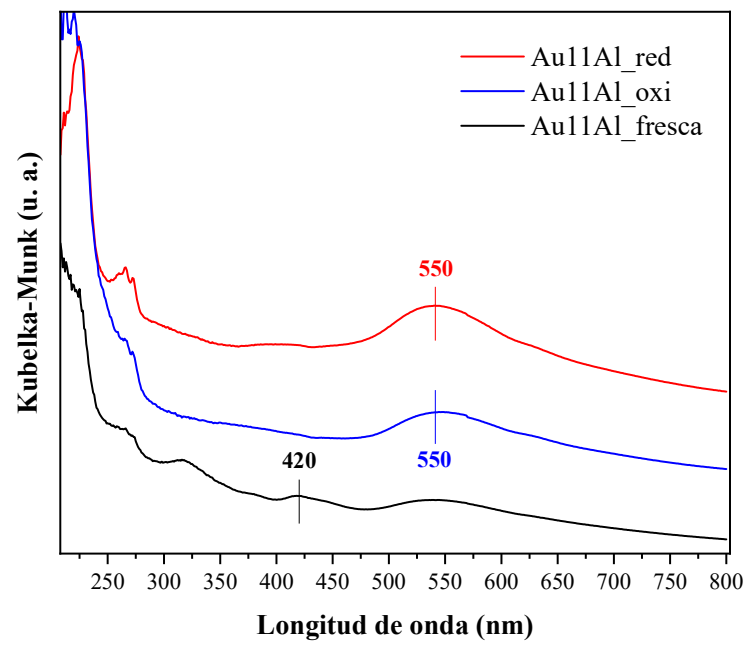

Figura 77. Espectros UV-Vis del catalizador $\mathrm{Au}_{11} / \mathrm{Al}_{2} \mathrm{O}_{3}$ antes (fresca) y después de los distintos pretratamientos.

El espectro del nanocluster sin soportar muestra una banda a $420 \mathrm{~nm}$ que es característica de estos nanoclusters y que indica una estructura electrónica cuantizada [221]. El espectro UV-Vis de los nanoclusters soportados sobre $\mathrm{Al}_{2} \mathrm{O}_{3}$ (Au11Al_fresca) también muestra esta banda característica, indicando que la estructura de los nanoclusters no se ve afectada durante el proceso de soporte de los mismos. Sin embargo, después de ambos pretratamientos térmicos, esta banda desaparece, y aparece una banda intensa y ancha alrededor de $550 \mathrm{~nm}$ que se relaciona con la aglomeración de los nanoclusters en la superficie del óxido al eliminar parte de los ligandos que inicialmente protegen al nanocluster, confirmando la hipótesis de que después de estos pretratamientos se destruyen los ligandos, lo que resulta en una mejor actividad catalítica.

Las diferencias en la selectividad de los catalizadores pretratados con hidrógeno y con oxígeno se relacionarían con la formación de nanopartículas de oro con distintos tamaños según el tipo de pretratamiento empleado. Se ha descrito que se forman nanopartículas más pequeñas en el caso del pretratamiento del hidrógeno [222]. Así mismo, este pretratamiento reductivo también da lugar a la 
reducción de especies oxidadas que inicialmente podrían existir en el catalizador [222], lo que también afectaría a la selectividad.

Los resultados obtenidos con los catalizadores frescos y con los pretratados, junto con los descritos para los nanoclusters de oro en otras reacciones [83,91], muestran una fuerte influencia de las propiedades del soporte en el comportamiento catalítico. Es por ello por lo que se profundizó en el estudio del efecto del soporte, investigando la actividad catalítica de los catalizadores pretratados con hidrógeno a $300{ }^{\circ} \mathrm{C}$, ya que estas eran las condiciones de pretratamiento que mejores resultados mostraron. Este estudio se realizó con los catalizadores de nanoclusters de $\mathrm{Au}_{11}$ soportados sobre dos materiales diferentes, $\mathrm{MgO}$ y $\mathrm{Al}_{2} \mathrm{O}_{3}$. Como se muestra en la Figura 78 (izquierda y medio), no se aprecian diferencias significativas en cuanto a la conversión obtenida con ambos materiales. Sin embargo, los resultados de selectividad sí que varían entre ambos soportes. El catalizador $\mathrm{Au}_{11} / \mathrm{MgO}$ presenta una selectividad del $59 \%$ a estireno, mientras que la selectividad del catalizador $\mathrm{Au}_{11} / \mathrm{Al}_{2} \mathrm{O}_{3}$ al mismo producto es del $33 \%$. Al igual que se observó con las muestras frescas, las propiedades ácido/base de los soportes parecen tener un papel importante en la actividad de los catalizadores. Esto podría estar relacionado con las propiedades electrónicas de los soportes, las cuales afectan directamente a la adsorción de los reactivos en la superficie metálica, lo que influye directamente en su selectividad. 


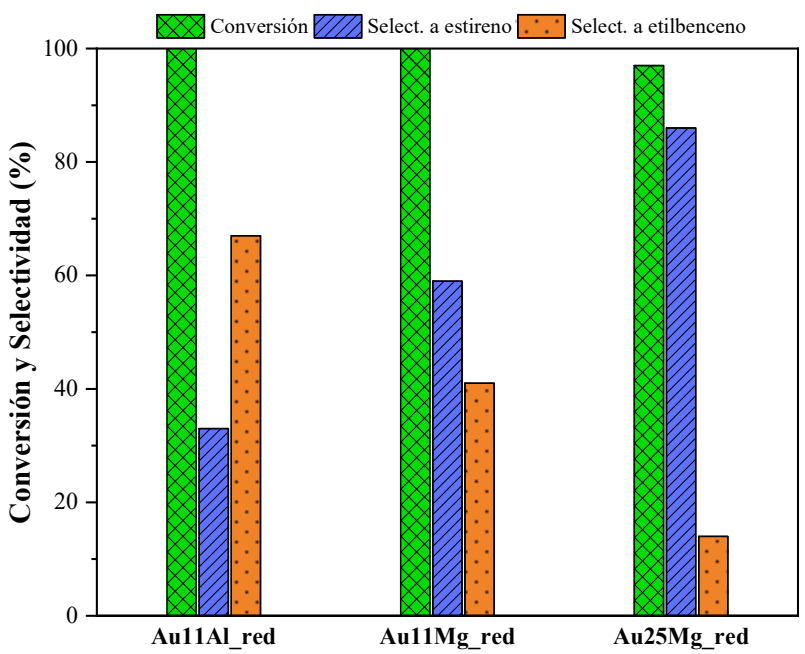

Figura 78. Actividad catalítica de los catalizadores $\mathrm{Au}_{11} / \mathrm{Al}_{2} \mathrm{O}_{3}, \mathrm{Au}_{11} / \mathrm{MgO}$ y $\mathrm{Au}_{25} / \mathrm{MgO}$ después del pretratamiento con $\mathrm{H}_{2}$ a $300{ }^{\circ} \mathrm{C}$ en la reacción de hidrogenación del fenilacetileno. (0.1 g. de catalizador, $0.1 \mathrm{mmol}$ de fenilacetileno y $0.2 \mathrm{mmol}$ de piridina, 20 horas, $100{ }^{\circ} \mathrm{C}, 10$ bar de $\mathrm{H}_{2}$ ).

En los procesos de hidrogenación, la etapa limitante suele ser la activación del hidrógeno. Se ha descrito que, al emplear catalizadores basados en nanopartículas de oro para esta reacción, la activación del $\mathrm{H}_{2}$ se ve favorecida al añadir al medio de reacción moléculas básicas que contienen nitrógeno [118]. Es por ello que, en la reacción descrita en este capítulo, se ha añadido piridina al medio de reacción. La coadsorción de estas moléculas básicas aumenta tanto la actividad como la selectividad de los catalizadores. Esto se explica debido a la formación de pares Lewis frustrados entre las nanopartículas de oro y las moléculas básicas que contienen átomos de $\mathrm{N}$, los cuales activan heterolíticamente al hidrógeno [118]. El hidrógeno activado reacciona con el alquino adsorbido dando lugar al alqueno. Es por ello que la disociación del $\mathrm{H}_{2}$ depende de la interacción entre el oro y las moléculas básicas. Sin embargo, una interacción demasiado fuerte podría llegar a producir incluso la extracción del metal, mientras que una interacción demasiado débil no da lugar a la formación del par Lewis frustrado, por lo que el $\mathrm{H}_{2}$ no sería activado. De esta manera, tanto la basicidad de las moléculas con 
nitrógeno, como las propiedades ácido/base de la superficie del catalizador, donde se depositan los nanoclusters de oro determinan la fortaleza de la interacción.

La piridina es una molécula fuertemente básica, lo que podría dar lugar a una interacción demasiado fuerte con las nanopartículas de oro. Además, en un soporte con propiedades ácidas, como la alúmina, la interacción de la piridina con la superficie del catalizador se ve favorecida, pudiendo darse una sobreactivación del $\mathrm{H}_{2}$, que resultaría en una mayor selectividad hacia el etilbenceno. Sin embargo, si el oro está soportado en superficies con propiedades básicas, como el $\mathrm{MgO}$, la interacción de la molécula básica con los átomos de oro depositados sobre la superficie básica sería moderada, por lo que el par Lewis frustrado se formaría en la superficie del catalizador, activando el $\mathrm{H}_{2}$, pero evitando la sobrehidrogenación del alquino. Esto explicaría la mayor selectividad hacia estireno de los catalizadores de oro soportados sobre $\mathrm{MgO}$ en comparación con los catalizadores soportados en $\mathrm{Al}_{2} \mathrm{O}_{3}$.

Los resultados anteriores muestran que el empleo del $\mathrm{MgO}$ como soporte y el pretratamiento con hidrógeno proporcionan la mejor actividad catalítica y las selectividades a estireno más altas. Por ello, se estudió la actividad en estas condiciones de los catalizadores que tenían un número diferente de átomos de $\mathrm{Au}$, es decir, los nanoclusters $\mathrm{Au}_{25}$ soportados sobre MgO. (Figura 78 derecha). La conversión obtenida es similar a la del catalizador $\mathrm{Au}_{11} / \mathrm{MgO}$, pero la selectividad hacia estireno es considerablemente mayor, probablemente debido a la mayor estabilidad de los nanoclusters $\mathrm{Au}_{25}$ frente al pretratamiento reductivo. Para investigar este efecto, ambos catalizadores fueron analizados después del pretratamiento con $\mathrm{H}_{2}$ por DRS UV-Vis y los espectros se muestran en la Figura 79. 


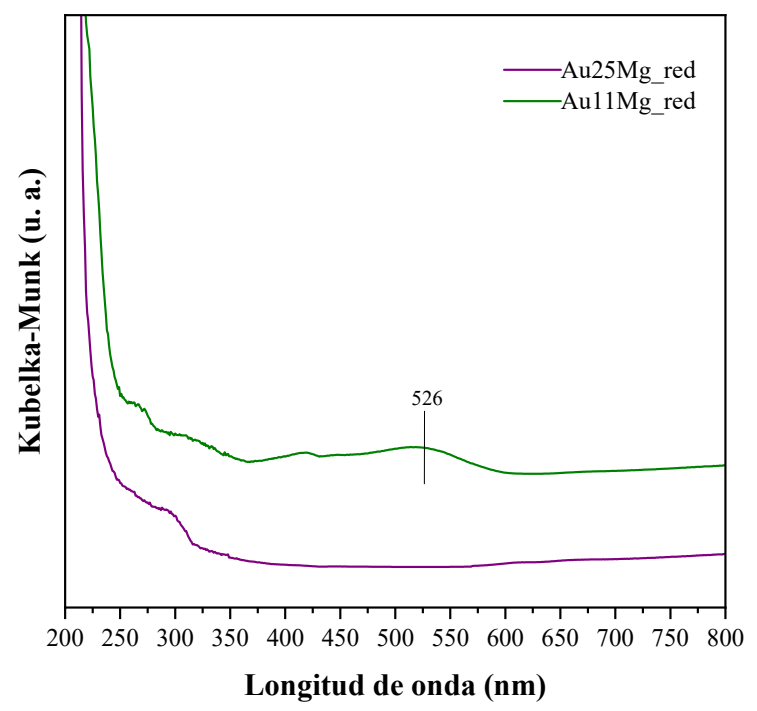

Figura 79. Espectro UV-Vis de los catalizadores $\mathrm{Au}_{11} / \mathrm{MgO}$ y $\mathrm{Au}_{25} / \mathrm{MgO}$ después del pretratamiento con $\mathrm{H}_{2}$.

La principal diferencia entre ambos espectros es la banda a $526 \mathrm{~nm}$ correspondiente a nanopartículas de oro. Esta banda únicamente se observa en el catalizador $\mathrm{Au}_{11} / \mathrm{MgO}$, lo que indicaría que se ha producido la sinterización de los nanoclusters de oro, mientras que la misma no aparece en el espectro del catalizador $\mathrm{Au}_{25} / \mathrm{MgO}$, mostrando una mayor estabilidad de los nanoclusters de oro presentes en este catalizador, lo que podría explicar la mayor selectividad de este catalizador.

Una vez seleccionados el pretratamiento y el tamaño de nanoclusters que proporcionan los mejores resultados, se ha preparado un catalizador empleando un hidrotalcita de $\mathrm{Mg}$ y $\mathrm{Al}(\mathrm{Mg} / \mathrm{Al}$ de 4). Las hidrotalcitas (HT) son materiales laminados que tienen una basicidad intermedia entre el $\mathrm{MgO}$ y la alúmina. Este soporte fue impregnado con nanoclusters $\mathrm{Au}_{25}$ y pretratado con $\mathrm{H}_{2}$, y se comparó su actividad catalítica con los catalizadores de $\mathrm{Au}_{25}$ sobre $\mathrm{MgO}_{\text {y }} \mathrm{Al}_{2} \mathrm{O}_{3}$ activados con el mismo pretratamiento (Figura 80). Como puede observarse, el catalizador de $\mathrm{Au}_{25}$ soportado sobre la alúmina es el menos activo, mientras que los 
nanoclusters $\mathrm{Au}_{25}$ soportados en los materiales más básicos ( $\mathrm{MgO}$ y HT) son mucho más activos. Tal y como se ha mencionado anteriormente, esto puede estar relacionado con la menor interacción de la piridina con el oro soportado en los soportes más básicos, lo que evitaría la formación de enlaces fuertes piridinasoporte, permitiendo que esta active el $\mathrm{H}_{2}$.

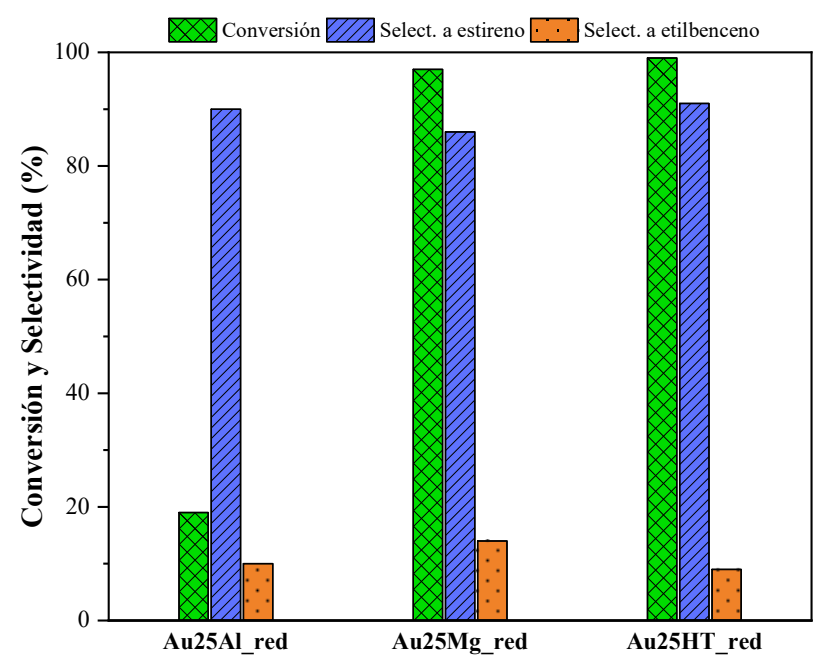

Figura 80. Actividad catalítica y selectividad a estireno de los catalizadores de Au25 soportados sobre distintos materiales tras el pretratamiento con $\mathrm{H}_{2}$. (0.1 g. de catalizador, $0.1 \mathrm{mmol}$ de fenilacetileno y $0.2 \mathrm{mmol}$ de piridina, 20 horas, $100{ }^{\circ} \mathrm{C}, 10$ bar de $\mathrm{H}_{2}$ ).

Para investigar esto, se realizó un proceso de adsorción-desorción de piridina seguido por espectroscopía infrarroja. Como puede verse en la Figura 81, la piridina se adsorbe en los tres catalizadores a través de los centros ácidos Lewis principalmente, cuyas bandas se encuentran sobre $1450 \mathrm{~cm}^{-1}$. El área de esta banda es mayor para el catalizador más ácido, es decir, para el catalizador soportado sobre alúmina, indicando un mayor número de centros ácidos en el mismo. Por otro lado, cuanto mayor es la temperatura necesaria para la desorción de la piridina, más fuerte es su interacción con los centros ácidos. Por tanto, se 
puede decir que los centros ácidos de la alúmina interaccionan más fuertemente con la piridina que los centros Lewis del $\mathrm{MgO}$ o de la hidrotalcita, ya que la intensidad de las bandas es mayor a $250-350{ }^{\circ} \mathrm{C}$ para el caso del catalizador soportado sobre alúmina. Por el contrario, se produce una menor interacción de la piridina con la superficie de los catalizadores más básicos, y esto, tal y como se ha discutido anteriormente, puede favorecer la formación de pares Lewis frustrados que activan el $\mathrm{H}_{2}$ heterolíticamente.

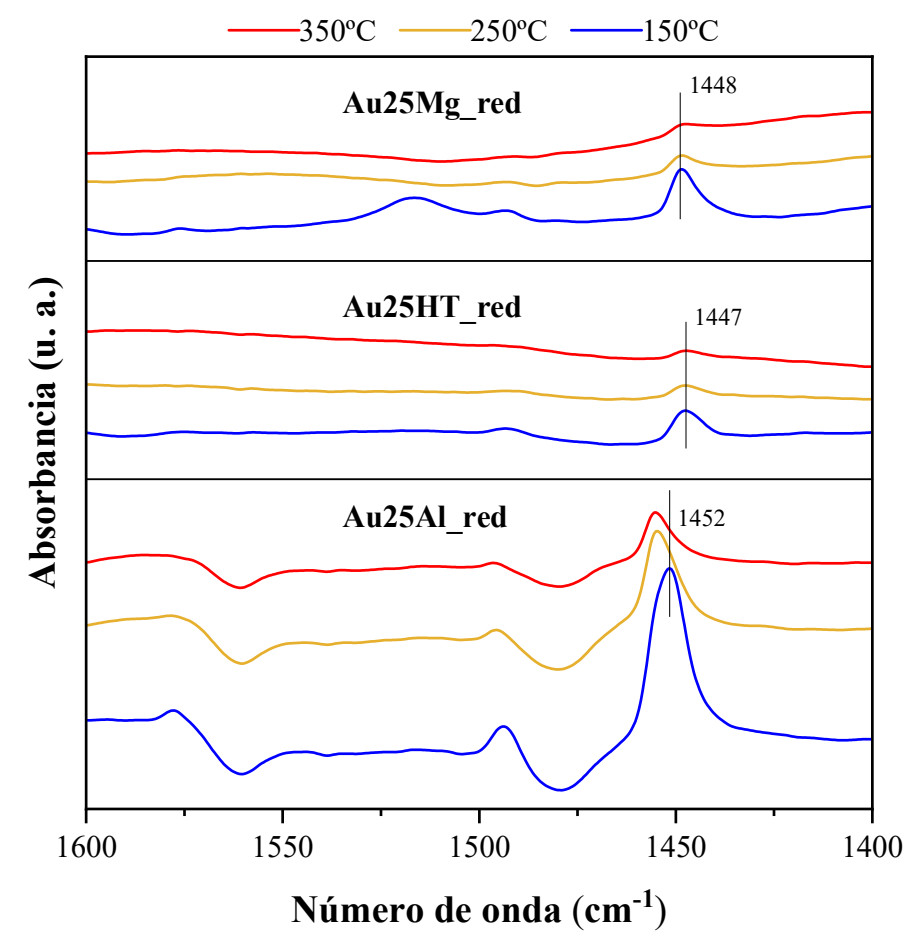

Figura 81. Espectro IR de desorción de piridina a $150{ }^{\circ} \mathrm{C}, 250{ }^{\circ} \mathrm{C}$ y $350{ }^{\circ} \mathrm{C}$ de los nanoclusters $\mathrm{Au}_{25}$ soportados sobre $\mathrm{MgO}, \mathrm{Al}_{2} \mathrm{O}_{3}$ e hidrotalcita y pretratados con $\mathrm{H}_{2}$.

Comparando la selectividad de los catalizadores soportados sobre los materiales básicos, $\mathrm{MgO}$ y HT, se obtiene una selectividad a estireno algo mayor (91\%) con 
el catalizador $\mathrm{Au}_{25} / \mathrm{HT}$. Esto sugiere que la hidrotalcita es un soporte ideal para los nanoclusters de oro, obteniéndose una mejor actividad y selectividad a estireno que la obtenida con los catalizadores soportados sobre $\mathrm{Al}_{2} \mathrm{O}_{3}$ y sobre $\mathrm{MgO}$. Algunos autores [222-224], han descrito que existe un efecto sinérgico entre los centros básicos de la hidrotalcita y las nanopartículas de oro, favoreciendo la disociación heterolítica del $\mathrm{H}_{2}$ al producir hidruro de oro y $\mathrm{H}^{+}$en la superficie de este material. Estas especies de hidrógeno reaccionarían con el alquino adsorbido produciendo el alqueno correspondiente. Este efecto es similar al producido por la presencia de la piridina en el medio de reacción, pero con la ventaja de que los catalizadores $\mathrm{Au} / \mathrm{HT}$ son inactivos para la hidrogenación de los enlaces $\mathrm{C}=\mathrm{C}[222,223]$, lo que aumenta la selectividad de la reacción hacia el alqueno al inhibir la formación del alcano.

La interacción del $\mathrm{H}_{2}$ con la superficie del catalizador fue evaluada por un análisis de reducción a temperatura programada (TPR). En la Figura 82 se comparan los perfiles de TPR obtenidos con los tres catalizadores

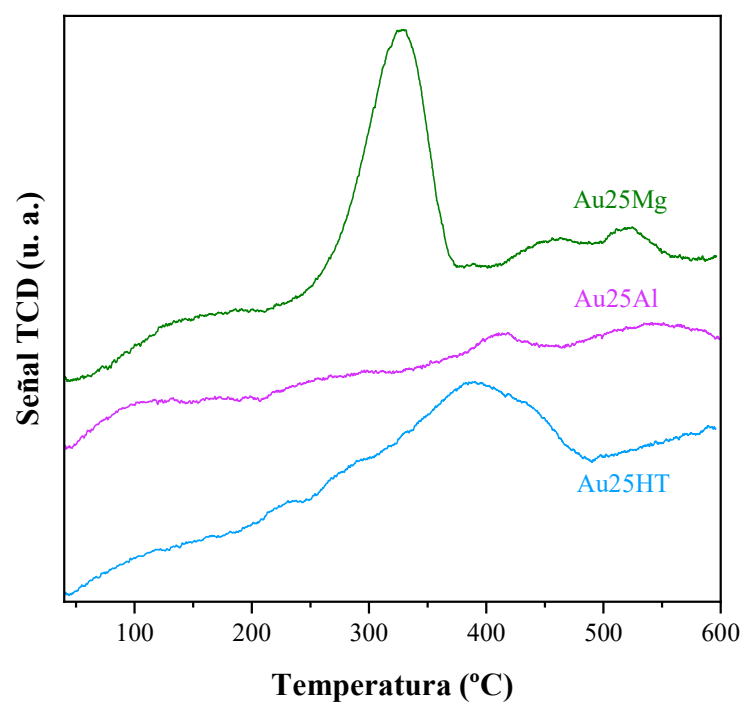

Figura 82. Perfiles TPR de los catalizadores de nanoclusters Au25 soportados sobre MgO, $\mathrm{Al}_{2} \mathrm{O}_{3}$ e hidrotalcita. 
En el termograma del catalizador soportado sobre $\mathrm{MgO}$ predomina un pico intenso y definido centrado en $327^{\circ} \mathrm{C}$. En el caso del catalizador soportado sobre la hidrotalcita, el termograma presenta un pico intenso y más ancho sobre $388^{\circ} \mathrm{C}$. Por otra parte, el catalizador soportado sobre alúmina no presenta picos definidos, sino bandas anchas a 400 y $550^{\circ} \mathrm{C}$. Esto indica que las especies reducibles en el catalizador $\mathrm{Au}_{25} / \mathrm{MgO}$ interactúan más fácilmente con el $\mathrm{H}_{2}$ que las especies presenten en el catalizador $\mathrm{Au}_{25} / \mathrm{HT}$, mientras que el catalizador soportado sobre alúmina no presenta interacciones de este tipo en el rango de temperatura estudiado. Esto se puede explicar por las características básicas de los soportes que, al igual que la piridina, favorecen la activación del $\mathrm{H}_{2}$ dando lugar a actividades más altas. Sin embargo, una activación demasiado fuerte del $\mathrm{H}_{2}$ resultaría en una sobrehidrogenación del alquino, lo que explicaría que los catalizadores con una basicidad intermedia, como las hidrotalcitas, proporcionen una mejor selectividad hacia los alquenos.

\subsection{Conclusiones parciales}

Los catalizadores basados en nanoclusters de oro soportados son activos en la semihidrogenación del fenilacetileno a estireno en presencia de piridina. La actividad depende tanto de las condiciones del pretratamiento empleado como de las propiedades ácido/base del soporte.

El pretratamiento con atmósfera de $\mathrm{H}_{2}$ a $300{ }^{\circ} \mathrm{C}$ da lugar a la formación de partículas de oro más pequeñas que cuando el catalizador se activa con $\mathrm{O}_{2}$. Asimismo, se favorece la reducción de las especies oxidadas que están presentes en el catalizador inicialmente, lo que da lugar a una mejor actividad y selectividad de los catalizadores.

Se ha comprobado que los nanoclusters $\mathrm{Au}_{25}$ presentan una mayor estabilidad que los nanoclusters $\mathrm{Au}_{11}$ durante el pretratamiento evitando la sinterización de las nanopartículas. 
Los mejores resultados se obtuvieron con los nanoclusters $\mathrm{Au}_{25}$ soportados la hidrotalcita $\mathrm{MgAl}$, la cual presenta una basicidad intermedia entre el $\mathrm{MgO}$ y la alúmina. La presencia de estos centros básicos más débiles favorece la disociación heterolítica del $\mathrm{H}_{2}$ a la vez que impide la sobrehidrogenación de los alquinos a alcanos. 
7. GENERAL CONCLUSIONS 

The analysis of the results obtained in this work leads to the following conclusions, that have been summarized in three blocks associated to the different studied reactions.

\section{Selective catalytic reduction of nitrogen oxides:}

- The activity of Mn-Fe catalysts for SCR-NOX with $\mathrm{NH}_{3}$ supported on different materials (zeolites oxides and mesoporous materials) mainly depends on the stability, surface area and acid properties of the supports.

- Mn-Fe catalysts supported on zeolites are active in the selective catalytic reduction of $\mathrm{NO}_{\mathrm{X}}$ with ammonia and highly selective to $\mathrm{N}_{2}$. It has been shown that the catalytic activity mostly depends on the acid properties of the support, this is on the $\mathrm{Si} / \mathrm{Al}$ ratio of the zeolites. The best results are obtained with the zeolites containing a higher density of strong and isolated acid sites, obtaining the higher catalytic activity at low temperatures $\left(<350^{\circ} \mathrm{C}\right)$ with $\mathrm{Mn}$-Fe catalysts supported on CHA zeolite with $\mathrm{Si} / \mathrm{Al}$ ratio of 10 , while $\mathrm{BEA}$ catalysts are more active above this temperature.

- The mesoporous materials (MCM-41 and SBA-15) are not adequate supports for the $\mathrm{Mn}-\mathrm{Fe}$ catalysts due to their low stability in presence of water.

- Metallic oxides can be used as supports for the Mn-Fe catalysts, but there is a strong influence of the acid/base characteristics, the redox properties, and the surface area of the supports. The worst results have been obtained with the basic supports $(\mathrm{MgO})$, whilst the best results are present by the catalysts supported on acidic oxides as $\mathrm{TiO}_{2}$ or $\gamma-\mathrm{Al}_{2} \mathrm{O}_{3}$ with high surface area.

- The addition of water to the feed produces a partial and reversible deactivation of the catalysts supported on metallic oxides, whilst the activity of Mn-Fe/zeolite catalysts is not affected by the presence of this molecule. Nevertheless, the hydrothermal aging of the catalysts results in a decrease of the activity in all $\mathrm{Mn}-\mathrm{Fe}$ catalysts, except for the $\mathrm{Mn}-\mathrm{Fe}$ catalyst supported on $\mathrm{CHA}(\mathrm{Si} / \mathrm{Al}=10)$ that shows the same catalytic 
activity after the aging. The results have shown that this support is stable under these conditions, whilst other supports produce a sintering of the metals, or even a change in the support phase.

\section{Catalytic oxidation of carbon monoxide:}

- $\mathrm{Ag}$ and Ag-Au catalysts supported on ITQ-2 zeolite are active catalysts for the catalytic oxidation of $\mathrm{CO}$. However, their activity depends on the way that the metal has been incorporated to the support, and on the pretreatment applied.

- In the case of Ag/ITQ-2 catalysts, the active species are nanoparticles of $\mathrm{Ag}^{0}$. For this reason, the catalysts based on silver nanoclusters improve their activity after consecutive activation/reaction cycles as ligands are removed and metallic silver is formed. On the other hand, catalysts prepared by ion exchange containing mainly stable silver cationic species are less active than those prepared by incipient wetness impregnation and pretreated with $\mathrm{H}_{2}$ or with $\mathrm{O}_{2}$ (in presence of light), as most of the silver species present in these catalysts are reduced to metallic silver by $\mathrm{H}_{2}$ or by the light.

- The activity of silver catalysts based on nanoclusters can be improved by using bimetallic nanoclusters containing $\mathrm{Ag}$ and $\mathrm{Au}$. In this case, activity also depends on the pretreatment conditions, obtaining the best activity with reductive conditions as Ag-Au alloyed sites are formed. The coadsorption of $\mathrm{CO}$ and $\mathrm{O}_{2}$ in these bimetallic sites is stronger that in monometallic sites, explaining the best catalytic activity showed by $\mathrm{Ag}_{\mathrm{x}} \mathrm{Au}_{25-\mathrm{x}} / \mathrm{ITQ} \mathrm{T}$ catalysts compared with the monometallic ones.

- CO oxidation can be used as a test reaction in order to determine the nature of the species present in the catalysts, as their activity depends on the presence of metallic sites, avoiding the use of sophisticated characterization techniques. 


\section{Semihydrogenation of phenylacetylene to styrene:}

- Catalysts based in Au-nanoclusters are active for the semihydrogenation of phenylacetylene to styrene in presence of pyridine. The activity and selectivity of the catalysts strongly depends on the nanoclusters composition, on the pretreatment conditions and on the acid/base properties of the supports.

- In this case, medium basic supports are preferred over acidic ones, as they favour the $\mathrm{H}_{2}$ activation, allowing the semihydrogenation but avoiding the overreduction to produce alkanes instead of alkenes.

- The use of oxidative or reductive pretreatments significantly increases the conversion of the catalysts in comparison with the fresh samples. The increase in the activity is related to the removal of the ligands during the pretreatments, that leads to the formation of small gold nanoparticles. Nevertheless, the formation of these nanoparticles depends on the type of gold nanoclusters, this is on the number of $\mathrm{Au}$ atoms and/or on the type of ligands. The best results in terms of conversion and selectivity are obtained with the gold nanoclusters containing 25 atoms and with thiolate ligands supported on the $\mathrm{Mg} / \mathrm{Al}$ hydrotalcite. This support provides the optimal acidity to activate the $\mathrm{H}_{2}$, favouring the hydrogenation of phenylacetylene to styrene and avoiding the overhydrogenation to ethylbenzene. The size of the nanoclusters and the type of ligands also favour the formation of stable nanoparticles that are active and selective in this reaction.

As summary, the results obtained with the different structured catalysts in the different reactions studied in this thesis have shown that support-metal interaction is essential in order to design active catalysts, and this interaction must be tuned depending on the reaction. The interaction depends on the acid/base properties of the support, and on the different pretreatments applied. Together with this, surface area and topology of the supports are factors that must be taken into 
account. The results have also shown that active species may evolve during reaction, leading sometimes to more active sites and other times to inactive sites, being necessary the characterization of this evolution in the different reactions. 
8. BIBLIOGRAFÍA 

[1] B.A. de Marco, B.S. Rechelo, E.G. Tótoli, A.C. Kogawa, H.R.N. Salgado, Evolution of green chemistry and its multidimensional impacts: A review, $\begin{array}{lllll}\text { Saudi Pharm. } & \text { J. } & 27 & \text { (2019) } & 1-8 .\end{array}$ https://doi.org/10.1016/j.jsps.2018.07.011.

[2] A. Ivanković, Review of 12 Principles of Green Chemistry in Practice, Int. J. Sustain. Green Energy. $6 \quad$ (2017) 39. https://doi.org/10.11648/j.jirse.20170603.12.

[3] M. Tobiszewski, A. Mechlińska, B. Zygmunt, J. Namieśnik, Green analytical chemistry in sample preparation for determination of trace organic pollutants, TrAC - Trends Anal. Chem. 28 (2009) 943-951. https://doi.org/10.1016/j.trac.2009.06.001.

[4] R. Carson, Silent Spring, Houghton Mifflin Company, Nueva York, 1962.

[5] Brundtland CG, Our commun future, Oxford University Press, Oxford, UK: World Commission on Environment and Development, 1987.

[6] T. Welton, Solvents and sustainable chemistry, Proc. R. Soc. A Math. Phys. Eng. Sci. 471 (2015). https://doi.org/10.1098/rspa.2015.0502.

[7] P.T. Anastas, J.C. Warner, Química Verde: Teoría y Práctica, Oxford University Press, Nueva York, 1998.

[8] P.T. Anastas, Green Chemistry and the role of analytical methodology development, Crit. Rev. Anal. Chem. 29 (1999) 167-175. https://doi.org/10.1080/10408349891199356.

[9] C. Blum, D. Bunke, M. Hungsberg, E. Roelofs, A. Joas, R. Joas, M. Blepp, H.C. Stolzenberg, The concept of sustainable chemistry: Key drivers for the transition towards sustainable development, Sustain. Chem. Pharm. 5 (2017) 94-104. https://doi.org/10.1016/j.scp.2017.01.001.

[10] D. Rodríguez-Padrón, A.R. Puente-Santiago, A.M. Balu, M.J. MuñozBatista, R. Luque, Environmental Catalysis: Present and Future, $\begin{array}{llll}\text { ChemCatChem. } & 11 & \text { (2019) }\end{array}$ 
https://doi.org/10.1002/cctc.201801248.

[11] A.D. McNaught, A. Wilkinson, IUPAC Compendium of Chemical Terminology, Blackwell Scientific Publications, Oxford, 1997. https://doi.org/https://doi.org/10.1351/goldbook.

[12] H.C. Erythropel, J.B. Zimmerman, T.M. De Winter, L. Petitjean, F. Melnikov, C.H. Lam, A.W. Lounsbury, K.E. Mellor, N.Z. Janković, Q. Tu, L.N. Pincus, M.M. Falinski, W. Shi, P. Coish, D.L. Plata, P.T. Anastas, The Green ChemisTREE: 20 years after taking root with the 12 principles, Green Chem. $20 \quad$ (2018) 1929-1961. https://doi.org/10.1039/c8gc00482j.

[13] B. Cornils, W.A. Herrmann, C.-H. Wong, H.-W. Zanthoff, Catalysis from A to Z, 4th ed., Wiley-VCH, Weinheim, 2013. https://doi.org/10.1016/s1351-4180(07)70462-2.

[14] V.S. Shende, V.B. Saptal, B.M. Bhanage, Recent Advances Utilized in the Recycling of Homogeneous Catalysis, Chem. Rec. 19 (2019) 2022 2043. https://doi.org/10.1002/tcr.201800205.

[15] J.K. Norskov, F. Studt, F. Abild-Pedersen, T. Bligaard, Fundamental Concepts in Heterogeneous Catalysis, John Wiley \& Sons, Inc., Hoboken, 2014. https://doi.org/10.1016/j.focat.2015.08.045.

[16] R.A. Sheldon, J.M. Woodley, Role of Biocatalysis in Sustainable Chemistry, Chem. Rev. 118 (2018) 801-838. https://doi.org/10.1021/acs.chemrev.7b00203.

[17] J. Tao, R. Kazlauskas, Biocatalysis for Green Chemistry and Chemical Process Development, John Wiley \& Sons, Inc., Hoboken, 2011.

[18] A. Illanes, A. Cauerhff, L. Wilson, G.R. Castro, Recent trends in biocatalysis engineering, Bioresour. Technol. 115 (2012) 48-57. https://doi.org/10.1016/j.biortech.2011.12.050.

[19] K.P. de Jong, Synthesis of Solid Catalysts, Wiley-VCH, Weinheim, 2009. 
[20] G. Rothenberg, Catalysis: Concepts and Green Applications, 2nd ed., Wiley-VCH, Weinheim, 2017. https://doi.org/978-3-527-34305-8.

[21] Catalyst Market Size, Share \& Trends Analysis Report By Raw Material (Chemical Compounds, Zeolites, Metals), By Product (Heterogeneous, Homogeneous), By Application, By Region, And Segment Forecasts, 2020 - 2027, (n.d.). https://www.grandviewresearch.com/industryanalysis/catalyst-market.

[22] Boletín Oficial del Estado, Ley 34/2007 de calidad del aire y protección de la atmósfera, España, 2007. https://www.boe.es/buscar/pdf/2007/BOEA-2007-19744-consolidado.pdf.

[23] P. Brimblecombe, Air composition and chemistry, 2nd ed., Cambridge University Press, Cambridge, 1996.

[24] Organización Mundial de la Salud, Calidad del aire y salud, (n.d.). https://www.who.int/es/news-room/fact-sheets/detail/ambient-(outdoor)air-quality-and-health.

[25] J.A. Mendoza Roca, M.T. Montañés Sanjuan, A.E. Palomares Gimeno, Ciencia y Tecnología del Medio Ambiente, Editorial Universitat Politècnica de València, Valecia, 1998.

[26] Boletín Oficial del Estado, BOE núm. 87, España, 2005. https://www.boe.es/boe/dias/2005/04/12/pdfs/A12465-12505.pdf.

[27] Agencia Europea del Medio Ambiente, Air pollutant emissions data viewer (Gothenburg Protocol, LRTAP Convention) 1990-2018, (n.d.). https://www.eea.europa.eu/data-and-maps/dashboards/air-pollutantemissions-data-viewer-3.

[28] R. Kikuchi, Environmental management of sulfur trioxide emission: Impact of SO3 on human health, Environ. Manage. 27 (2001) 837-844. https://doi.org/10.1007/s002670010192.

[29] P. De Voogt, Reviews of Environmental Contamination and Toxicology, 
Springer International Publishing, Gewerbestrasse, n.d.

[30] H.L. Wang, L. Nie, J. Li, Y.F. Wang, G. Wang, J.H. Wang, Z.P. Hao, Characterization and assessment of volatile organic compounds (VOCs) emissions from typical industries, Chinese Sci. Bull. 58 (2013) 724-730. https://doi.org/10.1007/s1 1434-012-5345-2.

[31] Y. Sun, E. Zwolińska, A.G. Chmielewski, Abatement technologies for high concentrations of $\mathrm{NO} \mathrm{x}$ and so 2 removal from exhaust gases: A review, Crit. Rev. Environ. Sci. Technol. 46 (2016) 119-142. https://doi.org/10.1080/10643389.2015.1063334.

[32] K. Skalska, J.S. Miller, S. Ledakowicz, Trends in NOx abatement: A review, Sci. Total Environ. 408 (2010) 3976-3989. https://doi.org/10.1016/j.scitotenv.2010.06.001.

[33] M. Tayyeb Javed, N. Irfan, B.M. Gibbs, Control of combustion-generated nitrogen oxides by selective non-catalytic reduction, J. Environ. Manage. 83 (2007) 251-289. https://doi.org/10.1016/j.jenvman.2006.03.006.

[34] R.K. Lyon, Thermal DeNOx. Controlling nitrogen oxides emissions by a noncatalytic process., Environ. Sci. Technol. 21 (1987) 231-236.

[35] S. Mahmoudi, J. Baeyens, J.P.K. Seville, NOx formation and selective non-catalytic reduction (SNCR) in a fluidized bed combustor of biomass, Biomass and Bioenergy. $34 \quad$ (2010) 1393-1409. https://doi.org/10.1016/j.biombioe.2010.04.013.

[36] I. López-Hernández, J. Mengual, A.E. Palomares, The influence of the support on the activity of $\mathrm{mn}-\mathrm{fe}$ catalysts used for the selective catalytic reduction of NOx with ammonia, Catalysts. 10 (2020). https://doi.org/10.3390/catal10010063.

[37] A.E. Palomares, J.G. Prato, F.E. Imbert, A. Corma, Catalysts based on tin and beta zeolite for the reduction of NOx under lean conditions in the presence of water, Appl. Catal. B Environ. 75 (2007) 88-94. https://doi.org/10.1016/j.apcatb.2007.03.013. 
[38] Z. Gholami, G. Luo, F. Gholami, F. Yang, Recent advances in selective catalytic reduction of NOx by carbon monoxide for flue gas cleaning process: a review, Catal. Rev. - Sci. Eng. 63 (2021) 68-119. https://doi.org/10.1080/01614940.2020.1753972.

[39] P. Sazama, L. Čapek, H. Drobná, Z. Sobalík, J. Dědeček, K. Arve, B. Wichterlová, Enhancement of decane-SCR-NOx over Ag/alumina by hydrogen. Reaction kinetics and in situ FTIR and UV-vis study, J. Catal. 232 (2005) 302-317. https://doi.org/10.1016/j.jcat.2005.03.013.

[40] S. Shuai, J. Wang, R. Li, J. Sun, L. Xiang, H. He, X. Shi, Performance evaluation and application of diesel NOx-SCR catalyst by ethanol reductant, SAE Tech. Pap. 2005 (2005). https://doi.org/10.4271/2005-011089.

[41] A.E. Palomares, J.G. Prato, A. Corma, Co-exchanged IM5, a stable zeolite for the selective catalytic reduction of $\mathrm{NO}$ in the presence of water and SO2, Ind. Eng. Chem. Res. 42 (2003) 1538-1542. https://doi.org/10.1021/ie0203451.

[42] A.E. Palomares, J.G. Prato, A. Corma, A new active zeolite structure for the selective catalytic reduction (SCR) of nitrogen oxides: ITQ7 zeolite: The influence of NO2 on this reaction, Catal. Today. 75 (2002) 367-371. https://doi.org/10.1016/S0920-5861(02)00066-4.

[43] P. Forzatti, I. Nova, E. Tronconi, Enhanced NH3 Selective Catalytic Reduction for NOx Abatement, Angew. Chemie. 121 (2009) 8516-8518. https://doi.org/10.1002/ange.200903857.

[44] P. Forzatti, Present status and perspectives in de-NOx SCR catalysis, Appl. Catal. A Gen. 222 (2001) 221-236. https://doi.org/10.1016/S0926860X(01)00832-8.

[45] Y. Liu, J. Zhao, J.M. Lee, Conventional and New Materials for Selective Catalytic Reduction (SCR) of NOx, ChemCatChem. 10 (2018) 14991511. https://doi.org/10.1002/cctc.201701414.

[46] S. Cai, D. Zhang, L. Zhang, L. Huang, H. Li, R. Gao, L. Shi, J. Zhang, 
Comparative study of 3D ordered macroporous $\mathrm{Ce} 0.75 \mathrm{Zr} 0.2 \mathrm{M} 0.05 \mathrm{O} 2-\delta$ $(\mathrm{M}=\mathrm{Fe}, \mathrm{Cu}, \mathrm{Mn}, \mathrm{Co})$ for selective catalytic reduction of $\mathrm{NO}$ with $\mathrm{NH} 3$, Catal. Sci. Technol. 4 (2014) 93-101. https://doi.org/10.1039/c3cy00398a.

[47] C. Zhou, Y. Zhang, X. Wang, H. Xu, K. Sun, K. Shen, Influence of the addition of transition metals ( $\mathrm{Cr}, \mathrm{Zr}, \mathrm{Mo}$ ) on the properties of $\mathrm{MnOx}-\mathrm{FeOx}$ catalysts for low-temperature selective catalytic reduction of NOx by Ammonia, J. Colloid Interface Sci. 392 (2013) 319-324. https://doi.org/10.1016/j.jcis.2012.10.002.

[48] J. Liu, X. Li, Q. Zhao, J. Ke, H. Xiao, X. Lv, S. Liu, M. Tadé, S. Wang, Mechanistic investigation of the enhanced NH3-SCR on cobalt-decorated Ce-Ti mixed oxide: In situ FTIR analysis for structure-activity correlation, Appl. Catal. B Environ. $200 \quad$ (2017) 297-308. https://doi.org/10.1016/j.apcatb.2016.07.020.

[49] G. Busca, L. Lietti, G. Ramis, F. Berti, Chemical and mechanistic aspects of the selective catalytic reduction of $\mathrm{NO}(\mathrm{x})$ by ammonia over oxide catalysts: A review, Appl. Catal. B Environ. 18 (1998) 1-36. https://doi.org/10.1016/S0926-3373(98)00040-X.

[50] H. Schneider, M. Maciejewski, K. Köhler, A. Wokaun, A. Baiker, Properties of different chromium oxide phases in the catalytic reduction of NO by NH3 studied by in Situ diffuse reflectance FTIR spectroscopy, J. Catal. 157 (1995) 312-320. https://doi.org/10.1006/jcat.1995.1296.

[51] Z. Chen, Q. Yang, H. Li, X. Li, L. Wang, S. Chi Tsang, Cr-MnOx mixedoxide catalysts for selective catalytic reduction of NOx with NH3 at low temperature, J. Catal. $276 \quad$ (2010) 56-65. https://doi.org/10.1016/j.jcat.2010.08.016.

[52] Z. Chen, F. Wang, H. Li, Q. Yang, L. Wang, X. Li, Low-temperature selective catalytic reduction of $\mathrm{NO} x$ with $\mathrm{NH} 3$ over Fe-Mn mixed-oxide catalysts containing Fe 3Mn 308 Phase, Ind. Eng. Chem. Res. 51 (2012) 202-212. https://doi.org/10.1021/ie201894c.

[53] Z. Wu, B. Jiang, Y. Liu, Effect of transition metals addition on the catalyst 
of manganese/titania for low-temperature selective catalytic reduction of nitric oxide with ammonia, Appl. Catal. B Environ. 79 (2008) 347-355. https://doi.org/10.1016/j.apcatb.2007.09.039.

[54] F. Liu, H. He, C. Zhang, Z. Feng, L. Zheng, Y. Xie, T. Hu, Selective catalytic reduction of $\mathrm{NO}$ with $\mathrm{NH} 3$ over iron titanate catalyst: Catalytic performance and characterization, Appl. Catal. B Environ. 96 (2010) 408 420. https://doi.org/10.1016/j.apcatb.2010.02.038.

[55] X. Yao, T. Kong, L. Chen, S. Ding, F. Yang, L. Dong, Enhanced lowtemperature $\mathrm{NH} 3$-SCR performance of $\mathrm{MnO} \times / \mathrm{CeO} 2$ catalysts by optimal solvent effect, Appl. Surf. Sci. 420 (2017) 407-415. https://doi.org/10.1016/j.apsusc.2017.05.156.

[56] P.M. Sreekanth, D.A. Peña, P.G. Smirniotis, Titania supported bimetallic transition metal oxides for low-temperature SCR of NO with NH 3, Ind. Eng. Chem. $\quad$ Res. $45 \quad$ (2006) 6444-6449. https://doi.org/10.1021/ie0604851.

[57] D.A. Peña, B.S. Uphade, P.G. Smirniotis, TiO2-supported metal oxide catalysts for low-temperature selective catalytic reduction of $\mathrm{NO}$ with NH3: I. Evaluation and characterization of first row transition metals, J. Catal. 221 (2004) 421-431. https://doi.org/10.1016/j.jcat.2003.09.003.

[58] T. Boningari, P.G. Smirniotis, Impact of nitrogen oxides on the environment and human health: Mn-based materials for the NOx abatement, Curr. Opin. Chem. Eng. 13 (2016) 133-141. https://doi.org/10.1016/j.coche.2016.09.004.

[59] J. Li, H. Chang, L. Ma, J. Hao, R.T. Yang, Low-temperature selective catalytic reduction of NOx with $\mathrm{NH} 3$ over metal oxide and zeolite catalysts-A review, Catal. Today. 175 (2011) 147-156. https://doi.org/10.1016/j.cattod.2011.03.034.

[60] P.G. Smirniotis, P.M. Sreekanth, D.A. Peña, R.G. Jenkins, Manganese Oxide Catalysts Supported on $\mathrm{TiO} 2, \mathrm{Al} 2 \mathrm{O} 3$, and $\mathrm{SiO} 2$ : A Comparison for Low-Temperature SCR of NO with NH3, Ind. Eng. Chem. Res. 45 (2006) 6436-6443. https://doi.org/10.1016/j.chemosphere.2009.11.049. 
[61] S. Roy, B. Viswanath, M.S. Hegde, G. Madras, Low-Temperature Selective Catalytic Reduction of NO with NH3 over Ti0.9M0.1O2- $\delta(M$ ) Cr, Mn, Fe, Co, Cu), J. Phys. Chem. C. 112 (2008) 6002-6012.

[62] G. Qi, R.T. Yang, Low-temperature selective catalytic reduction of NO with NH3 over iron and manganese oxides supported on titania, Appl. Catal. B Environ. 44 (2003) 217-225. https://doi.org/10.1016/S09263373(03)00100-0.

[63] G. Qi, R.T. Yang, R. Chang, MnOx-CeO2 mixed oxides prepared by coprecipitation for selective catalytic reduction of NO with $\mathrm{NH} 3$ at low temperatures, Appl. Catal. B Environ. 51 (2004) 93-106. https://doi.org/10.1016/j.apcatb.2004.01.023.

[64] X. Wang, S. Wu, W. Zou, S. Yu, K. Gui, L. Dong, Fe-Mn/A12O3 catalysts for low temperature selective catalytic reduction of $\mathrm{NO}$ with $\mathrm{NH} 3$, Cuihua Xuebao/Chinese J. Catal. $37 \quad$ (2016) 1314-1323. https://doi.org/10.1016/S1872-2067(15)61115-9.

[65] S. Mohan, P. Dinesha, S. Kumar, NOx reduction behaviour in copper zeolite catalysts for ammonia SCR systems: A review, Chem. Eng. J. 384 (2020) 123253. https://doi.org/10.1016/j.cej.2019.123253.

[66] K. Leistner, O. Mihai, K. Wijayanti, A. Kumar, K. Kamasamudram, N.W. Currier, A. Yezerets, L. Olsson, Comparison of $\mathrm{Cu} / \mathrm{BEA}, \mathrm{Cu} / \mathrm{SSZ}-13$ and $\mathrm{Cu} / \mathrm{SAPO}-34$ for ammonia-SCR reactions, Catal. Today. 258 (2015) 4955. https://doi.org/10.1016/j.cattod.2015.04.004.

[67] S. Sankar, R. Putluru, L. Schill, J. Degn, R.S.N. Fehrmann, Selective Catalytic Reduction of NOx with $\mathrm{NH} 3$ on $\mathrm{Cu}-$, Fe- , and Mn-Zeolites Prepared by Impregnation: Comparison of Activity and Hydrothermal Stability, J. Chem. 2018 (2018).

[68] F. Gao, M. Kollár, R.K. Kukkadapu, N.M. Washton, Y. Wang, J. Szanyi, C.H.F. Peden, Environmental Fe / SSZ-13 as an NH 3 -SCR catalyst : A reaction kinetics and FTIR / Mössbauer spectroscopic study, "Applied Catal. B, Environ. $164 \quad$ (2015) 407-419. https://doi.org/10.1016/j.apcatb.2014.09.031. 
[69] A. Sultana, M. Sasaki, K. Suzuki, H. Hamada, Tuning the NOx conversion of Cu-Fe/ZSM-5 catalyst in NH3-SCR, Catal. Commun. 41 (2013) 2125. https://doi.org/10.1016/j.catcom.2013.06.028.

[70] S. Dey, G.C. Dhal, Deactivation and regeneration of hopcalite catalyst for carbon monoxide oxidation: a review, Mater. Today Chem. 14 (2019) 100180. https://doi.org/10.1016/j.mtchem.2019.07.002.

[71] S. Dey, G.C. Dhal, R. Prasad, D. Mohan, Effects of doping on the performance of $\mathrm{CuMnOx}$ catalyst for $\mathrm{CO}$ oxidation, Bull. Chem. React. $\begin{array}{lllll}\text { Eng. } & \text { Catal. } & 12 & \text { (2017) }\end{array}$ https://doi.org/10.9767/bcrec.12.3.901.370-383.

[72] X. Bin Zhang, K.Y. Ma, L.H. Zhang, G.P. Yong, Y. Dai, S.M. Liu, Effect of precipitation method and Ce doping on the catalytic activity of copper manganese oxide catalysts for CO oxidation, Chinese J. Chem. Phys. 24 (2011) 97-102. https://doi.org/10.1088/1674-0068/24/01/97-102.

[73] G. Glaspell, H.M.A. Hassan, A. Elzatahry, V. Abdalsayed, M. Samy ElShall, Nanocatalysis on supported oxides for CO oxidation, Top. Catal. 47 (2008) 22-31. https://doi.org/10.1007/s11244-007-9036-1.

[74] D.A.J.M. Ligthart, R.A. van Santen, E.J.M. Hensen, Supported Rhodium Oxide Nanoparticles as Highly Active CO Oxidation Catalysts, Angew. Chemie. 123 (2011) $5418-5422$. https://doi.org/10.1002/ange.201100190.

[75] G.R. Bamwenda, S. Tsubota, T. Nakamura, M. Haruta, The influence of the preparation methods on the catalytic activity of platinum and gold supported on $\mathrm{TiO} 2$ for CO oxidation, Catal. Letters. 44 (1997) 83-87. https://doi.org/10.1023/a:1018925008633.

[76] S.H. Oh, G.B. Hoflund, Chemical state study of palladium powder and ceria-supported palladium during low-temperature $\mathrm{CO}$ oxidation, J. Phys. Chem. A. 110 (2006) 7609-7613. https://doi.org/10.1021/jp060435u.

[77] W. Liu, M. Flytzani-Stephanopoulos, Transition metal-promoted oxidation catalysis by fluorite oxides: A study of $\mathrm{CO}$ oxidation over $\mathrm{Cu}-$ 
CeO2, Chem. Eng. J. Biochem. Eng. J. 64 (1996) 283-294. https://doi.org/10.1016/S0923-0467(96)03135-1.

[78] X. Xie, Y. Li, Z.Q. Liu, M. Haruta, W. Shen, Low-temperature oxidation of CO catalysed by Co 3 O 4 nanorods, Nature. 458 (2009) 746-749. https://doi.org/10.1038/nature07877.

[79] A. Biabani-Ravandi, M. Rezaei, Low temperature $\mathrm{CO}$ oxidation over FeCo mixed oxide nanocatalysts, Chem. Eng. J. 184 (2012) 141-146. https://doi.org/10.1016/j.cej.2012.01.017.

[80] N.K. Soliman, Factors affecting CO oxidation reaction over nanosized materials: A review, J. Mater. Res. Technol. 8 (2019) 2395-2407. https://doi.org/10.1016/j.jmrt.2018.12.012.

[81] M. Haruta, T. Kobayashi, H. Sano, N. Yamada, Novel Gold Catalysts for the Oxidation of Carbon Monoxide at a Temperature far Below $0{ }^{\circ} \mathrm{C}$, Chem. Lett. 16 (1987) 405-408. https://doi.org/10.1246/cl.1987.405.

[82] Y. Zhu, H. Qian, R. Jin, Catalysis opportunities of atomically precise gold nanoclusters, J. Mater. Chem. 21 (2011) 6793-6799. https://doi.org/10.1039/c1jm10082c.

[83] B. Zhang, C. García, A. Sels, G. Salassa, C. Rameshan, J. Llorca, K. Hradil, G. Rupprechter, N. Barrabés, T. Bürgi, Ligand and support effects on the reactivity and stability of Au38(SR)24 catalysts in oxidation reactions, Catal. Commun. $130 \quad$ (2019) 105768. https://doi.org/10.1016/j.catcom.2019.105768.

[84] J. Zhao, R. Jin, Heterogeneous catalysis by gold and gold-based bimetal nanoclusters, Nano Today. 18 (2018) 86-102. https://doi.org/10.1016/j.nantod.2017.12.009.

[85] C. Schilling, M. Ziemba, C. Hess, M.V. Ganduglia-Pirovano, Identification of single-atom active sites in $\mathrm{CO}$ oxidation over oxidesupported $\mathrm{Au}$ catalysts, J. Catal. 383 (2020) 264-272. https://doi.org/10.1016/j.jcat.2020.01.022. 
[86] Y. Du, H. Sheng, D. Astruc, M. Zhu, Atomically Precise Noble Metal Nanoclusters as Efficient Catalysts: A Bridge between Structure and Properties, Chem. Rev. 120 (2020) 526-622. https://doi.org/10.1021/acs.chemrev.8b00726.

[87] Y. Zhu, H. Qian, R. Jin, An atomic-level strategy for unraveling gold nanocatalysis from the perspective of Aun(SR)m nanoclusters, Chem. - A Eur. J. 16 (2010) 11455-11462. https://doi.org/10.1002/chem.201001086.

[88] B. Zhang, S. Kaziz, H. Li, M.G. Hevia, D. Wodka, C. Mazet, T. Bürgi, N. Barrabés, Modulation of active sites in supported Au38( $\mathrm{SC} 2 \mathrm{H} 4 \mathrm{Ph}) 24$ cluster catalysts: Effect of atmosphere and support material, J. Phys. Chem. C. 119 (2015) 11193-11199. https://doi.org/10.1021/jp512022v.

[89] B. Zhang, A. Sels, G. Salassa, S. Pollitt, V. Truttmann, C. Rameshan, J. Llorca, W. Olszewski, G. Rupprechter, T. Bürgi, N. Barrabés, Ligand Migration from Cluster to Support: A Crucial Factor for Catalysis by Thiolate-protected Gold Clusters, ChemCatChem. 10 (2018) 5372-5376. https://doi.org/10.1002/cctc.201801474.

[90] M. Sankar, Q. He, R. V. Engel, M.A. Sainna, A.J. Logsdail, A. Roldan, D.J. Willock, N. Agarwal, C.J. Kiely, G.J. Hutchings, Role of the Support in Gold-Containing Nanoparticles as Heterogeneous Catalysts, Chem. Rev. $120 \quad$ (2020) 3890-3938. https://doi.org/10.1021/acs.chemrev.9b00662.

[91] C. García, S. Pollitt, M. van der Linden, V. Truttmann, C. Rameshan, R. Rameshan, E. Pittenauer, G. Allmaier, P. Kregsamer, M. Stöger-Pollach, N. Barrabés, G. Rupprechter, Support effect on the reactivity and stability of Au25(SR)18 and Au144(SR)60 nanoclusters in liquid phase cyclohexane oxidation, Catal. Today. 336 (2019) 174-185. https://doi.org/10.1016/j.cattod.2018.12.013.

[92] S. Pollitt, V. Truttmann, T. Haunold, C. Garcia, W. Olszewski, J. Llorca, N. Barrabés, G. Rupprechter, The Dynamic Structure of Au38(SR)24Nanoclusters Supported on CeO2upon Pretreatment and CO Oxidation, ACS Catal. $10 \quad$ (2020) 6144-6148. https://doi.org/10.1021/acscatal.0c01621. 
[93] Y. Li, Y. Chen, S.D. House, S. Zhao, Z. Wahab, J.C. Yang, R. Jin, Interface Engineering of Gold Nanoclusters for CO Oxidation Catalysis, ACS Appl. Mater. Interfaces. 10 (2018) 29425-29434. https://doi.org/10.1021/acsami.8b07552.

[94] X. Nie, H. Qian, Q. Ge, H. Xu, R. Jin, CO oxidation catalyzed by oxidesupported $\mathrm{Au}$ 25(SR) 18 nanoclusters and identification of perimeter sites as active centers, ACS Nano. 6 (2012) 6014-6022. https://doi.org/10.1021/nn301019f.

[95] A. Ghosh, O.F. Mohammed, O.M. Bakr, Atomic-Level Doping of Metal Clusters, Acc. Chem. Res. 51 (2018) 3094-3103. https://doi.org/10.1021/acs.accounts.8b00412.

[96] D. Jiang, S. Dai, From Superatomic Au25(SR)18 - to Superatomic M@Au24(SR)18 q Core-Shell Clusters, Inorg. Chem. 48 (2009) 27202722.

[97] S. Yamazoe, W. Kurashige, K. Nobusada, Y. Negishi, T. Tsukuda, Preferential Location of Coinage Metal Dopants $(\mathrm{M}=\mathrm{Ag}$ or $\mathrm{Cu})$ in [Au25-xMx(SC2H4Ph)18]- (x 1) As Determined by Extended X-ray Absorption Fine Structure and Density Functional Theory Calculations, J. Phys. Chem. C. 118 (2014) 25284-25290. https://doi.org/10.1055/s-00371610671.

[98] W. Li, C. Liu, H. Abroshan, Q. Ge, X. Yang, H. Xu, G. Li, Catalytic CO Oxidation Using Bimetallic MxAu25-x Clusters: A Combined Experimental and Computational Study on Doping Effects, J. Phys. Chem. $\quad$ C. $\quad 120 \quad$ (2016) 10261-10267. https://doi.org/10.1021/acs.jpcc.6b00793.

[99] M. Lamoth, M. Plodinec, L. Scharfenberg, S. Wrabetz, F. Girgsdies, T. Jones, F. Rosowski, R. Horn, R. Schlögl, E. Frei, Supported Ag Nanoparticles and Clusters for CO Oxidation: Size Effects and Influence of the Silver-Oxygen Interactions, ACS Appl. Nano Mater. 2 (2019) 2909-2920. https://doi.org/10.1021/acsanm.9b00344.

[100] L. Yu, Y. Shi, Z. Zhao, H. Yin, Y. Wei, J. Liu, W. Kang, T. Jiang, A. 
Wang, Ultrasmall silver nanoparticles supported on silica and their catalytic performances for carbon monoxide oxidation, Catal. Commun. 12 (2011) 616-620. https://doi.org/10.1016/j.catcom.2010.12.012.

[101] H. Liu, D. Ma, R.A. Blackley, W. Zhou, X. Bao, Highly active mesostructured silica hosted silver catalysts for $\mathrm{CO}$ oxidation using the one-pot synthesis approach, Chem. Commun. (2008) 2677-2679. https://doi.org/10.1039/b804641g.

[102] H.J. Freund, G. Meijer, M. Scheffler, R. Schlögl, M. Wolf, CO oxidation as a prototypical reaction for heterogeneous processes, Angew. Chemie Int. Ed. 50 (2011) 10064-10094. https://doi.org/10.1002/anie.201101378.

[103] S. Royer, D. Duprez, Catalytic Oxidation of Carbon Monoxide over Transition Metal Oxides, ChemCatChem. 3 (2011) 24-65. https://doi.org/10.1002/cctc.201000378.

[104] R.A. Sheldon, H. van Bekkum, Fine Chemicals through Heterogeneous Catalysis, Wiley-VCH, Weinheim, 2001. https://doi.org/10.1016/s00223182(12)80690-x.

[105] H.U. Blaser, Heterogeneous catalysis for fine chemicals production, Catal. Today. 60 (2000) 161-165. https://doi.org/10.1016/S09205861(00)00332-1.

[106] J.A. Delgado, O. Benkirane, C. Claver, D. Curulla-Ferré, C. Godard, Advances in the preparation of highly selective nanocatalysts for the semihydrogenation of alkynes using colloidal approaches, Dalt. Trans. 46 (2017) 12381-12403. https://doi.org/10.1039/c7dt01607g.

[107] B.A. Wilhite, M.J. McCready, A. Varma, Kinetics of phenylacetylene hydrogenation over Pt/ $\gamma$-Al2O3 catalyst, Ind. Eng. Chem. Res. 41 (2002) 3345-3350. https://doi.org/10.1021/ie0201112.

[108] R. Shen, T. Chen, Y. Zhao, R. Qiu, Y. Zhou, S. Yin, X. Wang, M. Goto, L.B. Han, Facile regio- and stereoselective hydrometalation of alkynes with a combination of carboxylic acids and group 10 transition metal complexes: Selective hydrogenation of alkynes with formic acid, J. Am. 
Chem. Soc. 133 (2011) 17037-17044. https://doi.org/10.1021/ja2069246.

[109] J. Li, R. Hua, T. Liu, Highly chemo- and stereoselective palladiumcatalyzed transfer semihydrogenation of internal alkynes affording cis alkenes, J. Org. Chem. 75 (2010) 2966-2970. https://doi.org/10.1021/jo100247a.

[110] T. Mitsudome, Y. Takahashi, S. Ichikawa, T. Mizugaki, K. Jitsukawa, K. Kaneda, Metal-ligand core-shell nanocomposite catalysts for the selective semihydrogenation of alkynes, Angew. Chemie - Int. Ed. 52 (2013) 14811485. https://doi.org/10.1002/anie.201207845.

[111] K. Tani, A. Iseki, T. Yamagata, Efficient transfer hydrogenation of alkynes and alkenes with methanol catalysed by hydrido(methoxo)iridium(III) complexes, Chem. Commun. (1999) 18211822. https://doi.org/10.1039/a905765j.

[112] C. Belger, N.M. Neisius, B. Plietker, A selective Ru-catalyzed semireduction of alkynes to $\mathrm{Z}$ olefins under transfer-hydrogenation conditions, Chem. - A Eur. J. 16 (2010) 12214-12220. https://doi.org/10.1002/chem.201001143.

[113] J. Li, R. Hua, Stereodivergent ruthenium-catalyzed transfer semihydrogenation of diaryl alkynes, Chem. - A Eur. J. 17 (2011) 84628465. https://doi.org/10.1002/chem.201003662.

[114] C. Belger, B. Plietker, Aryl-aryl interactions as directing motifs in the stereodivergent iron-catalyzed hydrosilylation of internal alkynes, Chem. Commun. 48 (2012) 5419-5421. https://doi.org/10.1039/c2cc31395b.

[115] S. Carenco, A. Leyva-Pérez, P. Concepción, C. Boissire, N. Mézailles, C. Sanchez, A. Corma, Nickel phosphide nanocatalysts for the chemoselective hydrogenation of alkynes, Nano Today. 7 (2012) 21-28. https://doi.org/10.1016/j.nantod.2011.12.003.

[116] D. Ren, L. He, L. Yu, R.S. Ding, Y.M. Liu, Y. Cao, H.Y. He, K.N. Fan, An unusual chemoselective hydrogenation of quinoline compounds using supported gold catalysts, J. Am. Chem. Soc. 134 (2012) 17592-17598. 
https://doi.org/10.1021/ja3066978.

[117] A. Arcadi, Alternative synthetic methods through new developments in catalysis by gold, Chem. Rev. 108 (2008) 3266-3325. https://doi.org/10.1021/cr068435d.

[118] J.L. Fiorio, N. López, L.M. Rossi, Gold-Ligand-Catalyzed Selective Hydrogenation of Alkynes into cis-Alkenes via H2 Heterolytic Activation by Frustrated Lewis Pairs, ACS Catal. 7 (2017) 2973-2980. https://doi.org/10.1021/acscatal.6b03441.

[119] A.C. Gluhoi, J.W. Bakker, B.E. Nieuwenhuys, Gold, still a surprising catalyst: Selective hydrogenation of acetylene to ethylene over $\mathrm{Au}$ nanoparticles, Catal. Today. $154 \quad$ (2010) 13-20. https://doi.org/10.1016/j.cattod.2010.02.021.

[120] J. Jia, K. Haraki, J.H. Kondo, K. Domen, K. Tamaru, Selective Hydrogenation of Acetylene over Au/A12O3 Catalyst, J. Phys. Chem. B. 104 (2004) 11153-11156. https://doi.org/10.1021/jp001213d.

[121] G.C. Bond, P.A. Sermon, Gold catalysts for olefin hydrogenation, Gold Bull. 6 (1973) 102-105. https://doi.org/10.1007/bf03215018.

[122] M. Okumura, T. Akita, M. Haruta, Hydrogenation of 1,3-butadiene and of crotonaldehyde over highly dispersed Au catalysts, Catal. Today. 74 (2002) 265-269. https://doi.org/10.1016/S0920-5861(02)00034-2.

[123] G. Li, R. Jin, Gold nanocluster-catalyzed semihydrogenation: A unique activation pathway for terminal alkynes, J. Am. Chem. Soc. 136 (2014) 11347-11354. https://doi.org/10.1021/ja503724j.

[124] A. Corma, V. Fornés, J.M. Guil, S. Pergher, T.L.M. Maesen, J.G. Buglass, Preparation, characterisation and catalytic activity of ITQ-2, a delaminated zeolite, Microporous Mesoporous Mater. 38 (2000) 301-309. https://doi.org/10.1016/S1387-1811(00)00149-9.

[125] R.A. Jesus, A.S. Rabelo, R.T. Figueiredo, L.C. Cides Da Silva, I.C. 
Codentino, M.C.A. Fantini, G.L.B. Araújo, A.A.S. Araújo, M.E. Mesquita, Synthesis and application of the MCM-41 and SBA-15 as matrices for in vitro efavirenz release study, J. Drug Deliv. Sci. Technol. 31 (2016) 153-159. https://doi.org/10.1016/j.jddst.2015.11.008.

[126] J.C. Yu, L. Zhang, Z. Zheng, J. Zhao, Synthesis and characterization of phosphated mesoporous titanium dioxide with high photocatalytic activity, Chem. Mater. $15 \quad$ (2003) 2280-2286. https://doi.org/10.1021/cm0340781.

[127] J.K. Bartley, C. Xu, R. Lloyd, D.I. Enache, D.W. Knight, G.J. Hutchings, Simple method to synthesize high surface area magnesium oxide and its use as a heterogeneous base catalyst, Appl. Catal. B Environ. 128 (2012) 31-38. https://doi.org/10.1016/j.apcatb.2012.03.036.

[128] M.M. Bourgogne, CHA Chabazite, Asoc. Int. Zeolitas. (n.d.). $\mathrm{http}: / / \mathrm{www}$. iza-online.org/.

[129] A. Shivhare, S.J. Ambrose, H. Zhang, R.W. Purves, R.W.J. Scott, Stable and recyclable Au25 clusters for the reduction of 4-nitrophenol, Chem. Commun. 49 (2013) 276-278. https://doi.org/10.1039/c2cc37205c.

[130] V. Truttmann, C. Herzig, I. Illes, A. Limbeck, E. Pittenauer, M. StögerPollach, G. Allmaier, T. Bürgi, N. Barrabés, G. Rupprechter, Ligand engineering of immobilized nanoclusters on surfaces: Ligand exchange reactions with supported Au11(PPh3)7Br3, Nanoscale. 12 (2020) 1280912816. https://doi.org/10.1039/c9nr10353h.

[131] C.P. Joshi, M.S. Bootharaju, M.J. Alhilaly, O.M. Bakr, [Ag25(SR)18]-: The "golden"Silver Nanoparticle Silver Nanoparticle, J. Am. Chem. Soc. 137 (2015) 11578-11581. https://doi.org/10.1021/jacs.5b07088.

[132] E. Gottlieb, H. Qian, R. Jin, Atomic-level alloying and de-alloying in doped gold nanoparticles, Chem. - A Eur. J. 19 (2013) 4238-4243. https://doi.org/10.1002/chem.201203158.

[133] S. Brunauer, P.H. Emmett, E. Teller, Adsorption of Gases in Multimolecular Layers, J. Am. Chem. Soc. 60 (1938) 309-319. 
https://doi.org/10.1021/ja01269a023.

[134] G. Guilera, F. Rey, J. Hernández-Fenollosa, J.J. Cortés-Vergaz, One body, many heads; The Cerberus of catalysis. A new multipurpose in-situ cell for XAS at ALBA, J. Phys. Conf. Ser. 430 (2013). https://doi.org/10.1088/1742-6596/430/1/012057.

[135] B. Ravel, M. Newville, ATHENA, ARTEMIS, HEPHAESTUS: Data analysis for X-ray absorption spectroscopy using IFEFFIT, J. Synchrotron Radiat. 12 (2005) 537-541. https://doi.org/10.1107/S0909049505012719.

[136] J.J. Rehr, R.C. Albers, Theoretical approaches to x-ray absorption fine structure, Rev. Mod. Phys. 72 (2000) 621-654. https://doi.org/10.1103/RevModPhys.72.621.

[137] J. Li, C. Yang, Q. Zhang, Z. Li, W. Huang, Effects of Fe addition on the structure and catalytic performance of mesoporous Mn/Al-SBA-15 catalysts for the reduction of NO with ammonia, Catal. Commun. 62 (2015) 24-28. https://doi.org/10.1016/j.catcom.2015.01.003.

[138] J. Shi, Z. Zhang, M. Chen, Z. Zhang, W. Shangguan, Promotion effect of tungsten and iron co-addition on the catalytic performance of $\mathrm{MnOx} / \mathrm{TiO} 2$ for NH3-SCR of NOx, Fuel. 210 (2017) 783-789. https://doi.org/10.1016/j.fuel.2017.09.035.

[139] N. Husnain, E. Wang, K. Li, M.T. Anwar, A. Mehmood, M. Gul, D. Li, J. Mao, Iron oxide-based catalysts for low-temperatue selective catalytic reduction of NOx with NH3, Rev. Chem. Eng. 35 (2019) 239-264. https://doi.org/https://doi.org/10.1515/revce-2017-0064.

[140] B. Thirupathi, P.G. Smirniotis, Co-doping a metal (Cr, Fe, Co, Ni, Cu, Zn, $\mathrm{Ce}$, and $\mathrm{Zr}$ ) on $\mathrm{Mn} / \mathrm{TiO} 2$ catalyst and its effect on the selective reduction of NO with NH3 at low-temperatures, Appl. Catal. B Environ. 110 (2011) 195-206. https://doi.org/10.1016/j.apcatb.2011.09.001.

[141] Y.J. Kim, H.J. Kwon, I. Heo, I.S. Nam, B.K. Cho, J.W. Choung, M.S. Cha, G.K. Yeo, Mn-Fe/ZSM5 as a low-temperature SCR catalyst to remove NOx from diesel engine exhaust, Appl. Catal. B Environ. 126 
(2012) 9-21. https://doi.org/10.1016/j.apcatb.2012.06.010.

[142] J. Huang, Z. Tong, Y. Huang, J. Zhang, Selective catalytic reduction of $\mathrm{NO}$ with $\mathrm{NH} 3$ at low temperatures over iron and manganese oxides supported on mesoporous silica, Appl. Catal. B Environ. 78 (2008) 309314. https://doi.org/10.1016/j.apcatb.2007.09.031.

[143] International Zeolite Association, (n.d.). http://www.iza-online.org/.

[144] M.A. Camblor, J. Pérez-Pariente, Crystallization of zeolite beta: Effect of $\mathrm{Na}$ and $\mathrm{K}$ ions, Zeolites. 11 (1991) 202-210. https://doi.org/10.1016/S0144-2449(05)80220-9.

[145] A. Corma, V. Fornés, S. Pergher, Patente Internacional, WO 97/17290, 1997.

[146] U. Díaz, Layered Materials with Catalytic Applications: Pillared and Delaminated Zeolites from MWW Precursors, ISRN Chem. Eng. 2012 (2012) 1-35. https://doi.org/10.5402/2012/537164.

[147] R. Nedyalkova, C. Montreuil, C. Lambert, L. Olsson, Interzeolite conversion of FAU type zeolite into CHA and its application in NH3SCR, Top. Catal. 56 (2013) 550-557. https://doi.org/10.1007/s11244013-0015-4.

[148] L.E. Sandoval-Díaz, J.A. González-Amaya, C.A. Trujillo, General aspects of zeolite acidity characterization, Microporous Mesoporous Mater. 215 (2015) 229-243. https://doi.org/10.1016/j.micromeso.2015.04.038.

[149] M. Moliner, C. Franch, E. Palomares, M. Grill, A. Corma, Cu-SSZ-39, an active and hydrothermally stable catalyst for the selective catalytic reduction of NOx, Chem. Commun. 48 (2012) 8264-8266. https://doi.org/10.1039/c2cc33992g.

[150] H. Lin, Detailed Structural Characterizations of SBA-15 and MCM-41 Mesoporous Silicas on a High-Resolution Transmission Electron 
Microscope, (2002) 981-988.

[151] L. Angiolini, B. Cohen, A. Douhal, Single crystal FLIM characterization of clofazimine loaded in silica-based mesoporous materials and zeolites, Int. J. Mol. Sci. 20 (2019) 9-12. https://doi.org/10.3390/ijms20122859.

[152] M. V. Landau, S.P. Varkey, M. Herskowitz, O. Regev, S. Pevzner, T. Sen, Z. Luz, Wetting stability of Si-MCM-41 mesoporous material in neutral, acidic and basic aqueous solutions, Microporous Mesoporous Mater. 33 (1999) 149-163. https://doi.org/10.1016/S1387-1811(99)00133-X.

[153] J. Gao, Y. Han, J. Mu, S. Wu, F. Tan, Y. Shi, X. Li, 2D, 3D mesostructured silicas templated mesoporous manganese dioxide for selective catalytic reduction of NOx with NH3, J. Colloid Interface Sci. 516 (2018) 254-262. https://doi.org/10.1016/j.jcis.2018.01.048.

[154] V.R. Choudhary, S.D. Sansare, Thermal, hydrothermal and acid-base stability of highly siliceous MCM-41 mesoporous material, Proc. Indian Acad. Sci. Chem. Sci. $109 \quad$ (1997) 229-233. https://doi.org/10.1007/BF02872560.

[155] A. Corma, From microporous to mesoporous molecular sieve materials and their use in catalysis, Chem. Rev. 97 (1997) 2373-2419. https://doi.org/10.1021/cr960406n.

[156] J.M.R. Gallo, C. Bisio, G. Gatti, L. Marchese, H.O. Pastore, Physicochemical characterization and surface acid properties of mesoporous [Al]-SBA-15 obtained by direct synthesis, Langmuir. 26 (2010) 5791-5800. https://doi.org/10.1021/la903661q.

[157] J. Li, J. Guo, X. Shi, X. Wen, Y. Chu, S. Yuan, Effect of aluminum on the catalytic performance and reaction mechanism of Mn/MCM-41 for NH3SCR reaction, Appl. Surf. Sci. 534 (2020) 147592. https://doi.org/10.1016/j.apsusc.2020.147592.

[158] M. Kang, J.H. Park, E.D. Park, J.M. Kim, D.J. Kim, J.E. Yie, The effect of Si/Al ratio on selective catalytic reduction of NOx with $\mathrm{NH} 3$ over Pt/Al-SBA-15, Solid State Phenom. 135 (2008) 61-64. 
https://doi.org/10.4028/www.scientific.net/SSP.135.61.

[159] S.S.R. Putluru, L. Schill, A.D. Jensen, B. Siret, F. Tabaries, R. Fehrmann, $\mathrm{Mn} / \mathrm{TiO} 2$ and $\mathrm{Mn}-\mathrm{Fe} / \mathrm{TiO} 2$ catalysts synthesized by deposition precipitation-promising for selective catalytic reduction of $\mathrm{NO}$ with $\mathrm{NH} 3$ at low temperatures, Appl. Catal. B Environ. 165 (2015) 628-635. https://doi.org/10.1016/j.apcatb.2014.10.060.

[160] Z. Wu, B. Jiang, Y. Liu, W. Zhao, B. Guan, Experimental study on a lowtemperature SCR catalyst based on $\mathrm{MnOx} / \mathrm{TiO} 2$ prepared by sol-gel method, J. Hazard. Mater. 145 (2007) 488-494. https://doi.org/10.1016/j.jhazmat.2006.11.045.

[161] N.C. Jeong, J.S. Lee, E.L. Tae, Y.J. Lee, K.B. Yoon, Acidity scale for metal oxides and Sanderson's electronegativities of lanthanide elements, Angew. Chemie - Int. Ed. 47 (2008) 10128-10132. https://doi.org/10.1002/anie.200803837.

[162] D. Fang, D. Li, F. He, J. Xie, C. Xiong, Y. Chen, Experimental and DFT study of the adsorption and activation of NH 3 and $\mathrm{NO}$ on Mn-based spinels supported on $\mathrm{TiO} 2$ catalysts for SCR of $\mathrm{NO}$ x, Comput. Mater. Sci. $\quad 160 \quad$ (2019) 374-381. https://doi.org/10.1016/j.commatsci.2019.01.025.

[163] A. Ko, Y. Woo, J. Jang, Y. Jung, Y. Pyo, H. Jo, O. Lim, Y.J. Lee, Availability of NH3 adsorption in vanadium-based SCR for reducing NOx emission and NH3 slip, J. Ind. Eng. Chem. 78 (2019) 433-439. https://doi.org/10.1016/j.jiec.2019.05.024.

[164] S. Deng, K. Zhuang, B. Xu, Y. Ding, L. Yu, Y. Fan, Promotional effect of iron oxide on the catalytic properties of $\mathrm{Fe}-\mathrm{MnOx} / \mathrm{TiO} 2$ (anatase) catalysts for the SCR reaction at low temperatures, Catal. Sci. Technol. 6 (2016) 1772-1778. https://doi.org/10.1039/c5cy01217a.

[165] N. Fang, J. Guo, S. Shu, H. Luo, Y. Chu, J. Li, Enhancement of lowtemperature activity and sulfur resistance of $\mathrm{Fe} 0.3 \mathrm{Mn} 0.5 \mathrm{Zr} 0.2$ catalyst for NO removal by NH3-SCR, Chem. Eng. J. 325 (2017) 114-123. https://doi.org/10.1016/j.cej.2017.05.053. 
[166] M. Sun, B. Lan, L. Yu, F. Ye, W. Song, J. He, G. Diao, Y. Zheng, Manganese oxides with different crystalline structures: Facile hydrothermal synthesis and catalytic activities, Mater. Lett. 86 (2012) 18 20. https://doi.org/10.1016/j.matlet.2012.07.011.

[167] Y.B. Tu, J.Y. Luo, M. Meng, G. Wang, J.J. He, Ultrasonic-assisted synthesis of highly active catalyst $\mathrm{Au} / \mathrm{MnOx}-\mathrm{CeO} 2$ used for the preferential oxidation of $\mathrm{CO}$ in H2-rich stream, Int. J. Hydrogen Energy. 34 (2009) 3743-3754. https://doi.org/10.1016/j.ijhydene.2009.03.015.

[168] R. Fiorenza, L. Spitaleri, A. Gulino, S. Scirè, Ru-Pd bimetallic catalysts supported on $\mathrm{CeO} 2-\mathrm{MnOx}$ oxides as efficient systems for $\mathrm{H} 2$ purification through CO preferential Oxidation, Catalysts. 8 (2018) 1-18. https://doi.org/10.3390/catal8050203.

[169] E.R. Stobbe, B.A. De Boer, J.W. Geus, The reduction and oxidation behaviour of manganese oxides, Catal. Today. 47 (1999) 161-167. https://doi.org/10.1016/S0920-5861(98)00296-X.

[170] G. Marbán, R. Antuña, A.B. Fuertes, Low-temperature SCR of NOx with $\mathrm{NH} 3$ over activated carbon fiber composite-supported metal oxides, Appl. Catal. B Environ. 41 (2003) 323-338. https://doi.org/10.1016/S09263373(02)00170-4.

[171] A.E. Palomares, F. Márquez, S. Valencia, A. Corma, On the researching of a new zeolite structure for the selective catalytic reduction of NO the possibilities of Cu-Exchanged IM5, J. Mol. Catal. A Chem. 162 (2000) 175-189. https://doi.org/10.1016/S1381-1169(00)00288-0.

[172] M. Boveri, C. Márquez-Álvarez, M.Á. Laborde, E. Sastre, Steam and acid dealumination of mordenite. Characterization and influence on the catalytic performance in linear alkylbenzene synthesis, Catal. Today. 114 (2006) 217-225. https://doi.org/10.1016/j.cattod.2006.01.012.

[173] N. Martín, P.N.R. Vennestrøm, J.R. Thøgersen, M. Moliner, A. Corma, Iron-Containing SSZ-39 (AEI) Zeolite: An Active and Stable HighTemperature NH3-SCR Catalyst, ChemCatChem. 9 (2017) 1754-1757. https://doi.org/10.1002/cctc.201601627. 
[174] Y. Shan, W. Shan, X. Shi, J. Du, Y. Yu, H. He, A comparative study of the activity and hydrothermal stability of Al-rich Cu-SSZ-39 and Cu-SSZ13, Appl. Catal. B Environ. 264 (2020) 118511. https://doi.org/10.1016/j.apcatb.2019.118511.

[175] B. Zhao, R. Ran, X. Wu, D. Weng, X. Wu, C. Huang, Comparative study of $\mathrm{Mn} / \mathrm{TiO} 2$ and $\mathrm{Mn} / \mathrm{ZrO} 2$ catalysts for $\mathrm{NO}$ oxidation, Catal. Commun. 56 (2014) 36-40. https://doi.org/10.1016/j.catcom.2014.07.003.

[176] S. Takano, T. Tsukuda, Controlled Synthesis: Size Control, Elsevier, 2015. https://doi.org/10.1016/B978-0-08-100086-1.00002-6.

[177] R. Jin, Quantum sized, thiolate-protected gold nanoclusters, Nanoscale. 2 (2010) 343-362. https://doi.org/10.1039/b9nr00160c.

[178] D.M. Chevrier, L. Raich, C. Rovira, A. Das, Z. Luo, Q. Yao, A. Chatt, J. Xie, R. Jin, J. Akola, P. Zhang, Molecular-Scale Ligand Effects in Small Gold-Thiolate Nanoclusters, J. Am. Chem. Soc. 140 (2018) 15430 15436. https://doi.org/10.1021/jacs.8b09440.

[179] X. Bokhimi, R. Zanella, V. Maturano, A. Morales, Nanocrystalline Ag, and $\mathrm{Au}-\mathrm{Ag}$ alloys supported on titania for $\mathrm{CO}$ oxidation reaction, Mater. Chem. $\quad$ Phys. $138 \quad$ (2013) 490-499. https://doi.org/10.1016/j.matchemphys.2012.12.008.

[180] Y. Kang, M. Sun, A. Li, Studies of the catalytic oxidation of CO over $\mathrm{Ag} / \mathrm{CeO} 2$ catalyst, Catal. Letters. 142 (2012) 1498-1504. https://doi.org/10.1007/s10562-012-0893-2.

[181] S.G. Aspromonte, M.D. Mizrahi, F.A. Schneeberger, J.M.R. López, A. V. Boix, Study of the nature and location of silver in Ag-exchanged mordenite catalysts. characterization by spectroscopic techniques, J. Phys. Chem. C. 117 (2013) 25433-25442. https://doi.org/10.1021/jp4046269.

[182] E. Kolobova, A. Pestryakov, A. Shemeryankina, Y. Kotolevich, O. Martynyuk, H.J. Tiznado Vazquez, N. Bogdanchikova, Formation of silver active states in Ag/ZSM-5 catalysts for CO oxidation, Fuel. 138 (2014) 65-71. https://doi.org/10.1016/j.fuel.2014.07.011. 
[183] K.I. Shimizu, K. Sugino, K. Kato, S. Yokota, K. Okumura, A. Satsuma, Formation and redispersion of silver clusters in Ag-MFI zeolite as investigated by time-resolved QXAFS and UV-Vis, J. Phys. Chem. C. 111 (2007) 1683-1688. https://doi.org/10.1021/jp066995a.

[184] D. Chen, Z. Qu, S. Shen, X. Li, Y. Shi, Y. Wang, Q. Fu, J. Wu, Comparative studies of silver based catalysts supported on different supports for the oxidation of formaldehyde, Catal. Today. 175 (2011) 338-345. https://doi.org/10.1016/j.cattod.2011.03.059.

[185] F. Schuricht, W. Reschetilowski, Simultaneous selective catalytic reduction (SCR) of $\mathrm{NO} \times$ and $\mathrm{N} 2 \mathrm{O}$ over Ag/ZSM-5 - Catalytic studies and mechanistic implications, Microporous Mesoporous Mater. 164 (2012) 135-144. https://doi.org/10.1016/j.micromeso.2012.07.018.

[186] K.O. Sulaiman, V. Sudheeshkumar, R.W.J. Scott, Activation of atomically precise silver clusters on carbon supports for styrene oxidation reactions, RSC Adv. 9 (2019) 28019-28027. https://doi.org/10.1039/c9ra05566e.

[187] J. Liu, K.S. Krishna, C. Kumara, S. Chattopadhyay, T. Shibata, A. Dass, C.S.S.R. Kumar, Understanding Au 98Ag 46(SR)60 nanoclusters through investigation of their electronic and local structure by X-ray absorption fine structure, RSC Adv. 6 (2016) 25368-25374. https://doi.org/10.1039/c5ra27396j.

[188] D.M. Chevrier, R. Yang, A. Chatt, P. Zhang, Bonding properties of thiolate-protected gold nanoclusters and structural analogs from X-ray absorption spectroscopy, Nanotechnol. Rev. 4 (2015) 193-206. https://doi.org/10.1515/ntrev-2015-0007.

[189] S. Yamazoe, T. Tsukuda, X-ray absorption spectroscopy on atomically precise metal clusters, Bull. Chem. Soc. Jpn. 92 (2019) 193-204. https://doi.org/10.1246/bcsj.20180282.

[190] D.B. Akolekar, S.K. Bhargava, Adsorption of NO and CO on silverexchanged microporous materials, J. Mol. Catal. A Chem. 157 (2000) 199-206. https://doi.org/10.1016/S1381-1169(00)00055-8. 
[191] K. Tarach, K. Góra-Marek, M. Chrzan, S. Walas, Quantification of silver sites in zeolites: Carbon monoxide sorption monitored by IR spectroscopy, J. Phys. Chem. C. 118 (2014) 23751-23760. https://doi.org/10.1021/jp506820v.

[192] R. Jin, K. Nobusada, Doping and alloying in atomically precise gold nanoparticles, Nano Res. 7 (2014) 285-300. https://doi.org/10.1007/s12274-014-0403-5.

[193] Z. Qu, G. Ke, Y. Wang, M. Liu, T. Jiang, J. Gao, Investigation of factors influencing the catalytic performance of $\mathrm{CO}$ oxidation over $\mathrm{Au}-\mathrm{Ag} / \mathrm{SBA}-$ 15 catalyst, Appl. Surf. Sci. 277 (2013) 293-301. https://doi.org/10.1016/j.apsusc.2013.04.051.

[194] A. Pal, S. Shah, S. Devi, Synthesis of Au, Ag and Au-Ag alloy nanoparticles in aqueous polymer solution, Colloids Surfaces A Physicochem. Eng. Asp. $302 \quad$ (2007) 51-57. https://doi.org/10.1016/j.colsurfa.2007.01.054.

[195] M.P. Mallin, C.J. Murphy, Solution-Phase Synthesis of Sub-10 nm Au Ag Alloy Nanoparticles, Nano Lett. 2 (2002) 1235-1237.

[196] D.H. Chen, C.J. Chen, Formation and characterization of Au-Ag bimetallic nanoparticles in water-in-oil microemulsions, J. Mater. Chem. 12 (2002) 1557-1562. https://doi.org/10.1039/b110749f.

[197] J.N. O'Shea, J. Schnadt, S. Andersson, L. Patthey, S. Rost, A. Giertz, B. Brena, J.O. Forsell, A. Sandell, O. Björneholm, P.A. Brühwiler, N. Mårtensson, X-ray photoelectron spectroscopy of low surface concentration mass-selected Ag clusters, J. Chem. Phys. 113 (2000) 9233-9238. https://doi.org/10.1063/1.1319700.

[198] T. Chen, S. Yang, J. Chai, Y. Song, J. Fan, B. Rao, H. Sheng, H. Yu, M. Zhu, Crystallization-induced emission enhancement: A novel fluorescent $\mathrm{Au}-\mathrm{Ag}$ bimetallic nanocluster with precise atomic structure, Sci. Adv. 3 (2017) 1-8. https://doi.org/10.1126/sciadv.1700956.

[199] P. Zhang, X - ray Spectroscopy of Gold - Thiolate Nanoclusters, J. Phys. 
Chem. $\quad$ C. $118 \quad$ (2014) 25291-25299. https://doi.org/dx.doi.org/10.1021/jp507739u.

[200] C. Garcia, V. Truttmann, I. Lopez, T. Haunold, C. Marini, C. Rameshan, E. Pittenauer, P. Kregsamer, K. Dobrezberger, M. Stöger-Pollach, N. Barrabés, G. Rupprechter, Dynamics of Pd Dopant Atoms inside Au Nanoclusters during Catalytic CO Oxidation, J. Phys. Chem. C. 124 (2020) 23626-23636. https://doi.org/10.1021/acs.jpcc.0c05735.

[201] K.I. Hadjiivanov, IR study of CO and NOx sorption on Ag-ZSM-5, Microporous Mesoporous Mater. 24 (1998) 41-49. https://doi.org/10.1016/S1387-1811(98)00147-4.

[202] M. Stucchi, A. Jouve, A. Villa, G. Nagy, M. Németh, C. Evangelisti, R. Zanella, L. Prati, Gold-Silver Catalysts: Ruling Factors for Establishing Synergism, ChemCatChem. 11 (2019) 4043-4053. https://doi.org/10.1002/cctc.201900591.

[203] Z. Qu, S. Zhou, W. Wu, C. Li, X. Bao, CO adsorption and correlation between $\mathrm{CO}$ surface coverage and activity/selectivity of preferential $\mathrm{CO}$ oxidation over supported Ag catalyst: An in situ FTIR study, Catal. Letters. 101 (2005) 21-26. https://doi.org/10.1007/s10562-004-3742-0.

[204] J. Velasquez, B. Njegic, M.S. Gordon, M.A. Duncan, IR photodissociation spectroscopy and theory of $\mathrm{Au}+(\mathrm{CO}) \mathrm{n}$ complexes: Nonclassical carbonyls in the gas phase, J. Phys. Chem. A. 112 (2008) 1907-1913. https://doi.org/10.1021/jp711099u.

[205] R. Atwi, A. Tuel, M. Maffre, L. Burel, J.L. Rousset, F. Meunier, Highly dispersed $\mathrm{Au}, \mathrm{Ag}$ and $\mathrm{Au}-\mathrm{Ag}$ alloy nanoparticles encapsulated in single crystal multi-hollow silicalite-1, Appl. Catal. A Gen. 569 (2019) 86-92. https://doi.org/10.1016/j.apcata.2018.10.028.

[206] W.R. Tyson, W.A. Miller, Surface free energies of solid metals. Estimation from liquid surface tension measurements, Surf. Sci. 62 (1977) 267-276.

[207] S. Hannemann, J.D. Grunwaldt, F. Krumeich, P. Kappen, A. Baiker, 
Electron microscopy and EXAFS studies on oxide-supported gold-silver nanoparticles prepared by flame spray pyrolysis, Appl. Surf. Sci. 252 (2006) 7862-7873. https://doi.org/10.1016/j.apsusc.2005.09.065.

[208] I. López-Hernández, C. García, V. Truttmann, S. Pollitt, N. Barrabés, G. Rupprechter, F. Rey, A.E. Palomares, Evaluation of the silver species nature in Ag-ITQ2 zeolites by the CO oxidation reaction, Catal. Today. 345 (2020) 22-26. https://doi.org/10.1016/j.cattod.2019.12.001.

[209] B. Zhang, O. V. Safonova, S. Pollitt, G. Salassa, A. Sels, R. Kazan, Y. Wang, G. Rupprechter, N. Barrabés, T. Bürgi, On the mechanism of rapid metal exchange between thiolate-protected gold and gold/silver clusters: A time-resolved: In situ XAFS study, Phys. Chem. Chem. Phys. 20 (2018) 5312-5318. https://doi.org/10.1039/c7cp08272j.

[210] N. V., P.L. Clement, R.P. Brown, M.O.P. Krause, J.A. Pedersenc, C.L. Haynes, Research highlights: speciation and transformations of silver released from Ag NPs in three species Natalie, Environ. Sci. Technol. 3 (2016) 1236. https://doi.org/10.1039/c6en90025a.

[211] G. Veronesi, A. Deniaud, T. Gallon, P.H. Jouneau, J. Villanova, P. Delangle, M. Carrière, I. Kieffer, P. Charbonnier, E. Mintz, I. MichaudSoret, Visualization, quantification and coordination of $\mathrm{Ag}+$ ions released from silver nanoparticles in hepatocytes, Nanoscale. 8 (2016) 17012 17021. https://doi.org/10.1039/c6nr04381j.

[212] R. Kaegi, A. Voegelin, B. Sinnet, S. Zuleeg, H. Hagendorfer, M. Burkhardt, H. Siegrist, Behavior of metallic silver nanoparticles in a pilot wastewater treatment plant, Environ. Sci. Technol. 45 (2011) 3902-3908. https://doi.org/10.1021/es1041892.

[213] A.I. Frenkel, Applications of extended X-ray absorption fine-structure spectroscopy to studies of bimetallic nanoparticle catalysts, Chem. Soc. Rev. 41 (2012) 8163-8178. https://doi.org/10.1039/c2cs35174a.

[214] C.H. Wu, C. Liu, D. Su, H.L. Xin, H.T. Fang, B. Eren, S. Zhang, C.B. Murray, M.B. Salmeron, Bimetallic synergy in cobalt-palladium nanocatalysts for CO oxidation, Nat. Catal. 2 (2019) 78-85. 
https://doi.org/10.1038/s41929-018-0190-6.

[215] T.S. Kim, J. Kim, H.C. Song, D. Kim, B. Jeong, J. Lee, J.W. Shin, R. Ryoo, J.Y. Park, Catalytic Synergy on PtNi Bimetal Catalysts Driven by Interfacial Intermediate Structures, ACS Catal. 10 (2020) 10459-10467. https://doi.org/10.1021/acscatal.0c02467.

[216] J. Kim, W.H. Park, W.H. Doh, S.W. Lee, M.C. Noh, J.J. Gallet, F. Bournel, H. Kondoh, K. Mase, Y. Jung, B.S. Mun, J.Y. Park, Adsorbatedriven reactive interfacial $\mathrm{Pt}-\mathrm{NiO} 1-\mathrm{x}$ nanostructure formation on the Pt3Ni(111) alloy surface, Sci. Adv. 4 (2018) 1-8. https://doi.org/10.1126/sciadv.aat3151.

[217] A.Q. Wang, C.M. Chang, C.Y. Mou, Evolution of catalytic activity of Au$\mathrm{Ag}$ bimetallic nanoparticles on mesoporous support for $\mathrm{CO}$ oxidation, $\mathrm{J}$. $\begin{array}{lllll}\text { Phys. } & \text { Chem. } & \text { B. } & 109 & \text { (2005) }\end{array}$ https://doi.org/10.1021/jp051530q.

[218] Y. Chi, L. Zhao, X. Lu, C. An, W. Guo, C.M.L. Wu, Effect of alloying on the stabilities and catalytic properties of $\mathrm{Ag}-\mathrm{Au}$ bimetallic subnanoclusters: a theoretical investigation, J. Mater. Sci. 51 (2016) 5046-5060. https://doi.org/10.1007/s10853-016-9808-8.

[219] L.C. Mckenzie, T.O. Zaikova, J.E. Hutchison, Structurally Similar Triphenylphosphine-Stabilized Undecagolds, Au11(PPh3)7Cl3 and [Au11(PPh3)8C12]Cl, Exhibit Distinct Ligand Exchange Pathways with Glutathione, J. Am. Chem. Soc. 136 (2014) 13426-13455. https://doi.org/https://doi.org/10.1021/ja5075689.

[220] X.-K. Wan, J.-Q. Wang, Z.-A. Nan, Q.-M. Wang, Ligand effects in catalysis by atomically precise gold nanoclusters, Sci. Adv. 3 (2017) e1701823. https://doi.org/10.1126/sciadv.1701823.

[221] Y. Liu, H. Tsunoyama, T. Akita, T. Tsukuda, Preparation of $\sim 1 \mathrm{~nm}$ Gold Clusters Confined within Mesoporous Silica and Microwave-Assisted Catalytic Application for Alcohol Oxidation, J. Phys. Chem. C. 113 (2009) 13457-13461. https://doi.org/10.1021/jp904700p. 
[222] A. Noujima, T. Mitsudome, T. Mizugaki, K. Jitsukawa, K. Kaneda, Unique catalysis of gold nanoparticles in the chemoselective hydrogenolysis with H2: Cooperative effect between small gold nanoparticles and a basic support, Chem. Commun. 48 (2012) 6723-6725. https://doi.org/10.1039/c2cc32850j.

[223] A. Noujima, T. Mitsudome, T. Mizugaki, K. Jitsukawa, K. Kaneda, Selective deoxygenation of epoxides to alkenes with molecular hydrogen using a hydrotalcite-supported gold catalyst: Aconcerted effect between gold nanoparticles and basic sites on a support, Angew. Chemie - Int. Ed. 50 (2011) 2986-2989. https://doi.org/10.1002/anie.201007679.

[224] T. Mitsudome, A. Noujima, Y. Mikami, T. Mizugaki, K. Jitsukawa, K. Kaneda, Supported gold and silver nanoparticles for catalytic deoxygenation of epoxides into alkenes, Angew. Chemie - Int. Ed. 49 (2010) 5545-5548. https://doi.org/10.1002/anie.201001055. 
